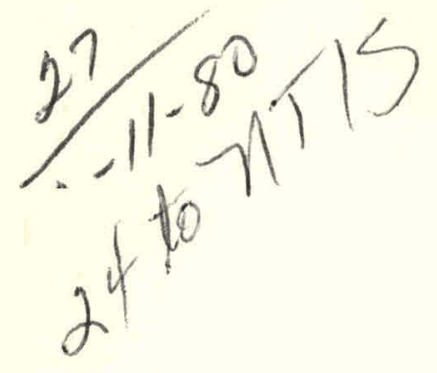

ANL/CNSV-TM-23

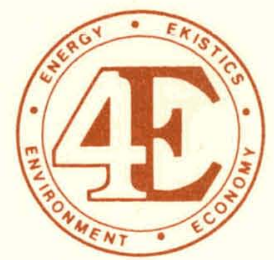

\title{
Heat-Pump-Centered Integrated Community Energy Systems
}

System Development

Georgia Institute of Technology Final Report

\section{ENERGY AND ENVIRONMENTAL SYSTEMS DIVISION}

\section{ARGONNE NATIONAL LABORATORY}

INTEGRATED COMMUNITY ENERGY SYSTEMS

OPERATED FOR THE U.S. DEPARTMENT OF ENERGY UNDER CONTRACT W-31-109-ENG-38 


\section{DISCLAIMER}

This report was prepared as an account of work sponsored by an agency of the United States Government. Neither the United States Government nor any agency Thereof, nor any of their employees, makes any warranty, express or implied, or assumes any legal liability or responsibility for the accuracy, completeness, or usefulness of any information, apparatus, product, or process disclosed, or represents that its use would not infringe privately owned rights. Reference herein to any specific commercial product, process, or service by trade name, trademark, manufacturer, or otherwise does not necessarily constitute or imply its endorsement, recommendation, or favoring by the United States Government or any agency thereof. The views and opinions of authors expressed herein do not necessarily state or reflect those of the United States Government or any agency thereof. 


\section{DISCLAIMER}

Portions of this document may be illegible in electronic image products. Images are produced from the best available original document. 
The facilities of Argonne National Laboratory are owned by the United States Government. Under the terms of a contract (W-31-109-Eng-38) among the U. S. Department of Energy, Argonne Universities Association and The University of Chicago, the University employs the staff and operates the Laboratory in accordance with policies and programs formulated, approved and reviewed by the Association.

\section{MEMBERS OF ARGONNE UNIVERSITIES ASSOCIATION}

The University of Arizona

Carnegie-Mellon University

Case Western Reserve University

The University of Chicago

University of Cincinnati

Illinois Institute of Technology

University of Illinois

Indiana University

The University of Iowa

Iowa State University
The University of Kansas

Kansas State University

Loyola University of Chicago

Marquette University

The University of Michigan

Michigan State University

University of Minnesota

University of Missouri

Northwestern University

University of Notre Dame
The Ohio State University

Ohio University

The Pennsylvania State University

Purdue University

Saint Louis University

Southern Illinois University

The University of Texas at Austin

Washington University

Wayne State University

The University of Wisconsin-Madison

This report was prepared as an account of work sponsored by an
agency of the United States Government. Neither the
United States nor any agency thereof, nor any of their
employees, makes any warranty, expressed or implied, or
assumes any legal liability or responsibility for any third party's
use or the results of such use of any information, apparatus,
product or process disclosed in this report, or represents that its
use by such third party would not infringe privately owned
rights. Mention of commercial products, their manufacturers,
or their suppliers in this publication does not imply or connote
approval or disapproval of the product by Argonne National
Laboratory or the United States Government.

This informal report presents preliminary results of ongoing work or work that is more limited in scope and depth than that described in formal reports issued by the Energy and Environmental Systems Division.

Printed in the United States of America. Available from National Technical Information Service, U. S. Department of Commerce, 5285 Port Royal Road, Springfield, Virginia 22161 


\title{
ARGONNE NATIONAL LABORATORY
}

9700 South Cass Avenue

Argonne, Illinois 60439

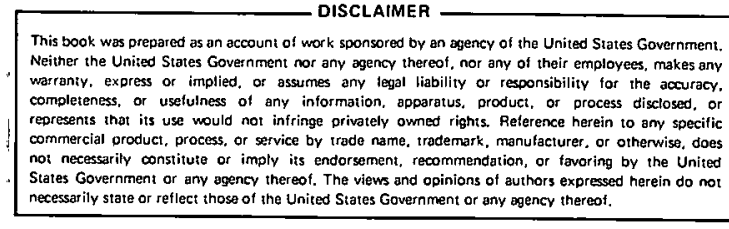

HEAT -PUMP-CENTERED

INTEGRATED COMMUNITY ENERGY SYSTEMS:

System Development.

Georgia Institute of Technology Final Report*

by

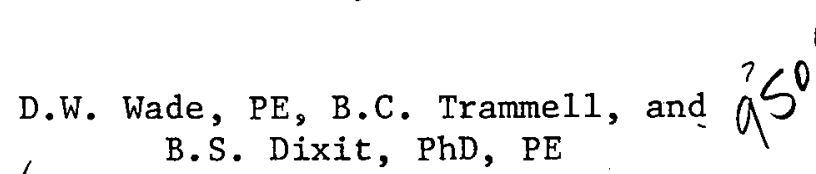

$\sqrt{ }$ GEORGIA TECH RESEARCH INSTITUTE

and

D.C. McCurry, $P E$, and B.A. Rindt, $P E$

McCurry and Associates, Inc.

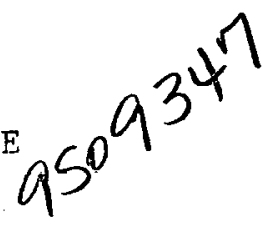

December 1979

Prepared for

Energy and Environmental Systems Division

Argonne National Laboratory

Under Argonne Contract No. 31-109-38-4551

Argonne Pruject Manager: James M. Cálm, PE

\author{
Work sponsored by \\ U.S. DEPARTMENT OF ENERGY \\ Assistant Secretary for Conservation and Solar Energy \\ office of Buildings and Communlty Systems \\ Community Systems Division \\ Community Systems Technology Branch
}

*This report supersedes ANL/ICES-TM-28: Heat-Pump-Centered Integrated Comminity Energy Systems, System Development, Georgia Institute of Technology Interim Report. 


\section{THIS PAGE WAS INTENTIONALLY LEFT BLANK}




\section{PREFACE}

More than one-quarter of the energy consumed in the United States is used to heat and cool buildings and to heat service water. Approximately $83 \%$ of the energy for these services is supplied from natural gas and oil. Recognition of the need to conserve these and other natural resources has been spurred, in large part, by the oil embargo of 1973 and subsequent escalation in fuel prices, by energy shortages, by increasing electricity "brownouts" in urban centers, and by the crippling effects of labor strikes and stoppages in the energy supply industries. In recent years, development and acceptance of energy conserving systems which avoid dependence on scarce or interruptible fuels has increased markedly both in the United States and abroad.

Integrated community energy systems (ICES) are a comprehensive approach to increasing the efficiency of the varied ways in which energy is provided to and utilized by a community. ICES also offer opportunities to reduce dependence on scarce resources, protect environmental quality, reduce costs of energy and energy-consuming services, and, perhaps most importantly, meet energy needs without adversely affecting lifestyles.

The ICES approach to meeting these goals is embodied in three levels of integration. First, by incorporating innovative technology to maximize the resource-utilization efficiency, energy requirements can be reduced. Included in this method are cogeneration (or more precisely coproduction) and cascading uses of energy to minimize the thermodynamic mismatch of sourceenergy qualities and actual energy needs. Also included is fuel substitution in centralized community-scale systems which would be impractical in independent, individual-building and separate-service energy systems. Second, by integrating the energy and energy-consuming systems with the functional design and layout of the community, load-management advantages $c$ an be achieved and distribution losses can be minimized. At the same time, resource needs $c$ an be reduced through appropriate land utilization and planned growth. And third, the community systems development is integrated with the financial and regulatory mechanisms common to communities to permit widespread implementation.

A specific ICES may consist of either a partial or complete integration of these approaches, as appropriate to strike the desired balance among a community's economic, social, environmental, and energy-conservation goals. An ICES $c$ an be applied to a total community as we 11 as to portions of a community and the services provided need not be the same for all areas served. While ICES include a broad spectrum of technologies to meet energy service requirements, the ICES concept does not arbitrarily define either the energy services to be provided or the type, size, or function of the area to be served. As a result, an ICES is tailored for each application. The determination of the kind and number of energy services provided and the size of the service area for each such service is based on an optimum combination of energy efficiencies, indigenous resource and labor supplies, economics, and environmental conditions.

Heat-pump-centered integrated community energy systems (HP-ICES) are energy systems for communities which provide heating, cooling andor 
other thermal energy services through the use of heat pumps. Since heat pumps primarily transfer energy from existing and otherwise probably unused sources, rather than convert it from electrical or chemical to thermal form, HP-ICES offer significant potential for energy savings. By powering these heat pumps with nonscarce fuels, the use of which would be impractical in most conventional systems, less-abundant. fuels including natural gas and oil can be conserved. Secondary benefits of HP-ICES include reduction of adverse environmental effects as compared to conventional systems, reliable production of services in contrast to the increasingly frequent utility curtailments and interruptions, and delivery of services to consumers at costs lower than those for conventional systems (including acquisition, operation, and maintenance costs).

The report which follows is a result of the System Development Phase of the HP-ICES Project. The objective of this multiphase project is development and demonstration of HP-ICES concepts leading to one or more operational systems by the end of 1984. The seven phases include System Development, Demonstration Design, Design Completion, HP-ICES Construction, Operation and Data Acquisition, HP-ICES Evaluation, and Upgraded Continuation.

This Project is sponsored by the Community Systems Technology Branch, Community Systems Division, Office of Buildings and Community Systems, Assistant Secretary for Conservation and Solar Energy, U.S. Department of Energy (DOE). It is a part of the Community Systems Program and is managed by the Energy and Environmental Systems Division of Argonne National Laboratory.

The report which follows presents the findings in the development and analysis of one concept under investigation. This report was prepared by the Georgia Institute of Technology. 
WASTEWATER HEAT RECOVERY

HEAT PUMP CENTERED-INTEGRATED COMMUNITY

ENERGY SYSTEMS

TABLE OF CONTENTS

PAGE NO.

LIST OF FIGURES

ix

LIST OF TABLES

$\mathrm{xi}$

AB̈BREVIATIONS AND SYṂBOLS

ABSTRACT

1.0 SYSTEM CONCEPT

1.1 Introduction

3

1.2 System Energy Flow

5

1.3 System Description

1.4 System Operation 20

1.5 Operation as a Thermal Utility 24

1.6 System Applications . 25

2.0 POTENTIAL APPLICATIONS 27

2.1 Introduction $\quad 27$

2.2 Factors Affecting Application 27

2.3 Projections $\quad 42$

3.0 EXPECTED PERFORMANCE 55

3.1 Introduction

3.2 Selection of Conditions 55

3.3 System COP and Energy Consumption 58

3.4 Analysis of Results $\quad 59$

$3.5 \mathrm{HP}-$ WHR Systems using only Distributed 68

3.6 Second Law Analysis $\quad 70$

4.0 EXPECTED ECONOMICS $\quad 81$

4.1 Introduction 81

4.2 System Design 81

4.3 First Costs . 83 
4.4 Operating Costs

4.5 Operation as a Thermal Utility 93

4.6 Life Cycle Costs 94

4.7 Summary 96

5.0 ENVIRONMENTAL IMPACT $\quad \cdots \cdots$

5.1 Introduction 97.

5.2 Environmental Impacts of Construction 100

5.3 Environmental Impacts of Operation 103

6.0 PROJECTED GROWTH 111

6.1 Introduction 111

6.2 Methodology for Projecting Growth 111

6.3 Central Plant and Maịn Pumping Facilities 117

6.4 Distribution and Return System 121

7.0 IDENTIFIED VARIATIONS $\quad 125$

7.1 Introduction $\quad \cdot \quad 125$

7.2 Thermal Energy Sources $\quad 125$

7.3 Components 128

7.4 System Variation 131

$\begin{array}{lll}7.5 & \text { Summary } & 135\end{array}$

8.0 SITE-SPECIFIC FEASIBILITY STUDY FOR CONYERS, GEORGIA 137

8.1 Introduction 137

8.2 Community Description $\quad 1399$

$\begin{array}{ll}\text { 8.2.1 Population Growth } & 140\end{array}$

8.2.2 Economic Characteristics 140

8.2.3 Land Use 141

8.2.4 Climate 142

8.2.5.. Proposed Seṛvice Area 144

$\begin{array}{ll}8.2 .6 \text { Building Construction } & 147\end{array}$

8.2.7 Heating and Cooling Loads 148

8.2.8 Thermal Energy Resources 153

8.3 Conyers System Description . 165

$\begin{array}{lll}\text { 8.3.1 System Design Calculations . } & 171\end{array}$ 
8.3.2 Component Descriptions 180

8.3.3 Expected Performance 184

8.3.4 Expected Economics 196

8.3.5 Plan for System Phasing 206

8.4 Institutional Considerations 210

$\begin{array}{ll}8.4 .1 & \text { Ownership and Operations of } \\ \end{array}$

8.4.2 Financing Alternatives 213

8.4.3 Comparison of Allernative Methods of Ownership, Operation and Financing of an HP-ICES

8.4.4 State of Georgia - Review of Legal and Regulatory Factors

8.4.5 City of Conyers, Georgia - Review of Local Ordinances and Codes

9.0 SITE-SPECIFIC FEASIBILITY STUDY FOR CORNELIA, GEORGIA 221

9.1 Community Description - Cornelia Georgia 221

9.1.1 Population Growth 221

9.1.2 Economic Characteristics 222

9.1 .3 Land Use 223

9.1 .4 Climate $\quad .224$

9.1.5 Proposed Service Area . 226

$\begin{array}{ll}9.1 .6 & \text { Building Construction }\end{array}$

9.1.7 Heating and Coolings Loads 230

9.1.8 Thermal Energy Resources 234

9.2 Cornelia System Description · 250

9.2.1 System Design Calculations 252

9.2.2 Component Descriptions . 263

9.2.3 Expected Performance 264

9.2.4 Expected Economics 275

9.2.5 Plan for System Phasing . . 284 
9.3 Institutional Considerations

9.3.1 City of Cornelia, Georgia - Review of Local Ordinances and Codes

288

10.0 COMPONENT TESTING 289

10.1 Introduction $\quad 289$

10.2 Thermal Energy Source - Baseline Data $\quad 289$

10.3 Central Station Heat Pump Equipment 294

10.4 End-User Heat Pump Equipment 299

$\begin{array}{lll}10.5 & \text { Summary } & 301\end{array}$

$\begin{array}{lll}10.6 & \text { Methodology } & 301\end{array}$

11.0 ANALYSIS DESCRIPTION 303

11.1 Introduction . . . 303

11.2 Potential Applications . 303

11.3 Expected Performance $\quad 304$

11.4 Expected Performance 305

$\begin{array}{ll}\text { REFERENCES } & 335\end{array}$

APPENDICES

Appendix A - Technical Data for Chapter 2.0 341

Appendix B - Technical Data for Chapter $4.0 \quad 349$

Appendix C - Technical Data for Chapter 8.0 353

Appendix D - Technical Data for Chapter $9.0 \quad 375$

Appendix E - Technical Data for Chapter 10.0

Appendix F - Technical Data for Chapter $11.0 \quad 405$ 
Figure No. 1-1

1-2

1-3

$1-4$

$1-5$

$1-6$

$1-7$

$1-8$

$1-9$

2-1

3-1

3-2

3-3

3-4

3-5

3-6

3-7

$3-8$

4-1

4-2

4-3

$4-4,5$

7-1

$7-2$

$8-1$

$8-2$

$8-3$
Title

Page No:

Wastewater Heat Recovery Scheme - System Concept

4

Conventional Systems - Energy Flow 6

HP-ICES: Heating Mode - Energy Flow. 8

HP-ICES: Cooling Mode - Energy Flow 8

$\begin{array}{ll}\text { Wastewater Flow Cycle } & 10\end{array}$

Centrifugal Chiller Performance : 15

Heat Pump Cycles. 19

HP-WHR System Schematic - Heating Mode 21

HP-WHR System Schematic - Cooling Mode 23

Heating Degree-Day Map of the U. S. 30

HP-WHR System $\quad 56$

HP-WHR System 57

Wastewater Temperature vs. HP-WHR System

C.O.P. (End-User Water Temp. $-80^{\circ} \mathrm{F}$ )

60

Wastewater Temperature vs. HP-WHR System

C.O.P. (End-User Water Temp. - $95^{\circ} \mathrm{F}$ )

61

Distributed Heat Pump System Schematic 60

Availability Analysis - Conventional Systems 73

Availability Analysis - HP-WHR System

(Heating Mode)

76

Availability Analysis - HP-WHR System

(rnnling Mnde)

77

HP-WHR System Central Plant Costs 89

Total HP-WHR Utility Cost Per End-User $\quad 89$

Total Annual Energy Costs . 91

Present Value of Expenditures (Northern

Climate, Southern (1.imate)

95

Composite Thermal Energy Supply for HP-ICES 129

Industrial HP-WHR System Schematic 134

Location Map - Demonstration Communities 138

Conyers, Ga. and Contiguous Areas 143

Conyers, Ga. HP-WHR System - Service Area 146 
List of Figures (Cont'd)

Figure No.

Title

Page No.

$8-4$

Almand Branch Sewage Treatment Plant - General

Layout

155

$8-5$

Wastewater Temperature and Flow vs. Time

157

8-6

Plant Effluent Temperature vs. Duration

161

8-7

Plant Effluent Flow vs. Duration

161

8-8

HP-WHR System Schematic

166

8-9

HP-WHR System - Proposed C.entral Station Layout

169

8-10

HP-WHR System - Service Areas and Distribution

Piping

170

$8-11$

Plot of Electrical Consumption - Conyers Central Plant 189

9-1

Cornelia, Ga, and Contiguous Areas

225

9-2

Cornelia, Ga. HP-WHR System - Service Areas

9-3

Cornelia, Ga. - Sewer System

236

$9-4$

Cornelia, Ga. - Wastewater Treatment Plant

237

$9-5$

Wastewater Temperature and Flow vs. Time

239

$9-6$

Flow Area Schematic, Cornelia Wastewater

System

245

$9-7$

Plant Influent Temperature vs. Duration

246

9-8

HP-WHR System Schematic

251

9-9

HP-WHR System - Proposed Central Station Layout

253

$9-10$

HP-WHR System - Service Areas and Distribution Piping

254

$10-1$

Kennison Flow Nozzle Installation

10-2

Parshall Flume Installation

10-3

C.O.P. vs. Fouling Factor

Heat Pump - Basic Vapor Compression Cycle

HP-WHR System - Model for Simultaneous

Heating and Cooling

$11-3$

Block Diagram - Thermal Storage Analysis

$11-4$

Water-to-Air Heat Pump (C.O.P., Heating

Capacity vs. Water Temperature: 2 ton Nominal

Rated Unit)

$11-5$

Water-to-Air Heat Pump (C.0.P., Heating

Capacity vs. Water Temperature: 4 ton Nominal

Rated Unit)

Heat Pump - Air-to-Air Cycle 


\section{LIST OF TABLES}

Table No.

2-1

3-1

3-2

3-3

$3-4$

3-5

4-1

4-2

$4-3$

4-4

8-1

8-2

8-3

8-4

8-5

$8-6$

8-7

8-8

8-9

$8-10$

8-11

9-1

9-2
Title

Page No.

Heat Extracted from Wastewater

HP-WHR System - C.O.P. and System

Energy Requirements

62

Air-to-Air Heat Pump - C.O.P. and

System Energy Requirements

63

HP-WHR System Performance: Cooling Mode 65

Annual Energy Consumption 67

Distributed Heat Pump System Performance

69

Typical End-User Heating and Cooling

Load Data

82

Central Plant - Electrical Energy

Requirements

87

End-User - Electrical Energy Requirements

88

Conventional System Energy Costs

Annual Heating and Cooling Degree

Days - Conyers, Ga.

150

Conyers HP-WHR System Loads

151

Sewage Treatment Plant - Temperature and Flow Data Summary

158

Heat Available from Wastewater. 163

Distribution Piping Specifications 180

Annua 1. System Performance 185

Power Usage Analysis - Conyers

Central Plant

188

System Component Energy Use

190

Thermal Utility Charges - Cash Flow

201

Conventional Systems - Life Cycle

Cost Analysis

HP-WHR System - Life Cycle Cost

Analysis

Population and Projections for

Cornelia

222

Annual Heating and Cooling Degree

Days = Cornelia, Ga. 
Table No.

$9-3$
$9-4$
$9-5$
$9-6$
$9-7$
$9-8$
$9-9$
$9-10$
$9-11$
$9-12$
$9-13$
$11-1$
$11-2$
$11-2$

Appendices

A -1

A-2

A-3

$\dot{\mathrm{A}}-4$

A-5

E-1
Title

Cornelia HP-WHR System Loads

Cornelia Sewage Treatment Plant Temperature and Flow Data Summary

Flow Data, Cornelia Wastewater System

241

243

Heat Available from Wastewater

248

Distribution Piping Specifications

263

Annual System Performance

265

Power Usage Analysis - Cornelia

Central Plant

267

System Component Energy Use

269

Thermal Utility Charges - Cash Flow

279

Conventional Systems - Life Cycle

Cost Analysis

281

HP-WHR System - Life Cycle Cost

Analysis

282 .

Thermal Conductivity of Soil

319

Central Chiller C.O.P.

327

Central Heat Pump C.O.P.

Weather Data for Test Cities

Commercial Building Heating and Cooling Loads

Residential Heating and Cooling Loads

344

Sewage Treatment Facilities Data

347

Sewage Treatment Facilities Data

348

Fouling Factors

404 
SYMBOL

A

$\mathrm{A}_{\mathrm{S}}$

$\mathrm{ADF}$

$\mathrm{AMC}_{i}$

$\mathrm{ADC}_{i}$

APDC

ARI

ASHRAE

avg.

BOD

Btu

Btuh

C

C

$\mathrm{C}_{\mathrm{V}}$

$c_{\mathrm{p}}$

c

CDD

CFT

C.O.P.

cu.ft.
DEFINITION

area (orifice), $\mathrm{ft}^{2}-(\sec , 10.2 .2)$

heat transfer surface area, $f t^{2}$

Average Daily Flow

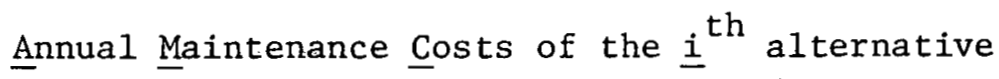

Annual Operating Costs of the $\underline{i}^{\text {th }}$ alternative

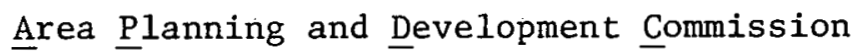

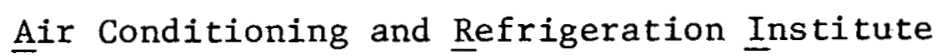

American Society of Heating, Refrigerating and Air Conditioning Engineers

average

Biochemical Oxygen Demand

British thermal unit

British thermal units per hour

thermal conductance of pipe, $\frac{\mathrm{Btu}}{\mathrm{hr}-\mathrm{ft}^{2}-\mathrm{OF}}$ (sec. 11.4.7)

specific heat of water, $\frac{\mathrm{Btu}}{\mathrm{Lbm}-\mathrm{OF}}$ (sec. 2.3.1)

specific heat of water, $\frac{\mathrm{Btu}}{\mathrm{Lbm}-\mathrm{OF}} \cdot(\mathrm{sec} \cdot 11.4 .7)$

specific heat of water, $\frac{\mathrm{Btu}}{\mathrm{Lbm}^{\mathrm{O} F}}$ (sec, 11.4.4)

weir or orifice constant (sec. 10.2.2)

Cooling Degree Days

cubic feet

Coefficient of Performance

cubic feet 


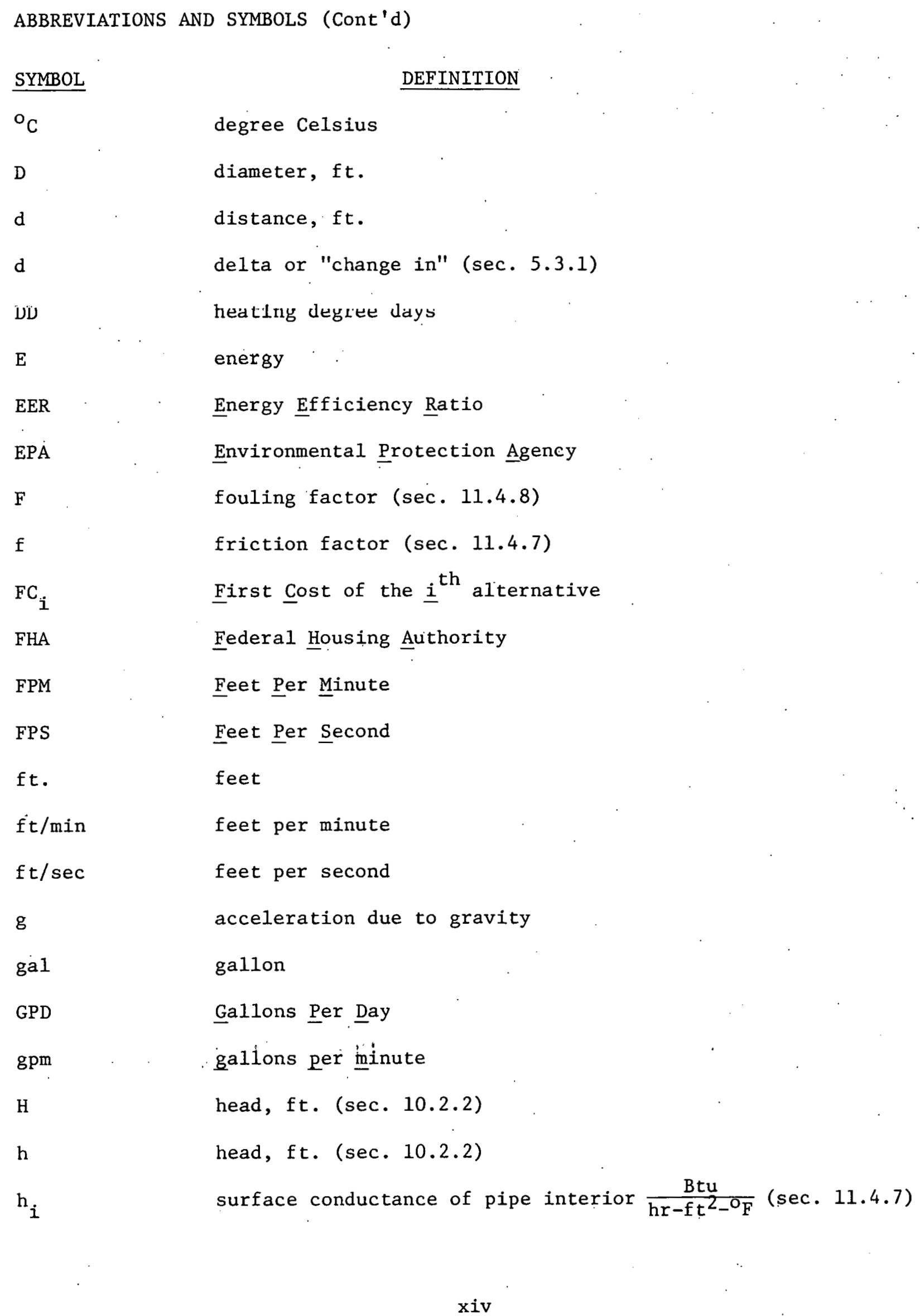




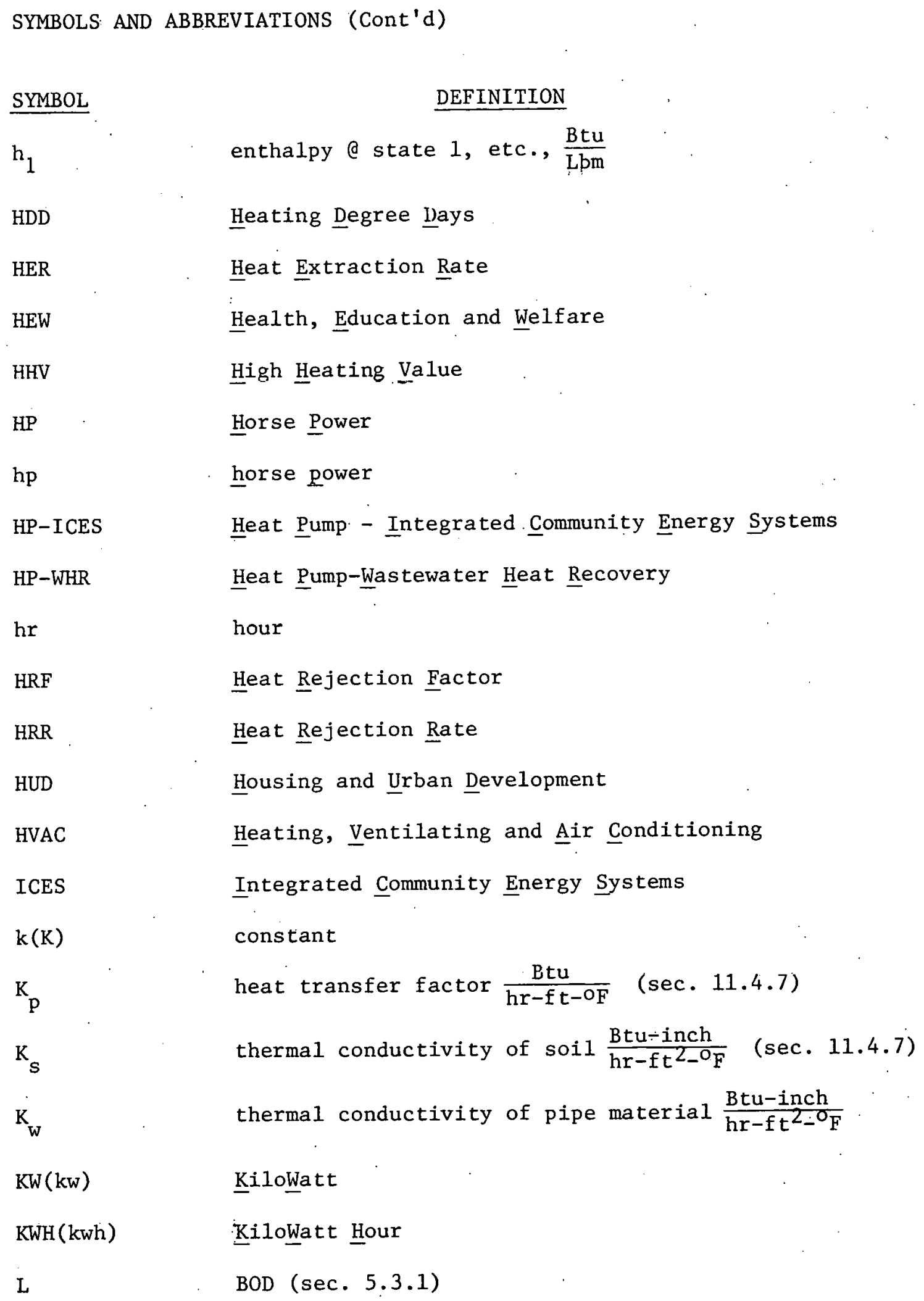




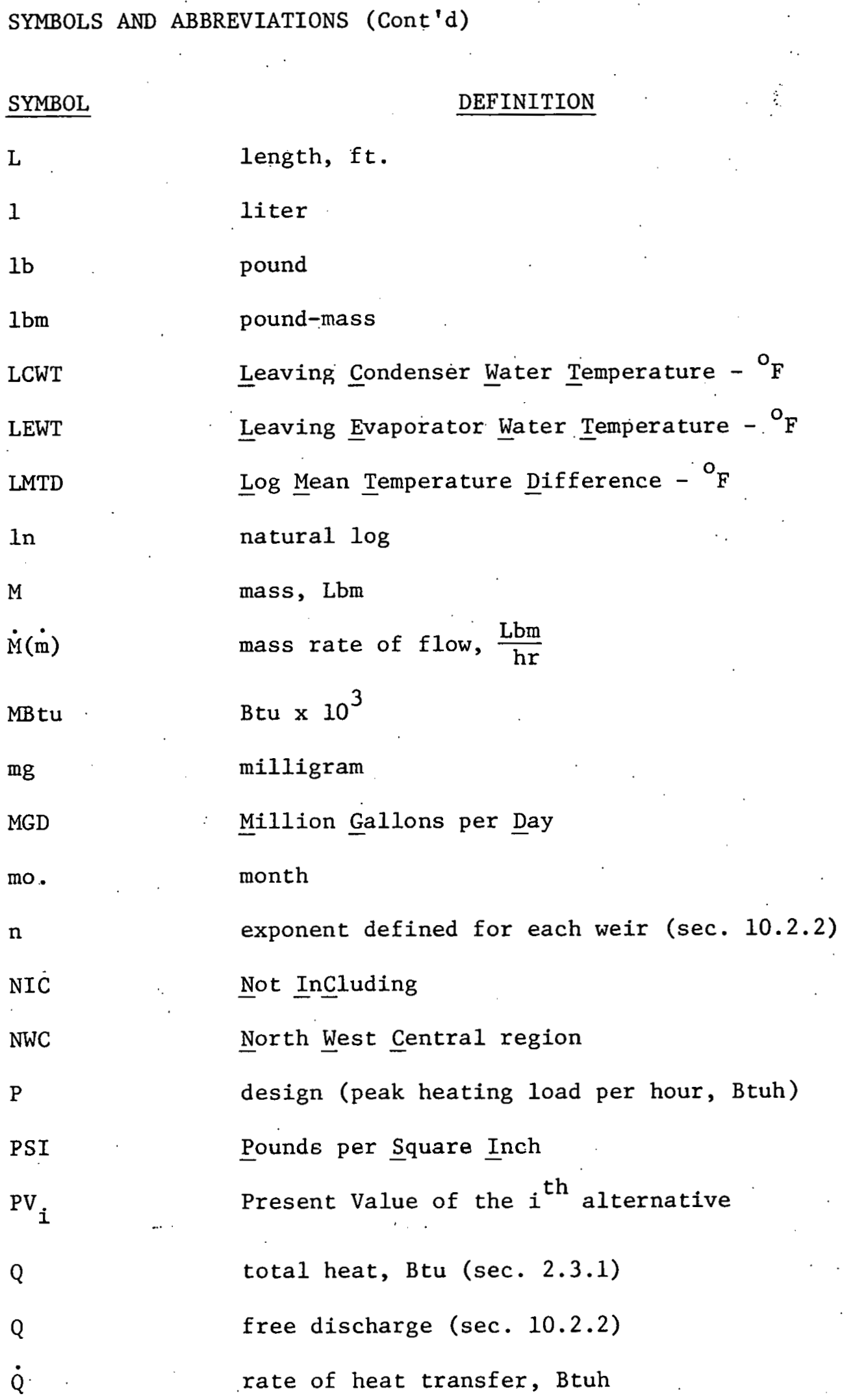


SYMBOLS AND ABBREVIATIONS (Cont'd)

SUMBOL

QUAD

R

r

RTD

SA

$\mathrm{sq} \cdot \mathrm{ft}$.

$\mathrm{T}$

t

therm

TD

$\mathrm{U}_{\mathrm{u}}$

V

$\bar{v}$

VA

W

$\mathrm{W}_{\mathrm{C}}$

$\mathrm{W}_{\text {losses }}$

yr.

$\Delta$

II

$\rho$

$\theta$

\section{DEFINITION}

Btu $\times 10^{15}$

universal gas constant

radius, ft.

Resistance Temperature Device

South Atlantic region

square feet

temperature, ${ }^{\circ} \mathrm{F}$

time, hrs.

natural gas Btu $\times 10^{5}$

design temperature difference, ${ }^{\circ} \mathrm{F}$

overall heat transfer coefficient, $\frac{\mathrm{Btu}}{\mathrm{hr}-\mathrm{ft} \mathrm{t}^{2}-\mathrm{OF}}$ (sec. 11.4.7)

velocity, ft/sec (sec. 10.2.2)

velocity, $\mathrm{ft} / \mathrm{sec}$ (sec. 11.4 .7 )

Veterans Administration

flow of wastewater, $\frac{\mathrm{Lbm}}{\mathrm{hr}}$ (sec. 2.3.1)

compressor work, KWH or

work of thermal losses, Btuh

year

chainge in

cfficicncy

density $\frac{\mathrm{Lbm}}{\mathrm{ft}^{3}}$

time, hrs 


\section{THIS PAGE \\ WAS INTENTIONALLY \\ LEFT BLANK}


Heat Pump Centered-Integrated Community Energy Systems (HP-ICES) show the promise of utilizing low-grade thermal energy for low-quality energy requirements such as space heating and cooling. The Heat Pump - Wastewater Heat Recovery (HP-WHR) scheme is one approach to an HP-ICES that proposes to reclaim low-grade thermal energy from a community's wastewater effluent. This report develops the concept of an HP-WHR system, evaluates the potential performance and economics of such a system, and examines the potential for application. A thermodynamic performance analysis of a hypothetical system projects an overall system Coefficient of Performance (C.O.P.) of from 2.181 to 2.264 for wastewater temperatures varying from $50^{\circ} \mathrm{F}$ to $80^{\circ} \mathrm{F}$. Primary energy source savings from the nationwide implementation of this system is projected to be 6.0 QUADSfuel oil, or 8.5 QUADS - natural gas, or 29.7 QUADS - coal for the period 1980 2000, depending upon the type and mix of conventional space conditioning systems which could be displaced with the HP-WHR system. Site-specific HP-WHR system designs are presented for two application communities in Georgia. Performance analyses for these systems project Annual cycle system C.O.P.'s of 2.049 and 2.519. Economic analysis on the basis of a life cycle cost comparison shows one site-specific system design to be cost competitive in the immediate market with conventional residential and light commercial HVAC systems. The second site-specific system design is shown through a similar economic analysis to be more cuslly than conventional systems due mainly to the current low energy costs for natural gas. It is anticipated that, as energy costs escalate, this HP-WHR system will also approach the threshold of economic viability. 
THIS PAGE

\section{WAS INTENTIONALLY \\ LEFT BLANK}




\subsection{SYSTEM CONCEPT}

\subsection{INTRODUCTION}

The Heat Pump Centered-Integrated Community Energy System (HP-ICES) concept presented in this report is essentially a cascaded heat recovery scheme which extracts low-grade thermal energy from a community's wastewater effluent by means of electrically driven heat pumps. The extracted thermal energy is distributed into the community via a moderate temperature water piping system. At each point of end-use the thermal energy is extracted from the transport media by unitary heat pumps and utilized for space heating purposes. The system can also operate in a cooling mode by utilizing the community wastewater flow as a sink for heat rejected during space cooling. From an energy utilization standpoint, the concept represents a method of utilizing portions of the lowest quality energy available in the community energy degradation cycle.

Figure No. 1-1 is a simplified schematic of the basic system elements. These elements consist of: a primary heat source, a central station heat pump, a thermal distribution system, and individual end-user heat pumps. Detailed discussions of each element will be presented in the following sections.

The technical. feasibility of wastewater heat recovery' appears well within the realm of believability. Institutional acceptance barriers, economic viability and the efficiency of resource utilization by such a scheme are somewhat in doubt and will be addressed by various sections of this report and by detailed application analyses in the final keport.

The remainder of this section will describe each of the system elements, component configurations, system operating modes, applications and potential benefits from adoption of the scheme. In-depth analyses of system characteristics 


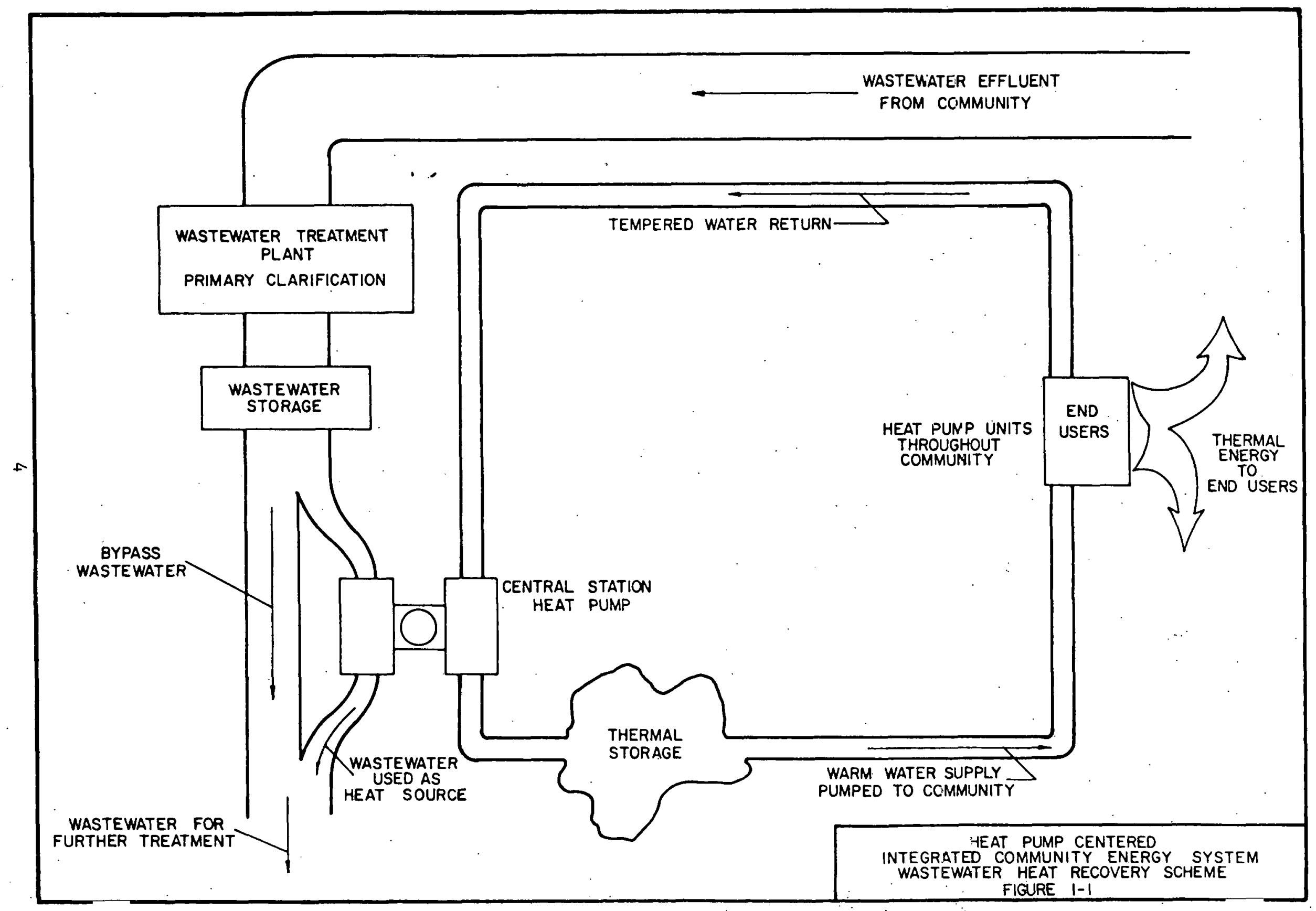


are presented in subsequent sections.

\subsection{SYSTEM ENERGY FLOW}

Conventional space conditioning systems utilize high-grade energy sources, such as natural gas or oil, in direct combustion in building heating equipment or electricity generated at efficiencies of less than 40 percent. As depicted in.Figure 1-2, both processes lose substantial amounts of energy in the conversion process from primary fuel source to end-use.

One way to improve the utilization efficiency of high grade energy sources is to use waste heat from high quality energy processes to satisfy lower quality requirements. The effect is to degrade energy quality in a cascading arrangement so that the highest quality energy is not used to satisfy low quality needs.

In the case of our community energy system discussed previously, it may be possible to utilize waste energy streams from a community's industries, electric generating plants and other high-grade energy users to satisfy portions of the community low-grade energy needs such as space heating. Waste heat utilization schemes such as this would lessen the requirements for new highgrade energy sources and improve the energy utilization efficiency of the resources currently consumed by high quality energy users.

One virtually untapped low-grade energy source is wastewater effluent streams generated by industry, power generation, residences and the commercial sector. Admittedly, the desirability of this energy source is low due to its low-energy qualicy and cunlaulnaled state, however, the amount of energy contained is significant when one considers the quantities involved. If we are to fully integrate energy use by the community, we must consider every available encrgy source. 


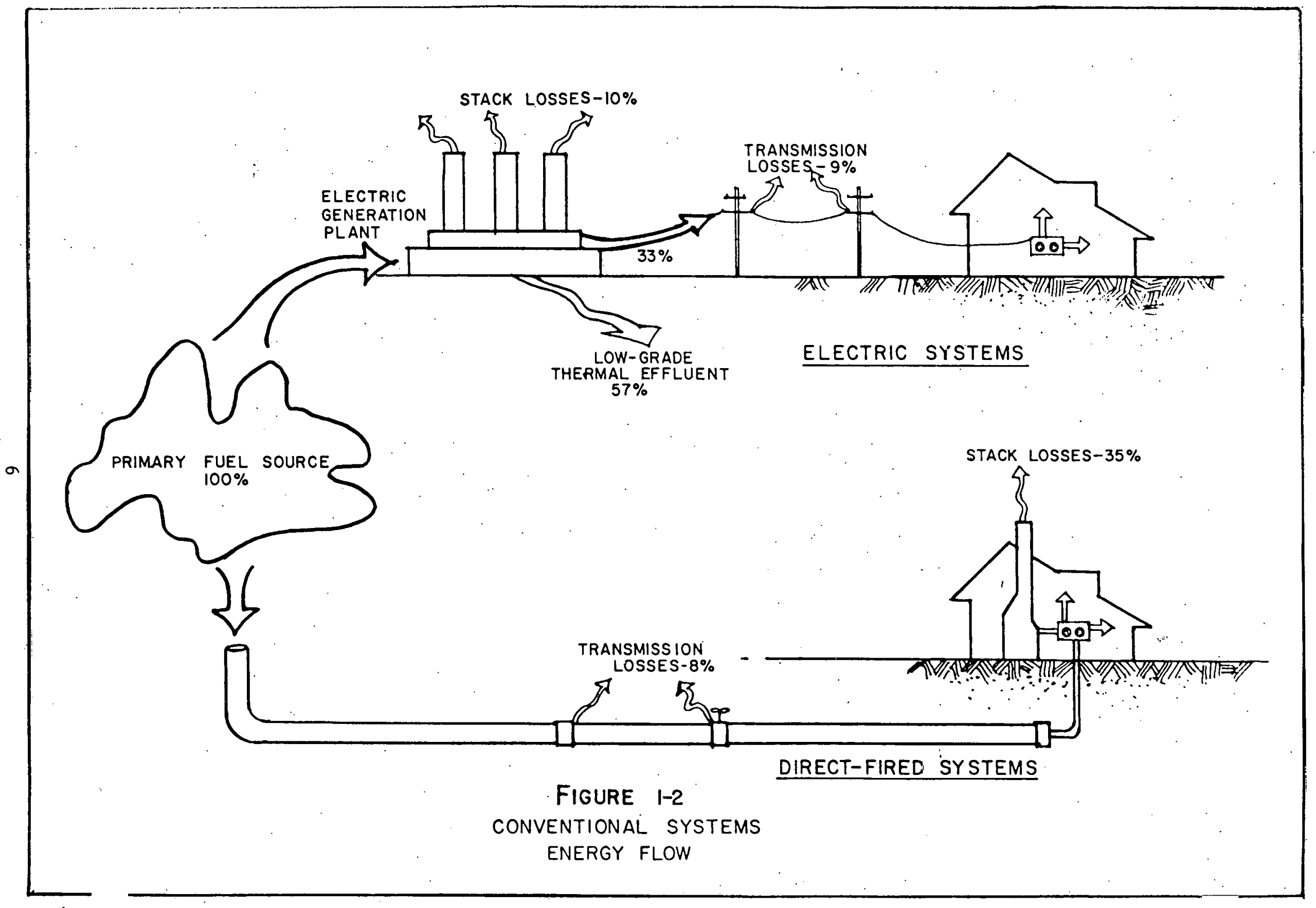


The energy flow scheme presented by Figure 1-3 is a representation of how low-grade heat from a community's wastewater stream could be utilized for building space heating. Heat could be extracted from industrial and residential sanitary sewer effluent and from cooling water streams discarded from power plants and industrial users by means of heat pumps. The heat pumps would be used to elevate the temperature of the heat sufficiently for use in space heating. The Heat Pump Wastewater Heat Recovery Scheme (HP-WHR) applied to a community would require elements which would:

- Insure adequate energy supply to the Community

- Distribute the thermal energy to the Community

- Allow the end-users in the Community to utilize the thermal energy.

Additionally, the distribution system and end-user heat pumps could dissipate heat extracted from buildings during the cooling season. This process is depicted by Figure 1-4.

\subsection{SYSTEM DESCRIPTION}

A complete description of the HP-WHR scheme requires a discussion of each of the system's major components, their characteristics, and how they interact. Referring again to Figure 1-1, these compunenls are:

- Primary Heat Source

- Central Station Heat Pump

- Thermal Distribution System

- Individual End-User Heat Pumps

\subsubsection{PRIMARY HEAT SOURCE}

The primary waste heat source the HP-WHR scheme seeks to utilize is the commun1ty wastewater effluent. This source can include sanitary sewer discharges, 


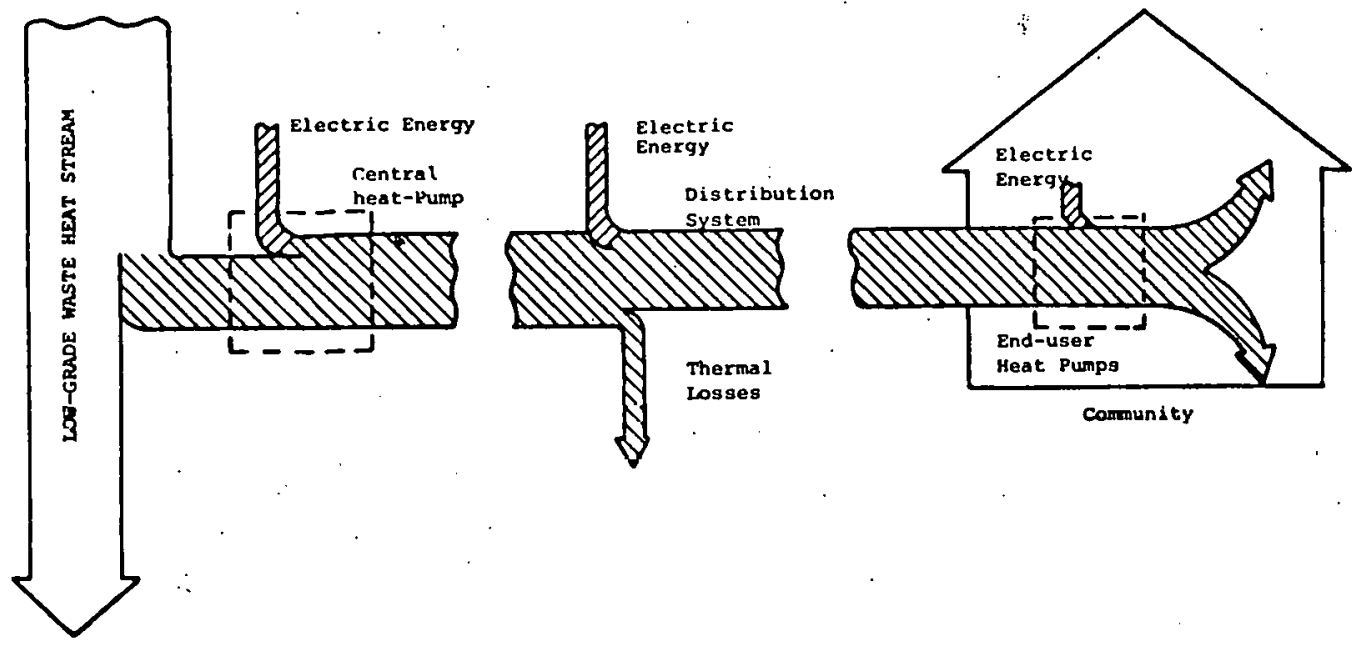

\section{HP-ICES ENERGY FLOW \\ HEATING MODE}

FIGURE 1-3

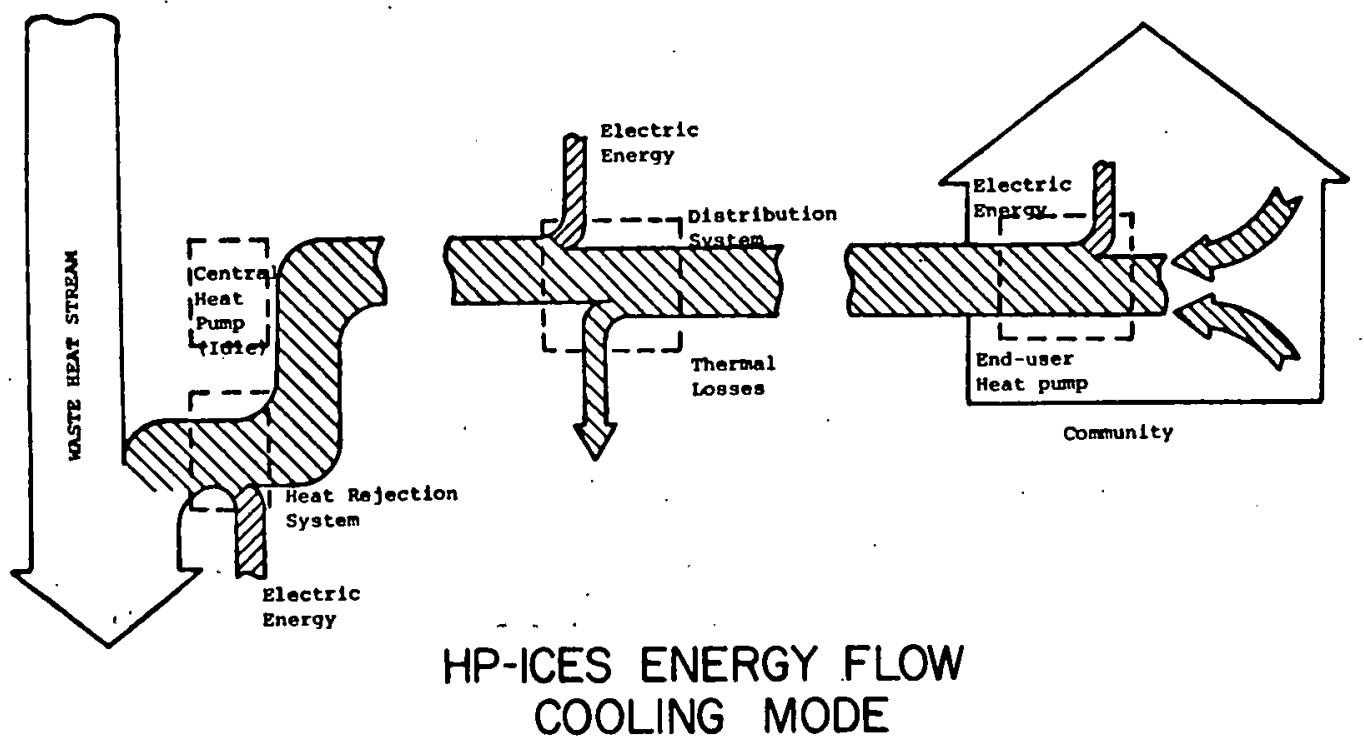

FIGURE $1-4$ 
storm sewer discharges and cooling water discharges. However, only sanitary sewer discharges will be addressed in this report.

We are all aware of the numerous warm water discharges into the sanitary sewer from our own residences. Bathing, cooking, washing and many other home activities use hot or warm water which is eventually discharged to the sanitary sewer system. Similarly, but on a much larger scale, industrial and commercial activities create large volumes of warm water which is discharged to the sanitary sewer system. Common industrial sources are cooling water, spent process water, wash water and blowdown from heating and cooling systems.

Many disadvantages associated with using sewage effluent are apparent due to the dirty nature of wastewater. The incentives which must be kept in mind when approaching the problem are that the collection system for the energy contained in the stream is already installed and new capital is not required to build the collection system. Secondly, the potential for energy recovery will be greatest where it is needed most, i.e. in heavily populated, dense metropolitan areas.

The most important characteristics of the sewage effluent will be its quantity, thermal quality and physical properties. These characteristics will of course, be site specific and vary somewhat on a daily, weekly and seasonal basis. It is possible to make several general comments about the nature of each characteristic. The quantity of wastewater from a community is generally expresșed by sanitary engineers in terms of gallons per day. on an hourly. basis the flow can vary substantially over weekend and holiday periods in areas where there are a large number of industrial discharges. 


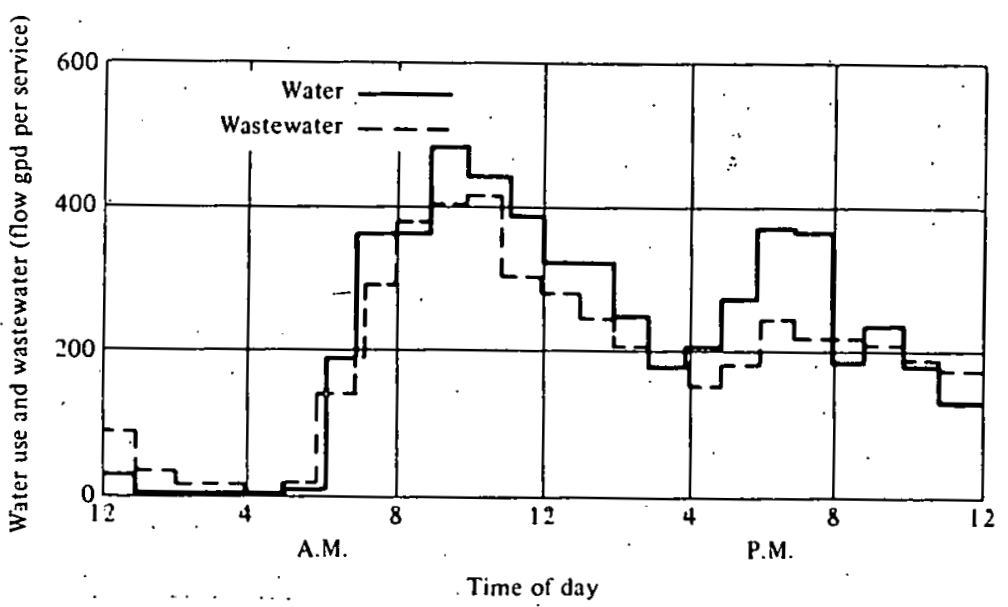

WASTEWATER FLOW CYCLE

FIG. $1-5$

SOURCE: WATER SUPPEY \& POLLUTION CONTROL ${ }^{8}$

One other significant factor that can influence the quantity of wastewater is ground and surface water infiltration. Infiltration of ground and surface water into the sewer system will vary seasonally and with the age and design of the sewer system. In older systems where storm and sanitary sewers are combined, an extreme variation in flow of several hundred percent can occur during heavy rains. Additionally, the influx of surface water during the winter months will tend to lower sewage temperatures. This could be significant, especially where melting snow infiltrates into the sanitary sewer system.

Thermal quality of the wastewater will vary according to. site specific conditions. Industrial waste streams tend to be at higher temperatures than residential discharges. For that reason, communities with high industrial concentrations may offer more potential for energy recovery than strictly residential communities. It is even conceivable that some wastewater effluents may be utilized without the need for an initial temperature boost by the central station heat pump. 
In predominantly residential communities there will be some concern over the thermal content of the wastewater streams being tapped. Typically, wastewater treatment systems are designed to operate satisfactorily at the lowest wastewater temperatures that might be expected in the particular region in which the treatment facility is to be located. Indeed, a thorough search of literature on wastewater treatment revealed that actual plant influent temperatures are not generally considered or required in the design of treatment systems. Consequently, it is rare for existing treatment plants to record the temperature of the plant wastewater influent. The only regulations now existing deal with the thermal pollution of the body of water receiving a wastewater treatment plant's discharge and thus are meant to restrict the maximum temperature of discharge. Obviously, the operation of an HP-WHR system in conjunction with a wastewater treatment system could significantly affect the operating conditions and thus the treatment efficiency of the wastewater facility. The potential effects are discussed in more detail in Chapter 5.0 - ENVIRONMENTAL IMPACT. In general though, the change in operating temperatures must be given consideration during the design phase of new wastewater treatment plants to properly size biological treatment units or, when exisitng plants are considered for retrofit of an HP-WHR system, to predict lost treatment efficiencies. However, it is anticipated that, as long as the discharge quality and temperature of the effluent from wastewater facilities serving in conjunction with HP-WHR systems meet existing requirements, no further regulations regarding effluent temperature levels will be necessary.

The lack of temperature data will hinder initial HP-WHR system designs. However, if the concept appears feasible, temperature measurements are relatively 
simple to obtain with recording thermometers. The necessary measurements will be discussed further in Chapter 8.0 - COMPONENT TESTING.

A lower temperature limit approaching ground temperature seems appropriate for most sewer collection systems. Since ground temperature is relatively constant throughout the year and is considerably above ambient air temperatures in the winter months, it would appear that even in the worst case the wastewater stream would be preferable as a heat source to the lower temperature ambient air.

Physical properties of wastewater streams deserve special attention on a site specific basis. Like the other properties of effluents, industrial discharges will introduce a variety of contaminants into the sanitary sewer system. In some cases the corrosive or fouling nature of industrial discharges may render the wastewater stream unusable.

As a rule, the sanitary sewer effluent entering a sewage treatment plant will have the viscosity and density which is approximately the same as pure water. The major impurities in the effluent are suspended particles which may be removed by settling or filtration, colloidal particles smaller than $1 \mu M$, dissolved impurities such as volatiles and minerals and, of course, a considerable microbiological population. A typical analysis of impurities in sanitary sewer effluent will be as follows:

$$
\begin{aligned}
& 300 \mathrm{mg} / \text { liter Suspended Solids } \\
& 500 \mathrm{mg} / \text { liter Dissolved Solids }
\end{aligned}
$$

The remainder of the effluent is essentially water.

The impurities normally found in municipal sewage are routinely handled by conventional treatment practices. The highly polluted nature of the effluent has caused designers to avoid using it whenever possible due to expected fouling problems. 
In the actual design of an HP-WHR scheme, considerable attention will be required to provide adequate fouling allowances for heat transfer surfaces and provisions for cleaning and inspecting components subjected to contact with effluent streams.

\subsubsection{CENTRAL STATION HEAT PUMP}

The Central Station heat pump equipment element of the system will serve to extract energy from the primary heat source and elevate its temperature sufficiently for distribution and use throughout the community. Although only one unit is shown throughout the schematics in this report, it may be advantageous to achieve the desired temperature elevation or improve part load performance characteristics.

Central station heat pumps have been used extensively over the past thirty years in business and industry. The most notable example of this is "water chilling" machines used by the air conditioning industry in large scale building air conditioning. The central station heat pump used in the HP-WHR scheme will be similar to the machine used for building air conditioning systems, except selection procedures will be modified for the required service conditions.

The central station heat pump operates on a closed refrigerant cycle consisting of working fluid compression, condensation, and evaporation. Typically, the working fluid will be one of the freon refrigerants selected for characteristics suitable for the temperature rise required and the machinery's compressor characteristics.

The evaporator and condenser heat transfer components are commonly shell and turbe heat exchangers comprised of steel shell and non-ferrous tubes. Depending on temperature rises and flow quantities, the water in the tubes may make multiple paзscc. Tube material and thickness is of special importance in 
the HP-WHR scheme due to the abusive nature of wastewater effluent. Some experience may be required before an optimum heat exchanger design can be settled on for this application.

The compressor of the central station heat pump can be of the reciprocating, screw or centrifugal type driven by an electric motor. In practice, it is anticipated that the reciprocating compressor will have little applicability due to its limited capacity and somewhat lower operating C.O.P. than centrifugal or screw type compressors. For the purposes of this study, a centrifugal compressor is used as the central heat pump since it is widely used by the air conditioning industry for central station air conditioning applications in the temperature ranges suggested.

A screw compressor will have similar performance characteristics to the centrifugal type. However, commercially available units have somewhat lower capacity than their centrifugal counterparts. In some cases a screw compressor may be advantageous due to its ability to operate at higher temperature and pressure differentials.

The compressor of the central station heat pump is thus assumed to be a centrifugal type driven by an electric motor. Capacity control will be accomplished by. inlet vanes to the centrifugal impeller. It is also anticipated that the machine will be a hermetic design, thus allowing the refrigerant to absorb the heat given off by the electric motor.

Figure $1-6$ is a performance curve for a typical central station water chilling machine used in heat recovery application. The data is presented in terms of Heat Rejection Factor (HRF), which is a ratio of the heat rejected at the condenser to heat absorbed by the evaporator. For refrigerant-gas-cooled hermetic compressors the Coefficient of Performance is defined approximately 
by the following formula:

$$
\mathrm{COP}=[\mathrm{HRF} \times .99] /[\mathrm{HRF}-1]
$$

Note that the on-site COP of the central machine is quite high, ranging from 5 to 7 for the machine shown in Figure 1-6. In actual practice machine COP could be maximized within economic constraints by judicious selection of central station heat pump components. The overall coefficient of performance of the central station will be reduced somewhat by power requirements for auxiliary equipment ${ }^{*}$ such as pumps, controls, etc.

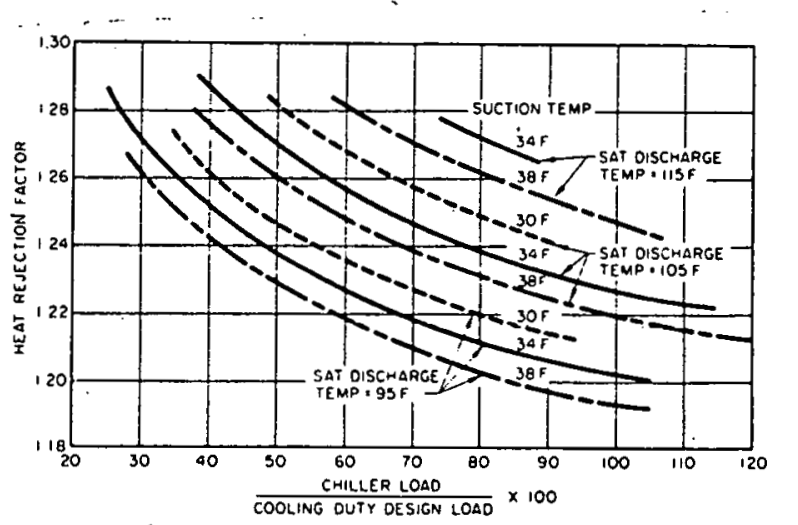

Performance of Typical Large, Moderate Head, Hermetic Centrifugal Compressor (R-11)

FIG. $1-6$

SOIRCE: ASHRAE SYSTEMS HANDBOOK ${ }^{49}$

Similar performance data for cooling COP's are available from equipment manufacturers or may be derived from the ICES Technology Evaluation Number ANL/CES/78-2 entitlcd, "Central Cooling-Compressive Chiller"; J.E. Christian, 1975.

\subsubsection{THERMAL DISTRIBUTION SYSTEM}

Two types of thermal distribution systems were considered fur use with the HP-WHR system. One system would utilize portions of the wastewater which 
has been clarified to transport thermal energy from the central station to the end-users. Once the energy was extracted from the transport media it would be discarded to the sanitary sewer system and returned to the waste treatment plant.

The other distribution system would be a closed loop circulating system utilizing supply and return piping from the central heat source. The closed loop circulating system is commonly used in heating and air conditioning systems or thermal energy transport.

Both thermal distribution systems would incorporate some form of storage component to provide for optimum storage of heat extracted from the primary heat source and for adequate peaking capacity during maximum energy demand periods.

The numerous problems associated with the proposed utilization of clarified wastewater for a thermal transport media lead us to adopt a more conventional circulating water system as a basis for analysis. The clarified wastewater scheme is presented in Chapter 7.0 - IDENTIFIED VARIATIONS for consideration in specialized cases.

\section{3 .4 CLOSED LOOP SYSTEM}

A closed loop thermal distribution system would incorporate supply and return piping mains throughout the community. This would allow the transport media to be returned to the central station to be regenerated.

closed loop circulating water systems are commonly used in heating and air conditioning systems and industrial process applications. The advantage of the closed loop system is primarily its freedom from external contamination. Its disadvantages are higher installed cost and greater pumping friction loss due to the increased distance of pressure-flow piping. 
It is anticipated that the energy requirements for thermal transport media circulation could be minimized by proper design of the pumping system to Incorporate variable pumping or parallel pump staging. Likewise, two pipe circulating systems will enjoy some installation economies since trenching and associated construction costs for one or two pipes are essentially the same.

One final paragraph concerning either system is appropriate on the subject of piping materials. Recent advances in piping materials have made plastictype piping almost an industry standard for municipal water distribution piping systems. The low termperature application discussed here will be constructed with plastic or fiberglass piping, taking advantage of the latest cost reduction techniques.

\section{3 .5 THERMAL STORAGE}

Regardless of the type distribution system selected, it will generally be desirable to include a device for storing the thermal energy extracted from the wastewater stream and apportioning it to the community as required. Consideration of the storage volume will be of prime importance when actual design is undertaken.

In most cases it is anticipated that the quantity of transport media will dictate some form of underground, covered vessel. To be cost-effective this may take the form of a plastic-lined earthen reservoir with a floating or airsupported canopy.

In the case of a clarified wastewater system, it may be advantageous to split the storage requirements between underground and elevated vessels. This would allow optimum pump sizing since peak flows could be supplied from the elevated tank, as in potable water systems. 


\section{3 .6 SYSTEM INSULATION}

Insulation for piping and thermal storage systems will have to be evaluated on a case-by-case basis. The systems presented in this report assume that distribution system thermal losses will be kept to a small percentage of the heat content of the transport media.

Calculations presented in the analysis section of this report for the thermal losses from buried plastic pipe at low temperature differentials are expected to indicate that underground pipe insulation may not be cost effective. For that reason, the analyses presented in this report assume no thermal insulation on the underground piping system.

\subsubsection{END-USER HEAT PUMPS}

The end-user heat pump system utilized in the HP-WHR scheme would be the type commercially available in the $1 / 2$ to 25 ton cooling range. No substantially different application techniques from common practices currently employed are anticipated for the end-user systems.

An excellent technology evaluation of unitary water-to-air heat pumps is available in a report by the same name prepared by J. E. Christian of the Oak Ridge National Laboratory ANL/CES/TE 77-9 (Reference 7). Figure 2.1 of that report is included here as Figure 1-7 and serves to describe the operation of the unitary water-to-air heat pumps which will be utilized by this scheme.

Performance characteristics vary substantially with manufacturer and size of the specific equipment. Typical manufacturer's COP's at standard rating conditions range from 2.5 to 3.4 on the heating cycle and from 2.44 to 2.66 on the cooling cycle. Part load and seasonal performance factors will also vary substantially.

The use of a relatively constant temperature water source offers substantian energy performance improvement and the promise of more reliable system 
The water-to-air heat pump actually is a reverse-cycle, selfcontained refrigeration system as shown in Fig. 2.1. In the cooling cycle, heat is absorbed through the air coil from the conditioned space and transferred through the refrigeration process, to water circulating through a water-to-refrigerant heat exchanger. In the heating cycle, heat is absorbed from water circulating through the water coil and transferred to the air coil by the refrigeration process where it is then supplied to the space being heated.
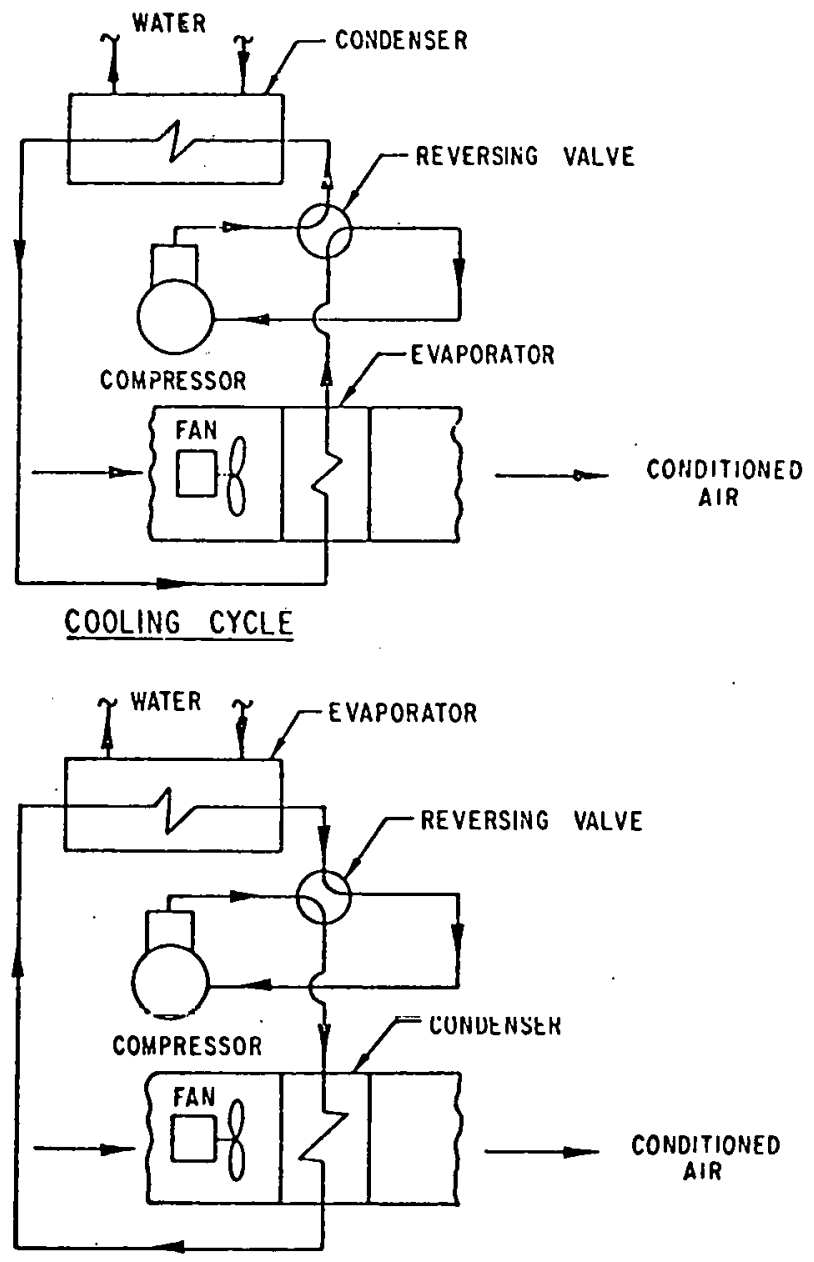

HEATING CYCLEE

Fig. 2.1 Water-to-Air Heat Pump Showing Cooling and Heating Cycles

\section{ICES TECHNOLOGY EVALUATION}

FIG. $1-7$

HEAT PUMP CYCLES 
operation. Improved heating performance is especially attractive when compared to air-source heat pumps due to the absence of the attending defrost cycle and supplemental electric strip heat output.

Heat pump technology has advanced considerably over the last few years. Further improvements in new heat pump design can be expected in the areas of compressor capacity control and prime mover types. Widespread interest in water-to-air heat pumps for residential use should produce even further improvements and decreased unit costs associated with increased quantity production.

\subsection{SYSTEM OPERATION}

The Heat Pump Wastewater Heat Recovery Scheme presented in this report is intended to operate in a heating and cooling mode. Actual operating procedures will vary with the size and complexity of the system so for simplicity's sake the description presented here will consider only a minimal number of functional components.

\subsubsection{HEATING MODE}

A schematic of the HP-WHR system operating in. the heating mode is presented in Figure 1-8. A clarified wastewater thermal transport media is utilized.

In the heating mode, wastewater effluent enters the treatment plant and goes through a primary clarification process, then passes through the evaporator of the central station heat pump. A retention pond is shown immediately after the primary clarification process to level out diurnal peaks in the sewage flow. After passing through the central heat pump, the wastewater effluent continues through the sewage treatment process.

The thermal transport media is circulated between the central heat pump condenser, where it picks up heat, and the storage vessel. A mixing valve is provided in the storage vessel to indicate that full advantage of thermal 


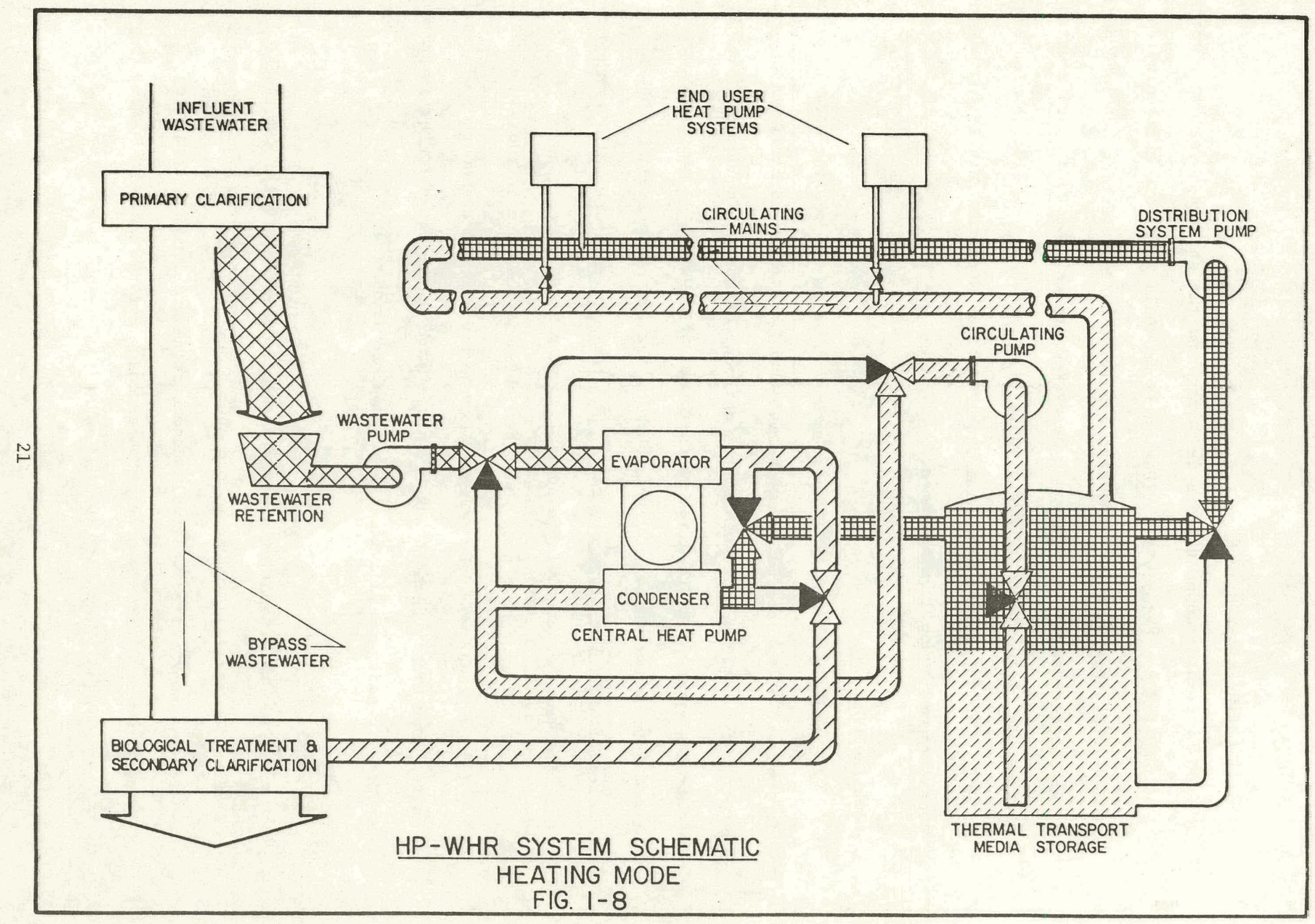


stratification will be taken.

The thermal transport media is drawn from the storage vessel in response to system loads. Primary distribution lines would have some recirculation or pressure relief to insure a constant supply temperature during low load periods.

Each end-user heat pump would be cycled in response to a space mounted thermostat. Used transport media would be returned to the distribution system according to individual heat pump requirements. When the unit is inactive, no transport media would be consumed.

\subsubsection{COOLING MODE}

A schematic of the HP-WHR system operating in the cooling mode is presented in Figure 1-9. A recirculating thermal transport media is utilized.

In the cooling mode, wastewater effluent enters the condenser side of the central heat pump and then passes on to normal sewage treatment practice. Warm thermal transport media is extracted from the storage vessel, cooled and then recirculated to the storage vessel. The thermal transport media is then drawn from the storage vessel in response to system loads.

Each end-user heat pump would be cycled in response to individual building loads. Heat would be rejected by the pump to the transport media acting as the heat sink. Spent transport media would be returned to the distribution system according to individual heat pump requirements.

\subsubsection{PART LOAD OPERATION}

The HP-WHR schematics presented in this section offer considerable flexibility for full and part load operation. Leveling wastewater flow over an 18 - 24 hour period will allow the central station heat pumps to operate under relatively constant high load factors. This will also 


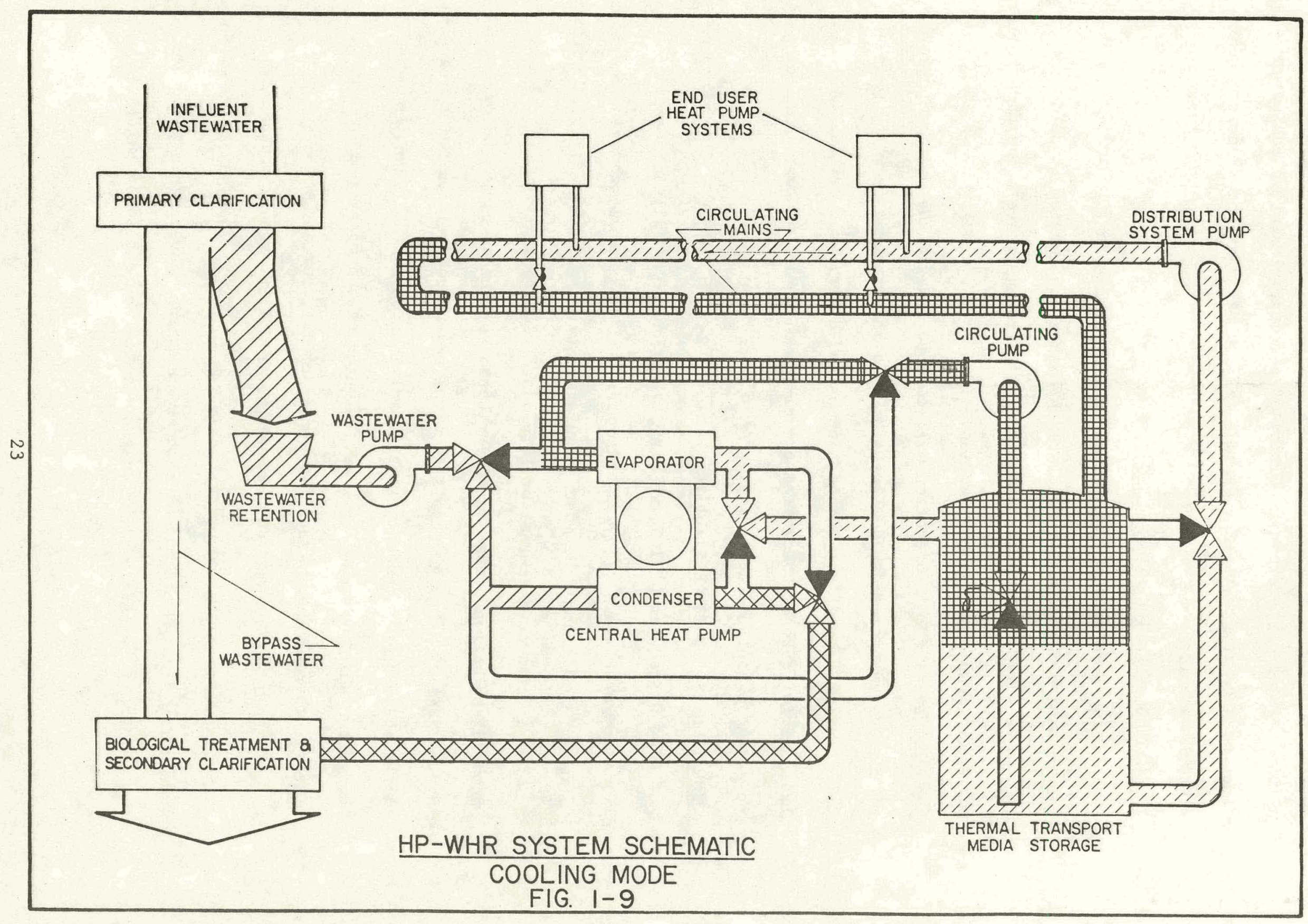


allow the most cost-effective sizing of the central station equipment since peak community thermal demands will be met from the transport media storage vessel.

\subsubsection{SIMULTANEOUS HEATING AND COOLING}

During mild weather conditions it is probable that simultaneous heating and cooling will take place throughout the system at different end-users. This will be especially true where there are commercial buildings mixed with residential construction.

In general, this operation will tend to benefit the heating performance of the system since less heat will need to be extracted from the wastewater stream. In effect, the heat pumps and distribution system will be transferring unwanted heat from the air conditioning process to heating needs throughout the community.

\subsection{OPERATION AS A THERMAL UTILITY}

The wastewater HP-ICES was originally conceived without regard to how the system would be owned and operated. In general, however, it appears that the system could be most advantageously operated as a thermal utility. Operation as a thermal utility would require that the central heat pump, distribution pumps, and distribution system be owned and operated by the utility. Energy supplied to the end-users would be metered at the point the end-user connects to the distribution system. Each end-user would own and operate his own water-source heat pump system in order to use the thermal energy supplied by the utility company.

It is conceivable that any number of utility arrangements ranging from landlord owned and operated systems in a building complex to metropolitan systems owned and operated by municipal governments would be possible. A private utility company scheme could also be initiated. 
An especially attractive arrangement would be a municipally owned and operated thermal utility serving the community's residential and commercial customers. Under this scheme the central heat pump and distribution system could be operated similar to or as a division of the water and sewer departments. Administrative matters pertaining to finance and revenue collection could be handled in a manner similar to water and sewer services.

The municipally operated utility scheme would enjoy a number of advantages including: overall responsibility and control of water, sewer and thermal energy distribution systems, the ability to finance the system through municipal bonds, administrative, operating and maintenance personnel familiar with utility operations and water distribution through piping systems. Municipal governments will also be better able to accept the risks associated with long term ownership and operation of the HP-ICES concept.

1.6 SYSTEM APPLICATIONS

The wastewater HP-ICES concept may be applied to both new construction areas and retrofit situations. In evaluating an application of the concept, consideration must be given to both new and retrofit conditions.

In general, it is anticipated that each end-user will own and operate his own water-source heat pump system. In operating his system the enduser would purchase thermal energy from the thermal utility either on a Btu basis or water fiow rate basis. There are, of course, special cases such as a building complex of rental units where ownership may be retained by the landlord and thermal energy may not be metered.

It is apparent that new construction will offer the most potential for economic inclusion of the wastewater HP-ICES concept. The advantages seen in new construction projects include lower initial cost for end-use 
systems, a minimum amount of prejudice associated with changing existing systems, and overall distribution system installation economies associated with initial infrastructure construction (such as common trenches for thermal, water, and sewer utility systems).

The more difficult case is the retrofit situation where the thermal utility must be installed in existing areas requiring relatively expensive unitary installation costs and the retrofit of conventional end-use systems. In any event, the retrofit case will be the more expensive per unit and will make the HP-ICES more difficult to economically justify. 


\subsection{POTENTIAL APPLICATIONS}

\subsection{INTRODUCTION}

The goal of the developing Integrated Community Energy System (ICES) technology is to optimize the available resources in meeting the energy needs of various communities through new and innovative methods. While the primary products of a Heat-Pump-Centered Integrated Community Energy System (HP-ICES) are low-level thermal energy services for space heating and/or cooling needs, the ultimate determination of the kind, number, and amount of energy services provided should be based on the optimum combination of energy efficiencies, economics, and environmental considerations. In the sections of this chapter, factors affecting the potential for application of this particular HP-ICES, including availability of resources, climate, economic considerations, institutional/community factors, system reliability, and unique application conditions, will be discussed. From these considerations, a projection of the potential for application (through the year 2000) will be developed.

\subsection{FACTORS AFFECTING APPLICATION}

The aim of an ICES is to optimize energy usage in a community, taking into account the many factors that may affect that energy usage. The focus of this section of Chapter 2 will be to catalogue and discuss the more important factors that will determine the applicability of this HPICES scheme to various communities.

\subsubsection{AVAILABILITY OF RESOURCES}

A viable but presently untapped source of low-grade thermal energy is the heat lischarged during domestic energy usage and rejected heat from industrial processes. Very low-grade thermal energy, degraded from higher quality sources through domestic chores such as cooking, 
washing, and bathing, is regularly discharged from the individual household because of its low thermodynamic availability. Likewise, waste heat from industrial processes and heavy machinery cooling systems is discharged because of its low thermodynymic availability. A common "sump" for this low-grade thermal energy is the sanitary sewer collection system in the community. Depending on the size and make-up of the community, and the degree of development of the attending sanitary sewer system, billions of Btu's per day may be available from this thermal source. The assumption that the energy availability of this source hinges upon is that the temperature of the community wastewater effluent will be higher than or equal to ground temperature. Several site-specific variables may affect the effluent temperature by a few plus or minus degrees, but preliminary investigation seems to validate this assumption. A quick estimate of the energy available from this source can be developed from flow and temperature data for each site of application. The principal advantage of utilizing this source is that it would be almost universally available; a community large enough to consider an integrated energy system would in all probability. have an interceptor sewer system and/or treatment facility capable of supplying enough thermal energy to make this scheme technically feasible. A second major advantage is that the thermal source would require no additional interface with the central station heat pump equipment(i.e. the effluent could be piped directly to the central heat pumps).

of course, several other thermal energy sources, such as solar, combustion of solid or gaseous wastes, or composite energy sources could be considered for easy adaption into an HP-ICES scheme. However, since a community with a thermal energy consumption density sufficient to justify an HP-ICES would likely have a well-developed wastewater collection system, 
wastewater heat recovery will be evaluated as the primary thermal energy source for this particular ICES scheme. Other variations in energy source are discussed in Chapter 7 - IDENTIFIED VARIATIONS.

\section{2 .2 CLIMATE}

It was mentioned in the preceding section that the base assumption for application of this scheme was that the minimum temperature of the wastewater effluent would be approximately equal to ground temperature. It is obvious from this assumption that climate will have a significant influence upon the operating conditions of the system by affecting the conditions of the thermal energy source, as well as affecting the capacity of the main heat pump components, and the heating/cooling loads at each end-user location. The conditions at the thermal source are site-specific (with climatological influences) and should be documented according to the recominended measurements discussed in Chapter 8 of this report. The addition of auxiliary thermal energy sources may also significantly affect the initial conditions. Climatological areas of the U.S., and the resultant typical heating loads and system capacities, have been well documented and will be discussed in this section.

For the purposes of analyzing heating and cooling loads, the United States can be divided into climatological sections according to the number of degree-days in a heating or cooling season. (A degree-day is based on the difference between actual average outside dry bulb temperature and a $65^{\circ} \mathrm{F}$ comfort index. As an example, one day with an average temperature

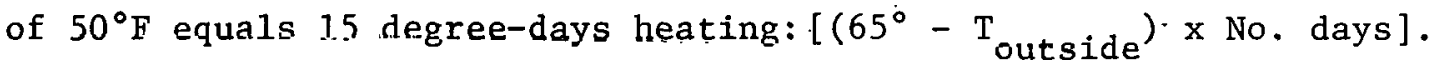
Figure 2-1 shows the heating degree-day regions in the continental U.S. 


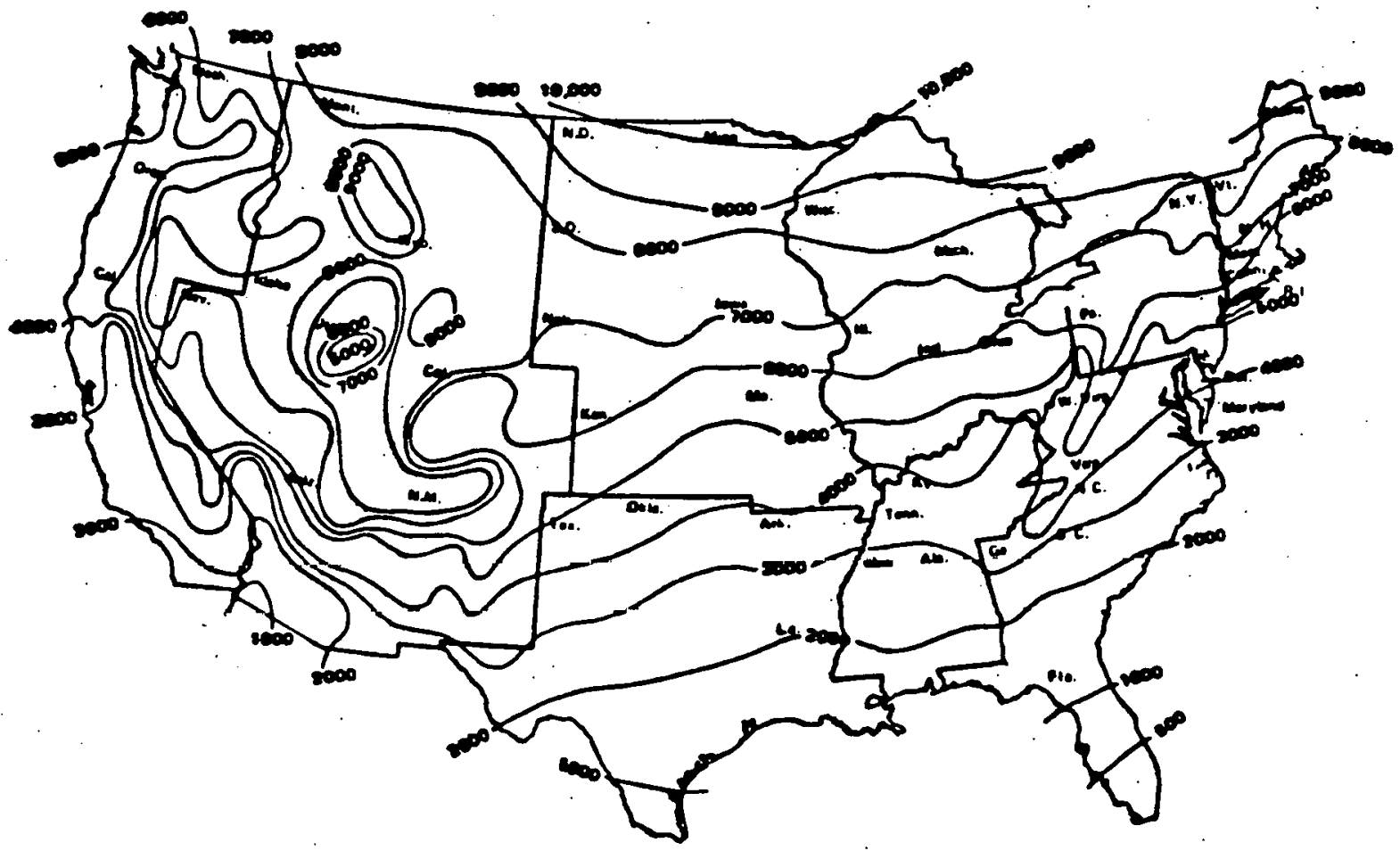

SOURCE: Energy Use and Conservation In The Residential Sector: A Regional Analysis, Rand Corporation 27

(Heating Degree-Day Map of The United States)

\section{FIGURE 2-1}

In a study entitled "Heat Pump Technology" by Gordian Associates a comprehensive computer stmulation of the heating and cooling load of a typical residence and commercial building was developed. As input, the program required various parameters such as building construction details and materials, orientation, geographic location, and local weather conditions. (Building details for the simulation model are contained in Appendix A .) With the validated computer model, the subject bulldings could be artificially moved to any climatic region in the country to obtain typical heating and cooling loads. Programs were run for 9 cities in the continental U.S. (Weather data for the test cities is shown in Table A-1 of Appendix A.) The results show loads in the commercial building ranging from 166,510 Btuh 
heating in Concord, N.H. to 206,119 Btuh cooling in Houston, Tr. and in the residential building ranging from 52,088 Btuh heating in Concord to 38,351 Btuh cooling in Tulsa, Okla. The tabulated results of the simulation can be found in Tables A-2 and A-3 in Appendix A. In general, the simulation showed that the heating and cooling load and the system heating or cooling capacity is dependent on outdoor temperature. This generalization from the computer simulation agrees with the performance data available from the equipment manufacturers - i.e., sensible and total (sensible + latent) cooling capacities are functions of indoor wet bulb and indoor and outdoor dry bulb temperatures. While the practice of artificially relocating the simulated buildings to different climatic regions may not give an entirely accurate indication of the community heating load to be placed on a proposed HPICES because of regional discrepancies in building construction and community composition and layout, it is effective to illustrate strictly the climatic effect on heating and cooling loads.

It must be explained at this point that the type heat pumps proposed for use in the HP-WHR scheme, water-source heat pumps, offer an advantage over the air-to-air heat pumps modeled in the computer program, especially in the colder regions. In the heating mode, with ambient temperatures lower than $47^{\circ} \mathrm{F}$ and relative humidities higher than $60 \%$, standard air-toair heat pumps show the tendency to frost on the outside (evaporator) coil. To remove the frost, the "defrost cycle" is automatically engaged and heat is taken from the conditioned space and circulated to the outdoor coil to melt the ice build-up. Essentially the unit is cooling the conditioned space during the duration of the defrost cycle, and the inside air must be tempered with auxiliary electric strip heat. The overall 
result is a lowered Coefficient of Performance (C.0.P.) for the air-to-air heat pump unit. Since, for a water-source heat pump, the heat exchange takes place with a water supply that is kept at temperatures well above the freezing point, no defrost cycle is needed. Therefore, the water source unit offers a higher C.O.P.

Because of the above-mentioned problem with icing on the outdoor coil and the required defrost cycle, (air-to-air) heat pumps have had higher acceptance in the regions of the U.S. with a small-to-moderate heating requirement and a proportionately larger cooling requirement (notably the South). However, with the thermal energy supplied in a circulating water medium and transferred (in the heating modes) into the conditioned space via a water source heat pump, and with a stable thermal energy supply (such as wastewater effluent), it is expected that system performance (in terms of overall C.O.P.) would be acceptable in any of the climatic regions of the U.S.

Climatic differences will obviously affect system sizing. From data developed in the subsequent chapters detailing performance and economics, it appears that an HP-WHR system sized at 1000 tons $(12,000,000$ Btuh extraction rate) and requiring a 3.0 MGD wastewater flow as the thermal source would serve approximately 470 typical homes in a New England clime (6820 Degree-days heating and approximate peak load of $41 \mathrm{MBtu} /$ home) compared to 980 typical homes in a Southern clime (2350 Degree-days heating and approximate peak load of $21 \mathrm{MBt}$ /home). To generalize the climatic effect on system sizing, systems located in colder climes will serve proportionately less end-users than systems in the warmer climes for a given size of central station installation. As a corollary, service to a given number of end-users will require a larger central station heat pump and 
proportionately more wastewater flow, in the colder climes.

Climatic influences may also affect the applicability of the HP-ICES concept in an indirect manner. Building design and construction and community composition and layout vary noticeably from climatic region to region. For example, in the colder northeast regions, housing patterns, tend to be more dense, the structures more well insulated, and typically there is a higher degree of industrial development for a given size community. These characteristics make the application of an HP-ICES desirable in these areas for the following reasons: the denser housing patterns make installation of a thermal energy distribution system more cost effective; better insulation decreases somewhat the heat loss from structures; and waste heat rejected from industrial processes into the community's wastewater collection system increases the amount of thermal energy available for extraction. with an HP-WHR system. However, indirect effects such as these are difficult, if not impossible, to quantify through calculations in order to determine their effect on the feasibility of the HP-ICES concept. They will figure significantly, though, into the technical and economic viability of a system as determined in the site-specific performance and economic analyses.

Unfortunately, it is beyond the scope of this study to develop detailed guidelines for determining the applicability of an HP-ICES on the basis of climatic factors. Instead, the methodology. for evaluating the climatic influences on the feasibility of such system on a site-specific basis will be developed in the Part II analysis of the demonstration communities. However, to summarize the previous discussions: 1.) Climate will directly affect the thermal demand related to space heating and cooling that will 
be placed on an HP-ICES. 2.) System design and sizing (including determining the number of end-users to be served by the system) will directly depend on the thermal demand on the system and thus will be affected, in turn, by climate. 3.) Indirect climatic effects seen in building construction and community composition will influence the feasibility of an HP-ICES, albeit through the procedures for performance and economic analyses. 4.) System performance (in terms of overall energy effectiveness) is expected to be acceptable in any of the climatic regions of the U.S.

\subsubsection{ECONOMIC CONSIDERATIONS}

A critical factor in judging the acceptability of an HP-ICES to the community is cost-effectiveness. "It should be stressed that, although the saving of fuel may be an acknowledged goal for the country, in a free market the individual consumer is expected only to pay for efficiency to the extent that the added investment could potentially be recovered through the savings in fuel consumption." 10 Thus, consumer acceptance can be expected to hinge upon a favorable comparison of savings in energy costs vs. additional cost of the individual heat pump unit plus the thermal utility expense. The factors entering into this comparison can be expressed in án equation for annualized cost:

Annualized Cost $=$ (Installed Cost) $x$ (Capital Recovery Factor)

+ (Annual Energy Use) $x$ (Unit Price of Energy)

+ Annual Maintenance

An HP - ICES can be categorized as a capital intensive venture by virtue of the large first-cost associated with constructing the Central Station and distribution system. Such an installation effectively centralizes a major portion of the energy-related expenses and offers the economies 
of scale available in the form of municipal or institutional energy rates. Being a capital intensive venture, though, the economic viability of such a system will be significantly affected by the availability and cost of capital. Inflationary trends will increase the installed cost of an ICES (note the importance of installed cost in the equation for annualized cost), thus adversely affecting the availability of capital for such a system. The current cost of capital would also figure prominently by way of influencing the capital recovery factor. As costs and interest rates rise, either independently or jointly, the result will be a higher system annualized cost which must be apportioned to the end-users by means of the thermal utility charge.

Individual end-user space conditioning systems, on the other hand, can be categorized as energy intensive systems. The affects of inflation on system installed costs and on availability and cost of capital are rarely noticed because of the proportionately small expense of the system as compared to the overall cost of a residence, especially when the system costs are amortized through a typical new home mortgage. Escalating energy costs (which translate into higher operating costs for space conditioning) are immediately noticed by the consumer, however, because this portion of the annualized system cost is paid "out-of-pocket." Because consumers have become so energy conscious of late, the rising trend of energy costs may be regarded as a major accelerating economic factor favoring an HP-ICES. In fact, purchascre of space conditioning equipment have indicated in recent survcye (Arkansas Power \& Light Co., 1974, l Professional Builder, $1976^{26}$ ) that lower operating and maintenance cost expectations were reasonable justification for purchasing a heat pump, and that an additional investment of up to $\$ 600$ for energy conservation would be acceptable if the 
payout were within six years:

It must be explained at this point that there is a trade-off to be optimized according to the end-users' best interest. If the consumer is to be expected to finance the incremental cost of a heat pump over conventional residential space conditioning alternatives, the Central Station and distribution system of an HP - ICES must be financed at the most advantageous costs and rates so that, when the annualized cost of the system is apportioned to the end-users through the thermal utility charge, the cost of the thermal utility plus the nominal charge for energy (electricity) required to run his system will compare favorably with the energy charge that could be expected for running a more conventional residential space conditioning system so that the expected payback period on the end-users' equipment would fall within an acceptable range.

It is expected that installation costs for an HP-ICES will remain well within the reasonable range. The major effect of high costs and interest rates would be to make the system less cost-competitive with other individual end-user system alternatives and thus slow the rate at which new, customers would be attracted to tie-in to the system.

\section{2 .4 INSTITUTIONAL/COMMUNITY CONS.IDERATIONS}

Acceptance of an HP-ICES in the community will depend heavily upon the acceptance from the individual consumer. Heat pump equipment marketed in the 1950's and early $1960^{\prime}$ 's had serious problems with performance and rellability, in addition to substantial problems with installation and servicing. The net result of these compounding problems was a general rejection of heat pump equipment by the public. However, recent strides in improving performance and the current focus on energy conservation seem to be changing the attitude of the consumer. Recent surveys have shown that consumers would be willing to invest the additional first cost 
of a heat pump (up to approximately $\$ 600$ ) for the improved performance and lower operating and maintenance costs. A brief look at consumer demographics supports this contention; the 1976 average new home cost of $\$ 48,600$ indicates that the housing market has shifted to a position where the heat pump could be considered an alternative for the average new residential building. Nonresidential consumers seem receptive to the heat pump market if an economic analysis of system owning and operating costs projects a payback period of from two (2) to five (5) years.

One potential stumbling block to community acceptance may be requirements set forth in state and local building codes. There are no specific provisions in the model building codes recognized by HUD and HEW (codes: BOCA, ICBO, National Board of Fire Underwriters, Southern Building Code Congress International) that cover heat pumps, although various related sections that cover mechanical refrigeration, electric strip heat, and general electrical requirements will apply. Generally, though, there are no provisions in the model building codes that are seen as overly restrictive.

A provision in the California Energy Code stating that electric resistance heating cannot exceed 10 percent of the building space heating requirement (for non-residential buildings) may prove troublesome. The electric strip heat of an air-to-air heat pump would fall under this restriction. However, it should be noted that, since the thermal energy in this HP-ICES is supplied in a circulating water medium whose temperature will not fall below the (watcr source) heat pump halance point, the use of auxiliary electric etrip heat is not. anticipated.

Separate performance codes for heat pumps based on the ASHRAE 90-75 performance standard (American Society of Heating, Refrigeration, and Air-Conditioning Engineers, Inc.) are now being developed by the model 
code organizations. However, since the codes are being developed from standards already generally accepted in the industry, these new provisions, whose requirements are presented below, are not seen as inhibiting factors. MINIMUM C.O.P. REQUIREMENT

$$
\text { OUTDOOR TEMP. }{ }^{\circ} \mathrm{F}
$$

47 Dry Bulb, 43 Wet Bulb

17. Dry Bulb, 15 Wet Bulb

\section{BY $1 / 1 / 77$}

2.2

1.2
BY $1 / 1 / 80$

2.5

1.5

A last major question in the community acceptance of an HP-TCES is whether the community, as an entity, will accept the idea of an additional municipal utility, to be billed in the same manner as electricity, water usage or natural gas. The growing acceptance of the public to heat pumps, plus the growing concern for energy conservation seem to indicate a receptiveness on the part of the community. However, the ultimate acceptance will depend upon the understanding of the benefits of an HP-ICES: its improved performance in the task of space conditioning (as compared to the more conventional end-user systems) and the resulting cost-effectiveness of such a system. Some form of community education may be necessary to facilitate community acceptance on this basis.

\subsubsection{RELIABILITY}

Overall system reliability will depend upon two factors: reliability of the energy supply and its associated conversion/delivery equipment, and the reliability of the Central Station heat pump equipment. In the residential sector, a reliability bonus is offered with this system in that the end-user will utilize a water source heat pump.

An additional consideration in specifying an energy source for a particular site of application is the degree of reliability that could be expected from each available source and its associated equipment: One 
principal reason, aside from availability, that solar energy or waste heat recovery boilers are not utilized as primary energy sources is the interruptable nature of the energy supply. A solar supply has the obvious disadvantage of overcast skies. A waste heat recovery boiler has a two-fold disadvantage in its dependence on a supply of prepared fuels such as trash or wood scraps (difficulties at the processing station or in transportation would effectively shut down the boiler station), in addition to the need for periodic maintenance (as per insurance regulations and various pressurized boiler codes) and the potential for forced outages. Wastewater effluent, on the other hand, is a continuous process flow that should provide a fairly constant energy supply. Flow quantities through the sewage treatment plant are cyclic, on daily and weekly patterns, but most treatment plants have a recirculation provision for the minimum required flow through the plant that may be utilized as a second tie-in point on the energy source. Some allowance can be made for down time on the energy supply subsystem in sizing the thermal storage capacity in the system. However, engineering judgement dictates that the least complicated energy supply subsystem be specified to improve system reliability and to avoid compounding problems in other segments of the system.

A second major consideration in optimizing system reliability is the expected reliability of the equipment to be utilized at the Central Station. All major brands of heavy HVAC equipment reflect state-of-the-art design and component selection for performance and reliability, and as such, could be expected to run for extended periods with little or no maintenance. However, in looking ahead to the inevitable maintenance outage, there are provisions in the design of the Central Station that will minimize the consequences of an equipment outage and thus enhance the system reliability. 
All major manufacturers offer guidelines for selecting and installing multiple units. Generally, this type application involves splitting the load of the station between two pumps (or more), each sized at approximately $60 \%$ (proportionately less if more units are utilized) of the estimated load. Depending on site-specific conditions and requirements such as temperature supply and required temperature of the distribution medium, the units may be connected in a parallel or series piping configuration. Such a design would lessen the load on both units under all but peak conditions and thus extend the life of the equipment. Necessary crossover and bypass piping at the station would also enable each unit to serve as a back-up to the other in the event of a forced or maintenance outage.

System reliability will be judged in the end-user segment not only by the reliability of the thermal service provided by the Central Station but also by the reliability of the equipment required to utilize it. This $\mathrm{HP}$ - ICES offers the advantages of utilizing water source heat pumps at the end-user. Water temperature is expected to range from $50^{\circ}$ to $90^{\circ} \mathrm{F}$, whereas air temperature may range from $-10^{\circ}$ to $95^{\circ} \mathrm{F}$. The water-to-air systems eliminate the need to operate at low heat source temperature conditions, while the air-to-air units operating at low ambient temperatures require a high compressor discharge gas temperature because of the high pressure ratio across which the refrigerant must be pumped. The effect is to place a stress on the air-to-air system compressor and reduce its reliability. Thus, it is believed that the reliability of a water-to-air heat pump unit would be greater than that of an air-to-air unit of similar compressor design. 7

\subsubsection{UNIQUE APPLICATION CONDITIONS}

It is not expected that this HP-ICES scheme will be overly depen- 
dent on any unique application conditions. With the wastewater effluent from a community providing the thermal energy input to the system, there will not be a dependence on an energy source that may be particular to a specific region or community configuration. Virtually any community with a thermal load demand and population density high enough to pake an HP-ICES cost effective will have a sewage treatment facility that could be utilized in this scheme. In areas where additional resources are available, the wastewater thermal source may be augmented with one or several alternative energy sources discussed in Chapter 7 - IDENTIFIED VARIATIONS. Industrial , installations within the community that discharge waste heat (such as a power plant) may dictate that the Central Station be located near that particular facility, or that a modular Central Station/distribution system (one with several thermal energy supplies located in different areas of the community) be adapted to this scheme. Generally, the universal availability of wastewater as the primary energy source will allow a broad scope of potential applications and the availability of additional resources will enhance the effectiveness of such a system.

\subsubsection{SUMMARY}

The following generalizations are offered in summary of the foregoing discussions of criteria that will determine the applicability of an ILES. A community is broadly defined as "a complex of facilities (and open spaces) that are employed in human activities and that are connected by networks for moving people, messages, goods, and services in the residential, commercial, industrial, agricultural, recreational, or institutional sectors. or combination of sectors" (from Request for Proposal 78-4327) 45 Thus any number of community configurations may be considered a candidate for some form of ICES. The common denominator requirement is that the candidate 
community show a thermal load demand and a population (user) density high enough to make a central facility for heat reclaim and its associated distribution system cost-effective. Waste heat in the community's wastewater effluent is expected to be the most universally available thermal energy source. However, the primary energy supply may be augmented with one or several other energy supply options, depending on their availability. Climate will affect significantly the heating/cooling load demanded from an ICES, and thus system sizing, although it will not significantly affect the general applicability of such a system. Economic conditions are favorable for the implementation of an HP-ICES if the system proves cost-competitive with the options now available in residential and commercial HVAC. State and local building codes should not prove to be overly restrictive to such an HP-ICES. However, some form of community education may be necessary to facilitate acceptance of an ICES. And finally, reliability will be a major consideration in the specification and design of the Central Station and its associated equipment. With this general categorization in mind, it is obvious that a broad range of communities will qualify for consideration for an HP-ICES based on the HP-WHR scheme.

\subsection{PROJECTIONS}

In order to assess the desirability of promoting the HP-ICES concept, it is necessary to quantify the applicability of any particular scheme by developing estimates of the possible points of application and of the energy savings that would result from implementation of such a scheme in these communities. Projections for evaluating the applicability of the HP-WHR scheme will be developed by examining the potential for thermal energy supply (from wastewater effluent) and the coincident community space conditioning load that could be handled by an HP-WHR system. 


\subsubsection{THERMAL ENERGY SUPPLY}

From the discussion in previous sections, it can be seen that the potential for application of this HP-WHR scheme in an Integrated Community Energy System (ICES) will be based on the availability of comunity wastewater effluent as the primary thermal energy source. The availability of this supply will, in turn, be based upon the population that is serviced by wastewater collection systems. The total flow of wastewater available as a thermal energy supply is defined by the following equation:

$$
\begin{aligned}
\text { Available Flow }= & {[\text { (Population at year } \mathrm{T}) } \\
& \times(\% \text { Sewered Population }) \\
& \mathbf{x}(\text { Per capita water consump- } \\
& \text { tion })]+ \text { Industrial Discharge }
\end{aligned}
$$

With the variables explained below.

Population - ultimate population of service area at the target date, year T. This projection will be made on a nationwide basis and thus will utilize national projections for total population. Percent Sewered Population - the portion of the total population that is served by wastewater collection systems and attending sewage treatment facilities which could be considered for retrofit of an HP-WHR system. A maximum percentage figure of $70 \%(.70)$. of the total U.S. population connected to sewage systems is taken from the Statistical Summary of the 1968 Municipal Waste Facility Inventory. 41 The ultimate figure used in the estimate will be somewhat lower, as explained in later discussion. Per Capita Water Consumption - total water use (and discharge) is estimated using the typical.figure for average consumption of 100 gallons per capita per day $(\mathrm{gpcd}) .^{3}$ Variations in flow range from $50 \%$ to $170 \%$ of the average on a daily cycle. Thus, the actual Instantaneous flow available for heat transfer may vary above or 
below the average ( in gpm - prorated from the average daily flow figure). However, it is expected that, over a 24-hour cycle, and accounting for the averaging effect of the thermal storage capacity incorporated into the system, the average figure of 100 gpcd will be available as the thermal energy supply.

Industrial Discharge - water discharged (in gallons per day average) from industrial processes into the wastewater collection system. This figure will vary with each site of application and thus will be used only when developing a site-specific estimate of available wastewater flow.

With the total flow of wastewater available as the thermal energy source defined, the total amount of heat available from the thermal supply can be calculated from the following equation:

$$
Q=W C(\Delta T)
$$

Where

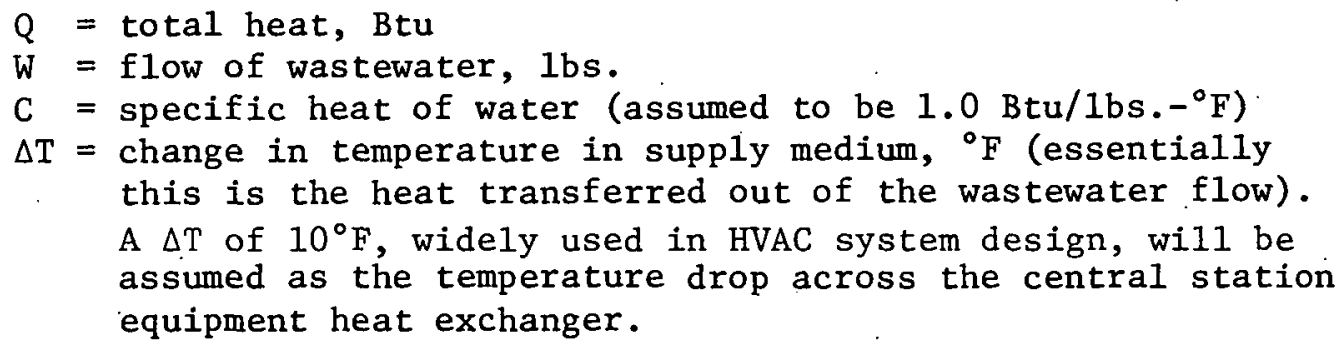
this is the heat transferred out of the wastewater flow). A $\Delta T$ of $10^{\circ} \mathrm{F}$, widely used in HVAC system design, will be assumed as the temperature drop across the central station equipment heat exchanger.

The two equations can be combined to define the total thermal energy available, Q (in Btu's), from wastewater effluent as a function of total population. Thus:

$$
\begin{aligned}
Q= & \{[(\text { Population at year } \mathrm{T}) \times(\% \text { Sewered Population) } \\
& \mathbf{x}\left(\text { Per Capita Water Consumption)]+ Industrial Discharge }\left(\frac{\mathrm{gal}}{\mathrm{day}}\right)\right\} \\
& \mathbf{x}\left\{8.33 \frac{\mathrm{Ibs} \cdot \mathrm{g}\}}{\mathrm{gal}}\left\{1.0 \frac{\mathrm{Btu}}{\mathrm{Ib}-{ }^{\circ} \mathrm{F}}\right\}\left\{\Delta \mathrm{T}\left({ }^{\circ} \mathrm{F}\right)\right\} \quad \frac{\mathrm{Btu}}{\mathrm{day}}\right.
\end{aligned}
$$


Which reduces to:

$$
\begin{aligned}
Q= & \text { (Population at year } \mathrm{T}) \times(\% \text { Sewered Population) } \\
& \times(100) \times(8.33) \times(1.0) \times(10) \frac{\mathrm{Btu}}{\text { day }} \\
= & 8330 \text { (Population) }\left(\% \text { Sewered Population) } \frac{\mathrm{Btu}}{\mathrm{day}}\right. \\
Q= & 3.040 \times 10^{6} \text { (Population) (\% Sewered Population) } \frac{\text { Btu }}{\text { year }}(2-3)
\end{aligned}
$$

Note that Industrial Discharge is deleted from equation 2-3 and will be used only in site-specific analyses.

\subsubsection{THERMAL ENERGY DEMAND}

With the quantities of thermal energy available from wastewater defined, some consideration must be given to the balance between energy supply and demand in order to determine the number and size of communities which may be considered for a HP-WHR system application.

From data developed in the subsequent performance and economic analyses (and discussed briefly in section 2.2.2 - CLIMATE), a central station installation of 1000 ton capacity would require 3 . 0 MGD wastewater flow to supply the heating requirements of 470 homes in a New England clime with approximately 6820 degree-days per heating season. (Note: System performance in a New England clime is used as the basis for this evaluation because performance during the heating season is seen as the limiting criterion in optimizing the balance between thermal energy supply and demand on the system. Thus, defining flow quantities on the basis of satisfactory performance in a cold climate will throw the ultimate estimate of the number of communities to be considered for such a system to the conservative side.) Prorating the flow requirements to each residence gives a minimum flow per home of 6383 gallons per home per day ( $\left.\frac{\text { gals }}{\text { home-day }}\right)$.

From a technical standpoint it would be possible to size, design, and 
install an HP-WHR system for perhaps as few as 5 homes, although the chances for economic viability of such a small system would be very slim. Therefore, to facilitate system design and construction and to accelerate the economic recovery of the system capital costs, the smallest system to consider would cover an approximate 100 hame service area. The wastewater flow required for this service area would then be 638,300 gallons per day. This figure, divided by the 100 gallon per capita per day average water consumption figure, gives the population of the theoretic minimum size community that could be considered as a candidate for an HP-WHR system: 6383 persons. With allowances for minor variations in heating loads, service areas, and industrial discharges, and to facilitate the derivation of community and population estimates from available statistics, communities with populations of 5000 persons or more will be considered candidates for an HP-WHR system. It should be noted here that an ICES (and in this case an HP-WHR system) can be applied to a total community or just to portions of it. The HP-WHR concept depends upon the idea of reclaiming waste heat from the total flow of community wastewater and distributing it into certain viable service areas, not necessarily the full community. Thus, an HP-WHR heating system serving a small area integrated with a wastewater collection system serving a larger area does not contradict the ICES concept. However, defining a miminum population limit for community size is necessary when considering the balance between thermal energy supply and demand on the minimum acceptable size system. With the considerations of thermal energy supply outlined in the preceeding section and the above mentioned guidelines on community size, estimates of the number of potential sites of application and the potential energy savings can be developed. 


\section{3 .3 ESTIMATES}

Estimates for points of application and for energy conservation to be made on a nationwide basis will necessarily be based on a set of assumptions. The following discussions detall the assumptions pertinent to the estimates to be developed in this section:

- A community of 5000 persons or more would discharge enough wastewater (and thus enough thermal energy) to service the minimum acceptable system size of 100 homes. As community population increases above 5000, a proportionate increase in thermal energy becomes available through the community wastewater, and the potential for expanding system service area increases correspondingly. Thus the additional thermal energy made available by increased populations will be utilized at some point in the HP-WHR system.

- The statistical breakdown of community sizes and attending sewage treatment facilities from the 1968 Municipal Waste Facilities Inventory ${ }^{41}$ (reproduced in Appendix A as TABLES A-4 and A-5) reveals that $59.53 \%$ of the total U.S. population resides in communities of 5000 or more and are connected to a municipal wastewater collection system with attending treatment plant. Deriving an estimate for the most optimistic market penetration, barring any acceptance barriers except technological, dictates that the full potential for wastewater heat reclaim be realized. Therefore, the full $59.53 \%$ (.5953) of the total population, who reside in communities of sufficient size to be consldered as candidates for an HP-WHR system, will be used as the percent sewered population figure in developing the estimate. 
- From the statistical breakdown in TABLE A-4, the number of potential sites of application (i.e. communities with populations of over 5000) is 3795. Extremely large communities (over 100,000) are included in this number because it is expected that, in these communities, wastewater collection and treatment will be segregated among several treatment facilities, thus providing the opportunity to install either segregated systems or modular central station facilities. The number of acceptable sites is not expected to change during the projection period due to the fact that new or planned communities would necessarily have to undergo several years of growth before arriving at a stage of development when an HP-WHR system would become a viable option. These communities should not be dropped from consideration, however, for such a system since new community developments would provide an ideal site of application for an ICES, designed from scratch and optimized for the particular community configuration. They simply cannot be included in this projection because of insufficient data.

- The population increase within each potential site of application will be assumed to be directly proportional to the national percentage increase in population during the projection period. Existing facilities or facilities now under construction will be assumed to supply sufficient sewage treatment capacity to handle the proportionate population increase during the projection period.

- It should be noted that the number of satisfactory sites and the estimate of percent sewered population is conservative due 
to the fact that they are based on somewhat outdated (1968) data. Bearing in mind the above assumptions and utilizing the thermal energy supply approximation shown as equation 2-3, the energy reclaimed from community wastewater, on a nationwide basis by community energy systems based on the HP-WHR concept, would be calculated thusly:

1980 U. S. Population - 221,848,000 (est.)

\% Sewered Population - 59.53\%

$$
\begin{aligned}
Q_{\text {WASTE }} & =3.040 \times 10^{6}(221,848,000)(.5953) \frac{\text { Btu }}{\text { year }} \\
& =401.48 \times 10^{12} \frac{\text { Btu }}{\text { year }}
\end{aligned}
$$

Derived through this approximative method, TABLE 2-1 summarizes the amount of thermal energy potentially available for space conditioning needs, from a starting date of 1980 to the year 2000 (inclusive), extracted from community wastewater through HP-WHR systems installed at the 3795 potential sites of application.

The utilization of this amount of low-grade thermal energy will require an energy expenditure by the system which will be in indirect proportion to the overall system C.O.P. and in direct proportion to the delivered load. This expenditure is also, by definition of system C.O.P., viewed as an energy addition to the total thermal load which is to be delivered to the end-users and is defined by the equation below:

$$
Q_{\text {power }}=\frac{Q_{\text {WASTE }}}{\text { C.0.P. SYSTEM }}
$$

The total load delivered is then the sum of the energy reclaimed, $Q_{\text {WASTE, }}$ and the energy expended in the system, $Q_{\text {power }}$, thus: 


\section{HEAT EXTRACTED FROM WASTEWATER}

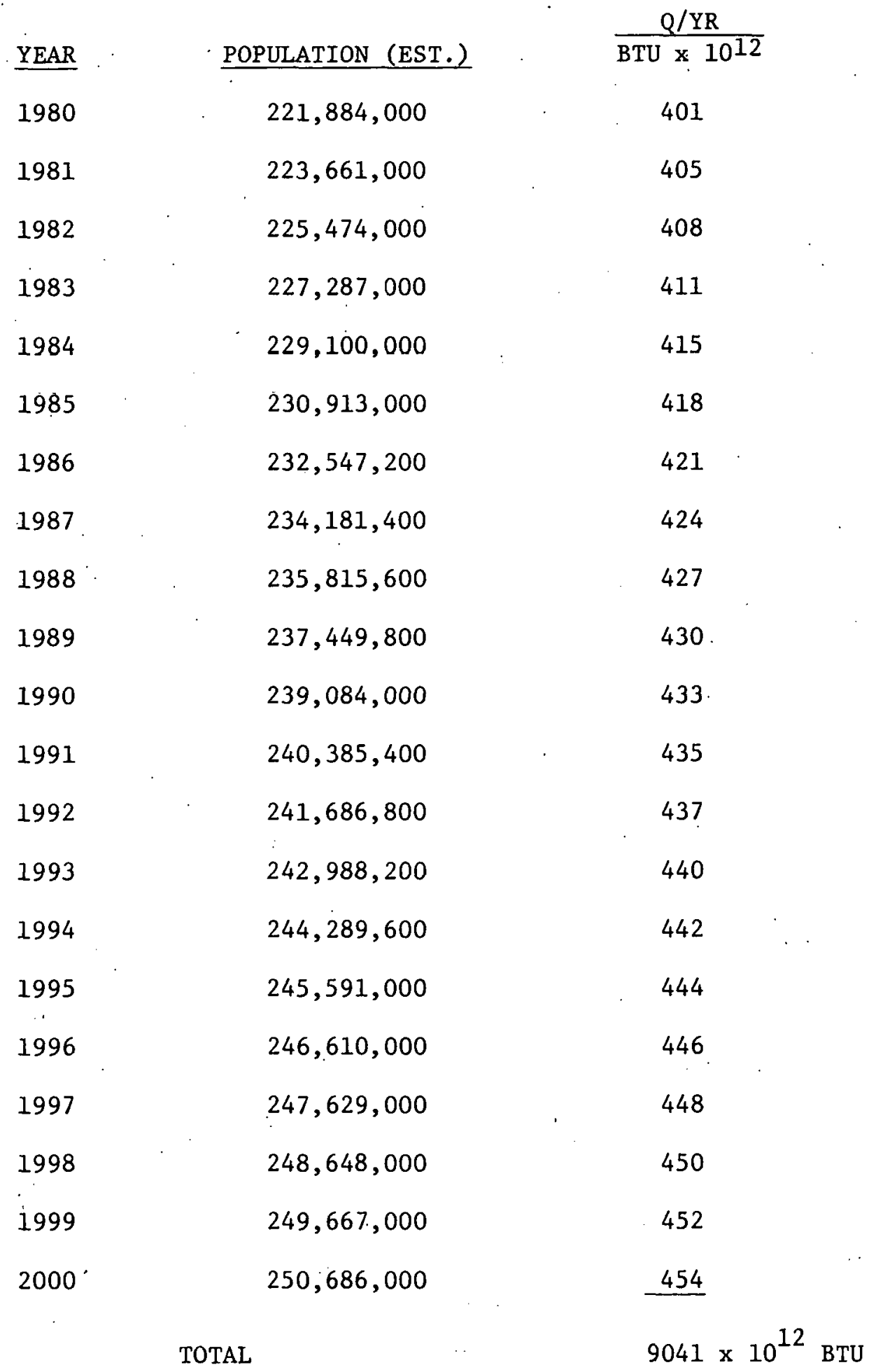

POPULATION ESTIMATES: "Population of the United State" 44 


$$
\begin{aligned}
Q_{\text {TOTAL }} & =Q_{\text {WASTE }}+Q_{\text {power }} \\
& =Q_{\text {WASTE }}+\frac{Q_{\text {WASTE }}}{C .0 . P \cdot \text { SYSTEM }} \\
& +Q_{\text {WASTE }}\left(1+\frac{1}{\text { C.0.P. SYSTEM }}\right)
\end{aligned}
$$

Substituting the estimate of $Q_{\text {WASTE }}$ from TABLE 2-1 and the overall HP-WHR system C.0.P. of 2.245 (from Chapter 3.0 - EXPECTED PERFORMANCE). yields:

$$
\begin{aligned}
Q_{\text {TOTAL }} & =9041 \times 10^{12}\left(1+\frac{1}{2.245}\right) \\
& =13,068 \times 10^{12} \mathrm{Btu}
\end{aligned}
$$

Thus, the utilization of the previously estimated quantity of reclaimed thermal energy is tantamount to the delivery of $13,068 \times 10^{12}$ Btu at an on-site energy expenditure of $Q_{\text {WASTE }} /$ C.O.P. SYSTEM or $4027 \times 10^{12} \mathrm{Btu}\left(1.18 \times 10^{12} \mathrm{KWH}\right)$.

This on-site energy expenditure by the HP-WHR system can be translated to primary fuel resource consumption under the following conditions:

\section{ELECTRIC GENERATION EFFICIENCY - Average coal-fired power plant heat} rate of $10,300 \mathrm{Btu} / \mathrm{kwh}$ is assumed. Transmission and distribution losses total 9\%. High heating value (HHV) of $12,000 \mathrm{Btu} / 1 \mathrm{bm}$ for coal is assumed.

Primary fuel resource consumption in the form of coal is thus $13,248 \times 10^{12}$ Btu or 552 million $\left(552 \times 10^{6}\right)$ tons for the delivery of the estimated 13.1 QUAD thermal load.

The above HP-WHR system energy consumption can be compared to that required for the delivery of a comparable thermal load via the conventional space conditioning system options. The following assumptions are in effect for the 
various options:

ELECTRIC STRIP HEATING UNITS - Heating C.0.P. is 1.0 , and the above mentioned assumptions for electric generation efficiency are also in effect.

FUEL-OIL FIRED FURNACE - Combustion and thermal transfer efficiency is taken as 65\%; HHV for fuel oil is assumed at $140,000 \mathrm{Btu} / \mathrm{gal}$; no transmission or distribution losses.

NATURAL GAS-FIRED FURNACE - Combustion and thermal transfer efficiency is taken as 65\%; HHV for natural gas is assumed constant at $1000 \mathrm{Btu} / \mathrm{CFT}$;

$8 \%$ transmission and distribution losses.

Under the above assumptions, the electric strip heat option would require $42,987 \times 10^{12}$ coal Btu's, or 1791 million $\left(1791 \times 10^{6}\right)$ tons. The HP-WHR system performance thus represents a $69 \%$ reduction in coal consumption in. meeting the equivalent thermal load.

For the operation of fuel oil-fired furnaces in meeting the approximate 13.1 QUAD thermal load, the primary fuel resource consumption would amount to $20,105 \times 10^{12}$ fuel oil Btu's, or 3.42 billion barrels. The HP-WHR system performance in comparison to this option represents a $35 \%$ reduction (on a Btuto-Btu basis) in consumption of primary fuel resources. It should also be noted that operation of the heat pump system would effectively force a shift in consumption from the more scarce fuel oil resources to the relatively abundant coal resources.

For the operation of natural gas-fired furnaces in meeting the estimated 13.1 QUAD thermal load, the primary fuel resource consumption would amount to $21,713 \times 10^{12}$ natural gas Btu's, or 21.7 trillion cubic feet. In comparison, the HP-WHR system performance represents a $39 \%$ reduction (on a Btu-to-Btu basis), in consumption of primary fuel resources. For this option, as for the fuel oil-fired furnace option, the operation of the heat pump 
system would force a significant shift away from consumption of scarce fuel resources.

In summary, the HP-WHR system exhibits the potential for conserving from $35 \%$ to $69 \%$ of the scarce fuel resources consumed in meeting the approximate 13.1 QUAD thermal load which potentially could be handled through wastewater heat reclaim. Primary fuel source savings can be quantified at:

$\begin{array}{lll} & \text { COAL } & -29.74 \text { QUADS } \\ \text { or } & \text { FUEL OIL } & -6.86 \text { QUADS } \\ \text { or } & \text { NATURAL GAS } & -8.47 \text { QUADS }\end{array}$

Fuel savings are of course dependent upon the type of conventional space heating system which would be displaced with the HP-WHR system.

It is duly noted that, while the estimate takes into account the full potential for wastewater heat reclaim for the 20 year time period between 1980 and 2000, it is highly improbable that HP-WHR systems could be installed and operational by the 1980 starting date of the study period and that widespread implementation of the system concept would be unlikely, even with a successful "fast-track" demonstration, before perhaps 1990. Obviously though, from the above comparison, a vast potential for primary energy resource conservation can be realized by the development and implementation of an HP-ICES based on the HP-WHR concept. 


\section{THIS PAGE \\ WAS INTENTIONALLY \\ LEFT BLANK}




\subsection{EXPECTED PERFORMANCE}

\section{$3: 1 \quad$ INTRODUCTION}

The scheme of HP-WHR system for a community is explained in the section on system description. For purposes of thermodynamic analysis of the heating mode, a schematic of the HP-WHR system that includes one end-user heat pump, one central station heat pump at the treatment plant, a water storage reseríoir, and distribution lines is shown in Figure 3-1. A similar system for analysis of the cooling mode is shown in Figure 3-2. It is possible that a number of central station heat pumps may be used depending on the application.

In the thermodynamic model for the heating mode, wastewater effluent at constant temperature from the treatment plant enters the central heat pump where its thermal energy (heat) is extracted and delivered to the distribution medium (water). The distribution water enters a thermal storage tank to provide a water supply at constant temperature to the end-user heat pumps, and after delivering heat to the end-user heat pumps, the water is then returned to the central unit. A reversal of heat flow takes place for the cooling mode in which the energy is ultimately rejected to the effluent. Calculations of the energy requirements of the HP-WHR system using a central heat pump are presented in Section 3.4 - ANALYSIS OF RESULTS along with the results of a distributed water-to-air heat pump system deleting the central heat pump. These performance results are compared with those of the conventional systems.

\subsection{SELECTION OF CONDITIONS}

In the selection of wastewater effluent temperatures for estimating the peak load and normal load performances of the HP-WHR system, efforts were made to correlate wastewater effluent temperature with the outside 


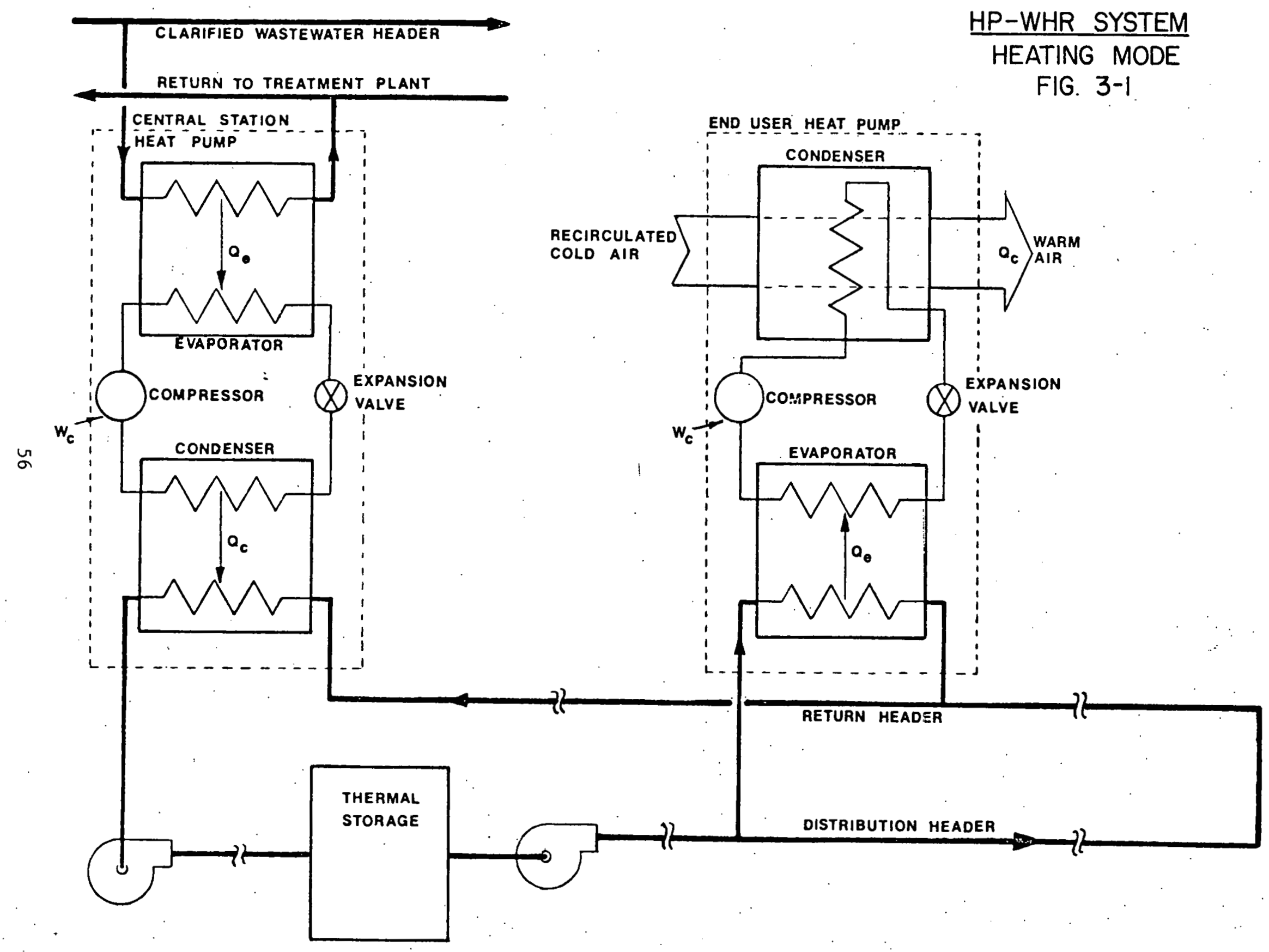




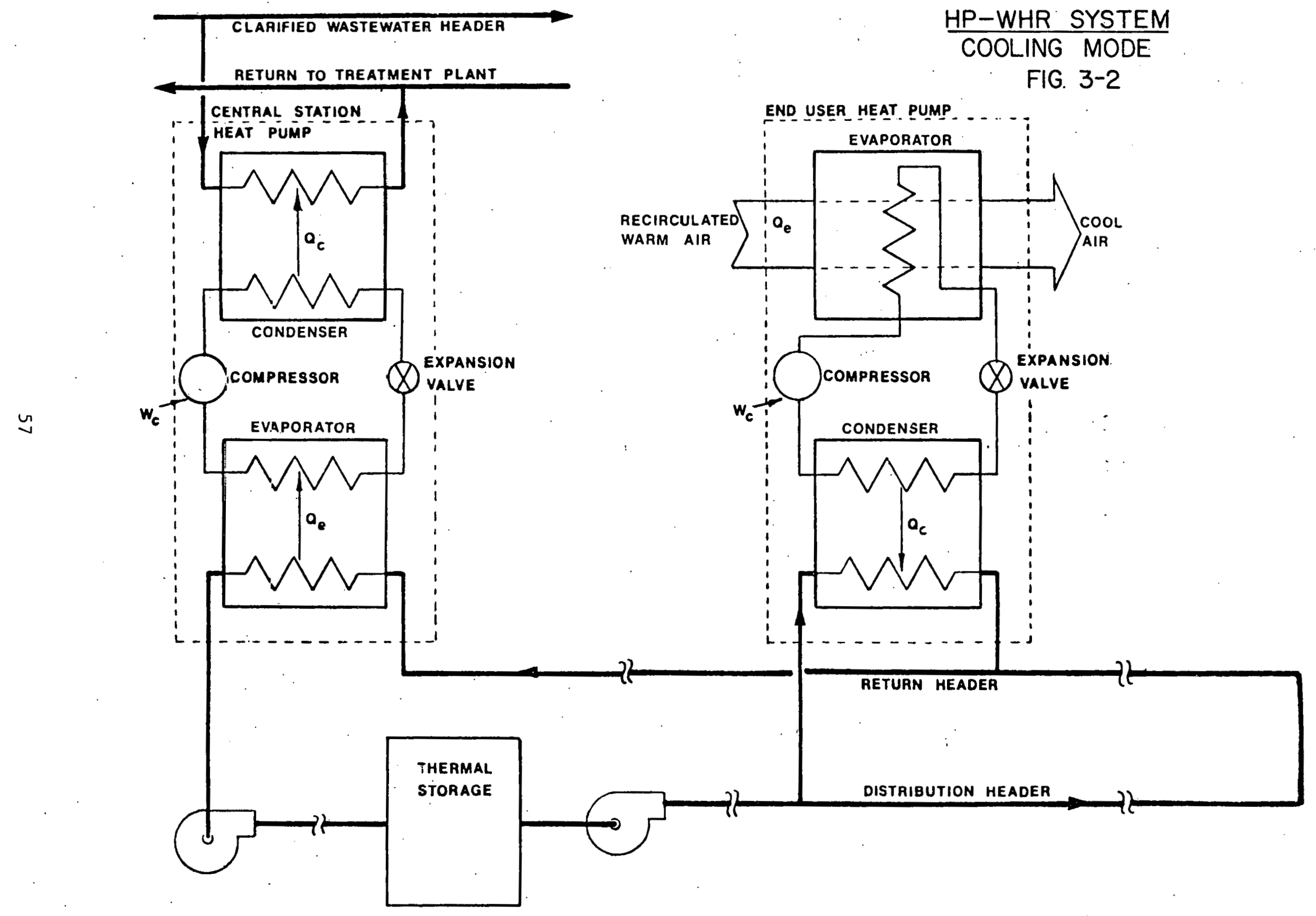


air temperature. The wastewater effluent temperature depends on factors such as the time of day, ground temperature, outside air temperature, and the presence of thermal discharges from industrial prociesses. There is also the time-lag associated with the temperature change of the reservoirs or lakes as the water supply is drawn into community systems when seasonal changes in air temperatures occur. It is therefore believed that there can be wide variations in wastewater temperatures even within the same geographical region. Based on site-specific observations and study of various reports it is observed that the wastewater effluent temperatures (in parts of Canada) have ranged from lower $40^{\prime} \mathrm{s}\left({ }^{\circ} \mathrm{F}\right)$ to upper $90^{\prime} \mathrm{s}\left({ }^{\circ} \mathrm{F}\right) .20,22$ One of the studies reports the average annual wastewater temperature at a plant in the North Chicago area to be between $50^{\circ} \mathrm{F}$ and $60^{\circ} \mathrm{F} .20$ It is also observed that wastewater effluents undergo temperature changes during the treatment processes.

In this study, effluent temperatures of $50^{\circ} \mathrm{F}, 60^{\circ} \mathrm{F}, 70^{\circ} \mathrm{F}$, and $80^{\circ} \mathrm{F}$ have been chosen for analysis. It is believed that these temperatures are representative of a number of locations in the United States.

\subsection{SYSTEM COP AND ENERGY CONSUMPTION}

The coefficient of performance of the HP-WHR system (or air-to-air system) is defined as the ratio of the heating or cooling effect provided to the space at the end-user location divided by the energy equivalent of all energy inputs including compressors, pumps, and 1osses. This provides a measure for comparing the energy consumption of the HP-WHR system with that of conventional systems.

The system energy consumption in providing heating or cooling is: 


$$
\mathrm{E}_{\text {system }}=\frac{1}{\mathrm{COP}_{\text {system }}}
$$

Primary Fuel Energy Consumption (based on fossil fuels) $=\frac{E_{\text {system }}}{0.31}$ (3-2)

Where

$$
0.31=n_{\text {generation }} x n_{\text {transmission }} x n_{\text {distribution }}
$$

NOTE: The value of 0.31 , which is the overall efficiency of conversion of primary fuel energy to useful electrical energy and transmission to application, is taken from Reference 4. This value is assumed for calculation, but is subject to variation.

\subsection{ANALYSIS OF RESULTS}

\subsubsection{HEATING MODE}

Peak Load - The system COP values were calculated for the given design loads (peak) as a function of the temperature of the effluent as it enters the evaporator of the central heat pump. The results are presented as Figures 3-3 and 3-4 and summarized in Table 3-1. The temperature of water entering the end-user unit was held constant at $80^{\circ} \mathrm{F}$. The Coefficient of Performance of the HP-WHR system increases by only $3.8 \%$ as the temperature of the effluent increases from $50^{\circ} \mathrm{F}$ to $80^{\circ} \mathrm{F}$. This is to be expected because the COP of the end-user unit is held at constant value (relatively high) at the entering water temperature of $80^{\circ} \mathrm{F}$, and the end-user unit consumes a greater share of the total energy input. Using equation 3-1, the energy required by the HP-WHR system to deliver 1 Btu of heating load is also listed in Table 3-1. These electrical energy values were translated to primary energy requirements by using equation $3-2$ and are also shown in Table 3-1. For the purposes of comparison, similar data for an air-to-air heat pump is presented as Table 3-2.

Typical Heating Load - At heating loads lower than design heating 
WASTEWATER TEMPERATURE VS HP-WHR SYSTEM C. $0 . P$

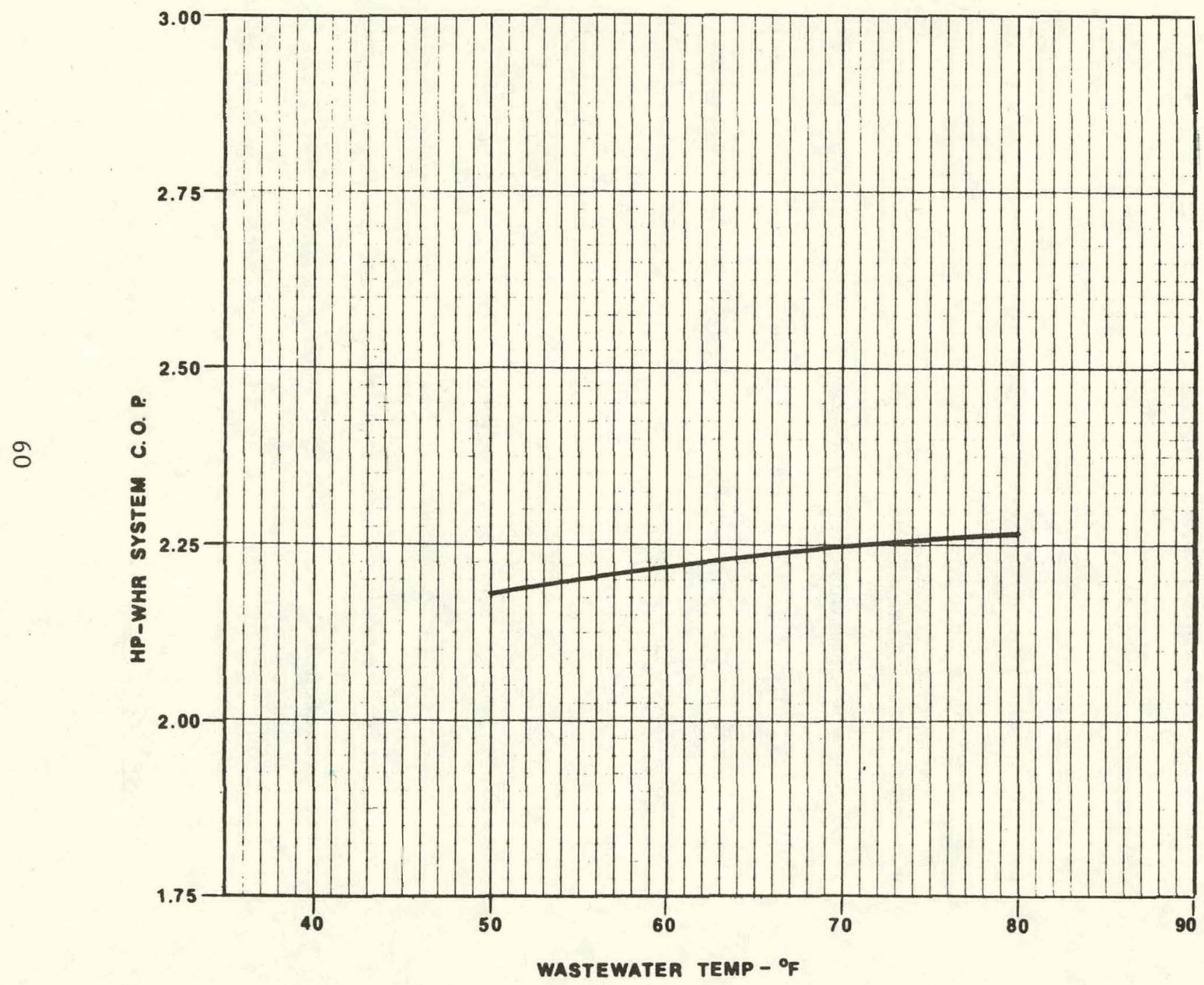

ENTERING WATER TEMPERATURE AT END USER UNIT $80^{\circ} \mathrm{F}$

\begin{tabular}{l|l}
$\begin{array}{l}\text { ENTERING } \\
\text { WASTEWATER } \\
\text { TEMP - }\end{array}$ & $\begin{array}{l}\text { HP-WHR } \\
\text { SYSTEM } \\
\text { C.QP }\end{array}$ \\
\hline 50 & 2.181 \\
60 & 2.219 \\
70 & 2.245 \\
80 & 2.264
\end{tabular}


WASTEWATER TEMPERATURE VS HP-WHR SYSTEM C. O. P

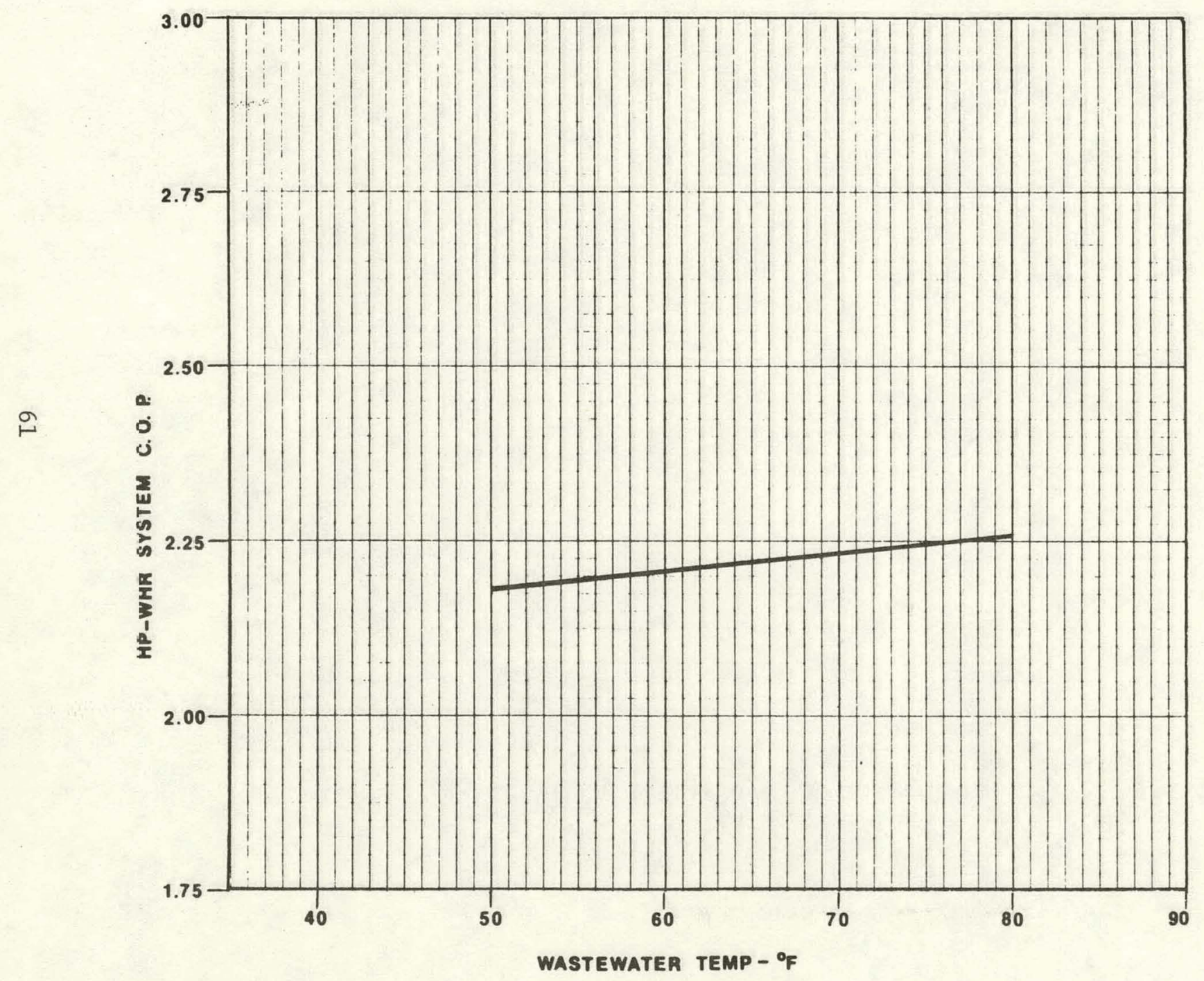

ENTERING WATER TEMPERATURE AT END USER UNIT $95^{\circ} \mathrm{F}$

\begin{tabular}{l|l}
$\begin{array}{l}\text { ENTERING } \\
\text { WASTEWATER } \\
\text { TEMP- }\end{array}$ & $\begin{array}{l}\text { HP-WHR } \\
\text { SYSTEM } \\
\text { C.Q. }\end{array}$ \\
\hline 60 & 2.209 \\
70 & 2.241 \\
80 & 2.260
\end{tabular}

FIG. 3-4 


\section{TABLE $\quad 3-1$ \\ HP-WHR SYSTEM}

Design Heating Load $=55000$ Btuh

(Based on $-20^{\circ} \mathrm{F}$ outside air temperature and $75^{\circ} \mathrm{F}$ inside air temperature)

\section{Effluent \\ Temperature ${ }^{\circ} \mathrm{F}$}

50

60

70

80

oิ
Temperature of Water

Entering End-user ${ }^{\circ} \mathrm{F}$

80

80

80

80

60

70

80

95

95
COP

System

2.181

2.219

2.249

2.264

2.228 Avg.

2.209

2.241

2.260

$2.233 \mathrm{Avg}$.
$\underline{E_{\text {System }} \frac{B t u}{B t u}} \quad$ E Primary Fuel Energy $\frac{B t u}{B t u}$

0.4585

1.479

0.4506

1.454

0.4446

1.434

0.4417

1.425
0.4527

0.4460

0.4425

1.427
1.460

1.440 


\section{TABLE $\quad 3-2$ \\ AIR-TO-AIR HEAT PUMP \\ Nominal $\mathrm{COP}=2.8$ Heating Mode}

\begin{tabular}{|c|c|c|c|}
\hline $\begin{array}{l}\text { Outside Air } \\
\text { Temperature- }{ }^{\circ} \mathrm{F}\end{array}$ & $\begin{array}{c}\text { C.JP } \\
\text { Heat Pump }\end{array}$ & $\mathrm{E}_{\text {Required }} \frac{\mathrm{Btu}}{\mathrm{Btu}}$ & $\mathrm{E}_{\text {Primary Fuel Energy }}$ \\
\hline-20 & 0.572 & 1.488 & 4.800 \\
\hline 0 & 1.552 & 0.605 & 1.953 \\
\hline 10 & 1.932 & 0.5175 & 1.669 \\
\hline 20 & 2.016 & 0.496 & 1.600 \\
\hline 25 & 2.219 & 0.4506 & 1.453 \\
\hline 47 & 2.753 & 0.363 & 1.170 \\
\hline
\end{tabular}

NOTE: The COP values of air-to-air heat pumps were computed using the information given in Unitary Air-to-Air Heat Pumps. 6 
the equipment would be operating at part load resulting in cyclic operation. Cyclic operation results in a loss of efficiency. Information in the form of an equation for the part load performance of water-to-water heat pumps is available (Reference 5) but precise information on the part load performance of water-to-air heat pumps is not available. Information from Reference 10 on part load performance of air-to-air heat pumps indicates that, at heat loads of $15 \%$ of rated capacity, the cyclic operation of a heat pump can result in a decreased COP of approximately $30 \%$ of the full load, steady state value. At loads on the order of $80 \%$ heating, the decrease in COP is about 4 to $5 \%$ of its steady state value. These figures apply to air-to-air heat pumps and are based on the experimental.work by Kelly \& Bean ${ }^{14}$, and Parken \& Beausoliel. 23

Cooling Mode - The results of the cooling mode analysis are presented in Table 3-3 for wastewater temperatures of $60^{\circ} \mathrm{F}$ and $80^{\circ} \mathrm{F}$, and the COP values are used in the calculation of annual energy requirements.

\subsubsection{SIMULTANEOUS HEATING AND COOLING}

The need for simultaneous heating and cooling arises where in certain buildings of the community, the internal heat gains exceed the heat loss from the building. This may happen in the early periods of the Fall and Spring seasons. Since the heat rejected to the distribution water by the end-user heat pumps operating in cooling mode acts as a heat source for the heat pumps operating on the heating mode, the work input to the central heat pump will be reduced. The extent of the energy saved during Lhis type of operation will depend on the relative distribution of heating and cooling loads. In the special case, when the total heat rejected 
TABLE $\quad 3-3$

HP-WHR SYSTEM PERFORMANCE COOLING MODE

Wastewater Temperature Entering Central Unit $-^{\circ} \mathrm{F}$

60

80

80
Water Temperature Entering End-User Unit- ${ }^{\circ} \mathrm{F}$

40

40

50
COP
System $\quad \mathrm{E}_{\text {System }} \frac{\mathrm{Btu}}{\mathrm{Btu}} \stackrel{\mathrm{E}_{\text {Primary Fuel Energy }}}{\mathrm{Btu}}$

$\begin{array}{lll}.913 & 0.523 & 1.686 \\ 1.874 & 0.534 & 1.721 \\ 1.843 & 0.543 & 1.750\end{array}$

1.750 
by the end-user heat pumps operating in the cooling mode is absorbed by the heat pumps operating in the heating mode, the central heat pump will require no work input. Such a situation can be obtained by several , combinations of heating and cooling loads, units with different COP's, etc. In the section on analysis, a model consisting of two end-user units is analyzed by means of an example: It is shown that, for two end-user units of identical COP values, the work input to the central unit is zero when the ratio of heating load/cooling load $=\mathrm{HRF}^{2}$, where HRF is called the heat rejection factor defined in the section on analysis.

\subsubsection{ANNUAL ENERGY CONSUMPTION}

The annual energy consumption by the HP-WHR system and other conventional systems are calculated and the total energy required by residences in the Northwest Central region and the South Atlantic region are listed in the Table 3-4. In the calculation of the annual energy consumptions by the HP-WHR system and other conventional systems, the chapters on energy estimating methods of the ASHRAE Handbook and Product Directory, Systems Volumes 1973 and $1976^{49}$ were consulted. The use of the bin method of calculation could not be used because data on part load performance of water-to-air heat pumps was not available. However, the dynamic efficiency loss factors were considered in accordance with the data derived from Reference 10.

\section{4 .4 OBSERVATIONS}

The results of this study indicate that HP-WHR systems perform better than the air-to-air heat pumps in northern locations, at outside air temperatures down to $25^{\circ} \mathrm{F}$ in the heating mode.

The coefficient of performance of the HP-WHR system varies with 
TABLE $\quad 3-4$

ANNUAL ENERGY CONSUMPTION*

\begin{tabular}{lrc} 
& $\begin{array}{c}\text { GEOGRAPHICAL } \\
\text { SYSTEM }\end{array}$ & $\begin{array}{c}\text { HEATING SEASON } \\
\text { RETU/SEASON }\end{array}$ \\
\cline { 2 - 3 } HP-WHR & NWC & 32096 \\
& SA & 17898 \\
AIR-TO-AIR & NWC & 47210 \\
HEAT PUMP & SA & 16478 \\
CONVENTIONAL & & \\
FUEL & NWC & 155717 \\
GAS (WARM-AIR) & SA & 87068 \\
ELECTRIC & & 65244 \\
& NWC & 36481
\end{tabular}

\begin{tabular}{|c|}
\hline $\begin{array}{c}\text { COOLING SEASON } \\
\text { MRTU/SEASON }\end{array}$ \\
\hline $\begin{array}{r}4398 \\
15306\end{array}$ \\
\hline $\begin{array}{r}3861 \\
14077\end{array}$ \\
\hline $\begin{array}{l}12454 \\
45409\end{array}$ \\
\hline $\begin{array}{r}3861 \\
14077\end{array}$ \\
\hline
\end{tabular}

ANNUAL PRIMARY

E ANNUAL

MBTU/YR

36934

32942 .

51071

30555

168171

$1324 i 7$

69105

50558
FUEL CONSUMPTION

MBTU/YR

119142

106264

164745

98564

168171

132477

222919

163090

*The annual energy consumption listed in this table is based on design loads.

NWC - North West Central Region

$\mathrm{SA}$ - South Atlantic Region 
effluent temperatures, but no to a great degree. As seen in Table 3-I and Figure $3-1$, the system COP. increased by only $3.8 \%$ when the effluent temperature changed from $50^{\circ} \mathrm{F}$ to $80^{\circ} \mathrm{F}$.

In the cooling mode, the air-to-air heat pump performs better than the HP-WHR system. Compared to a conventional heating system (gas warm-air furnace), the HP-WHR system consumes a greater amount of primary fuel both in the Northern and Southern locations.

Distributed water-to-air heat pumps consume less energy compared to the HP-WHR systems using central heat pumps. The results in Table 3-4 indicate that the system $C O P$ is high, and in general, the system performs better than conventional heating systems, such as air-to-aị and gas furnacewarm air heating systems on the basis of primary fuel consumption. A variation of the HP-WHR scheme is discussed in the next section. As shown in the example in Section 9.4.6, the simultaneous heating and cooling mode of operation improves the performance of the HP-WHR system.

3.5 HP-WHR SYSTEMS USING ONLY DISTRIBUTED WATER-TO-AIR HEAT PUMPS

The use of distributed heat pumps (with no central heat pump) using heat from wastewater effluent as the source of energy is possible if the wastewater is at a sufficiently high temperature to allow for heat transfer to the distribution water by means of a heat exchanger. If such conditions are obtainable, the scheme would be as shown in Figure 3-5. This system COP is found to be higher than the HP-WHR system using central heat pumps. But at lower effluent temperatures, the size of the heat exchangers would have to be very large to allow for sufficient quantities of heat transfer, and the pumping losses resulting from increased flow rates of water would be high.

The COP system and energy requirements are listed in Table 3-5. 


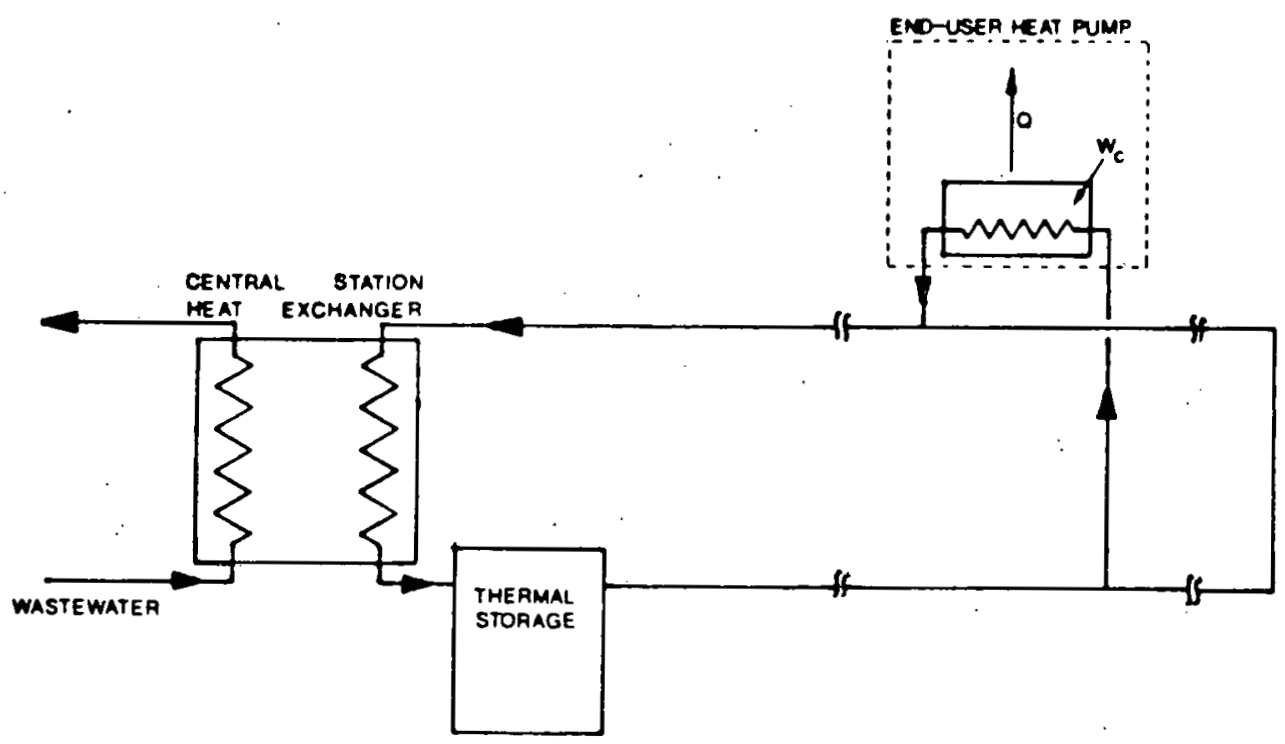

DISTRIBUTED WATER SOURCE HEAT PUMP SYSTEM

FIG. 3-5

TABLE 3-5

DISTRIBUTED HEAT PUMP SYSTEM

C.O.P. VS. EFFLUENT TEMPERATURE

Effluent Distribution System

$\mathrm{COP}$

$E$

E Primary

Iemperature

Supply Temperature

Distributed Syster

Systems

Fuel Energy

$80^{\circ} \mathrm{F}$

$60^{\circ} \mathrm{F}$

2.779

0.360

1.16

$70^{\circ} \mathrm{F}$

$50^{\circ} \mathrm{F}$

2.562

0.390

1.258

$65^{\circ} \mathrm{F}$

2.528

0.395

1.274 


\subsection{SECOND LAW ANALYSIS}

The previous performance analyses have used the first law of thermodynamics to determine the required system energy input. These analyses have been characterized by first law efficiencies defined as: Useful Energy Output divided by Required Energy Input. In the case of the HP-ICES system this analysis determines an overall system coefficient of performance. As expected, this analysis yields values greater than unity.

A second law thermodynamic analysis must be performed to determine the system's true thermodynamic efficiency. The second law recognizes that energy is characterized by quality as well as quantity. By comparing second law efficiencies a true determination of resource utilization efficiency can be made.

To recognize energy quality, the concept of availability is used. Availability is the thermodynamic property which measures the potential of a system to do work when restricted by surroundings at some ambient condition. Availability is not conserved. It is destroyed by friction and heat transfer through a finite temperature difference. This destruction of availability is the true thermodynamic loss which causes a process to be irreversible.

The availability analysis for the HP-ICES schemes utilizing wastewater heat recovery center on the system composed of a central heat pump or heat exchange device, distribution system and storage and end-user heat pumps. The energy and process streams crussing the boundaries of the system consist of the following:

1) The wastewater heat source entering at ambient conditions.

2) Electricity input to the central heat pump or heat exchange device. 
3) Thermal losses from the distribution and storage system.

4) Electricity input to circulating water pumps on the distribution system.

5) Electricity input to the end-user heat pumps.

6) Heat or cooling energy in the form of cool or warm air to the end-user .

7) Miscellaneous parasitic electricity requirements.

The analysis of the system must also take into account the second law thermodynamic efficiency of the electric generating plant supplying electricity to the HP-ICES.

This second law analysis of the HP-ICES system is somewhat limited since the central heat pump and end-user heat pumps must be considered as "black-boxes". It is obvious from a review of the literature that the heat pump devices within the system inherently destroy availability at their component heat exchangers, compressors, and throttling valves. Significant improvement in the overall system performance can be achieved by optimizing the internal components used for end-user heat pumps and central station heat pumps: An optimization of individual heat pump components was not undertaken in this study since that would constitute a heat pump design rather than a system application.

An availability analysis of a conventional system consisting of a natural gas space heater and electric air conditioning system was also made for comparative purposes.

\section{6 .1 ANALYSIS PROCEDURE}

For the system analyses it was recognized that the objective of the system was to provide heating or cooling for a space. This objective is 
accomplished by providing an appropriate quantity of warm or cold air to the space. For practical reasons a supply air temperature of $120^{\circ} \mathrm{F}$ was selected for heating and $55^{\circ} \mathrm{F}$ was selected for cooling. The space temperature was assumed to be $75^{\circ} \mathrm{F}$, which is also considered the' reference temperature for energy availability.

For the systems considered, the available energy balance is:

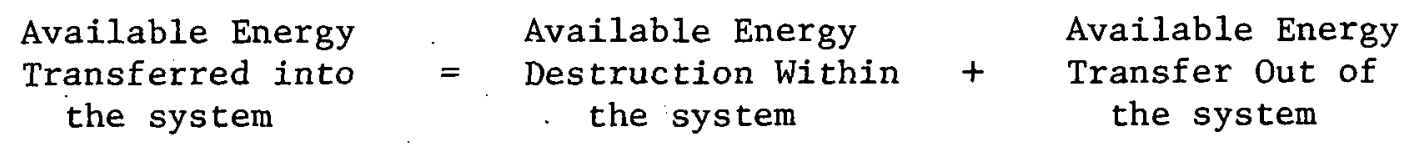

The availability of the energy contained in the air stream to the space is considered the desired output of the system and an indicator of the minimum (theoretical) amount of energy needed for space conditioning.

The ratio of the desired availability to the availability of the energy inputs to the system is termed the second law efficiency.

\subsubsection{CONVENTIONAL SYSTEMS}

A conventional system schematic composed of a natural gas heater and electric air conditioner is presented in Figure 3-6. A second law analysis 1

per unit input of primary fuel yields a second law heating efficiency of $2.6 \%$, assuming a first law efficiency of 65 percent.

With a C.O.P. of 2.2 the electric air conditioning system has a second law efficiency of $1.38 \%$.

\subsubsection{CONVENTIONAL SYSTEM PERFORMANCE}

HEATING

$1^{\text {st }}$ Law (efficiency $\left.-65 \%\right)$. 


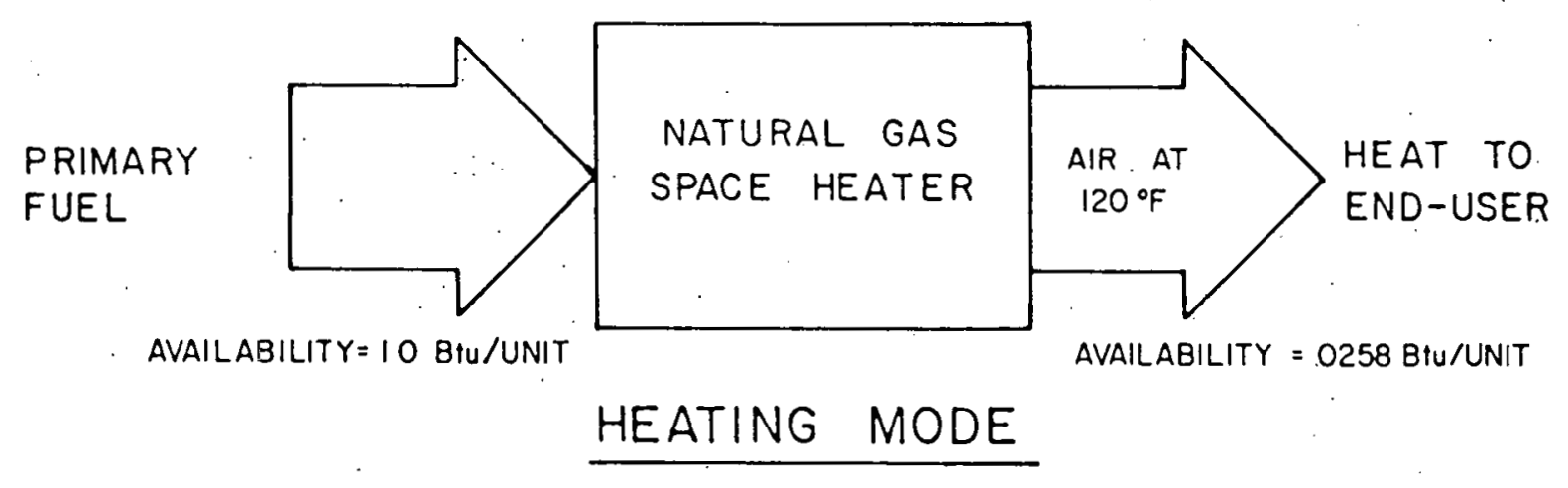

wे

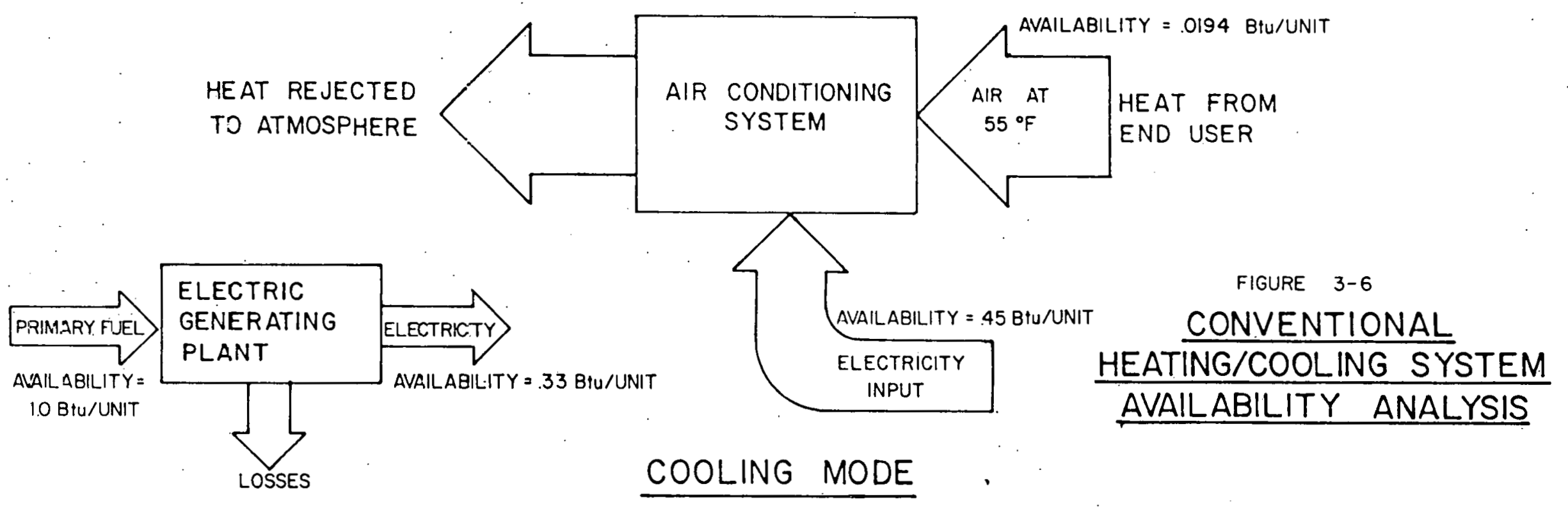




$$
\begin{aligned}
& \text { Primary fuel in }=1 \mathrm{Btu} / \mathrm{hr} \\
& 120^{\circ} \mathrm{F} \text { air out }=.65 \mathrm{Btu} / \mathrm{hr} \\
& \dot{M}_{\text {air out }}=\frac{.65}{.24(120-75)}=.060 \mathrm{1b} / \mathrm{hr} \\
& 2^{\text {nd }} \text { Law (Availability relative to } 75^{\circ} \mathrm{F} \text { ) } \\
& \text { Availability of fuel input }=1 \mathrm{Btu} / \mathrm{hr} \\
& \text { Availability of } 120^{\circ} \mathrm{F} \text { air out }=\dot{\mathrm{M}}\left(\mathrm{C}_{\mathrm{p}}\right)\left[\mathrm{T}-\mathrm{T}_{\mathrm{O}}-\left(\mathrm{T}_{\mathrm{O}} \ln \frac{\mathrm{T}}{\mathrm{T}_{\mathrm{O}}}\right)\right] \\
& =.060(.24)\left[580-535-\left(535 \ln \frac{580}{535}\right)\right] \\
& =.0258 \mathrm{Btu} / \mathrm{hr} \\
& \text { Second Law Efficiency } \\
& =\frac{.0258}{1.00}=.0258
\end{aligned}
$$

\section{COOLING}

$1^{\text {st }}$ Law (C.O.P. $=2.2$, Electric Gen. Eff $\left.=33 \%\right)$

Electricity to heat pump $\quad=.454 \mathrm{Btu} / \mathrm{hr}$

$55^{\circ} \mathrm{F}$ air heat removed $\quad=1.0 \mathrm{Btu} / \mathrm{hr}$

$\dot{\mathrm{M}}$ of $55^{\circ} \mathrm{F}$ air* $\quad=\frac{1.0}{.24(75-55)}=.208 \mathrm{lb} / \mathrm{hr}$

* Assumes Dry Air

$\underline{2^{\text {nd }}}$ Law (Availability relative to $75^{\circ} \mathrm{F}$ )

Availability of primary fuel input $=(.454) \div(.33)=1.377$

Availability of $55^{\circ} \mathrm{F}$ air out

$$
\begin{aligned}
& =.208(.24)\left[515-535-\left(535 \ln \frac{515}{535}\right)\right] \\
& =-.0191 \mathrm{Btu} / \mathrm{hr} \\
& =\frac{.0191}{1.377}=.0138
\end{aligned}
$$

Second Law Efficiency 


\section{- 6.4 HP-ICES WASTEWATER HEAT RECOVERY SCHEME}

HP-WHR system heating and cooling schematics are presented in Figures

3-7 and 3-8. The second law analysis for the system presented yields a heating efficiency of $3.0 \%$ and a cooling efficịency of $.94 \%$ at an overall system C.0.P. of 2.2 .

Significant improvements can be made in the system if individual component performance is improved. This is especially true where the end-user heat pump is concerned.

\section{HP-ICES WASTEWATER HEAT RECOVERY SCHEME}

\section{HEATING}

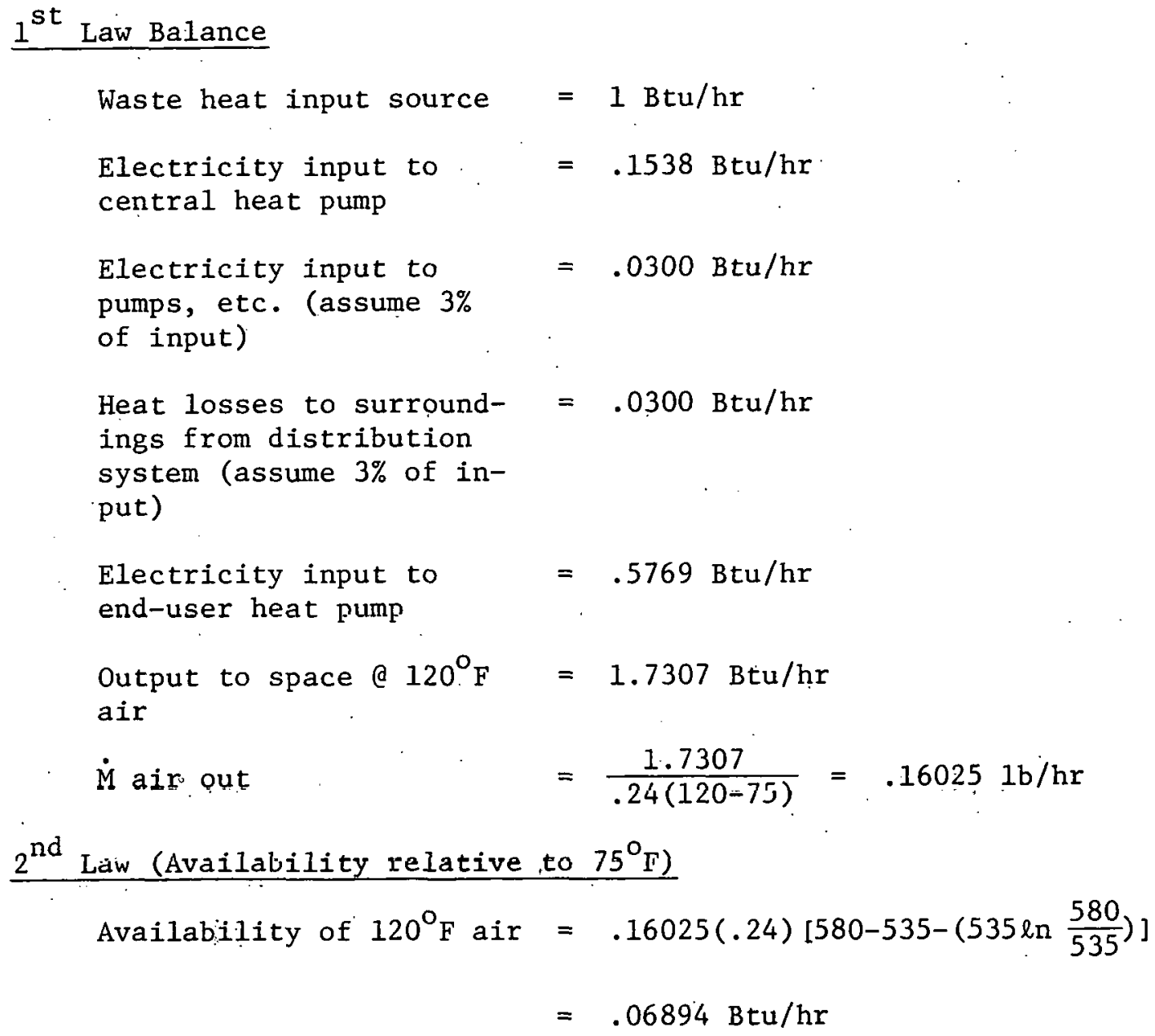



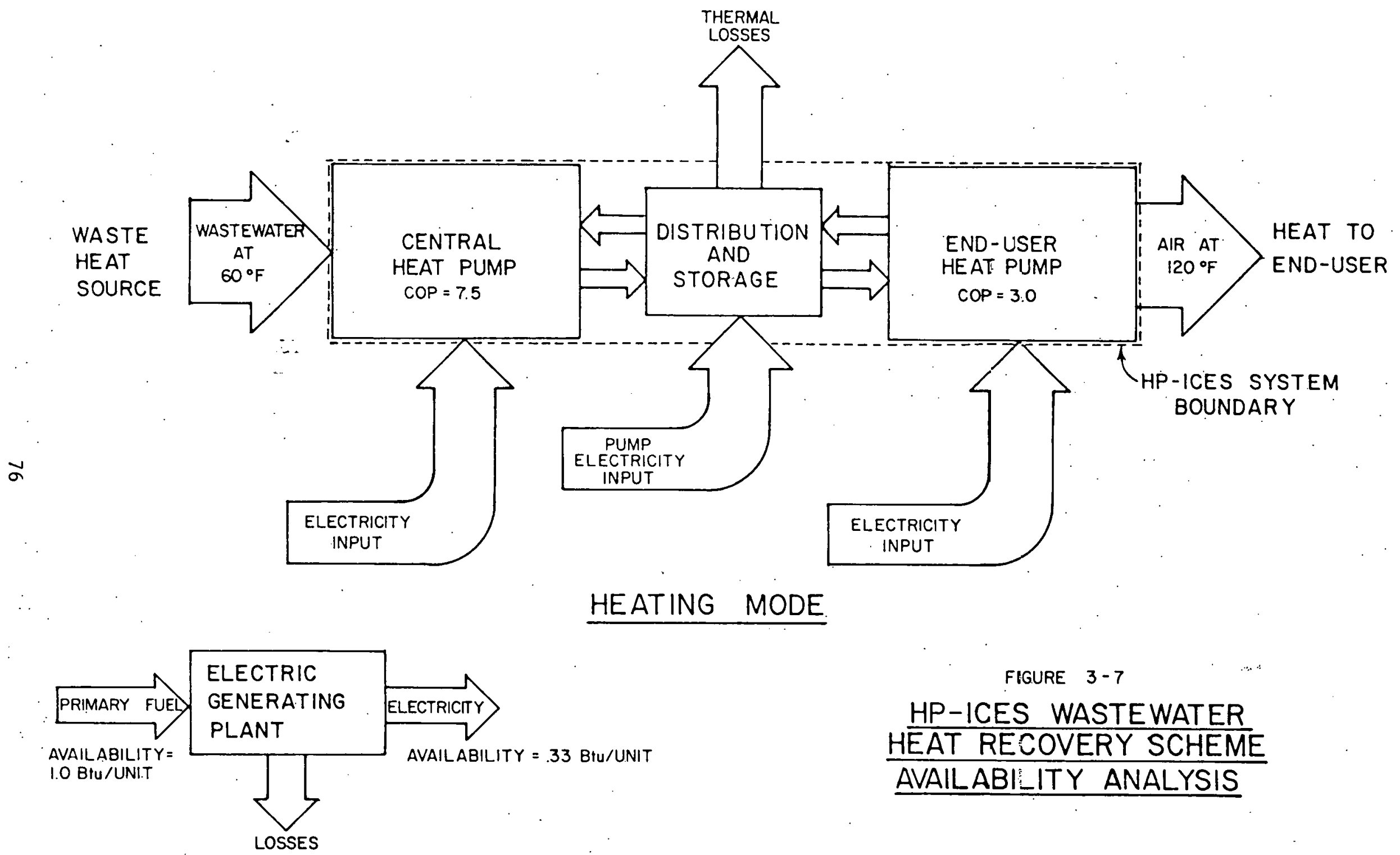

FIGURE 3-7

HP-ICES WASTEWATER HEAT RECOVERY SCHEME AVAILABI_ITY ANALYSIS 

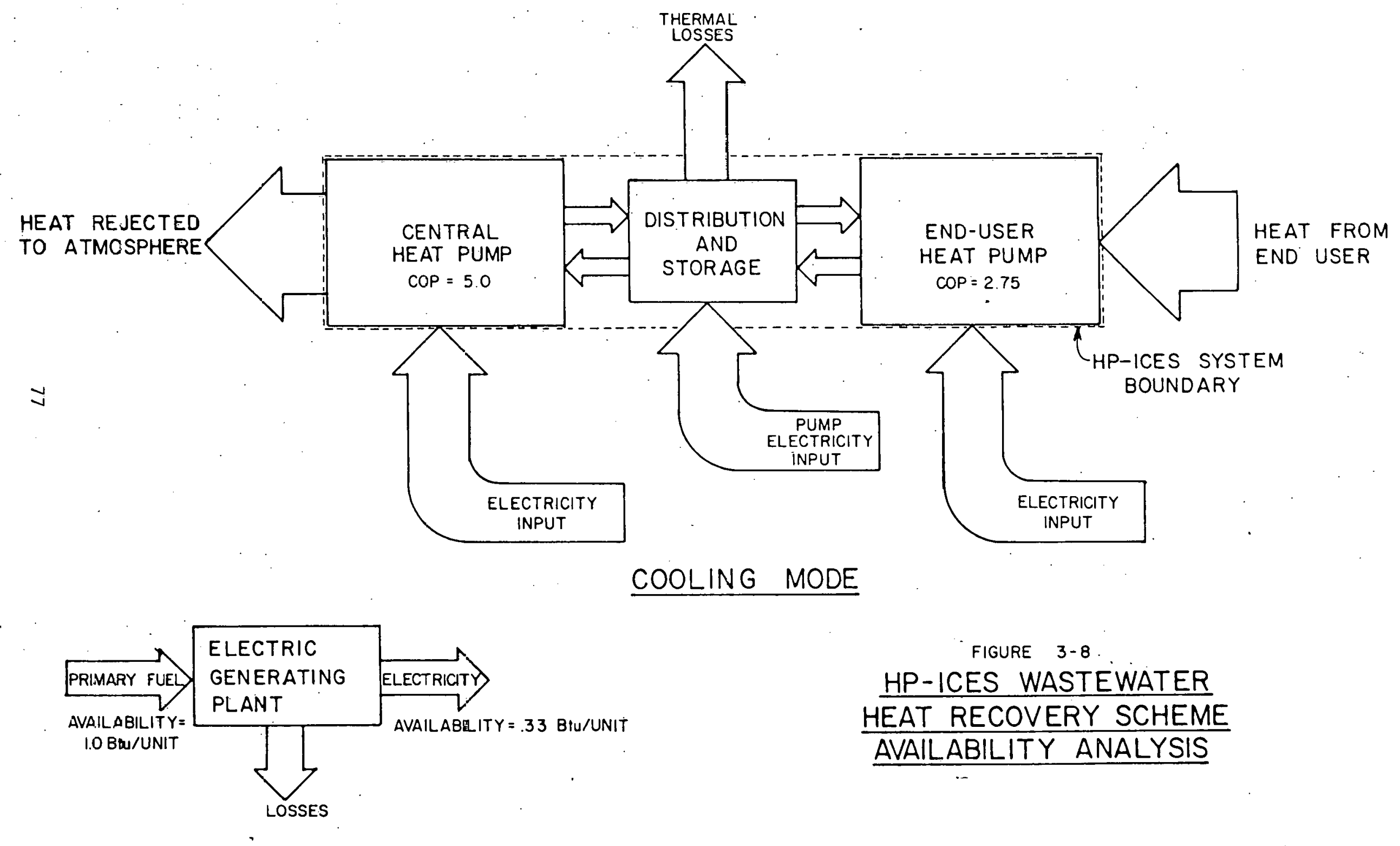
Availability of energy inputs

(primary fuel)

$$
\begin{aligned}
& \text { Electricity to Central Heat Pump }=.1538 \\
& \text { Electricity to Pumps }=.0300 \\
& \text { Electricity to End-User Heat Pump }=\frac{.5769}{.7607 \div .33=2.305 \mathrm{Btu} / \mathrm{hr}} \\
& =\frac{.06894}{2.305}=.0299
\end{aligned}
$$

Second Law Efficiency

\section{COOLING}

$1^{\text {st }}$ Law Balance

$$
\begin{aligned}
& \text { Heat from end-user. } \\
& \begin{array}{l}
\text { Electricity input to } \\
\text { end-user heat pump }
\end{array} \\
& \begin{array}{l}
\text { Electricity input to } \\
\text { pumps, etc. }
\end{array}
\end{aligned}
$$

Heat losses to surround- $=.03 \mathrm{Btu} / \mathrm{hr}$ ings

Electricity input to

$=.272 \mathrm{Btu} / \mathrm{hr}$

central heat pump

$\dot{\mathrm{M}}$ of air to space $a 55^{\circ} \mathrm{F}=\frac{1}{.24(75-55)}=.20833 \mathrm{lb} / \mathrm{hr}$

$\underline{2}^{\text {nd }}$ Law (Availability relative to $75^{\circ} \mathrm{F}$ )

$$
\begin{aligned}
\text { Availability of } 55^{\circ} \mathrm{F} \text { air } & =.20833(.24)\left[515-535-\left(535 \ln \frac{515}{535}\right)\right] \\
& =-.0191 \mathrm{Btu} / \mathrm{hr}
\end{aligned}
$$

Availability of energy inputs

(primary fuel)

$$
\begin{array}{ll}
\text { Electricity to Central Heat Pump } & =.272 \mathrm{Btu} / \mathrm{hr} \\
\text { Electricity to Pumps } & =.03 \\
\text { Electricity to End-User Heat Pump } & =\frac{.363}{.665} \div(.33)=2.015 \mathrm{Btu} / \mathrm{hr} \\
& =\frac{.0191}{2.015}=.0094
\end{array}
$$$$
\text { Second Law Efficiency }
$$ 
In summary, it is the belief of the authors that this chapter demonstrates the HP-WHR scheme as a potentially viable energy supply alternative for some specific applications. The actual determination of feasibility and expected performance is highly dependent on site-specific physical characteristics and local economic conditions, and will be addressed in the a.pplication study of Chapters 8.0 and 9.0 of this report. 


\section{THIS PAGE}

\section{WAS INTENTIONALLY \\ LEFT BLANK}




\subsection{EXPECTED ECONOMICS}

\subsection{INTRODUCTION}

The consumer will ultimately pay the costs for either a conventional heating and cooling system or a Heat Pump - Wastewater Heat, Recovery System. For that reason, any economic advantages the HP-WHR scheme may have to offer must be fully explored and documented.

This report section is concerned with the expected economic performance of the HP-WHR system and with conventional natural gas, air-to-air heat pump, and electric resistance heating systems. First costs, operating costs, and maintenance costs of the various systems will be estimated and used in a net present value comparison of the considered alternative.

\subsection{SYSTEM DESIGN}

It is demonstrated in the expected performance section that overall system efficiency is dependent on effluent source temperatures and enduser loads placed on the system. For the purpose of economic evaluation, two geographic locations were chosen as representatives of extremes in climatological differences encountered throughout the country. Effluent temperatures were assumed to average $60^{\circ} \mathrm{F}$ in the winter months and $80^{\circ} \mathrm{F}$ in the summer months.

\subsubsection{END-USER LOADS}

End-user heating and cooling loads were developed using the Rand Corporation's Energy Use and Conservation in the Residential Sector: A Regional Analysis, Report Number PB-254-468, June 1975.9 Data for the northern type climate was selected from the New England Area statistics and data for the southern type climate was selected from the West South Central Area. The size of a typical residence was taken 
as the national average of 1185 square feet. Table 4-1 is a summary of the data used.

Table 4-1

Typical End-User Heating and Cooling Load Data

\begin{tabular}{|c|c|c|c|c|c|c|}
\hline \multirow[b]{2}{*}{ CLIMATE } & \multirow{2}{*}{$\begin{array}{l}\text { Annual } \\
\text { HDD }\end{array}$} & \multirow{2}{*}{$\begin{array}{c}\text { Annual } \\
\text { CDD } \\
\end{array}$} & \multicolumn{2}{|c|}{$\frac{\text { Approx. Peak Load }}{\text { MBtu } / \mathrm{Hr}}$} & \multicolumn{2}{|c|}{$\begin{array}{c}\text { Annual Energy } \\
\text { Requirements* (MBtu) }\end{array}$} \\
\hline & & & Heating & Cooling & Heating & Cooling \\
\hline Northern & 6820 & 1200 & 41 & 25 & 105,465 & 18,960 \\
\hline Southern & 2350 & 2750 & 21 & 32 & 37,920 & 45,030 \\
\hline
\end{tabular}

HDD = Heating Degree Days

$\mathrm{CDD}=$ Cooling Degree Days

*Figure 7, Reference 27

\subsubsection{DESIGN ASSUMPTIONS}

In performing the economic analysis, several assumptions about the configuration of the HP-WHR system were made in order to develop unitized costs. These assumptions are not, in any way, intended to illustrate an optimum system design or limit the thinking of a perspective system designer when applying this concept.

The assumptions used were as follows:

1. The heat extraction by the central heat pump is 12,000 $\mathrm{MBtu} / \mathrm{Hr}$ for $20 \mathrm{hrs}$ per day, 5 days per week. Total heat extraction per month of $5.2 \times 10^{9}$ Btu.

2. Average system heating C.O.P. of 2.2 .

3. Number of end-users served is determined by dividing the monthly heating energy deliverable from the system by the typical end-user requirements in a January month.

4. Thermal storage capacity determined by the energy required by all end-users in 4 consecutive average heating days 
during the month of January. Temperature pull-down of storage of $30^{\circ} \mathrm{F}$.

5. Variable flow pumping, resulting in a constant percentage of pumping energy to system delivered energy.

6. Negligible thermal losșes. -

Using these assumptions, the following system configurations were

used.

Northern Climate

Central Heat Pump Extraction Rate

$5.2 \times 10^{9} \mathrm{Btu} / \mathrm{Mo}$.

Circulation Pump Horsepower

$75 \mathrm{hp}$

Thermal Storage Vessel

$5 \times 10^{6} \mathrm{gal}$

Distribution System Length

(run-outs to end-users not included)

$61,100 \mathrm{ft}$

Longest Piping Run (Supply \& Return)

$9,900 \mathrm{ft}$

Number of End-Users

470

Distribution Pump Horsepower

$450 \mathrm{hp}$

Southern Climate

Central Heat Pump Extraction Rate

$5.2 \times 10^{9} \mathrm{Btu} / \mathrm{Mo}$.

Circulation Pump Horsepower

$75 \mathrm{hp}$

Thermal Storage Vessel

$5 \times 10^{6}$ gal

Distribution System Length

(NIC run-outs to end-users)

$127,400 \mathrm{ft}$

Longest Piping Run (Supply \& Return)

$13,950 \mathrm{ft}$

Number of End-Users

980

Distribution Pump Horsepower

$625 \mathrm{hp}$

\subsection{FIRST COSTS}

First costs for the various system components were developed with

the aid of R.S. Means, "Building Construction Cost Data 1978." 9 Unitary 
equipment costs were taken from the ICES technology evaluation reports; ANL/CES/TE 77-9, "Unitary Water to Air Heat Pumps" and ANL/CES/TE 77-10, "Unitary Air-to-Air Heat Pumps". Supplemental information was also obtained from local equipment distributors.

\subsubsection{HEAT PUMP-WASTEWATER HEAT RECOVERY SYSTEM}

The HP-WHR system cost estimate is broken into three sections:

Central Plant, Distribution System, and End-User Sysțems. An approximation for each system was made on a unitized basis assuming a Central Heat Pump heat extraction rate of $12,000,000 \mathrm{Btu} / \mathrm{hr}$ and end-user heat pump systems with an installed heating capacity of $46.5 \mathrm{MBtu} / \mathrm{hr}$ and cooling capacity of $40 \mathrm{MBtu} / \mathrm{hr}$ at ARI standard 240-75 conditions. The distribution system was assumed to serve customers at an average piping length of $130 \mathrm{ft}$ per customer, and an additional $150 \mathrm{ft}$ of run-out piping from the distribution system to the end-user.

The following costs were developed for the Central Plant and the northern and southern climate distribution system schemes:

\section{CENTRAL PLANT}

\begin{tabular}{|c|c|}
\hline Item & $\begin{array}{c}\text { Material \& } \\
\text { Installation }\end{array}$ \\
\hline Central Heat Pump & $\$ 144,200$ \\
\hline Pump for Circulation & 30,000 \\
\hline Interconnecting Piping and Valves & 120,000 \\
\hline Control Systems & 18,000 \\
\hline Interface Modifications with Sewage Treatment Plant & 80,000 \\
\hline Building to House Components $(3,000 \mathrm{sq}$. ft. $x \$ 20 / \mathrm{sq}$. ft $)$ & 60,000 \\
\hline SUBTOTAL & $\$ 452,200$ \\
\hline $25 \%$ Contractor \& Engineering Fees & 113,050 \\
\hline TOTAL & $\$ 565,250$ \\
\hline
\end{tabular}


Central Storage Vesse1

Variable Speed - Distriburion Syslem Fümp

$7 n, \cap \cap n$

Distribution System Piping

$3,050 \mathrm{ft}$ (10" pipe) @ 12.80/ft

$6,100 \mathrm{ft}$ ( $8^{\prime \prime}$ pipe) a 10.10/ft

$6,100 \mathrm{ft}$ ( 6" pipe) a 7.45/ft

$33,500 \mathrm{ft}$ ( $4 "$ pipe) a 5.65/ft

$12,200 \mathrm{ft}$ ( $2 "$ pipe) a $3.15 / \mathrm{ft}$

374,085

SUBTOTAL

$\$ 494,085$

25\% Contractor \& Engineering Fees

123,520

TOTAL

$\$ 617,605$

Southern Climate

\section{Distribution System}

Material \& Installation

Central Storage Vessè

$5,000,000$ gallons a $\$ .01$ per gal

Variable Speed - Distribution System Pump

$\$ \quad 50,000$

80,000

Distribution System Piping

$6,370 \mathrm{ft}$ (10" pipe) d 12.80/ft

$12,740 \mathrm{ft}$ ( 8" pipe) (d 10.10/ft

$12,740 \mathrm{ft}$ ( 6" pipe) a 7.45/ft

$70,070 \mathrm{ft}$ ( $4 "$ pipe) c 5.65/ft

$25,480 \mathrm{ft}$ ( $2 "$ pipe) @ 3.15/ft

781,280

SUBTOTAL

$\$ 911,280$

25\% Contractor \& Engineering Fees

$\underline{227,820}$

TOTAL

$\$ 1,139,100$ 
Unit Costs Associated with Each End-User:

Water Metering Equipment $\quad$ \$200

150'-3/4" Run-Out Piping @ \$1.5 per ft 225

TOTAL $\$ 425$

\subsubsection{END-USER SYSTEM COST}

The installed cost of an end-user "water-to-air" heat pump system was taken to be $\$ 2,000$. Since all conventional systems comparisons will assume a forced air distribution system, the installed costs presented herein do. not make any allowance for ductwork, insulation, grilles, and associated installation. These costs also refer to new installation and are not necessarily representative of retrofit conditions.

\subsubsection{CONVENTIONAL SYSTEM COSTS}

Only end-user costs were developed for conventional systems since accounting for energy-supply equipment costs and distribution system costs are included in the energy charges paid by the consumer. The equipment costs for each of the conventional alternatives is as follows:

Gas Heat/3 Ton Elect. Cooling:

Air-to-Air Heat Pump:

Resistance Heating/Electric Cooling:

\subsection{OPERATING COSTS}

Operating costs were developed from the efficiency analyses presented in Section 3 of. this report. It was assumed that electrical power for central piant equipment is purchased from a utility at a reduced cost per kwh due to the tiered rate schedule applied to industrial/commercial type customers. Residential electric power would be purchased on an individual basis. Where combined energy costs are given for the HP-WHR 
scheme, it is assumed that residential electric energy cost per kwh is 1.5 times the central energy plant cost. The cost of thermal energy from the HP-WHR scheme to the end-user is discussed in a subsequent section.

4.4.1 CENTRAL STATION AND DISTRIBUTION SYSTEM OPERATING COSTS

The input energy for delivery of heating energy and dissipation of cooling energy by the central plant were developed from the performance analyses of Section 3. Appendix B gives a complete breakdown of how energy quantities were derived.

A summary of the electrical energy required for each of the central plant components is presented in Table 4-2.

Northern C1imate

Central Heat Pump

Heating

Cooling

\author{
Table 4-2 \\ CENTRAL PLANT \\ Electrical Energy Requirements
}

Circulating Pump

Distribution Pump

$1,027,858$

Auxiliaries

$\mathrm{kwh} / \mathrm{yr}$

$1,392,905$

632,485

224,282

12,000

TOTAL

$3,289,530$

Southern Climate

Central Heat Pump

Heating

Cooling

$1,043,600$

$3,131,060$

Circulating Pump

594,990

Distribution Pump

$1,190,615$

Auxiliaries

12,000

TOTAL

$5,972,265$ 
Figure 4-1 presents the annual electricity costs for the central plant under different average energy costs ranging from $2 \xi$ to $4 \xi$ per $k w h$.

\subsubsection{END-USER OPERATING COSTS}

The typical end-user is assumed to have the heating and cooling load requirements presented in Table 4-1. Based of those requirements and seasonal coefficients of performance of 2.75 for heating and 2.9 for cooling, the following end-user electric energy requirements were determined:

$$
\text { Table 4-3 }
$$$$
\text { HP-WHR System }
$$

End-User Electric Energy Requirements

Northern Climate

$$
\underline{\mathrm{Kwh} / \mathrm{Yr}} .
$$$$
1,915
$$

Cooling

Heating

TOTAL

Southern Climate

Cooling

Heating

TOTAL

$$
\underline{11,236}
$$$$
13,151
$$

Cost/Yr.

$\$ 115$

674

$\$ 789$

$\$ 273$

242

$\$ 515$

The cost per unit for electrical energy was estimated at $6 c$ per kwh.

In addition to the electric energy purchased by the end-user, an additional charge would be made for the thermal utility service from the central plant. These charges are explained in Section 4.6, and for the examples given, would be as follows:

Northern Climate - $\$ 590$ annually

Southern C1imate - $\$ 469$ annualiy 
ANNUAL HP-WHR SCHEME CENTRAL PLANT COSTS

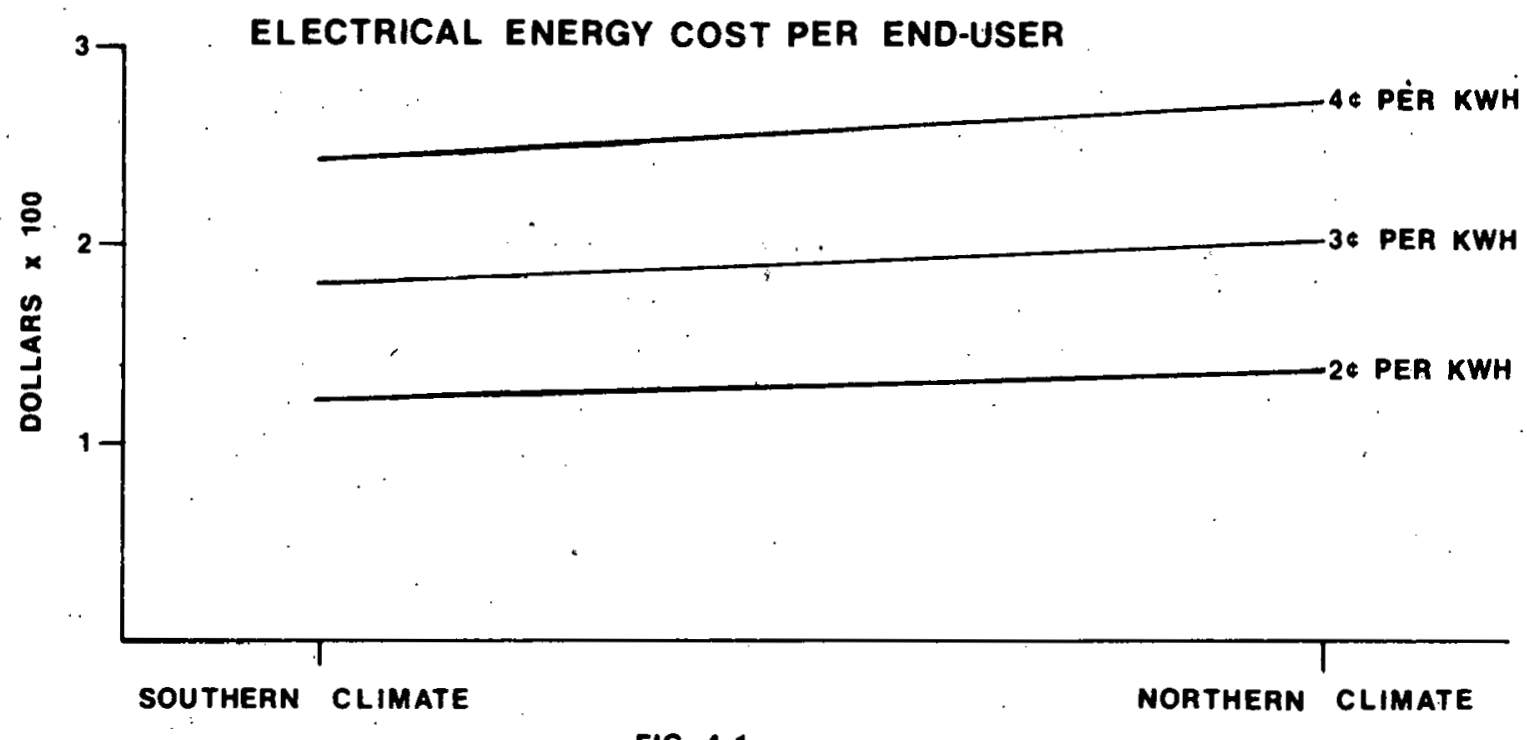

FIG. $4-1$

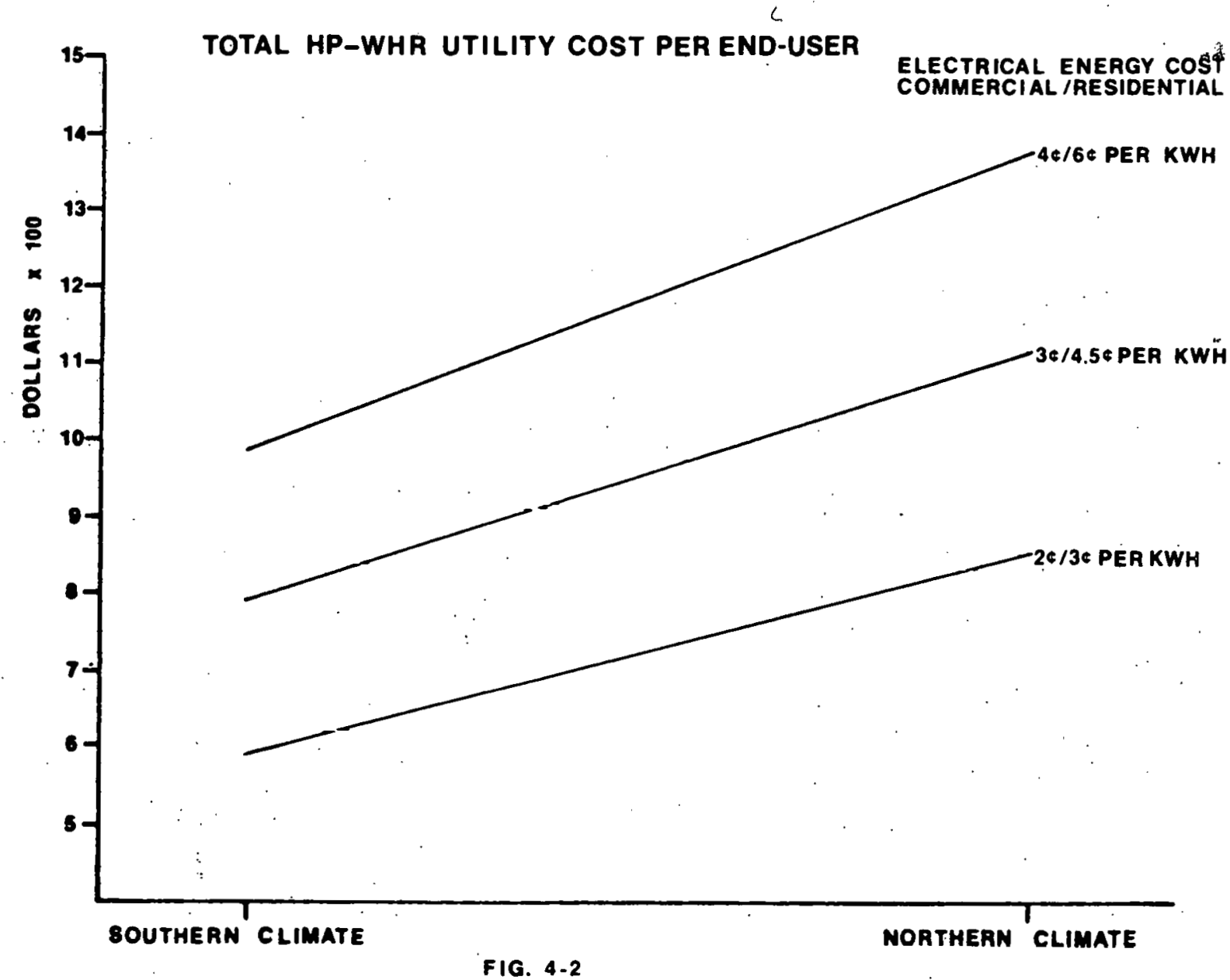

FIG. $4-2$ 


\subsubsection{TOTAL HP-WHR SYSTEM OPERATING COSTS}

Figure 4-2 is a graph of total system energy costs to the end-user at several electric energy rates. This graph was developed by adding the end-user's cost of electric and thermal energy. Comparisons with conventional systems presented in Figure 4-3 are made at an electric energy rate of $6 c$ per kwh.

\subsubsection{CONVENTIONAL SYSTEM OPERATING COSTS}

Based on the load assumption stated in the previous discussion on end-user heating and cooling requirements, operating costs were estimated for each conventional system. Direct fired heating was assumed to be 65 percent efficient, Air-to-Air heat pump seasonal performance factor was assumed to be 1.5 for northern climate and 2.3 for southern climates, and electric resistance heating was assumed to have a COP of $1.0 \mathrm{~A} 11$ systems for air conditioning were assumed to have energy efficiency ratios of 7.5 . The results are presented in Table 4-4.

Table 4-4

Conventional System Energy Costs

$$
\text { Northern Climate }
$$

\begin{tabular}{|c|c|c|c|c|}
\hline \multirow{2}{*}{ System } & \multicolumn{2}{|c|}{ HEATING } & \multicolumn{2}{|c|}{ COOLING } \\
\hline & $\begin{array}{c}\text { Energy } \\
\text { Consumption } \\
\end{array}$ & $\begin{array}{c}\text { Energy } \\
\text { Cost } \\
\end{array}$ & $\begin{array}{c}\text { Energy } \\
\text { Consumption } \\
\end{array}$ & $\begin{array}{c}\text { Energy } \\
\text { Cost } \\
\end{array}$ \\
\hline $\begin{array}{l}\text { NATGAS/Elect } \\
\text { Cooling }\end{array}$ & 1622.5 therms & $\$ 486$ & $2528 \mathrm{kwh}$ & $\$ 152$ \\
\hline $\begin{array}{l}\text { Elect Air-to- } \\
\text { Air hp }\end{array}$ & $20,600 \mathrm{kwh}$ & $\$ 1,236$ & $2528 \mathrm{kwh}$ & $\$ 152$ \\
\hline $\begin{array}{l}\text { Resistance } \\
\text { Heat/Elect } \\
\text { A.C. }\end{array}$ & 30,900 & $\$ 1,854$ & $2528 \mathrm{kwh}$ & $\$ 152$ \\
\hline
\end{tabular}


TOTAL ANNUAL ENERGY COSTS

NOTE: COMMEACIAL ELECTRICITY AT 4\%/KWH RESIDENTIAL ELECTRICITY AT $6 * / K W H$ nATURAL GAS AT 3OE/THERM

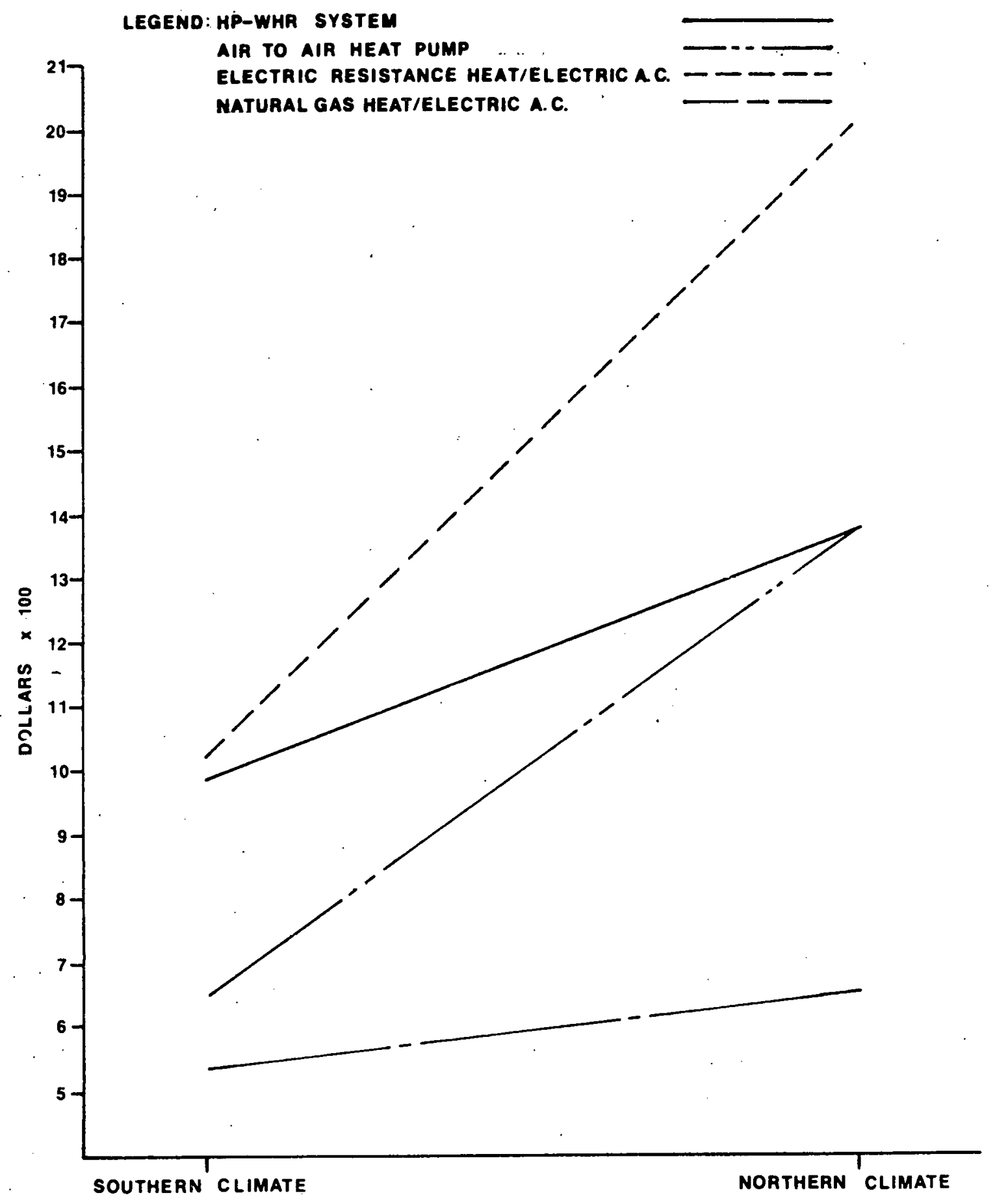

FIG. $4-3$ 
Table 4-4 (cont)

\section{Southern Climate}

\begin{tabular}{|c|c|c|c|c|}
\hline System & $\begin{array}{c}\text { Energy } \\
\text { Consumption }\end{array}$ & $\begin{array}{l}\text { Energy } \\
\text { Cost }\end{array}$ & $\begin{array}{c}\text { Energy } \\
\text { Consumption }\end{array}$ & $\begin{array}{c}\text { Energy } \\
\text { Cost }\end{array}$ \\
\hline $\begin{array}{l}\text { NATGAS/Elect } \\
\text { Cooling }\end{array}$ & 584 th & $\$ 175$ & $6,000 \mathrm{kwh}$ & $\$ 360$ \\
\hline $\begin{array}{l}\text { Elect Air-to- } \\
\text { Air hp }\end{array}$ & $4830 \mathrm{kwh}$. & $\$ 290$ & $6,000 \mathrm{kwh}$ & $\$ 360$ \\
\hline $\begin{array}{l}\text { Resistance } \\
\text { Heat/Elect } \\
\text { A.C. }\end{array}$ & $11,110 \mathrm{kwh}$ & $\$ 667$ & $6,000 \mathrm{kwh}$ & $\$ 360$ \\
\hline
\end{tabular}

The cost per unit for energy was estimated at $6 \mathrm{c} / \mathrm{kwh}$ for electricity and $\$ .30$ per therm for natural gas.

\subsubsection{MAINTENANCE COSTS}

Maintenance costs for unitary equipment were estimated with the aid of the ICES Technology Evaluation Documents.' ${ }^{6}$ Maintenance of the central heat pump equipment was estimated at 2 percent of installed costs per year for the central station equipment and 0.5 percent per year for the distribution system. The following maintenance costs were used:

HP-WHR SYSTEM Item

Central Station Equipment

Distribution System

Unitary, H.P. (Water to Air)

CONVENIITONAL SYSTEMS

Gas/Electric Cooling

Air-to-Air Heat Pump

Resistance/Elect. Cooling
ANNUAL MAINTENANCE COST

$$
\$ 11,305
$$

No. $\$ 3,090$ So. $\$ 5,695$

$\$ 165$ per unit

$\$ 130$ per unit

$\$ 180$ per unit

$\$ 160$ per unit 
Annual maintenance costs for the unitary end-user equipment was developed from references.

4.5 HP-WHR SCHEME OPERATION AS A THERMAL UTILITY

In order to compare the HP-WHR scheme to conventional utility supplied schemes, it is necessary to perform an analysis from the end-user's viewpoint. To account for thermal energy distributed from the central plant, it is anticipated that the system will be operated as a thermal utility. The charges to end-users will be made based on meter readings and will be sufficient to cover the central plant's operating and maintenance costs, debt service, and administrative costs associated with operation of the system.

The cost figures contained in this report were generated for the northern and southern locations using the stated electric energy costs, an administrative cost of five percent of total owning and operating costs, and debt service based on an interest rate of 7 percent per year. It is recognized that the seven percent interest rate is somewhat arbitrary and will vary with the application and type of financing arrangements actually implemented; however, it was selected to be between typical 1977 yields for Municipal Class A bonds and Utility bonds issued by private companies.

The cost per customer for thermal service was computed as follows: Northern Climate (serving 470 customers)

Energy Cost @ $4 c / k w h$ $\$ 131,581$

Debt Service Central Plant and Distribution System $\$ 1,182,855 \times .0858$ 101,489 End-User Connections $\$ 199,750 \times .0858$ 
Northern Climate (Continued)

Maintenance on Central Plant \& Dist. System

$\$ 14,395$

SUBTOTAL

$\$ 264,603$

5 percent administration

13,230

TOTAL

$\$ 277,833$

Annual Cost Per Customer $=\$ 591$

\section{Southern Climate (serving 980 customers)}

Energy Cost d $4 c / k w h$

$\$ 238,891$

Debt Service

Central Plant and Distribution System

$\$ 1,704,350 \times .0858$

146,233

End-User Connections

$\$ 416,500 \times .0858$

35,736

Maintenance on Central P1ant \& Dist. System

17,000

SUBTOTAL

$\$ 437,860$

5 percent administration

21,893

TOTAL

$\$ 459,753$

Annual Cost Per Customer $=\$ 469$

4.6 LIFE CYCLE COSTS

A net present value life cycle cost analysis was prepared for the HP-WHR system and each of the conventional system alternatives. The analysis was performed from the end-user point of view, since the consumer will ultimately pay all costs associated with each system. In the case of thermal energy distributed by the HP-WHR system, central plant capital and energy costs are embedded in the cost of service to the end-user. A range of interest rates was used for discounting future expenditures. The results are presented in Figures 4-4 and 4-5. 
PRESENT VALUE OF EXPENDITURES

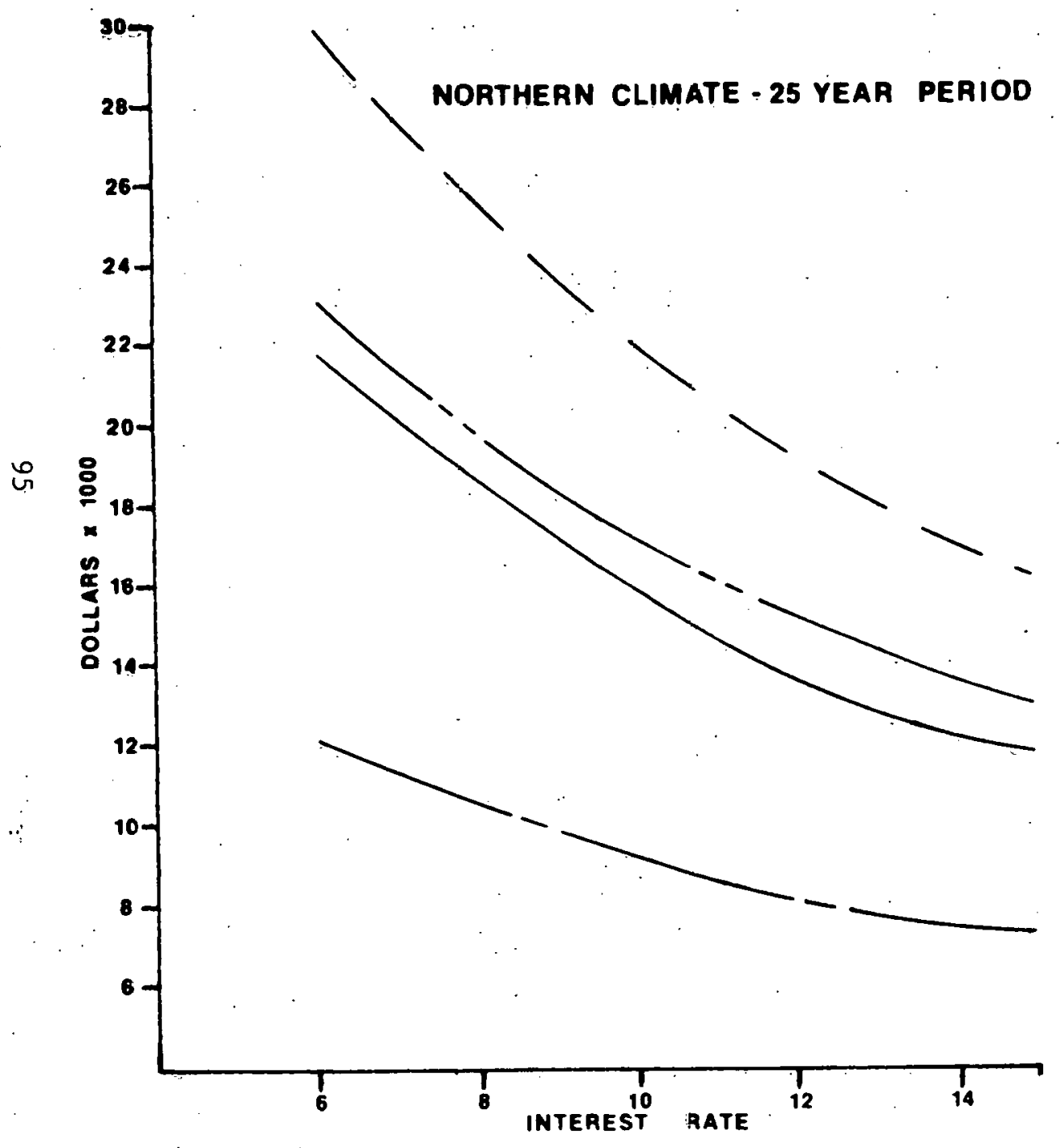

FIG. $4-4$
NOTE: COMMERCIAL ELECTAICITY AT 4t/KWH RESIDENTIAL ELECTRICITY AT $6 C / K W H$ NATURAL GAS AT 30E/THERM

LEGEND: HP-WHR SYSTEM

AIR TO AIR HEAT PUMP

ELECTRIC RESISTANCE HEAT/ELECTRIC A.C. - - - NATURAL GAS HEAT/ELECTRIC A.C.

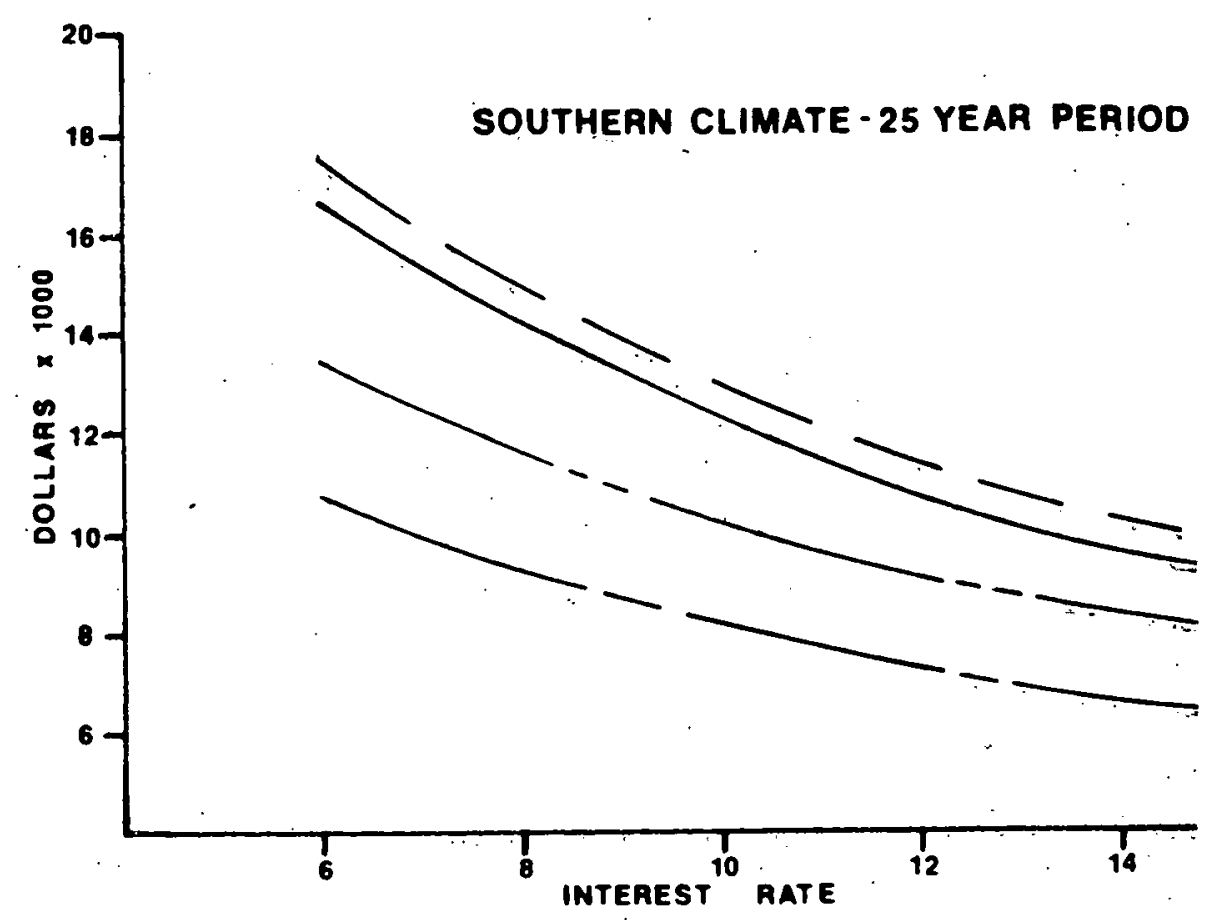

FIG. 4-5 


\subsubsection{DETERMINATION OF PRESENT VALUE}

The present value of each alternative was determined for a twenty-five year period at the stated discount factor. The following general formula was used:

$$
\mathrm{PV}_{i}=\mathrm{FC}_{i}+\mathrm{f}(\mathrm{j}, 25) \times\left(\mathrm{AOC}_{i}+\mathrm{AMC}_{i}\right)
$$

where

$$
\begin{aligned}
& \mathrm{PV}_{i}=\text { Present value of the } i^{\text {th }} \text { alternative } \\
& \mathrm{FC}_{i}=\text { First cost of the } i^{\text {th }} \text { alternative } \\
& \mathrm{f}(\mathrm{j}, 25)=\text { The present worth factor at } j \text { percent interest } \\
& \quad \text { for } 25 \text { years } \\
& \mathrm{AOC}_{i}=\text { Annual operating costs of the } i^{\text {th }} \text { alternative } \\
& \mathrm{AMC}_{i}=\text { Annual maintenance costs of the } i^{\text {th }} \text { alternative }
\end{aligned}
$$

The present value figure is given as a positive number; however, in actuality it should be realized that the number is a present value of present and future costs.

Figures 4-4, 4-5 present a comparison of the HP-WHR system and several conventional systems at 8 percent, 10 percent, and 12 percent present worth factors.

\subsection{SUMMARY OF EXPECTED ECONOMIC PERFORMANCE}

The net present value analysis of the HP-WHR scheme and the conventional schemes indicates that the HP-WHR scheme can be cost competitive with airto-air heat pump systems and electric resistance heating systems depending on comparative energy costs and geographic location. As expected, the conventional natural gas/electric scheme is much more cost effective at today's natural gas prices. 


\subsection{ENVIRONMENTAL IMPACT.}

\subsection{INTRODUCTION}

During the last 15 years there has been increasing concern within the United States for protection of all aspects of the environment. This concern has resulted in the passage of numerous Federal laws and the subsequent development of implementing regulations to protect various aspects of the environment. These laws have covered such diverse areas as air quality, water quality, noise control, archaeological and historic preservation, and protection of endangered species of plants and wildlife. The most significant of the Federal laws and Executive Orders affecting the environment are listed below:

1. The Archaeological and Historic Preservation Act of 1974;

2. The Clean Air Act;

3. The Coastal Zone Management Act of 1972;

4. The Endangered Species Act of 1973;

5. The Federal Water Pollution Control Act, as amended;

6. The Fish and Wildlife Coordination Act of 1958;

7. The Flood Disaster Protection Act of 1973;

8. The Marine Protection Research and Sanctuaries Act of 1972;

9. The National Environmental Policy Act of 1969;

10. The National Historic Preservation Act of 1966; Executive .order 11593 ("Protection and Enhancement of Cultural Environment," May 13, 1971): and 36 CFR Part 800 ("Procedures for the Protection of Historic and Cultural Property," January 25, 1974);

11. The Rivers and Harbors Act of 1899;

12. The Safe Drinking Water Act of 1974; 
13. The Solid Waste Disposal Act;

14. The Water Resources Planning Act of 1965;

15. The Wild and Scenic Rivers Act of 1968;

16. Executive Order 11296 ("Evaluation of Flood Hazards in Locating Federally Owned or Financed Buildings, Roads, and Other Facilities, and in Disposing of Federal Lands and Properties," August 10, 1966);

17. Federal Insecticide, Fungicide, and Rodenticide Act as amcnded, and

18. The Noise Control Act of 1972 .

Some of the laws noted above are concerned with one specific area of the environment, while others have a much broader area of concern. One of the most significant laws is the National Environmental Policy Act of 1969 which requires all Federal agencies to prepare detailed Environmental Impact Statements on major Federal actions that significantly affect the quality of the human environment. The National Environmental Policy Act requires that agencies include in their decision making process an appropriate and careful consideration of all environmental aspects of proposed actions, an explanation of potential environmental effects of proposed actions and their alternatives for public understanding, a discussion of ways to avoid or minimize adverse effects of proposed actions, and a discussion of how to restore or enhance environmental quality as much as possible. Facilities such as a Heat Pump Centered-Integrated Community Energy System (HP-ICES) which may be constructed in part with the assistance of Federal grant of loan funds, must be subjected to an environmental impact analysis to determine whether or not significant environmental impacts will result either directly or indirectly from the proposed project. This analysis is reviewed by appropriate Federal and State agencies and interested citizens or organizations and is submitted to the 
President's Council on Environmental Quality. If significant. environmental impacts will result from the proposed project, then a full Environment Impact. Statement must be developed along with the related reviews and public hearings required.

Some of the major points which must be addressed. in the preparation. of an environmental impact appraisal are as follnars:

1. Brief description of project;

2. Probable impact of the project on the environment;

3. Any probable adverse environmental effects which cannot be avoided;

4. Alternatives considered with evaluation of each;

5. Relationship between local short-term uses of man's environment and maintenance and enhancement of longterm productivity;

6. Steps to minimize harm to the environment;

7. Any irreversible and irretrievable comnitment of resources;

8. Public objections to project, if any, and their resolution; and

9. Agencies consulted about the project.

The environmental impacts of facilities such as an HP-ICES can be divided into two broad categories. These categories are:

1.. The environmental impacts of construction, and

2. The environmental impacts of operation.

The next two sections will address the environmental impacts in each of these categories for heat pump centered-integrated community energy systems. 


\subsection{ENVIRONMENTAL IMPACTS OF CONSTRUCTION}

\subsubsection{TEMPORARY. IMPACTS}

The environmental impacts of construction can be further divided into those temporary impacts that exist only during the construction phase and the permanent impacts of the facilities' construction and location. The temporary environmental impacts caused by construction activities are as follows:

1. Noise and dust generated by construction activities;

2. Removal of vegetation and pavement causing soll erosion and siltation during construction;

3. Disruption of normal traffic patterns caused by construction in streets;

4. Potential for broken gas and water mains and sewer lines; and

5. Temporary inconveniences for businesses and residences while individual connections are being made.

Most of the temporary impacts are the nuisance conditions that are usually associated with construction operations. Most of the impacts can be minimized by the proper planning and execution of various construction activities. For instance, the impact of noise in a residential neighborhood can be minimized by limiting the contractor's operations to normal daytime hours when many people are away from home at work or school. Since much of the distribution and return system will be constructed in existing streets and rights-of-way, some disruption of normal traffic patterns is unavoidable. However, by proper planning of construction operations, the actual time that a street must be closed can be minimized. One of the most significant potential impacts during the construction operations is the potential for breaking 
gas mains, water mains, and existing sewer lines while constructing the HP-ICES distribution and return system. In particular, a broken gas main or sewer line could create a significant environmental hazard. A broken gas main can create either an immediate or delayed explosion of disastrous proportions. 'A broken sewer line can result in the discharge of raw and untreated sewage to nearby drainage ditches, creeks and streams, and create serious public health hazards and water pollution problems. For those reasons it is important that the initial design carefully locate existing water and gas mains and sewer lines. In addition, it is important that the contractor take certain precautions during construction in the event that all such facilities are not properly and adequately located on the construction plans.

\subsubsection{PERMANENT IMPACTS}

The principal impacts of construction operations that are of a permanent nature are as follows:

1. Construction materials required for construction;

2. Energy utilized in the construction process;

3. Land occupied by proposed facilities; and

4. Disruption of previously undisturbed terrain.

The concrete, steel, and other materials required during construction are essentially irreversible and irretrievable commitments of these resources. : That is, once they are used in the proposed construction, it is highly unlikely that they will ever be used again for any other purpose. The energy utilized during the construction process wil be primarily gas, oil and diesel fuel that is. required for the operation of trucks, bulldozers, ditch diggers, and other construction equipment. Some electrical energy will also be utilized for electrical tools and equipment used during the construction of buildings and other structures. 
The land on which the proposed facilities are to be located will be committed to this use for a minimum of 20 years and possibly for as much as 40 to 50 years or longer. However, this commitment is not permanent, in that, if the facilities were to be abandoned in future years, they could be torn down and the land could be utilized for other purposes. The major land requirement will be associated with the central plant facility and related storage facilities and cooling ponds that will be constructed. Land required for the distribution and return system will only be a narrow easement that is only 10 to 15 feet wide. In most cases, the easement for the distribution and return system will be located in existing streets and highway rights-of-way. In most cases, the presence of the distribution and return system will not prevent the land itself from being utilized for other purposes. However, in some cases there may be a restriction in building a structure or building within the permanent easement.

One of the major environmental impacts of construction operations is the disruption of previously undisturbed terrain. During construction of the transmission and return system, rights-of-way must be cleared of vegetation and smoothly graded so that construction equipment can move easily along the right-of-way while digging the trench for the transmission main. Clearing and grading is also required at sites where buildings or other structures must be constructed. If the construction takes place in an area that has been previously undisturbed, then there is a danger that unique vegetation or wildlife habitat or previously undiscovered archaeological sites may be damaged or destroyed by the construction operations. For the Heat Pump Centered-Integrated Community Energy System, most of the construction for the transmission and distribution system is expected to be along existing streets and highways and therefore will not involve much construction in 
areas that have been previously undisturbed. The environmental impacts of construction that do occur in undisturbed terrain can be minimized by careful site selection and routing of transmission mains to avoid unique vegetation, wildlife, or archaeological sites.

\subsection{ENVIRONMENTAL IMPACT OF OPERATION}

\subsubsection{IMPACTS ON SEWERS AND WASTEWATER TREATMENT FACILITIES}

One of the most. significant potential impacts of the proposed Heat Pump Centered-Integrated Community Energy System is on the existing sewers and wastewater treatment facilities within the community. There are several aspects of the project that could create an impact on existing wastewater facilities. These impacts are:

1. The additional hydraulic loading on the sewer system if the sewer system is used as the means of returning the heat pump water supply to the central facility.

2. The additional hydraulic loading on the wastewater treatment facility itself if the sewer system is used as the means of returning the heat pump water supply to the central plant.

3. The effect on the wastewater treatment process if the temperature of the untreated wastewater is raised or lowered as a result of the operation of the heat pump system. (Lowering the wastewater temperature will slow down the biological treatment process and require larger aeration basins to increase the time of treatment.)

4. The environmental impact on water quality and aquatic life in the stream where the treated wastewater is discharged as a result of a change in temperature of the wastewater discharge. 
Because of the significant nature of these impacts, a separate discussion of each will be presented.

One of the schemes to be evaluated includes using the existing lines to transport the used water from the heat pump system back to the municipal wastewater treatment plant and central heat exchangers and pumping facilities. This additional discharge to the sewer system would constitute an additional hydraulic loading on the sewer system over and above the estimated wastewater flows that were used to design the sewers initially. Consequently, if the existing sewer system were to be utilized as a part of the return system, it would be necessary to evaluate the impact of this additional hydraulic flow on the existing sewers. Several questions would need to be addressed. These are:

1. Can the existing sewer lines carry the peak hydraulic flows that will result when the spent water from the heat pump system is discharged into the sewer system?

2. Which sewer lines will be overloaded and how much additional sewer capacity must be provided?

3. Even if the existing sewer lines have sufficient capacity to carry the additional hydraulic flows, the ultimate capacity of the sewers will be reached sooner than originally anticipated without the water. from the heat pump system. How soon will the capacity of existing sewer lines be reached?

4. If parallel or replacement sewer lines must be constructed to provide additional capacity, then the environmental impacts for this construction must be evaluated.

The hydraulic loading at the wastewater treatment plant would also be 
a point of concern in the HP-ICES scheme described above. The pumping facilities for the influent wastewater, the bar screen and grit removal facilities, and the primary clarifier would all have to be sized to handle the additional hydraulic loading. If these facilfties do not have adequate capacity to handle the additional hydraulic flow, their performance will be significantly impaired and the treatment facility will not achieve the degree of treatment for which it was designed. This could result in the discharge of raw or improperly treated wastewater to the stream.

A heat pump centered energy recovery system utilizing wastewater as the heat source and sink will raise or lower the temperature of the wastewater relative to the normally encountered temperatures. The temperature of the wastewater will be raised in the summer and lowered in the winter. Since the treatment of domestic wastewater usually depends upom some form of microbiological activity (e.g., activated sludge, trickling filters, etc.), and since temperature is an important factor affecting the biological activity rates, changing the temperature of wastewater will alter the rate at which the wastewater is biologically treated. Typically, the colder the temperature, the slower the rate of biological treatment. Hence, as the rate of the biological reaction is decreased, the time required to provide the same degree of treatment must be increased. This means that with lower biological reaction rates the volume of the aeration basin must be increased to provide a longer detention time (and reaction time) to achieve the same degree of treatment as the higher reaction rates. Biochemical reactions, in general, follow the van't Hoff rule of a doubling of reaction rate for a $10^{\circ} \mathrm{C}\left(18^{\circ} \mathrm{F}\right)$ increase in temperature over a restricted temperature range. Studies with activated sludge have shown the reaction 
rate to be more than doubled for a $10^{\circ} \mathrm{C}$ rise in temperature ${ }^{30}$.

Typically, biological wastewater treatment systems are designed to operate at the coldest wastewater temperature that might be expected in the particular region in which the treatment facility is to be located: Typical minimum design temperatures may range from $45^{\circ} \mathrm{F}$ to $55^{\circ} \mathrm{F}$. Since biological treatment rates would be slowed as a result of the lowered temperature in the winter, the lowered temperature would need to be considered during the design phase. to size biological treatment units or to predict lost treatment efficiencies for existing facilities.

The change in biological activity rates may be expressed mathematically by the Arrhenius equation ${ }^{31}$,

$$
\frac{\mathrm{dlnk}}{\mathrm{dT}}=\frac{\mathrm{E}_{\mathrm{a}}}{\mathrm{RT}} 2
$$

where $\mathrm{d} l \mathrm{nk} / \mathrm{dT}$ represents the change in the natural log of the biological activity rate constant with temperature, $R$ is the universal gas constant, and $E_{a}$ is a constant for the reaction termed the "activation energy." Integrating between the limits gives

$$
\ln \frac{\mathrm{k}_{2}}{\mathrm{k}_{1}}=\mathrm{E} a \frac{\left(\mathrm{T}_{2}-\mathrm{T}_{1}\right)}{\mathrm{RT}_{2} \mathrm{~T}_{1}}
$$

where $k_{2}$ and $k_{1}$ are rate constants at temperatures $T_{2}$ and $T_{1}$ respectively. Temperature is expressed in degrees Kelvin. By substituting the constant $\theta$ for $\mathrm{E}_{\mathrm{a}} / \mathrm{RT}_{2} \mathrm{~T}_{1}$, the equation becomes

$$
\ln \frac{\mathrm{k}_{2}}{\mathrm{k}_{1}}=\theta\left(\mathrm{T}_{2}-\mathrm{T}_{1}\right)
$$

or

$$
\mathrm{k}_{2}=\mathrm{k}_{1} \text { e }\left[\theta\left(\mathrm{T}_{2}-\mathrm{T}_{1}\right)\right]
$$

By using the expanded form of $e^{x}$, the equation can be approximated as 


$$
\mathrm{k}_{2}=\mathrm{k}_{1} \cdot\left[1+\theta\left(\mathrm{T}_{2}-\mathrm{T}_{1}\right)\right]
$$

The constant $\theta$ has been shown empirically to vary from 0.056 in the temperature range between $20^{\circ}$ and $30^{\circ} \mathrm{C}$ and 0.135 in the temperature range between $4^{\circ}$ and $20^{\circ} \mathrm{C}^{32}$. A value for $\theta$ often quoted in the 1iterature for biological wastewater treatment reaction rates is $0.047^{24}$.

Therefore, a decrease in the minimum wastewater temperature from $55^{\circ} \mathrm{F}$ to $50^{\circ} \mathrm{F}$ would theoretically decrease a typical domestic wastewater biological reaction rate constant from 0.25 to 0.22 ( $12 \%$ decrease) and a decrease to $45^{\circ} \mathrm{F}$ would decrease the reaction rate constant to 0.18 (28\% decrease). Once adjusted for temperature, the reaction rate constant, $k$, which also varies for varying wastes and treatment conditions, can be utilized in the following equation to size biological treatment units:

$$
L_{t}=L\left(10^{-k t}\right)
$$

where $\mathrm{L}$ is the initial BOD (biochemical oxygen demand, a measure of the organic strength of wastewater), and $\mathrm{L}_{t}$ is the treated $\mathrm{BOD}$ at retention time, $t$. Using this equation and assuming a decrease in the biological reaction rate from 0.25 to $0.18\left(55^{\circ} \mathrm{F}\right.$ to $\left.45^{\circ} \mathrm{F}\right)$ the detention time $t$ would have to be increased $38.7 \%$ in order to achieve the same degree of treatment. Hence, the volume of the aeration basin would need to be increased $38.7 \%$ and the aeration equipment would need to be designed for the larger volume and longer retention times.

Another aspect of the wastewater treatment process that is influenced by temperature is the anaerobic digestion of sewage solids or sludge. As with the liquid wastewater treatment, the biological activity rates are Lemperature dependent. In some areas of the country anaerobic digesters must be heated during the winter months in order to maintain acceptable rates of microbiological activity. However, since the digestion of sludge 
solids is separate from the liquid treatment process, the HPC-ICES scheme would not have any influence on the temperature in the anaerobic digester and hence would not affect the sludge digestion process.

Additionally, wastewater temperature changes affect oxygen transfer rates, disinfection rates, and under extreme conditions the aquatic biota in the receiving stream. Both oxygen transfer and disinfection rates follow the van't Hoff-Arrhenius relationship, but in the opposite manner. Elevated temperatures decrease oxygen transfer rates while increasing disinfection rates. Therefore, consideration would likely need to be given to the decreased disinfection kill rates in the winter and decreased oxygen transfer rates in the summer.

A detailed discussion of thermal pollution and the effects of temperature changes on aquatic life is beyond the scope of the report. However, it may be stated generally that as wastewater effluent temperatures increase, dissolved oxygen saturation concentrations decrease, and predominant aquatic lifeforms become less desirable in character. Heated water discharges, after initial mixing, should not increase the temperature of the main body of the receiving waters above $95^{\circ} \mathrm{F}$ if $\mathrm{fish}$ life is to be preserved. An excessive increase in the temperature of the wastewaterdiluting water mixture above thạt of the diluting water should not be permitted. Increases should be limited to $3^{\circ} \mathrm{F}$ to $5^{\circ} \mathrm{F}$, according to the report of the National Technical Advisory Committee 47 . At the present time, the permissible temperature increase is a matter of controversy. Detailed discussion of thermal pollution may be found in Krendel and Parker ${ }^{18}$.

\subsubsection{IMPACTS ON MUNICIPAL WATER SYSTEM}

The alternative scheme which utilizes primary clarified wastewater 
in the distribution system to each individual heat pump presents a potential environmental impact to the municipal water system. With this type of system there is always a danger that someone will make a mistake and connect the heat pump water system to the municipal water system and thereby cause contamination of the municipal water system.' Even if the primary clarified wastewater is chlorinated before going into the heat pump distribution system, a potential for contamination would exist if cross connections were made between the heat pump water distribution system and the potable water distribution system. Another potential danger is that a plumber or homeowner might by mistake connect into the heat pump water distribution system for the water supply for a home or business. Such a mistake would, of course, be a serious public health hazard.

\subsubsection{IMPACTS ON ENERGY SOURCES}

One of the most significant positive impacts of the proposed Heat Pump Centered-Integrated Community Energy System is a more efficient utilization of available energy for the heating and cooling of residential homes and commercial establishments. In addition, the heat pump system will utilize low-grade heat found in wastewater discharges which is now wasted. The primary energy requirements for the proposed heat pump system will be for the pumping facilities which will be a part of the distribution system, the electrical power for each individual heat pump and the energy required at the central plant facility for the pumps, heat exchangers, and other equipment needed there. Once a preliminary design and layout has been developed for a particular system, it will be possible to estimate the total energy that will be required in the system's operation and compare this energy consumption with the amount of energy that would have been required with a conventional heating and cooling system. 


\section{THIS PAGE \\ WAS INTENTIONALLY \\ LEFT BLANK}




\subsection{PROJECTED GROWTH}

\subsection{INTRODUCTION}

A Heat Pump Centered-Integrated Community Energy System will, in a sense, be a public utility that will be designed to serve all or part of the existing population of a community and all or part of future increases in the community's population. Consequently, the planning and design for such a system must carefully evaluate both the existing population of the community and future changes that are anticipated in the community's population. The purpose of this section is to review briefly the methods that are available to planners and engineers for determining future population changes and to describe how an HP-ICES would be expanded to meet various rates of increasing population.

\subsection{METHODOLOGY FOR PROJECTING GROWTH}

\section{2 .1 POPULATION PROJECTIONS}

There are numerous methods available to engineers and planners for projecting the future population of a given area. The most commonly used methods may be classified as:

1. graphical;

2. decreasing rate of growth (increase);

3. mathematical or logistic;

4. ratio and correlation;

5. component;

6. employment forecasts. 21

Using one or more of these methods, an individual researcher can gather the appropriate data for a particular area and develop a totally independent population projection for that area. The method utilized can be a simple graphical extension of population bașed on past population changes or it can be a complex and mathematically sophisticated method which requires considerable time and an involved analysis. For many years the preliminary planning that was done for public facilities 
required that such independent population projections be developed. However, many of these independent population projections were later found to be in errc due in part to the assumptions made by the investigators and in part to the personal bias of the investigators concerning the area in question. In recent years Federal and State agencies have become actively involved in developing State and National population projections which in turn are disaggregated to the local level. For most public facilities that are being financed in part with Federal grants or loans, it is usually required that population projections used in designing these facilities be in agreement with State and Federal projections that have been developed for the particular area in question.

In Georgia, the State Office of Planning and Budget has the responsibility for developing population projections in the State: A recent report by that office was entitled "Population Projections for Georgia Counties, 1980-2010."38 The population projections described in this publication are termed "baseline projections." The term "baseline" denotes an estimate of what can be expected if there are no substantial changes that would impact population growth. The . population projections for Georgia counties utilized data from each individual county along with data from each Area Planning and Development Commission. In Georgia each of the 159 counties is located in one of 18 Area Planning and Development Commissions (APDC). One of the main functions of an APDC is to maintain accurate and complete information on population changes and population trends for each of the counties within the APDC. In addition, most of the APDC's have developed population projections for individual communities and cities within their jurisdiction.

Within the Federal government, the Water Resources Council has in recent years coordinated the work of several Federal agencies in the area of population-projections. Under a cooperative agreement with the Water Resources 
Council, the Bureau of Economic Analysis, U. S. Department of Commerce, has worked jointly with the Economic Research Service, U. S. Department of Agriculture, to develop unified population projections for each state in the nation along with the counties within each state. Population projections developed. under this program have been commonly referred to by the acronym of "OBERS." A concerted effort has been made to assure cooperation between the Federal agencies involved, each responsible State agency, and the local Area Planning and Development Commissions to assure uniformity and agreement anong the population projections published by each of these agencies.

The most complete data available on existing population is the Federal Census of Population which is conducted every 10 years. The Census of Population contains extensive population data for each state and the counties and municipalities within each state. Between censuses, the Bureau of the Census in the U. S. Department of Comerce in conjunction with the State agency. that has responsibility for population projections publishes a yearly report which gives the estimated population of each state and the counties within the state for that year. These reports are referred to as "Current Population Reports Series $\mathrm{P}-25 . "{ }^{56}$ For individual communities and municipalities within a county, it may be necessary to utilize other sources of information to estimate existing population between censuses. Changes in population since the last census can be estimated by utilizing school enrollment records, records of births and deaths, records of building permits for residential construction and automobile registration records. Fairly accurate estimates of existing population can be made by properly utilizing such information as noted above.

\subsubsection{ECONOMIC ACTIVITY PROJECTIONS}

A Heat Pump Centered-Integrated Community Energy System would serve not only residential areas but commercial and industrial areas as well. Hence the 
planning and design for such a system would need to consider growth of commercial and industrial activities of the area. Projections of future economic activity within an area most frequently give consideration to past commercial and industrial growth that has occurred and the potential for future commercial and industrial growth based on the conditions generally considered necessary and desirable for economic growth to occur.

Area Planning and Development Commissions are frequently the best source of information concerning past commercial and industrial growth and projections of future commercial and industrial growth for a particular area. These agencies frequently conduct studies to analyze the type of economic growth which has occurred in a particular area and at the same time analyze the potential for future economic growth. Such studies often include estimates on the expansion of existing businesses that can be anticipated and projections of the type and size of new businesses and industry that may locate within the area during a particular time frame. In addition to the studies and reports published by the APDC's, the State government may have an office or department whose primary responsibility is promotion of commercial and industrial growth within the state. Data available from this office or department may be valuable in projecting the future economic growth of an area. However, it may be limited by the depth of coverage for a particular geographical area.

Other sources of information concerning the future economic growth of an area would include the planning departments in the larger cities and Chambers of Commerce. However, it should be noted that the economic growth which may be projected by a Chamber of Commerce is likely to be the ideal growth which the Chamber of Commerce desires to see and not necessarily the amount of economic growth that can be realistically anticipated. 


\subsubsection{FUTURE LAND USE PLANS AND EXISTING LAND USE PATTERNS}

Another important aspect in the design of a public facility such as an HP-ICES is determining where within the study area the residential, commercial and industrial growth will occur. The previous two sections have presented the data sources and methodology that can be utilized in projecting population and economic growth for a particular area. However, it is equally important that the specific areas within the community be delineated where residential, commercial and industrial growth is anticipated to occur. The most frequently used method for determining where future growth will occur is by analyzing future land use plans that have been adopted for the community. Future land use plans are generally developed by a city planning commission or an Area Planning and Development Commission and have taken into consideration existing land use, existing public facilities such as water and sewer lines, streets and major thoroughfares, and physical features such as flood plains, topography, soil and geological characteristics and other factors which might influence ultimate land use and development. Taking into consideration the factors that have been noted; future land use plans generally propose those land uses which appear to be most desirable for each particular tract of land. Before utilizing future land use plans in the planning process, it is important that planners and engineers determine the validity of a particular land use plan. In particular the following questions should be addressed:

1. Has the land use plan been formally adopted by the local government?

2. Are the goals and objectives of the land use plan being implemented through a program of planning and zoning regulations?

3. Is the land use plan used as a guide for decision making by local governmental officials? 
If the land use plan has been formally adopted and is being implemented through planning and zoning regulations, then it can be a valuable tool in determining where future growth within the community will occur. However, if the land use plan is not being implemented, then it may be more desirable to use other sources of information to project where growth will occur. In some cases future land use and growth can be more accurately projected by analyzing existing land uses and recent trends and changes in land use. In many cases, the past trends in land use and land use changes for the last five to ten years may continue for the next five to ten years. That is, a portion of town which was previously undeveloped but has seen heavy residential development in recent years is likely to continue to experience residential development in the coming years unless some limiting factor develops. In the same sense, areas of town which have recently experienced commercial or industrial development are likely to continue to experience such development if suitable land is available. Data and information on existing land use and land use patterns is available from several sources. Planning commmissions and Area Planning and Development Commissions often have published reports that contain extensive data and maps on existing land uses. In addition, maps that show existing zoning often accurately reflect existing land uses. Changes in land uses and changing land use patterns can be detected by reviewing zoning changes in recent years, location of new residential and commercial construction in recent years, aerial photographs taken of the same area over a period of years and maps of the community that were developed at several different time periods.

\subsubsection{ACCURACY OF GROWTH PROJECTIONS}

In projecting future population and economic growth for an area, it is important for planners and engineers to have an understanding of the degree of accuracy that can be anticipated with these projections. There are numerous 
factors which influence the population.and economic growth of an area and unexpected events or changes in existing conditions can have a significant influence on population and economic growth. As a general rule, the accuracy of population estimates decreases as

(1) the time period of the forecast increases,

(2) the population of the area decreases, and

(3) the population rate of change increases. ${ }^{21}$

Consequently, population projections for the next three to five years will generally be much more accurate than population projections for the next ten to 20 years. Also, population projections for a large city are more likely to be accurate than population projections for a small city. In small communities population growth is significantly influenced by unexpected events that may occur during the planning period. For small communities such things as the opening of a new industry or the closing of an existing industry or changes to a nearby military installation can significantly affect the population of the community.

For the reasons that have been noted, projections of future growth may not be highly accurate and, hence, this fact must be considered by planners and engineers in the planning and design of public facilities such as the Heat Pump Centered-Integrated Community Energy System.

\subsection{CENTRAL PLANT AND MAIN PUMPING FACILITIES}

\subsubsection{INITIAL DESIGN AND SIZING}

In the planning of public facilities such as water treatment plants, wastewater treatment plants or the central portion of an HP-ICES, one of the most important decisions to be made is the initial size and capacity of the facility. Since the design of such facilities often requires six to twelve months and the construction frequently requires' a minimum of one to two years, these 
facilities cannot be rapidly expanded in a short time frame. Hence, considerable thought has to be given to the initial design and capacity that is to be provided. The initial design should also include provișion for future expansions to be made in the most economical way possible. The layout of the central plant should show where future expansions will be located in relation to the initial facilities constructed. Under some circumstances, it may be more economical in the first phase of construction to go ahead and construct larger piping that will be sufficient to handle future flows during later expansions. In some cases, it is desirable to allow extra space in major structures such as buildings or pump stations so that additional facilities such as a pump or heat exchanger could be added at a later date with a minimum of additional cost involved.

For each community in which it is proposed to construct an HP-ICES, it will be necessary to conduct a study to determine what portions of the community can be economically served by such a system. This study would also project the anticipated growth within the community that would be served by the system in future years. The design and sizing of the central plant station would be based on the capacity needed to serve the existing population and future growth that is anticipated to occur within the next five to ten years and possibly longer. The next two sections will discuss the sizing of the central plant facilities to handle various rates of growth within different communities.

\subsubsection{PHASING TO HANDLE LOW TO MODERATE GROWTH SITUATION}

In recent years, the most common time frame that has been utilized in planning public facilities such as water and wastewater systems has been 20 years. By definition, the start of the planning period is the date that the initial facilities which are constructed begin operation. Hence, the time required for engineering study, design and construction is not included as a part of the planning period. There were a number of reasons that a 20-year 
planning period was chosen. One of the main reasons was that it is very difficult to accurately project population and economic growth beyond 20 years. For the purpose of this discussion, a 20-year planning period will be utilized to describe how a Heat Pump Centered-Integrated Community Energy System will be expanded to handle various rates of growth.

There are a number of different ways that can be used to describe the capacity of an HP-ICES. However, for this discussion, the capacity of the system will be discussed in terms of the number of customers served. To further simplify the discussion, it will be assumed that there are no commercial customers and that all customers are single family residential users. The purpose of this section is to explain how the central plant portion of an HP-ICES would be expanded to handle low to moderate growth that occurs within the community during the 20-year planning period. Low to moderate growth is defined here as being an increase of 0 to $50 \%$ over and above the initial number of customers served at the beginning of the planning period. By this definition, a system that has 1,000 customers at the beginning of the planning period might grow to 1,500 customers by the end of the planning period. The initial sizing of facilities and later expansion of facilities to serve a community will depend not only on the amount of growth that occurs during the planning period, but also on when the growth occurs during the planning period. In most cases, unless better data is available, it will be assumed that the growth will occur at a uniform rate over the entire 20-year planning period. However, in some cases, it may be possible to show that the maximum growth will take place in the early, middle or latter portions of the planning period. For communities that experience a fairly low rate of growth ( 0 to $20 \%$ ). during the 20-year planning period, it is generally more desirable to construct sufficient capacity initially to handle the anticipated growth rather than to attempt small scale expansions of the central plant. Moderate rates of growth (20 to 
50\%) can generally be handled by minor expansions to the central facilities during the 20-year planning period. Minor expansions at the central facilities would include such items as providing larger pump motors, changing pump impellers, adding a new heat exchanger, or a new pump in space that had been provided during the initial design and construction. The initial design and layout of the central facility plant would have made provisions for these minor expansions and, hence, major construction of expensive structures or buildings would not be required.

\subsubsection{PHASING TO HANDLE HIGH GROWTH SITUATION}

In this discussion a high rate of growth is defined as an increase in capacity of more than $50 \%$ over the initial capacity that is required. Hence, if a system initially serves 1,000 residential customers, by the end of the planning period the number of customers served will have increased to more than 1,500 customers. For communities that experience a high rate of growth, the central plant facilities may have to be expanded as much as 200 to $300 \%$ over their original capacity during the 20-year planning period. In situations such as this, there are several reasons that it is usually desirable to construct the total capacity needed at the central plant in several stages over the 20year planning period. Because of the inaccuracies involved with growth projections, it would be very risky to construct the total capacity required in the initial stage of construction. From a monetary standpoint, it is not desirable to spend large sums of money to construct excess capacity at the central facility that will not be needed until much later in the planning period. It is more desirable to postpone major capital expenditures until later in the planning period if possible. However, it should be pointed out that the monetary benefits of a program of phased expansion have been offset considerably in recent years by the rising costs of construction due to inflation. 
For communities that are expected to experience a high rate of growth during the planning period, the central plant and related facilities would be designed and constructed to provide sufficient capacity. for the first five to ten years with one or two planned expansions to provide the total capacity needed at the end of the 20-year planning period. The design and layout of the initial facility construction would take into consideration the future expansions that are proposed and to the maximum extent possible the initial design and construction would attempt to minimize the cost of future expansion.

\subsection{DISTRIBUTION AND RETURN SYSTEM}

\section{4 .1 INITIAL DESIGN AND SIZING}

The distribution and return system for a Heat Pump Centered-Integrated Community Energy System will consist of pressure distribution mains very similar to a water system and either a closed loop, pressure return system or a gravity return system utilizing the existing sewer system. In addition to the distribution and return system, other related facilities include the high pressure pumps and storage reservoirs that will be required. There are several characteristics about the design and construction of water and sewer lines that influence the manner in which distribution and return systems will be constructed and expanded. First of a11, water and sewer lines generally have a useful life of from 40 to 50 years. Second, a major portion of the cost of constructing water and sewer lines is not for the pipe and material involved, but for the manpower and equipment required in the construction process. Hence, the most economical way to provide additional capacity is generally to construct a larger line initially rather than a parallel line at a later date.

\subsubsection{INITIAL CONSTRUCTION PHASING}

Since construction of the distribution system may require from 12 to 36 months or more, a phased approach to construction may be desirable. The 
distribution system would be divided into operable segments each of which could be placed into operation upon completion. This procedure would eliminat the need for the total construction to be complete before the system was placed into operation.

\subsubsection{PHASING TO HANDLE LOW TO MODERATE GROWTH SITUATION}

Once it has been determined which areas of the community are to be served by the HP-ICES, a study should be made to determine which portions of the distribution and return system will be constructed immediately and which portions will be constructed later in the planning period. For those communities that are expected to experience low to moderate growth, the entire distribution and return system may be constructed initially. When the distribution and return system is constructed for a particular geographical area, the distribution and return mains are sized to handle the anticipated growth that will occur in that geographical area during the planning period. This means that if a subdivision has homes constructed on $70 \%$ of the lots, then the distribution and return system will be sized to handle the existing homes and also anticipated homes to be constructed on the remaining lots in the subdivision. In most cases, low to moderate rates of growth can be accommodated within the geographical area of the initial distribution and return system construction and new customers can be served by merely connecting onto the distribution and return system. In other cases, minor extensions of the distribution and return system may be sufficient to serve new areas of growth not served by the original system.

\subsubsection{PHASING TO HANDLE HIGH GROWTH SITUATION.}

As previously mentioned, a high rate of growth is defined here as an increase of $50 \%$ or more in the number of customers served initially by the system and may, in some cases, be an increase of 200 to $300 \%$ over the initial 
size of the system. For a community that experiences a high rate of growth, some of this growth will occur on undeveloped land that has already been served by the original distribution and return system. However, for communities that experience very high rates of growth, it is likely that significant residential and commercial development will occur in areas that have been previously undeveloped, but adjacent to the community. In such situations, completely new distribution and return systems must be constructed as these areas develop. An advantage to new residential and commercial development is that a distribution and return system can be constructed more economically if it is planned and constructed as a part of the initial development, as opposed to being constructed after the streets and other utilities have been constructed.

In order to serve new areas that are expected to develop during the planning period, it may be necessary to construct new transmission trunk lines from the central plant facility to the facility of the developing area. In some cases these new lines may parallel trunk lines that were built initially. In other cases it may be more economical to construct larger mains initially to handle the later growth in order to avoid the expense of constructing a parallel line at a later time. 


\section{THIS PAGE}

\section{WAS INTENTIONALLY \\ LEFT BLANK}




\subsection{IDENTIFIED VARIATIONS}

\subsection{INTRODUCTION}

In any system that utilizes the number of separate components that are required in the HP-WHR system, the possibilities for component variation and system mutation become virtually unlimited. However, several areas of system design show promise for performance and/or system economics improvement through innovative systems engineering. These areas include: possibilities of utilizing other sources of thermal energy, component selection and specification from the extensive varieties of available equipment, and variations in system design and utilization. Several of the obvious variations in each category are discussed in the sections that follow.

\subsection{THERMAL ENERGY SOURCES}

While it is expected that the most promising and most easily accessible source of low-grade thermal energy will be a community's wastewater effluent, a site-specific energy resource inventory may dictate that other sources be considered. Other promising alternatives include solar energy, waste heat from industrial processes (such as power generation), waste heat recovery through solid (or gaseous) waste incineration, or composite energy sources. Solar technology has produced active solar energy collectors, such as the General Electric model TC-100, that are proving effective in harnessing solar thermal energy. Another workable variation of collector-type is the solar pond collector design. This collector variation may prove economic and advantageous when large demand is placed on the HP-ICES system and when large land areas are available for siting the Central Station. The principal advantage to utilizing solar energy as the primary energy source in an HP-ICES scheme is harnessing a previously untapped, universa11y available thermal energy source. There are several major disadvantages, 
however, to utilizing solar energy in this scheme (at least as the primary energy source). First are the typical disadvantages associated with active solar systems - size and cost. A central solar facility proposed for a mi ldle Georgia location. required $3323 \mathrm{ft}^{2}$ of solar collectors at an estimated system cost of $\$ 246,298$ to supply the space heating and cooling needs for 15 houses (955 net (heated)ft. ${ }^{2}$ average). A second major disadvantage to utilizing solar energy is that a backup thermal energy source must be supplied for periods when solar energy is not available. The third disadvantage is that an additional interface is requixed between the thermal source and the Central Station heat pump equipment.

Waste heat rejected from industrial processes may be reclaimed in essentially the same manner as from community wastewater. Depending upon the process and the location of the industry in relation to the community; low-grade thermal energy may be available in amounts significant enough to warrant a modular system with several central station installations. A central station co-located on the site of a utility power plant and extracting thermal energy from the condenser circulating water is an attractive option as an alternative energy source. The advantages are similar to those of the wastewater heat recovery option; i.e. utilizing a previously untapped source of (low-grade) thermal energy at an easily accessible location. An additional advantage is that, as the hourly demand on the HP-ICES from the industrial sectors increases, a proportional increase in thermal energy rejected from the industrial processes becomes available. This inherent demand-tracking supply will simplify somewhat the load balance of an HP-ICES. A third major energy source for consideration is the heat of combustion from various waste materials. One or several waste-heat-type boilers 
could be utilized in the system to reclaim heat in the form of trash (deposited at sanitary landfills), wood scraps (available as waste from various wood processing operations), or combustible gasses (generated as by-products in certain processes). For example, methane gas is typically generated in anaerobic sludge digesting processes at sewage treatment plants and is sometimes utilized as an auxiliary fuel in the digestor heating furnaces. The principal advantage of these sources is that the primary fuels, where available, would be very inexpensive. However, several major disadvantages weigh against utilizing combustion heat as a primary thermal energy source. First, the fuels that are available in bulk (trash, wood scraps) would require transportation and preparation before firing in the heat reclaim boiler. Secondly, the additional first cost of the heat reclaim boiler(s) would extend the payback period of the initial installation of the central station and make it less attractive economically. Finally, the additional interface (the heat recovery boiler) between the thermal source and the central station equipment is again required.

Depending on a site-specific inventory of available resources, a composite thermal-source ICES may prove economically feasible and energy. effective. The basic design of the overall system, detailed in Chapter 1, can be adapted very easily to multi-thermal source form. An evaluation of the feastbility of utilizing one or more of the above mentioned sources will depend on the particular needs, characteristics, and resource inventories at each site of application. For a hypothetical example, though, let us consider a community with a sewage treatment plant of limited capacity: The entire thermal demand on the HP-ICES may not be supplied by the wastewater effluent. However, the primary energy source may be 
supplemented with a field of solar collectors that could be expected to supply. a certain percentage of the thermal load (optimized with regard to size and costs): Also available for peak demand periods or as a back-up thermal source for the solar segment of the thermal supply would be a limited supply of methane gas from the treatment plant's anaerobic sludge digestion system, to be converted in a small heat-reclaim boiler. In addition, a second large-scale solid waste utilization-type boiler could be incorporated for trash incineration (trash thal wuuld normally be disposed of at a sanitary landfill typically located at or near the sewage treatment facility). Such a system would provide a site-efficient composite thermal source for the HP-ICES; optimized for the particular energy supplies and demands of the community. Figure 7-1 details one possible configuration of such an installation.

SUMMARY

It is anticipated that the most promising source of thermal energy will be the low-grade heat available in the community's wastewater effluent. However, there is the possibility of augmenting the primary energy source with any combination of the other alternative sources. The overall consideration is that enough thermal energy must be available, through any combination of sources; to provide the community, or portions of it, with a continuous, consistent, and reliable thermal service, via the HP-ICES. For each particular site of application, an energy resource inventory must be performed according to the First and Second laws of Thermodynamics and the procedures of "Availability Analysis" (References 34 and 35).

\subsection{COMPONENTS}

System detail design and component specification is often a headache because of the wide variety and quality of components on the market. 


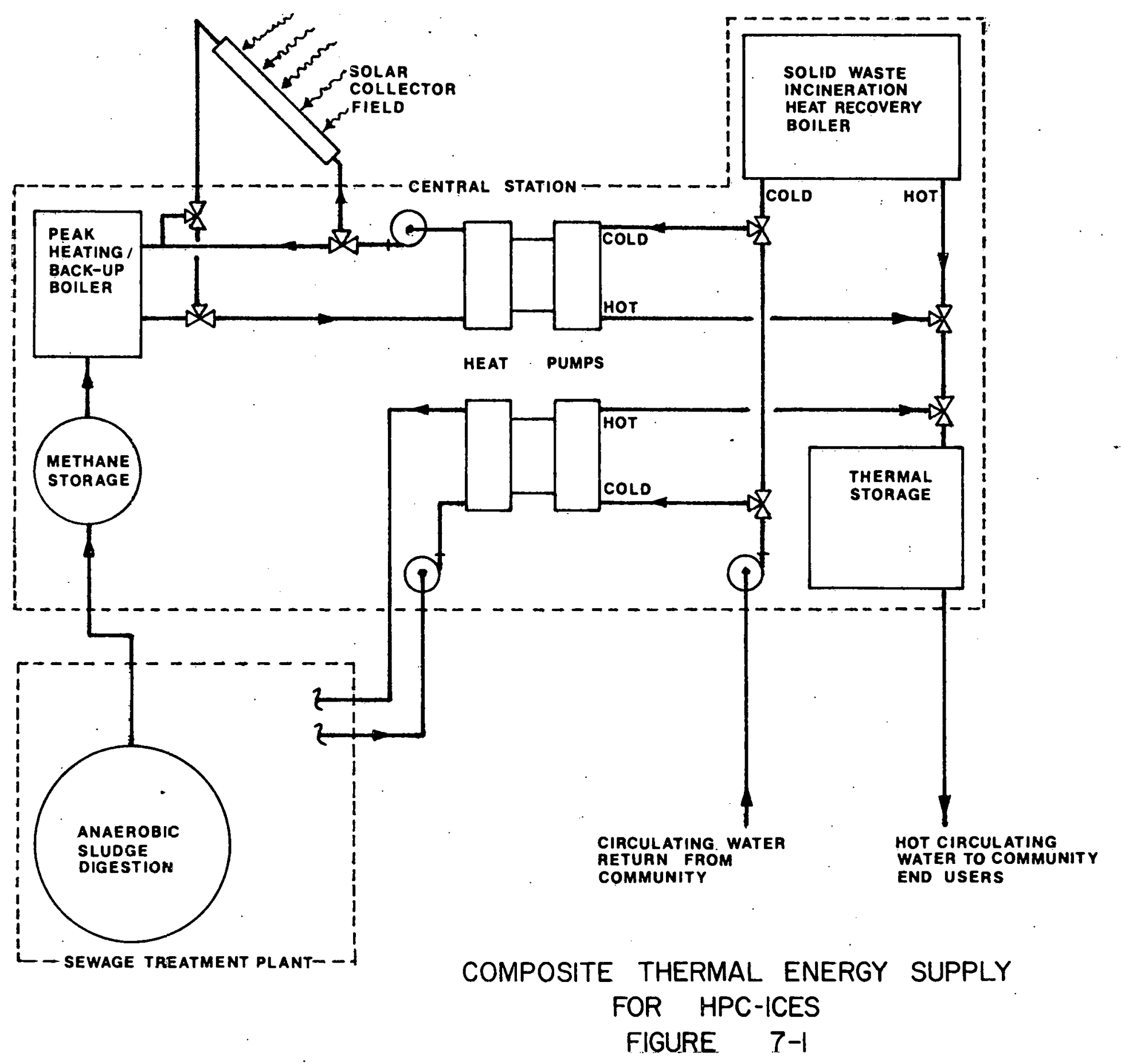


However, this same variety provides the engineer with extensive opportunity to improve system performance through judicious component selection and innovative subsystem design.

The most obvious candidate for component variation is the heat pump, either the Central Station pump or the end-user pump. The most widely available Central Station equipment is based on a fairly standard design with variations mainly in compressor design. (The most popular compressor designs are centrifuga1, reciprocating, and screw-type.) Available water source heat pumps (for residential use) are even more similar. While most pumps employ electric induction motors to drive the Rankine cycle compressor, there are obviously other means of providing power to the compressor. Innovations in the field of thermal engine heat pumps include several composite heat pump cycles. Stirling - Rankine, Rankine - Rankine, Brayton Rankine, Otto - Rankine, and the Ericsson - Ericsson. (Discussion of each of these cycles are found in Reference 10.) Refinement of the devices based on these cycles promises to make them competitive, both performance-wise and cost-wise, with equipment now available.

The distribution system will be designed according to standard water distribution system design practice. However, there is considerable latitude left for the design engineer in the specification of the piping materials to be used. There may be significant advantages to utilizing the new piping systems based on plastics such as polyvinyl chloride (PVC) or high density polyethylene. Advantages that are immediately obvious are reductions in materials costs; lower coeffictent of thermal conductivity of the material, and ease of installation of the integrated design piping systems.

Water quality of the thermal energy source/sink, i.e. wastewater, 
may cause problems that could be remedied by judicious component selection. The increased fouling factor of the water to be circulated through the Central Station equipment heat exchanger may dictate one of several options. Option one is the standard HVAC design technique of specifying a larger size heat exchanger to accomodate the increased resistance to heat transfer contributed by the high fouling factor of the circulated wastewater. Option two would be the specification of a plate-type heat exchanger which would allow easy disassembly and cleaning and thus a speedy turnaround time for scheduled maintenance. Option three would be the specification of a mechanical cleaning system for the heat exchanger such as reverse-flow actuated brush scrubbers or a continuous cycle spherical rubber scrubber system such as an Amertap. Which, if any, of the above options should be selected will depend on the quality of circulated water at each specific site: General guidelines covering expected wastewater fouling factors and the corresponding appropriate subsystem modifications may be developed in the component testing program outlined in Chapter 8 . However, the final judgement is best left to the system engineer performing the detail design and component specification.

\subsection{SYSTEM VARIATION}

The basic Heat Pump Wactowater Heat Recovery (HP-WHR) system concept lends itself nicely to variations within the system or even to variations in the utilization of the end-product thermal service.

One particular variation that shows promise is the addition to the system of an evaporative cooling component (cooling tower). Instead of sacrificing the power necessary to reject heat to the wastewater heat sink through the central station heat pump, the community circulating water could be cooled by means of a mechanical draft cooling tower. Some sacrifice 
would be necessary in the form of pump and fan horsepower, but it is expected that the combined operating and maintenance costs of the cooling tower during the cooling season would be less than those assaciated with running the central station equipment. Also, if necessary or advantageous, the distribution system could be segmented with several cooling towers located throughout the community to handle cooling of the circulating medium.

Another variation that may be considered is the clarified Wastewater system. This system involves utilizing an open distribution loop to deliver the reclaimed thermal energy. Delivery of thermal energy to the end-user is accomplished by utilizing partially clarified wastewater as the transport medium in a one pipe distribution network. However, several major disadvantages may eliminate this variation from consideration.

First, the demand for thermal energy in the heating mode will tend to coincide with the morning peak of wastewater effluent flow. Wastewater flow typically is on a 24-hour cycle with the major peak at mid-morning (9:00 11:00am) and a second, lesser peak at late afternoon. Peak thermal demand typically is early-to mid-morning due to the early morning heating load and cold start-up of many businesses and industrial processes. This coincidental peak may pose serious hydraulic overloads on existing sewage collection systems where thermal media flow at peak conditions might be a large percentage of the normal wastewater flow. No general rule is applicable since hydraulic loading of existing sewer systems is dependent on the specific application and will change with a number of variables such as sewer age and location in the sewage coliection network.

Another serious problem is the impurity and bacterfological content of the clarified effluent. Severe fouling of heat transfer surfaces is probable due to the high suspended solids (BOD) content of the effluent. A 
relatively serious public health hazard might also be introduced by accidental leakage of the contaminated effluent.

One further detrimental effect the clarifled wastewater system would impose when the transport medium is returned to the sanitary sewer system would be to lessen the overall thermal quality of the primary heat source. by lowering its temperature. The amount of available thermal energy would be decreased by the mixing process.

Even with all the drawbacks aforementioned, the clarified wastewater concept may be viable in specific instances and should not be wholly discarded without consideration. In general application, however, it would seem that the scheme poses an unacceptable number of problems which require specialized solutions. It is doubtful that the distribution system cost advantage can outweigh the penalties.

A third system variation (pictured in Figure 7-2), perhaps the most promising, proposes to supply the thermal services in a form suitable for use strictly in industrial processes, and to utilize wastewater treated and conditioned for industrial re-use as the thermal energy distribution medium. (This latter provision in the HP-WHR system variation is becoming more and more attractive as current Environmental Protection Agency 201 Facilities Etudice require an evaluation of the feasibility of re-using all or portions of the wastewater treated at sewage treatment facilities. Industrial re-use of treated wastewater is a logical first-step in implementing water re-use technology.) As shown in Figure 7-2, an open distribution system is proposed. However, since the amounts of water conditioned by this system will directly displace the amounts of (make-up) water discharged through industrial processes, the danger of hydraulicly. overloading existing wastewater collection systems is avoided. Also, the load balance on 


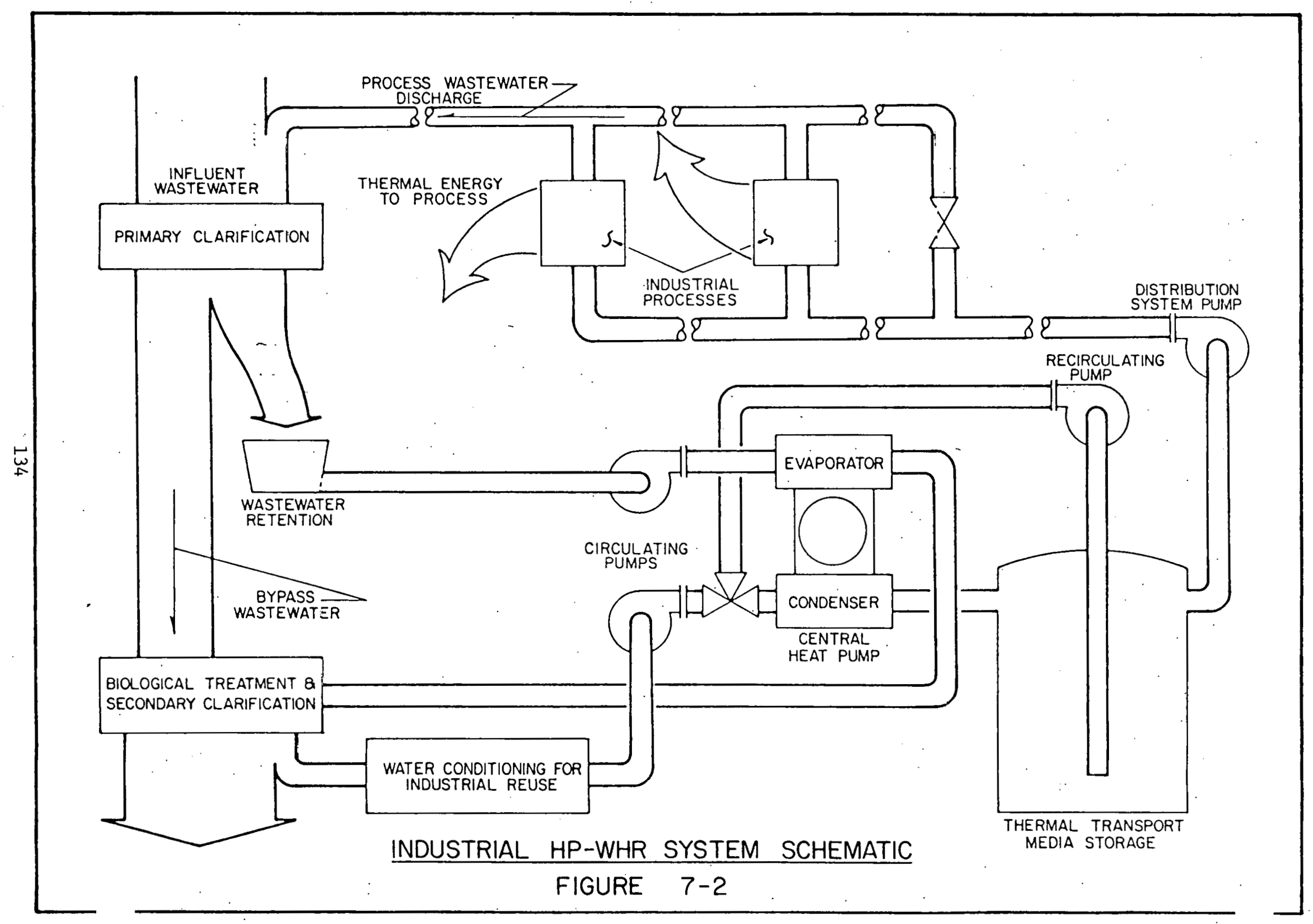


a system applied in this manner would be greatly simplified since the thermal demand placed on the system would directly coincide with the supply of available energy rejected through the industrial processes. This overall system concept is especially attractive to industrial communities requiring large quantities of high temperature water for any number of process uses.

\subsection{SUMMARY}

The energy source, component, and system variations discussed in the preceeding sections just begin to address the possibilities. The basic HP-WHR system concept is flexible enough to allow easy adaptation to a number of different applications. Technically speaking, the possibilities are limited only by the ingenuity of the design engineer. 
THIS PAGE

\section{WAS INTENTIONALLY \\ LEFT BLANK}




\subsection{SITE-SPECIFIC FEASIBILITY STUDY FOR CONYERS, GEORGIA}

\subsection{INTRODUCTION}

The preceeding chapters have detailed the development of the Heat Pump Wastewater Heat Recovery (HP-WHR) system concept. Thermodynamic and economic analyses on a hypothetical system seem to indicate the system would be competitive, both performance-wise and cost-wise, with the other more standard options for space conditioning. However, such analyses and projections are necessarily based on a set of assumptions which may or may not be valid for a particular site of application. Therefore, in order to determine the effectiveness of such an HP-WHR system on the community level, a site-specific examination must be performed.

Chapters 8.0 and 9.0 of this report develop the methodology, via case studies of two application communities, of examining the HP-WHR concept on a community basis and validate the feasibility of the concept on the community level. The two application communities, Conyers, Georgia and Cornelia, Georgia (shown on the following location map), were selected for their varieties of community characteristics and configurations which would affect the application of an HP-WHR system. The applications of the HP-WHR system concept to each of the demonstration communities make note of the different community characteristics and take advantage of them to emphasize the wide range of application possibilities of this system concept.

The City of Conyers, Georgia, located in close proximity to the metropolitan Atlanta area, is in a high growth area of the state for both residential and industrial developments. Additionally, the segmentation of the sewer system in Rockdale County (in which Conyers is located) facilitates the application 


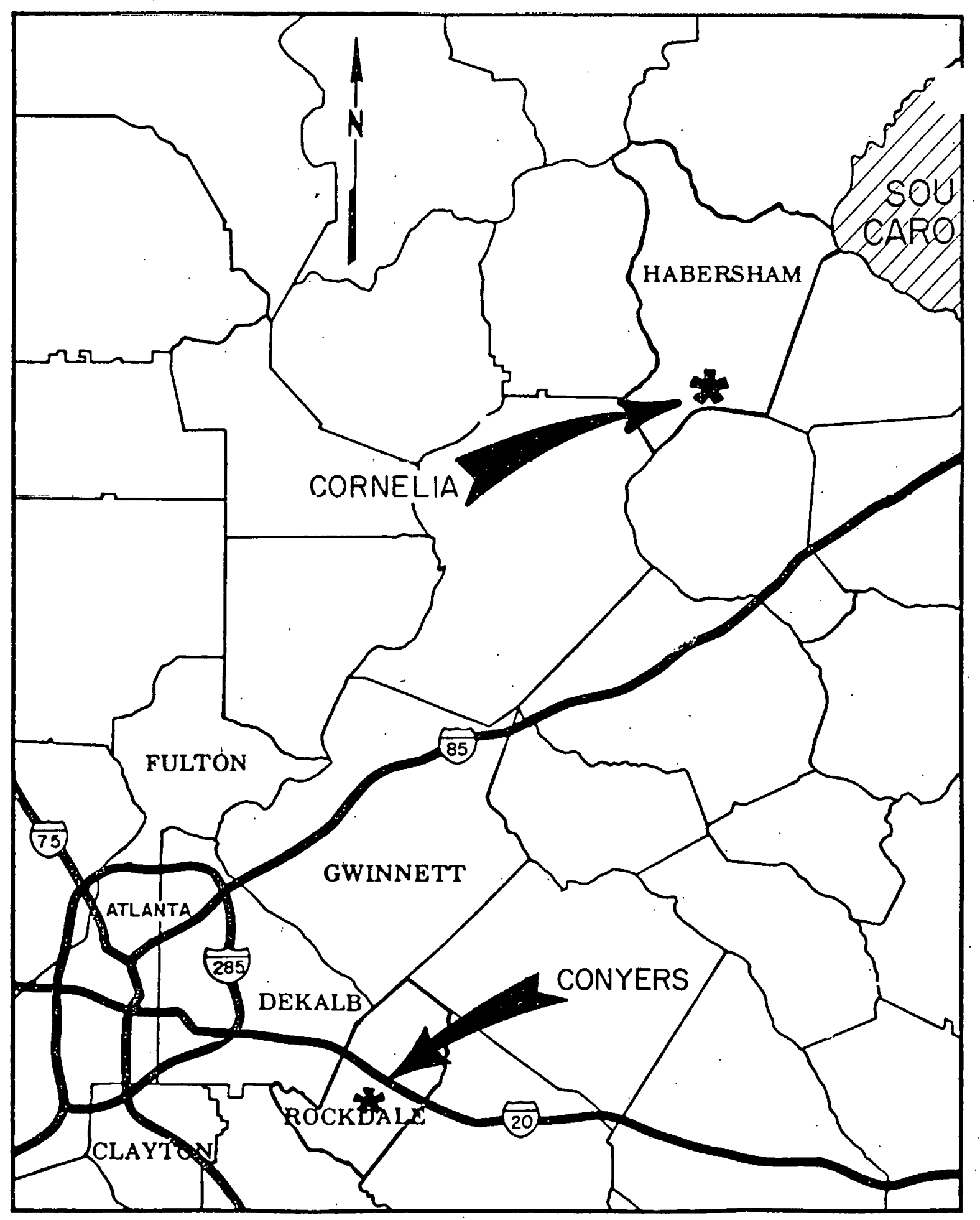

\section{LOCATION MAP \\ APPLICATION COMMUNITIES \\ FIGURE 8-1}


of the HP-WHR system concept to a developing residential area in close proximity to one of the wastewater treatment plants on the outskirts of the Conyers area. Thus, the opportunity to examine strategies for phasing construction in high growth residential areas is presented.

The City of Cornelia, located in the mountains of northeast Georgia in Habersham County, is in a low growth area of the state. Because of the low growth rate, application of an HP-WHR system to Cornelia will involve primarily system retrofits to existing structures. Additionally, due to the layout of the community and its attending sewer system, the primary focus of the Cornelia system will be to provide service to customers in the commercial category. Service for one large industrial customer is also included in the system plan. With the completion of these feasibility studies, the cost-and energyeffectiveness and the flexibility of application of the HP-WHR system concept should be successfully demonstrated.

\subsection{COMMUNITY DESCRIPTION - CONYERS, GEORGIA}

The City of Conyers, Georgia is located in the center of Rockdale County approximately 22 miles east of downtown Atlanta. The City and County are considered to be within the Atlanta Metropolitan area and have experienced significant commercial and residential growth as a result of the overall growth that has been occurring within the Metropolitan Atlanta Area. The building of Interstate Highway 20 through Rockdale County in the 1960's provided a corridor of rapid accessibility to Atlanta and to the later completed Interstate 285 Perimeter Highway around Atlanta. A large percentage of the population of Conyers and Rockdale County commute to the Atlanta area to work. 


\subsubsection{POPULATION GROWTH}

Population is a dynamic factor in the development of a geographical entity and the Conyers-Rockdale County area is no exception. Conyers and Rockdale County have experienced significant growth in recent years, influenced by their location within the Atlanta Metropolitan Region. The tremendous growth of Rockdale County in the period of 1960 - 1970, approximately $72 \%$, can be attributed largely to an in-migration of people caused by Atlanta's urban sprawl. Phenomenal residential development, principally in the form of detached, single-family dwelling subdivisions, has resulted. In addition, industrial development in Rockdale County has fluorished in response to the railroads and major traffic arteries which provide easy access to Atlanta. The City has almost matched the County's growth rate, showing an approximate $70 \%$ increase in population during the 1960 - 1970.period. During the first 6 years of this decade, the growth rate has shown no signs of declining. The County has exhibited a $43 \%$ growth rate and the City a $31 \%$ growth rate, despite the recession of 1974 - 1975. Based on the observation of historical population trends, the Conyers-Rockdale County area is expected to continue its rapid rate of growth over the next 20 years.

\subsubsection{ECONOMIC CHARACTERISTICS}

Over the last 20 years the economy of the Conyers-Rockdale County area has changed, from that of a sparsely populated rural and farming community to a rapidly ğrowing suburban residential community within the Metropolitan Atlanta Area. This change has caused a significant decrease in the number of people who are employed in farming and agricultrual-type activities. Consequently, there has been an increase in the percentage of the population involved 
in business, commercial and industrial-type jobs. In recent years the ConyersRockdale County area has experienced significant industrial growth which is located primarily in those areas served by Interstate Highway 20 and the Georgia Railroad. There has also been significant commercial growth in the form of shopping centers, banks, service stations, and other commercial activities needed to serve the increasing residential population. In the last ten years the Conyers-Rockdale County area has experienced a residential housing boom consisting of both apartments and single family dwellings. All indications are that this high level of residential construction activity will continue for some time into the future.

According to the 1970 Census, the median family income. for the City of Conyers was $\$ 8,992$ per year and the per capita income was $\$ 2,792$ per year. Most of the population of Conyers could be classified in the low to moderate income level with only 13.4 percent earning $\$ 15,000$ per year or more and 12.2 percent being below the poverty level.

\subsubsection{LAND USE}

The City of Conyers has within its corporate limits a total of 3572 acres. Due to a recent annexation of several land areas contiguous to the town core, the majority of the City's land is undeveloped. . Some 54.2\%, or 1935 acres, of the land area may be classified in this category. The second largest category is residential, with 924 acres or $25.9 \%$ of the land area. Streets and other public rights-of-way occupy approximately 372 acres or $10.4 \%$ of the land area. Public and semi-public land occupies 149 acres (4.2\%); commercial usage requires 159 acres (4.4\%), and industrial occupies 33 acres or $9 \%$ of the land arca. 
The City of Conyers and the contiguous area which will be considered for service with the HP-WHR system are shown on Figure 8-2.

\subsubsection{CLIMATE}

The climate of the Conyers-Rockdale area is humid and continental. The winters are mild, but they have very changeable temperatures. The prevailing wind during the winter is northerly. The weather is largely controlled by movement of areas of high and low barometric pressure and the accompanying winds. In winter these conditions cause frequent alteration of warm moist southerly winds and cold dry northerly winds.

The average winter temperature is $49.3^{\circ} \mathrm{F}$. The temperature usually rises rapidly in March and April. The difference in the mid-winter (January) average and the mid-summer (July) average is $27.9^{\circ} \mathrm{F}$, which is relatively small compared with a difference of $60^{\circ} \mathrm{F}$ in some of the more northern states. The summers are warm but are comparatively free from extreme heat due to the altitude and latitude of the area. The average summer temperature is $75.1^{\circ} \mathrm{F}$. The average date of the first killing frost is November 8 and for the last is March 29.

Rainfall varies somewhat from year to year, but its seasonal distribution is generally favorable for crops. Serious drought is not likely to occur more than once in $10-15$ years. The rainfall reaches a peak in the winter and again in mid-summer. Fall is the driest season of the year and about one-half of the rainfall comes in quantities of one inch or more in a 24-hour period.

The closest United States Climatological Station is located in Covington, Georgia in Newton County. Covington is eleven miles south of Conyers so the data should be applicable to the study area. 


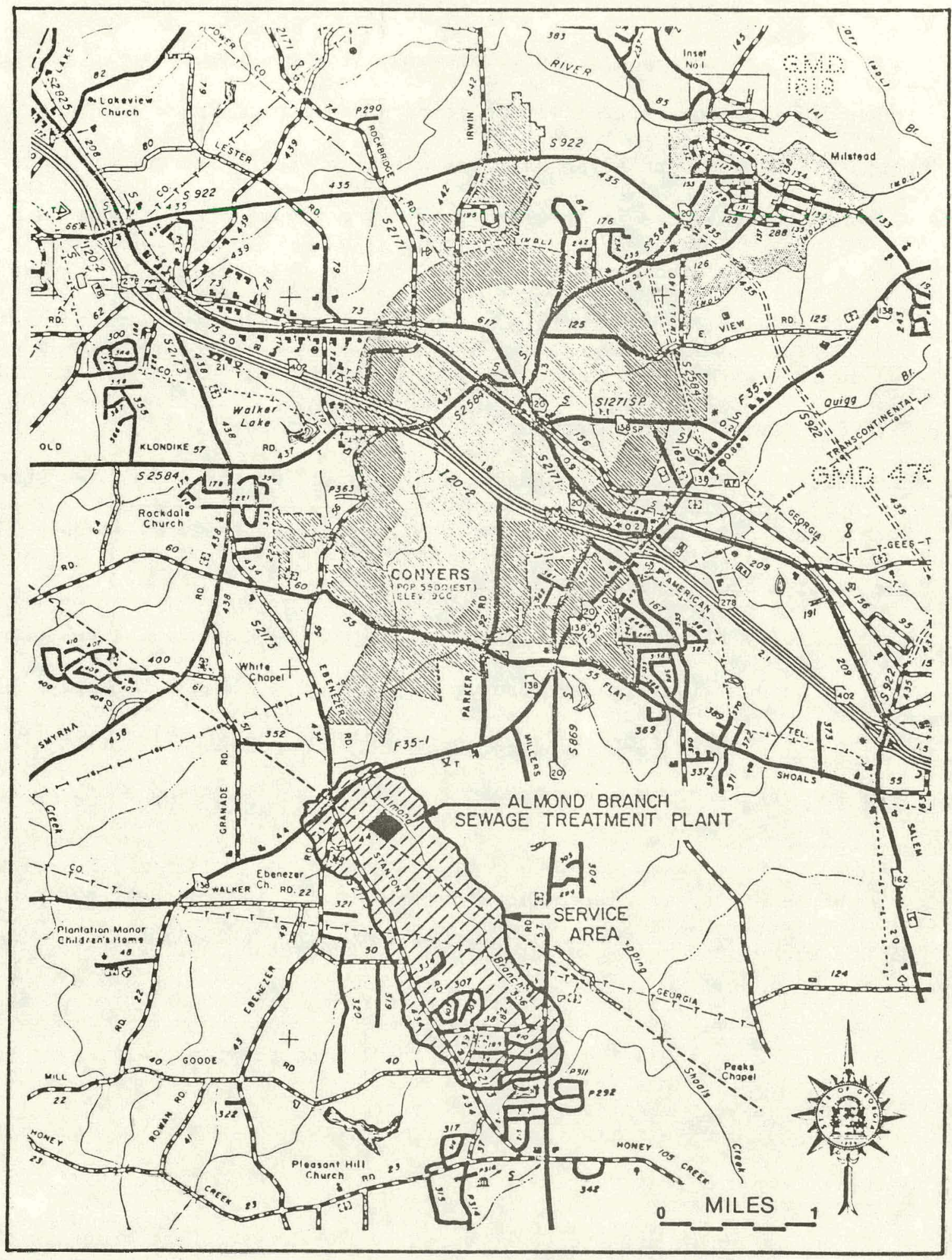

\section{CITY OF CONYERS}

HP-WHR SYSTEM SERVICE AREA

FIGURE 8-2 
The climate of the region is influenced by the Atlantic Ocean, the Gulf of Mexico, and the Appalachian Mountains. The mountains shield the area from the heavy snow and extreme winter temperatures found in eastern Tennessee, northern Alabama, and Arkansas. Likewise, the ocean and gulf affect the seasonal temperatures in the summer, and "continentality" is not as noticeable as the areas located further inland.

Because of the geographical location, temperatures are mild in winter and summer, with summers moderately warm and humid. During the summer, some extended periods of hot weather are experienced, but such periods are not unbearable. The hottest weather comes in brief spells during the summer. Even though days are hot, nights are mild with temperatures dropping into the sixties and seventies.

Humidity ranges around eighty to ninety percent during the summer causing an occasional early morning fog, and normally the humidity falls in early afternoon to fifty to sixty percent. The average wind velocity comes from the northeast or northwest in the winter and from the south in the spring and summer.

Winters are generally mild with cold spells lasting only a few days even in mid-winter. Temperature drops to 32 degree Fahrenheit or below about fifty days each winter. The temperature reaches the teens or twenties at least once a month during the winter and ten degree temperatures or below occur once a year about every fourth year.

\subsubsection{PROPOSED SERVICE AREA}

The community area to be serviced by the Conyers Heat Pump-Wastewater Heat Recovery System is located relatively close to the thermal energy source 
and will be composed of single family residential structures. The unique advantages of the Conyers service area are: 1) the proximity of the service area to the thermal energy source, and 2) the opportunity to service both existing structures through space conditioning system retrofit and new structures through initial system installation as the community grows.

The proposed service area of approximately 472 acres was subdivided into three zones for the purposes of estimating thermal energy consumption. The service zones, shown in Figure 8-3, vary in the degree of development. Zone 1, 149 acres, is approximately $40 \%$ complete with regard to its build-out potential of approximately 50 houses. Zone 2 is a presently undeveloped parcel of land, approximately 116 acres, which shows excellent potential for development during the later phases of the study period. Zone 3, 207 acres, is also a relatively new subdivision which is approximately $50 \%$ complete in its potential build-out of 150 houses. Obviously, there is significant room for expansion of the number of homes served from the HP-WHR system and for realizing the significant initial cost advantages of installing the system in new structures, as opposed to retrofitting existing structures and space conditioning systems.

The energy source analysis indicates that the energy reasonably available from the waste treatment plant will serve approximately 400 average homes in the Conyers area. This is 100 plus percent of the service area's projected requirements. However, energy augmentation by solar or other means might prove feasible if growth in the area exceeds projections.

The other significant point favoring the Conyers system is the proximity of the residential development to the waste treatment plant. While this situation is usually uncommon, the suburban nature of Conyers' recent growth 


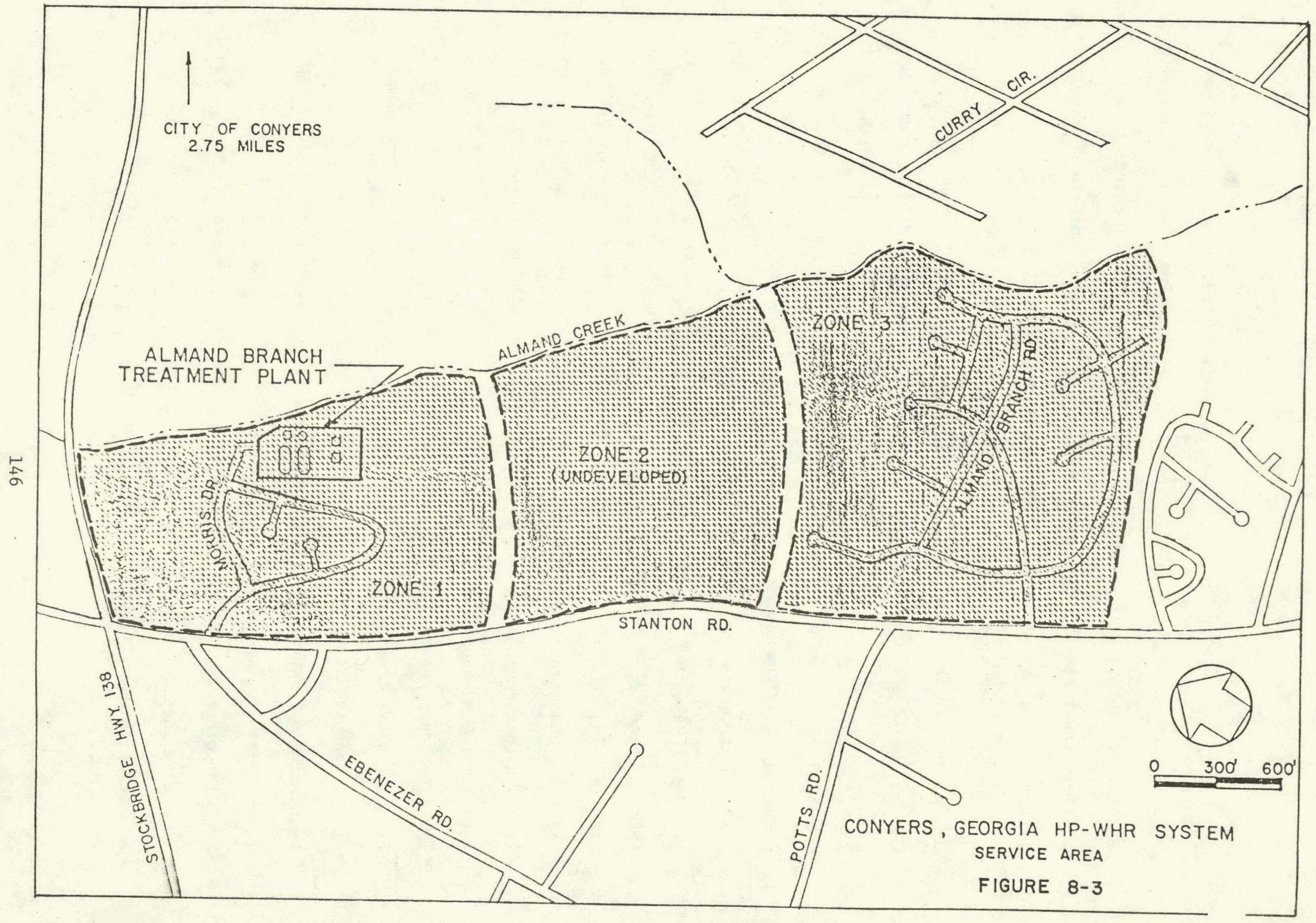


has promoted residential subdivision expansion in the outlying areas. This relatively dense growth in the area of the wastewater treatment facility will tend to decrease investment costs in the thermal distribution system and make the project more economically viable.

\subsubsection{BUILDING CONSTRUCTION}

The proposed service area was divided into three zones in order to facilitate estimating thermal energy consumption. All structures within the service area are detached, single family. dwellings. Building construction is similar within and between zones.

The housing units within the proposed service areas range in size from 1,000 to 1,600 square feet and are generally less than five years old. Spatially, they are arranged on land lots of approximately $1 / 4$ to $1 / 3$ acre. The units are predominately split level units with three bedroom units. However, some ranch type designs are intermingled throughout the subdivisions. FHA minimum property standards or VA standards were adhered to in the majority of units. Dwelling unit walls are the $31 / 2^{\prime \prime}$ cavity wall construction consisting of gypsum board inside face, 2" $\times 4^{\prime \prime}$ stud supports, $31 / 2$ " fiberglass insulation, particle board outside sheathing and exterior siding or brick exterior. Attic insulation, 4" to 8" of fiberglass loose fill or 6" batting, is used in the majority of construction. Floors are generally uninsulated, but carpet is normally included as a floor covering. Window construction is the double-hung sliding type with single pane glass. Storm windows are not used on the majority of the houses.

Typically, each house is heated by a forced air, natural gas furnace. Most houses are air conditioned by means of duct mounted refrigerant coil and 
air cooled condensing units. System sizes range from 2 to 5 tons capacity air conditioning. Furnaces are usually 80,000 to 100,000 Btu input size.

One especially attractive feature of the Conyers service area is that the area is less than 30 percent complete with respect to residential development. The fewer number of units that must be retrofitted will make the scheme more attractive. Substantial first cost benefits can be obtained by installing units at the time of original construction.

\subsubsection{HEATING AND COOLING LOADS}

A descriptive statistic in determining the overall desirability of providing central heating and cooling media for use by a community is the total number of hours per year when some amount of heating or cooling is required by most residences. To derive this statistic, cumulative totals were developed from hourly temperature distribution data to indicate the number of hours per year when heating or cooling is required in Conyers. Heating was assumed to be needed when the outside air temperature was $65^{\circ} \mathrm{F}$ and below. This basis yielded an approximate 4593 hours per year when some form of heating energy was required by most buildings. Likewise, cooling was assumed to be required when the outside air temperature was above $75^{\circ} \mathrm{F}$. For the Conyers area, this resulted in 1974 total hours per year which required some form of cooling. With such substantial heating and cooling seasons as the above, a central heating/cooling system shows obvious potential for service in the area.

\section{Monthly Loads}

Heating and cooling loads for the Conyers system were estimated on a monthly basis for those building structures within the projected service area. The primary emphasis in load development was placed on monthly figures since 
no greater degree of detail could be justified in a preliminary study of this type. Peak loads were also developed using design conditions from the 1977 Fundamentals Volume of the ASHRAE Handbook and Product Directory. 50

The estimate of monthly heating and cooling requirements was calculated by a computer program developed by the Community Energy Systems Branch of Georgia Tech. To estimate the total thermal load per service zone, the computer program, when appropriately input with the pertinent data, multiplies the number of building units of a particular type times the average floor area per unit for that building type times the monthly thermal integrity factor for that building type to obtain a total monthly BTU requirement for each building category. Total thermal requirements for all building categories are then summed to give an overall load for each zone. Finally, total zone loads are summed to give an overall system thermal load.

Input to the program included thermal integrity factors developed from the Rand Corporation's ENERGY USE AND CONSERVATION IN THE RESIDENTIAL SECTOR: REGIONAL ANALYSIS. ${ }^{27}$ Unitized energy consumption data was estimated on an annual basis. Heating energy required was $30 \mathrm{MBtu} / \mathrm{sq} . \mathrm{ft}$. annually. Cooling energy required was $20 \mathrm{MBtu} / \mathrm{sq}$.ft. annually. Monthly heating and cooling loads were determined by apportioning the annual requirement according to the percentage of heating or cooling degree days occurring in a particular month. Heating and cooling degree days were taken from "Monthly Normals of Heating and Cooling Degree Days 1941-1970", 55 published by the National Climatic Center, Asheville, North Carolina. Table 8-1 is a summary of the percentage figuree utilized in the load estimate. 
TABLE 8-1

Annual Heating and Cooling Degree Days

Conyers, Georgia

Heating

\begin{tabular}{|c|c|c|c|c|}
\hline Month & Degree Days & $\%$ Total & Degree Days & $\%$ Total \\
\hline Jan. & 701 & 22.6 & 0 & 0.0 \\
\hline Feb. & 560 & 18.1 & 0 & 0.0 \\
\hline March & 443 & 14.3 & 12 & .7 \\
\hline April & 144 & 4.6 & 27 & 1.7 \\
\hline May & 27 & 0.9 & 154 & 9.7 \\
\hline June & 0 & 0 & 321 & 20.2 \\
\hline July & 0 & 0 & 403 & 25.4 \\
\hline August & 0 & 0 & 388 & 24.4 \\
\hline Sept. & 8 & 0.3 & 227 & 14.3 \\
\hline Oct. & 137 & 4.4 & 57 & 3.6 \\
\hline Nov. & 408 & 13.2 & 0 & 0.0 \\
\hline \multirow[t]{2}{*}{ Dec. } & 667 & 21.6 & 0 & 0.0 \\
\hline & 3095 & 100.0 & $1589^{\circ}$ & 100.0 \\
\hline
\end{tabular}

The service area under consideration for Conyers contains only residential buildings. Building count and area were estimated from field surveys. Table 8-2 presents a month-by-month summary of the total projected thermal load on the HP-WHR system. The full results of the computerized load calculations and peak load determinations are presented in Appendix C. 
TABLE 8-2

CONYERS HP-WHR SYSSTEM LOOADS

\begin{tabular}{|c|c|c|}
\hline PERIOD & $\frac{\text { HEATING LOAD }}{\text { BTU } \times 10^{9}}$ & $\frac{\text { COOLING LOAD }}{\text { BTU } \times 10^{9}}$ \\
\hline Jan. & 2.915 & 0.0 \\
\hline Feb. & 2.335 & 0.0 \\
\hline March & 1.845 & 0.060 \\
\hline April & 0.593 & 0.146 \\
\hline May & 0.116 & 0.834 \\
\hline June & 0.0 & 1.737 \\
\hline July & 0.0 & 2.184 \\
\hline August & 0.0 & 2.098 \\
\hline Sept. & 0.039 & 1.230 \\
\hline Oct. & 0.568 & 0.310 \\
\hline Nov. & 1.703 & 0.0 \\
\hline Dec. & 2.786 & 0.0 \\
\hline
\end{tabular}

\section{Peak Heating Load}

As mentioned above, peak loads were estimated using the procedures and design conditions from the ASHRAE Handbook. 50 The degree day formula, with terms rearranged to solve for the peak load, $P$, was utilized as shown below: 


$$
P=\frac{(E) \times(T D)}{(D D) \times(24)}
$$

Where:

$$
\begin{aligned}
\mathrm{P} & - \text { Design heating load per hour } \\
\mathrm{E} & =\text { Heat energy required } \\
\mathrm{TD} & =\text { Design temperature difference } \\
\mathrm{DD} & =\text { Heating degree days }
\end{aligned}
$$

For this estimate:

$$
\begin{aligned}
E & =2.915 \times 10^{9} \mathrm{BTU}-\text { from the computer load estimate for January } \\
\mathrm{TD} & =70^{\circ}-17^{\circ}=53^{\circ} \mathrm{F}-\begin{array}{l}
\text { desired inside temperature minus the } 99 \% \\
\text { design temperature for Conyers }
\end{array} \\
\mathrm{DD} & =701-\text { from Table } 8-1
\end{aligned}
$$

Thus

$$
\begin{aligned}
P & =\frac{\left(2.915 \times 10^{9}\right) \times\left(53^{\circ}\right)}{(701) \times(24)} \\
& =9.18 \times 10^{6} \mathrm{Btu} / \mathrm{hr}
\end{aligned}
$$

Peak Cooling Load

Utilizing the design figure of an average 550 square feet per peak ton of refrigeration for residential structures, the peak cooling load was estimated as follows:

$$
\begin{aligned}
\text { Peak Cooling Load } & =\frac{430,000 \mathrm{ft}^{2} \text { (building area served) }}{550 \mathrm{ft}^{2} / \mathrm{ton}} \\
& =782 \text { tons }
\end{aligned}
$$




\subsubsection{THERMAL ENERGY RESOURCES}

From earlier discussions on the general HP-WHR system concept and from the descriptions of the specific system to be applied in the demonstration community of Conyers, Georgia, it is apparent that the low-grade heat in the community's wastewater will be utilized as the thermal energy source. Due to the site specific variables to be considered in characterizing a community's wastewater as the thermal energy source for this system; a determination of the quantities of thermal energy available from this source necessarily involves examination and analysis of the specific wastewater collection and treatment system to be evaluated for the application of this scheme. The following sections examine the wastewater facilities of the Conyers, Georgia community and develop estimates of the thermal energy available to an HP-WHR installation at a proposed site in Conyers. CITY OF CONYERS, GEORGIA WASTEWATER FACILITIES

The City of Conyers and contiguous unincorporated areas of Rockdale County are served by three sewage treatment facilities. Boar. Tusk Creek sewage treatment plant, approximately one mile outside the corporate city limits off of East View Road, is a 500,000 GPD activated sludge facility which handles approximately $75 \%$ of the domestic wastewater generated within the city limits. A second facility, the Almand Branch sewage treatment plant located approximately 2 miles outside the corporate limits off of Stockbridge Highway is a I.0 MGD, oxidation ditch type of treatment facility which handles the remaining $25 \%$ of the City's domestic wastewater plus significant amounts of industrial discharge. A third treatment facility, the Atlanta Suburbia sewage treatment plant, located near the Rockdale County line off of Underwood Road, is a 200,000 GPD activated sludge facility which serves the Salem East, Salem Lake, Salem Woods, and Salem 
Village residential subdivisions.

Because of advantages in system configuration and plant siting, and due to its proximity to a compact potential service area comprised of existing subdivisions, areas now under development, and several institutional structures (schools), the Almand Branch sewage treatment plant has been selected for evaluation of available thermal energy for the proposed Conyers HP-WHR system.

The Almand Branch plant, constructed in 1973, was designed for the treatment of domestic sewage of average pollutant concentrations and flow characteristics. The plant design is the oxidation ditch type, a modified form of activated sludge treatment, which may be classified in the extended aeration group. Average daily design flow is $1.0 \mathrm{MGD}$, and BOD removal efficiency was designed at $90 \%$ or better.

A flow sheet of the plant is provided in Figure 8-4. The principal components of the plant, along with pertinent design data, are as follows:

- Barminutor with manually cleaned by-pass bar screen.

- Raw Sewage Pumping Station with 2 variable speed vertical pumps and 1 constant speed vertical pump

- Aeration tanks (2) each at $194^{\prime}$ long and $64^{\prime}$ wide at the top with a $6^{\prime}$ ' water depth. Approximate capacity 413,000 gallons each. Mechanical aerators are $26^{\prime}$ rotor aerators. Theoretical retention time at design flow of $1.0 \mathrm{MGD}$ is 20 hours.

- Final clarifiers (2) circular with $35^{\prime}-0^{\prime \prime}$ diameter and $9^{\prime \prime}-0^{\prime \prime}$ side water depth. Approximate capacity of each tank is 64,000 gallons with a 3 hour retention time.

- Return sludge pumping station with 2 Midland Totally Submersible sewage pumps.

- Sludge drying beds (4) each at $26^{\prime}$ wide and $49^{\prime}$ long.

- Chlorine contact tank, 2 sections, each $18^{\prime}$ wide and $20^{\prime}$ long with a 7' water depth. Approximate capacity is 34,000 gallons with 50 minute retention time at design flow.

- Parshall flume, 9", with flow monitoring device.

- Control building containing laboratory and office, chlorine room, storage room and shop. 


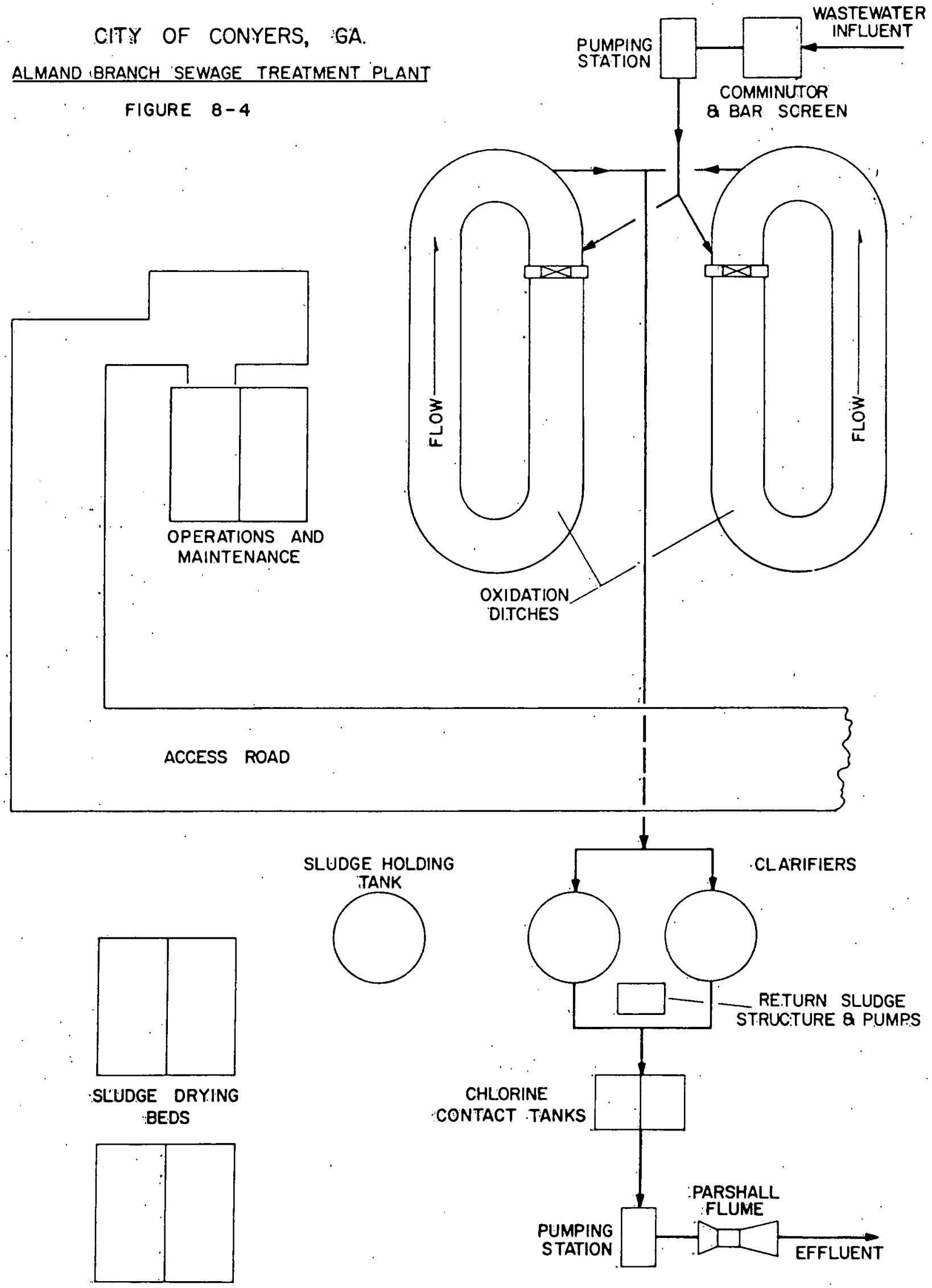


- Standby electric power system.

Due to the newness of the facility and a good operation and maintenance program by the City, very few operational problems with plant equipment have developed.

Sewers which are tributary to the Almand Branch Facility consist of 1390 lineal feet of $4^{\prime \prime}, 3750$ lineal feet of 6", 58,390 lineal feet of 8", 5940 lineal feet of 10", 7960 lineal feet of 12", 3080 lineal feet of 15", 7410 lineal feet of 18", 3890 lineal feet of $24 "$, and 2730 lineal feet of 30 " gravity sewers. There is one pumping station with 890 lineal feet of 6" force main.

FLOW AND TEMPERATURE DATA - CONYERS, GA.

As discussed in Chapter 10.0 - COMPONENT TESTING, site specific temperature and flow measurements are the necessary first step in developing a data base for determining the thermal energy available at any particular site of application. Plant effluent flow and temperature data from existing plant instrumentation was obtained for the period 10/14/78 to 11/16/78. Temperature sensors and flow instrumentation are located at the discharge of the treatment facility in the vicinity of the chlorine contact basin. Data for the period $11 / 8 / 78$ through $11 / 14 / 78$, selected as representative of plant conditions during the subject period, is presented graphically (Flow vs. Time, and Temperature vs. Time) in Figure $8-5$ and summarized in Table 8-3.

: $\vdots:$

Flow was noted to be on a daily cycle with miscellaneous peaks and dips during the weekdays. Weekend flow was relatively constant. Weekday flow rates averaged $0.662 \mathrm{MGD}$, and weekend rates averaged $0.534 \mathrm{MGD}$. Overall, flow rates did not vary from the average to the extent that might be expected from experience with wastewater flow cycles. Weighted average daily flow (ADF) for the seven day period was 0.623 MGD. 
CONYERS, GEORGIA

SEWAGE TREAT MENT PLANT

$11-8-78-11-14-78$

FIGURE 8-5

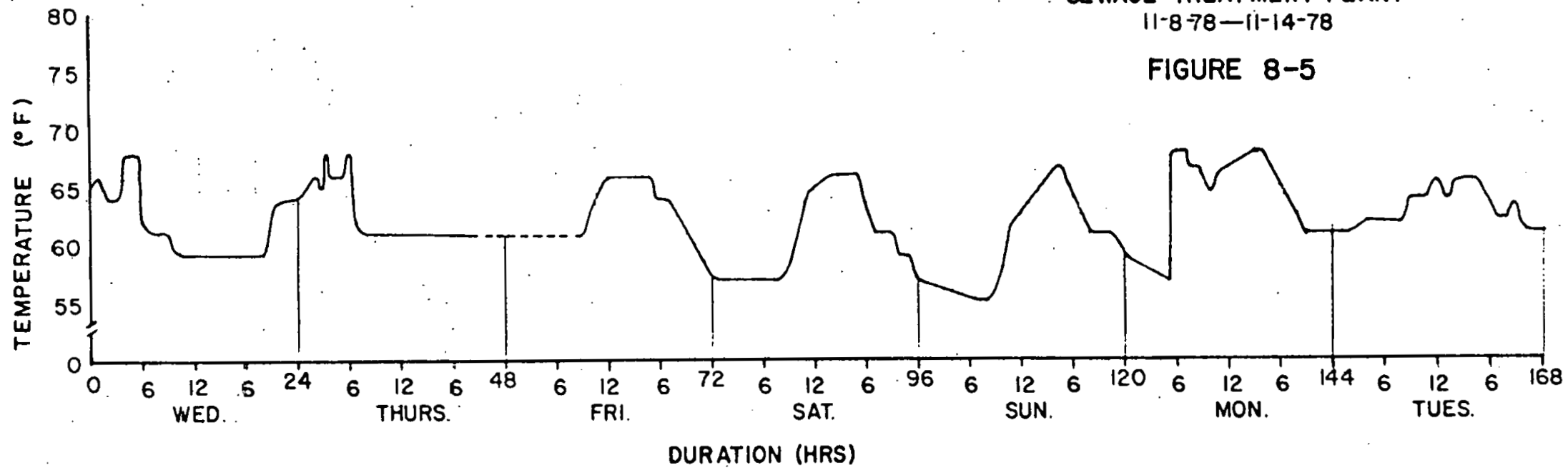

$\ddot{v}$

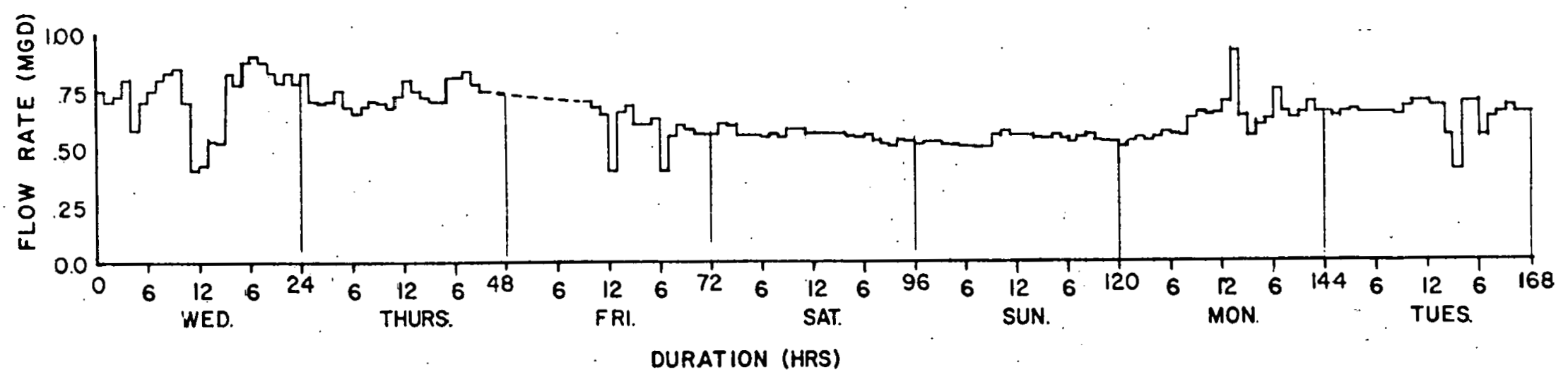




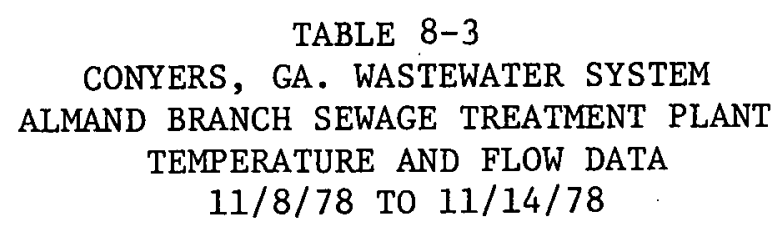

PLANT EFFLUENT TEMPERATURE

\begin{tabular}{lll}
\multicolumn{1}{c}{ DAY } & ${ }^{\circ} \frac{\mathrm{LOW}}{\mathrm{C} /{ }^{\circ} \mathrm{F}}$ & $\frac{\mathrm{HIGH}}{{ }^{\circ} \mathrm{C} /{ }^{\circ} \mathrm{F}}$ \\
WED $11 / 8$ & $14 / 57$ & $20 / 68$ \\
THUR $11 / 9$ & $16 / 61$ & $20 / 68$ \\
FRI $11 / 10$ & $14 / 57$ & $19 / 66$ \\
SAT $11 / 11$ & $14 / 57$ & $19 / 66$ \\
SUN $11 / 12$ & $13 / 55$ & $19 / 66$ \\
MON $11 / 13$ & $14 / 57$ & $20 / 68$ \\
TUES $11 / 14$ & $16 / 61$ & $19 / 66$
\end{tabular}

$\underline{\text { FLOW }}$

HIGH: $\quad 41,667 \frac{\mathrm{gal}}{\mathrm{hr}}(\simeq 1.0 \mathrm{MGD}) 11 / 131: 00 \mathrm{pm}$

LOW: $\quad 7083 \frac{\mathrm{gal}}{\mathrm{hr}}(\simeq .17 \mathrm{MGD}) 11 / 8 \quad 12: 00$ noon

AVG. WEEKDAY: $\quad 0.662$ MGD

AVG. WEEKEND: $\quad 0.534$ MGD

.WBIGHTED ÄVG.

DAILY FLOW: $\quad .623$ MGD 
Plant effluent temperatures showed a relatively smooth plot, rangïng only from $55^{\circ} \mathrm{F}$ to $68^{\circ} \mathrm{F}$. There seemed to be a pattern of higher temperatures during the daytime hours, likely due to the long retention time - 20 hours of the aeration tanks.

It is expected that, for this section of the Conyers/Rockdale County wastewater collection and treatment system, the operating conditions - flow and temperature - will continue to exhibit the trends illustrated in the foregoing graphs. Flow rates may show some escalation, to the extent that they reflect the growth in this area of the county. Extreme seasonal influences may reducc the operating temperatures somewhat, but will not significantly affect the availability of thermal energy at this source.

From the above characterization of the Conyers wastewater conditions, it is apparent that significant amounts of thermal energy are available for reclaim with a Conyers HP-WHR system. The next report section develops an estimate of the quantities of thermal energy available at the proposed plant location.

\section{THERMAL ENERGY ESTIMATE}

For the purposes of developing a nationwide projection of available thermal energy from wastewater, flow was defined as a function of national population, and industrial wastewater discharges (a significant source of rejected thermal energy) were ignored due to insufficient data. However, a more meaningful estimate can be developed on a site-specific basis because considerations of the local wastewater conditions may be taken into account. The temperature and flow data from the Conyers facility will serve as the basis for this energy estimate.

System design for the Conyers facility dictates that wastewater be extracted from the aeration basins and pumped to the central station (which would likely be sited at the treatment plant). Thus the combined capacity, 
826,000 gallons, of the two aeration basins would be utilized as system storage to absorb the diurnal fluctuations in flow and temperature. Therefore the figures for average plant effluent flow and temperature can be considered typical of the wastewater conditions which could be expected for the HP-WHR central station equipment. It is duly noted that the conditions documented herein are from a somewhat arbitrarily selected one-week period which may or may not have been representative of conditions to be expected over an annual cycle. However, inspection of the seven-day flow cycle reveals no characteristics which would indicate it to be atypical. Further, since there is adequate capacity within the system to "accumulate" the surges in influent wastewater flow and complete the treatment process at a more steady flow rate, it is anticipated that the documented weekly flow cycle can indeed be taken as typical. The temperature of the wastewater, on the other hand, will likely exhibit more significant variations due to seasonal influences. However, again due to the adequate storage capacity within the treatment system, it is anticipated that the affect of ambient temperature changes on the wastewater temperature will be moderated somewhat. The temperature and flow data presented here and utilized in the following estimate of available thermal energy are presented primarily to provide a firm base for this "ballpark" estimate. Figures 8-6, and 8-7, Temperature vs. Duration and Flow vs. Duration, respectively, for the period $11 / 8 / 78$ through 11/14/78, illustrate that the average conditions, Flow .623 MGD and Temperature $62^{\circ} \mathrm{F}$, are indeed indicative of typical conditions throughout the subject period (Note that 12 hours has been omitted from the one week period due to a blank in the temperature and flow data print outs.) 

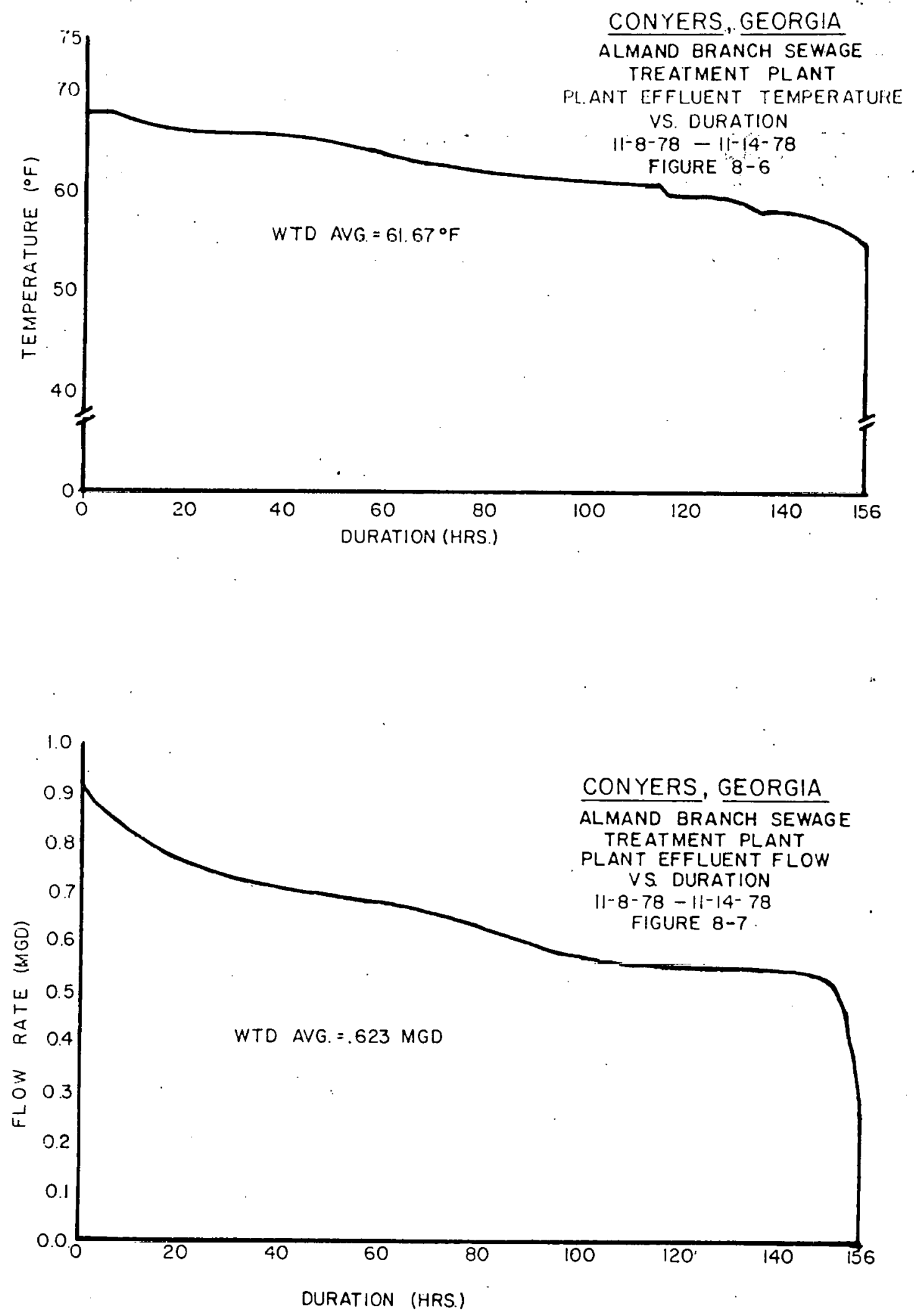
From Chapter 2.0 - POTENTIAL APPLICATIONS, the total amount of heat available from the thermal supply (wastewater) can be calculated from equation $(2-2)$, shown below:

$$
Q=W C(\Delta T)
$$

Where:

$$
\begin{aligned}
& Q=\text { total heat, Btu } \\
& \text { W - flow of wastewater, 1bm } \\
& \mathrm{C} \text { - specific heat of wastewater (assumed to be } 1.0 \mathrm{Btu} / 1 \mathrm{bm}-{ }^{\circ} \mathrm{F} \text { ) } \\
& \begin{array}{l}
\Delta T \text { - change in temperature in supply medium across the central station } \\
\text { equipment heat exchanger, }{ }_{F}
\end{array}
\end{aligned}
$$

Inspection of equation (2-2) reveals that for a given flow of wastewater, the quantity of heat available is directly proportional to $\Delta \mathrm{T}$. Theoretically, heat could be removed from a water source down to approximately $32^{\circ} \mathrm{F}$. However, due to equipment operating characteristics, a practical lower limit of $40^{\circ} \mathrm{F}$ can be set. General HVAC system design practice dictates a $\Delta \mathrm{T} \simeq 10^{\circ} \mathrm{F}$. However, for this particular application, larger $\Delta \mathrm{T}^{\prime}$ s may be necessary or desirable. Therefore, in order to bracket the operating conditions which may be in effect at the central station, $\Delta \mathrm{T}^{\prime} \mathrm{s}$ of $10^{\circ} \mathrm{F}$ (typical of HVAC operation), $15^{\circ} \mathrm{F}$, and $20^{\circ} \mathrm{F}$ (the approximate maximum which could be expected under the wastewater conditions at Almand Branch) will be considered. Estimates of the thermal energy available for reclaim at Conyers' Almand Branch sewage treatment plant can now be calculated.

As an example, and utilizing equation (2-2), the energy reclaimed from community wastewater would be calculated thusly:

$$
\begin{aligned}
& \text { AVG. DAILY FLOW }-623,000 \text { gallons } \\
& \qquad \begin{aligned}
\Delta \mathrm{T}- & 20^{\circ} \\
\text { DAILY }_{\text {DA }} & 623,000 \frac{\mathrm{gal}}{\mathrm{day}} \times\left(8.33 \frac{1 \mathrm{bm}}{\mathrm{gal}}\right) \times\left(1.0 \frac{\mathrm{Btu}}{1 \mathrm{bm}-\mathrm{O}} \overline{\mathrm{F}}\right) \times\left(20^{\circ} \mathrm{F}\right) \\
= & 103,791,800 \frac{\mathrm{Btu}}{\mathrm{day}} \\
& 162
\end{aligned}
\end{aligned}
$$


Derived through this estimative methodology, Table 8-4 summarizes the quantities of thermal energy potentially available, on a daily and annual basis, to an HP-WHR system installed at the proposed location in Conyers and operating at the various conditions discussed in the foregoing paragraphs.

\author{
TABLE 8-4 \\ HEAT AVAILABLE FROM WASTEWATER \\ CONYERS, GA. \\ ALMAND BRANCH WASTEWATER FACILITY
}

\begin{tabular}{|c|c|c|c|}
\hline \multirow{2}{*}{$\frac{\Delta \mathrm{T}}{(O F)}$} & \multicolumn{2}{|c|}{$\begin{array}{l}\text { WASTEWAIER } \\
\text { CONDITIONS }\end{array}$} & \multirow[t]{2}{*}{$\begin{array}{c}\text { Q }_{\text {DAILY }} \\
\text { AVG. DAILY } \\
\frac{\text { HEAT RECOVERY }}{\text { (BTU/DAY) }}\end{array}$} \\
\hline & $\overline{I N}(O F)$ & OUT(OF) & \\
\hline 10 & 62 & 52 & $51.90 \times 10^{6}$ \\
\hline 15 & 62 & 47 & $77.84 \times 10^{6}$ \\
\hline 20 & 62 & 42 & $103.79 \times 10^{6}$ \\
\hline
\end{tabular}

An important consideration in the application of an HP-WHR system to a community is the balance between the portions of the community served by the wastewater collection and treatment system and the portion of the community proposed for service by the heat pump system. Based upon the above estimate of thermal energy available at the Conyers plant and upon the assessment of the proposed service area, the space conditioning requirements of approximately 400 houses could be served under this system application. From the measured average flow rate of 623,000 gallons per day and utilizing the 100 gallon per capita per day design figure for wastewater consumption (from Chapter 2.0), an equivalent wastewater system service area of 6230 persons can be defined. Further agregating the population served by the average 3.26 persons per household, in conyers ${ }^{56}$ defines an equivalent service area of 1911 houses. The balance between the wastewater system service area (effectively the thermal energy supply to the heat pump system) and the HP-WHR system service area is 
thus 1911 houses to 400 houses, or approximately 4.8 to 1 . It should be re-emphasized that, as discussed in Chapters 2.0 and 4.0 , variations in climate can significantly affect the balance ratio, even to the extent of doubling the required number of houses served by the wastewater system for each house on the HP-WHR system. However, for this particular application and for communities exhibiting similar characteristics, the 4.8 to 1 balance ratio appears quite workable. 


\subsection{CONYERS SYSTEM DESCRIPTION}

The Conyers community proposed as the system service area offers several unique characteristics which enhance the viability of application of the Heat Pump-Wastewater Heat Recovery System concept. First, the wastewater treatment plant proposed for service as the HP-WHR system thermal source is located in. close proximity to the anticipatediservice area. Second, the anticipated service area is comprised of a mixture of existing residential units and land developed for residential: construction in the immediate future. This mixture represents. an excellent market potential for the heat pump system in new homes as well as for the retrofit of existing units. Third, the anticipated service area is projected, due to the historical high growth rate trend of the Conyers community, to reach its ultimate build-out potential within five to ten years. This rapid expansion will allow phasing of the central plant and distribution system to accommodate increases in thermal load and number of units served. Finally; the proposed service area is located outside the Conyers corporate limits and within the jurisdiction of the county government. With one less government.entity to deal with, the creation of an authority-type ownership and operation arrangement whould be somewhat. simplified.

The basic: system concept for the Conyers HP-WHR. facility is essentially the same. as the: cascaded heat pump concept presented in. the initial system discussion of Chapter 1.0. One addition will be made to the system in the form of an evaporative cooling device for the summer (cooling) mode of operation. The evaporative cooling device (cooling tower) will be used in lieu of the central heat pump and will reject the heat gain of the housing units to the. atmosphere rather: than. into the wastewater effluent. Figure $8-8$ is a. single: 


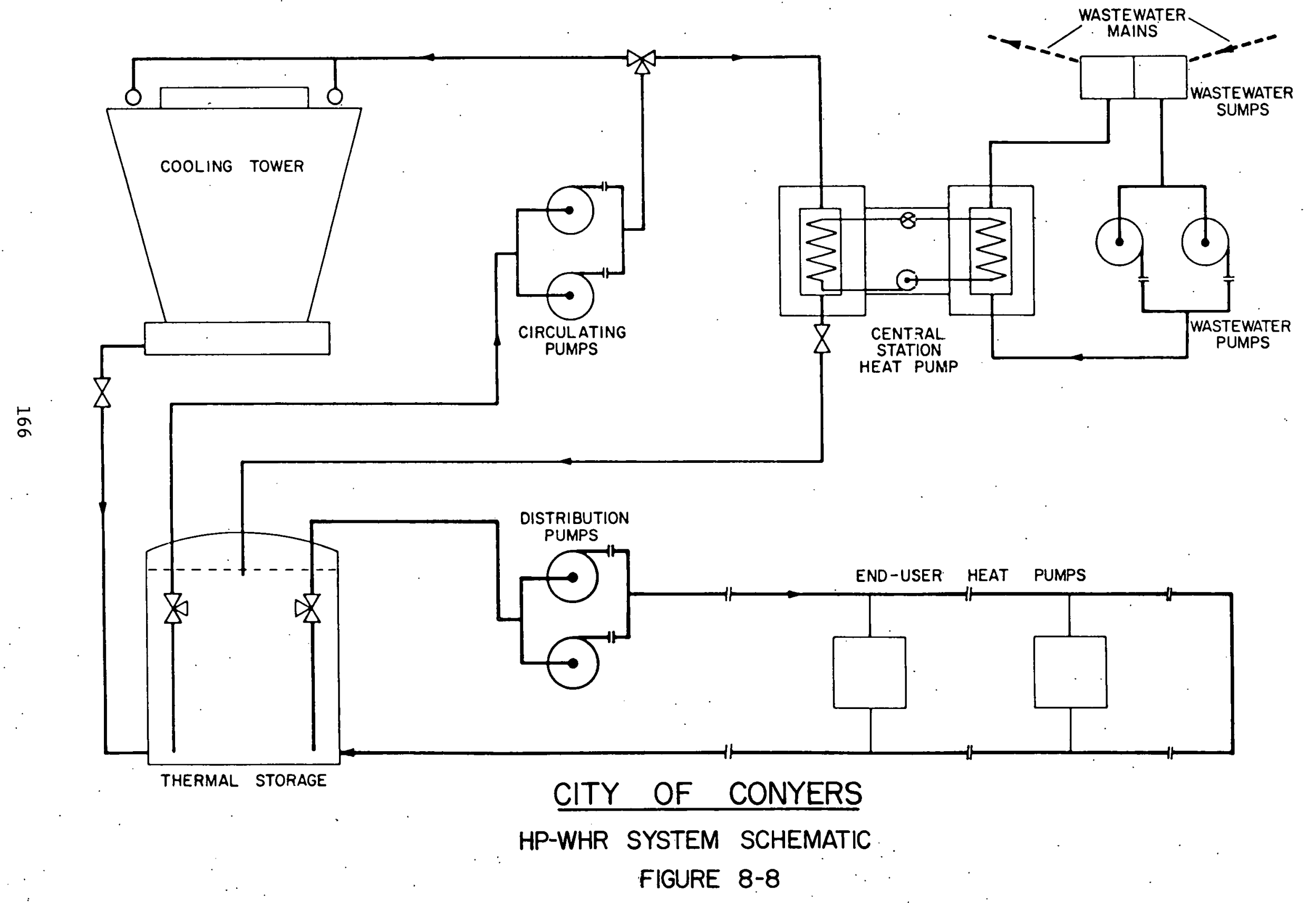


line schematic diagram of the basic system design.

The system is designed for operation in a heating or cooling mode. In the heating mode, wastewater is extracted from the treatment process immediately after primary clarification and pumped by the sewage pumps from the sump to the central heat pump. Low grade thermal energy is extracted from the wastewater in the heat pump evaporator, and the sewage is returned to the treatment: process. The thermal energy is transferred, via the refrigerant cycle, into the thermal transport media (potable water) at the heat pump condenser. The transport media then flows to the thermal storage vessel. The valve and piping arrangement inside the vessel and on the suction line of the distribution pumps takes advantage of the temperature stratification within the tank to extract the warmest media at the uppermost fluid levels for distribution. Water: is distributed into the community at approximately $90^{\circ} \mathrm{F}$ with return at approximately $80^{\circ} \mathrm{F}$. The cooler transport media at the lower fluid levels within the vessel is extracted and recirculated through the circulating pumps and the central heat pump to be thermally "re-charged". The cooling tower circuit is effectively excluded from the system in the heating mode through proper valving.

In the cooling mode, the cooler transport media, approximately $80^{\circ} \mathrm{F}$, is extracted from the lower levels of the storage vessel and distributed into the community. Warm water, at approximate $1 y=90^{\circ} \mathrm{F}$, is returned from the community and dumped into the thermal storage vessel, where it immediately stratifies according to the fluid temperatures within the vessel. The warmer media is then extracted from the upper fluid levels and circulated via the circulating pumps through the cooling tower where the excess thermal energy is rejected into the atmosphere. The now-cool media is then returned from the cooling tower basin to the storage vessel and again made available for distribution 
into the community. In this mode, the central heat pump component is effectively excluded from the system through proper valving.

In either mode, the end-user heat pumps are cycled in response to individual building loads, utilizing the thermal transport media as a heat source or sink, as appropriate.

During mild winter conditions and during the transitional seasons, it is possible that simultaneous heating and cooling may occur at different locations on the system. This situation can be expected particularly when the system serves a composite service area of commercial and residential structures. Operation in this mode will tend to benefit overall system performance because the heat rejected into the thermal transport media during space cooling is an effective energy addition which can be utilized at other locations on the system. In effect, the system will act to transfer unwanted heat from one . location to another where it is required.

The HP-WHR system central station will be sited on the grounds of the existing wastewater treatment facility, with the central station layout as illustrated on Figure 8-9. Piping interconnection with the existing treatment system will be made in such a manner so as to enable the HP-WHR system to utilize the full retention capacity of the two oxidation ditch components as effective warm wastewater storage.

The warm water distribution system into the community will be designed and routed as illustrated in Fígure 8-10. One major distribution trunk line will be routed out of the southwest corner of the central plant/sewage treatment plant site and into the Zone 1 servịce area. A second distribution trunk. line will be routed from the southeastern corner of the site, skirting the boundaries of the undeveloped zone 2, and into the partially developed Zone 3 . 


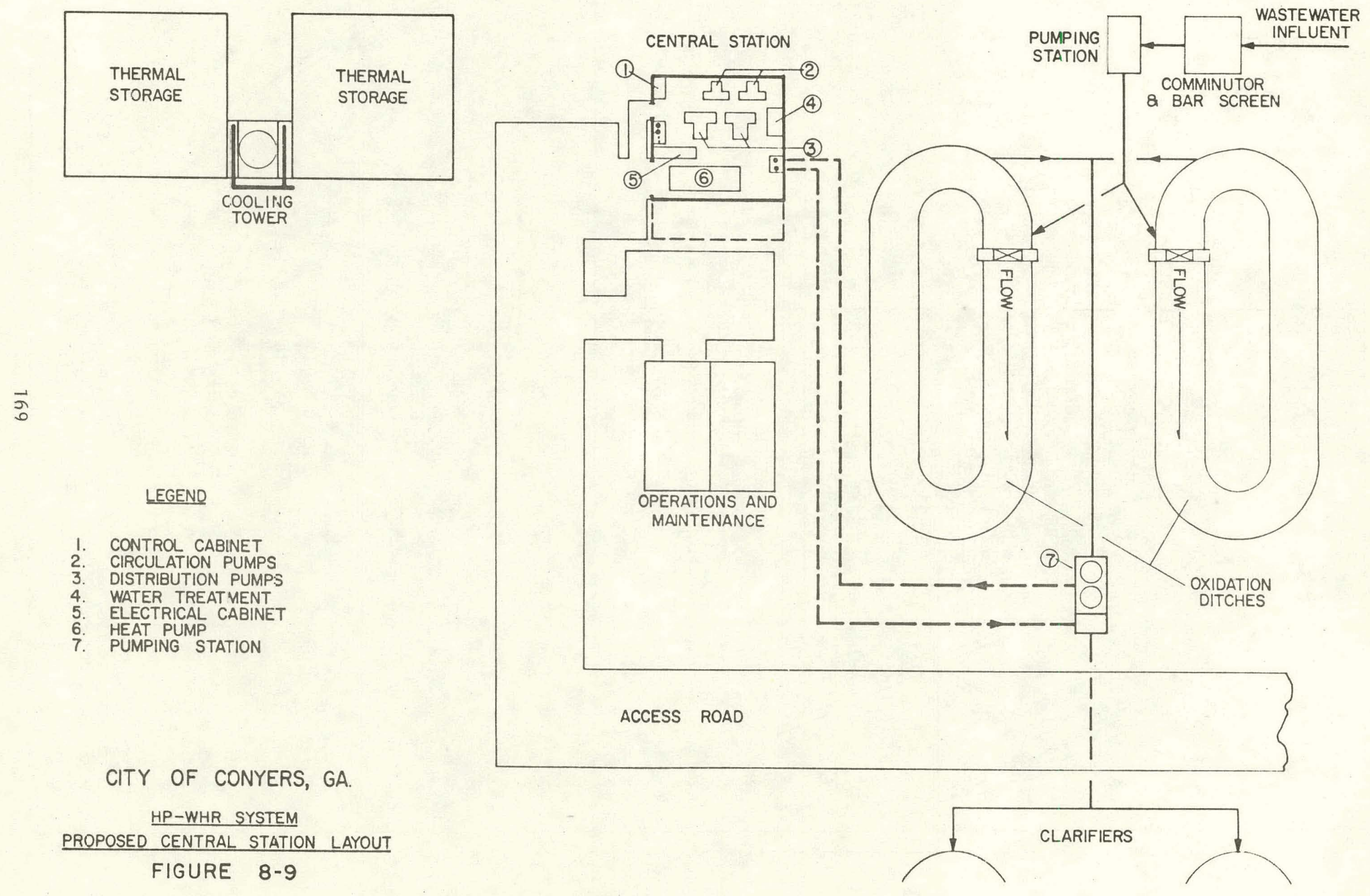




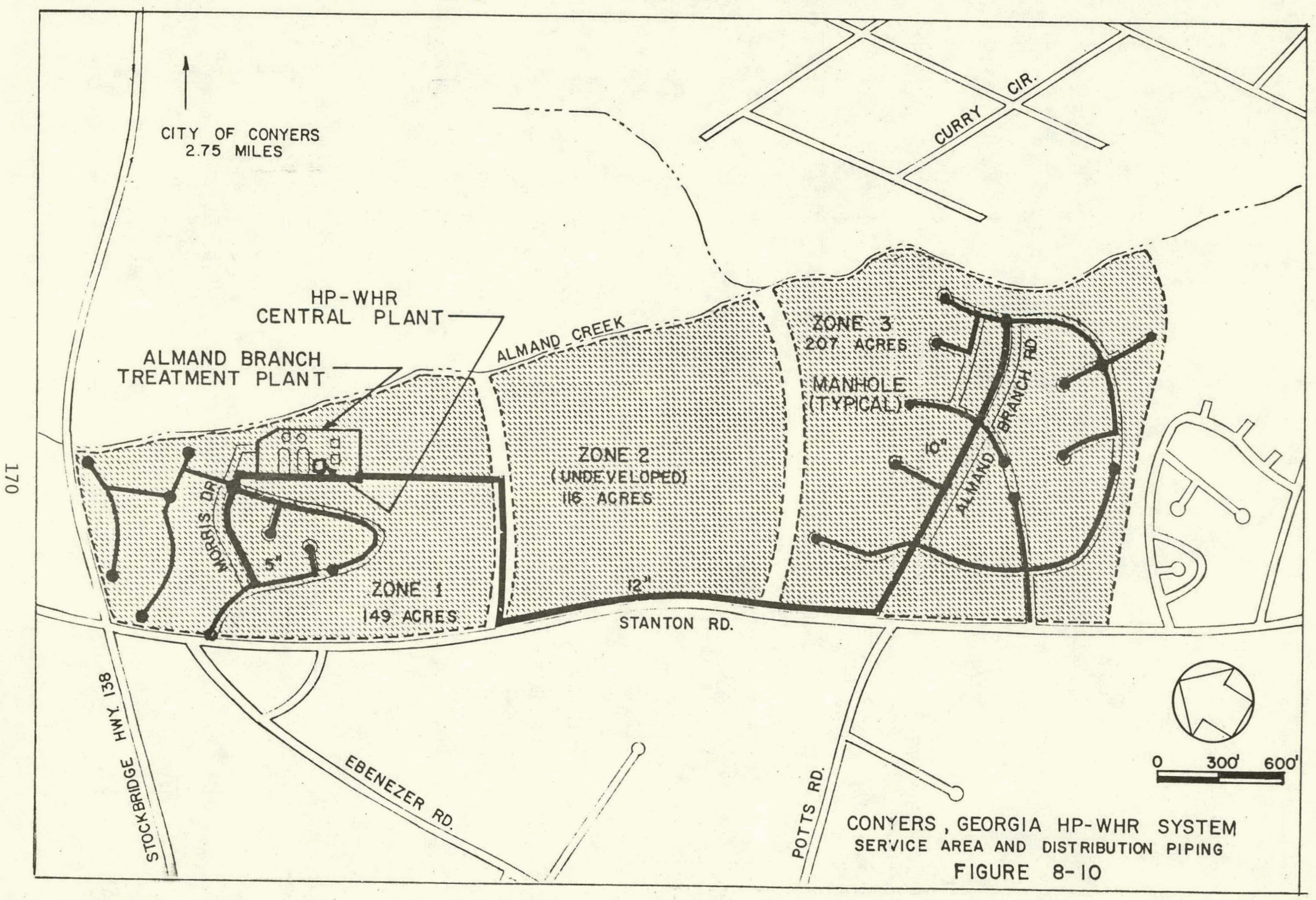


This line will be appropriately sized to handle the full build-out potential of both zones. Feeder lines for each zone are specified and routed as per typical water distribution system design practice.

System design and component specification for the Conyers HP-WHR system is presented in the following report sections.

\subsubsection{SYSTEM DESIGN CALCULATIONS}

The major components comprising the HP-WHR system which are to be specified in a system development study include the central heat pump, the thermal storage vessel, the cooling tower, auxiliary pumps, and end-user heat pumps. However, since for any system the end-user heat pump specification will be necessarily structure-specific, sizing of those components will not be addressed in this report section. The remainder of the major component design calculations are presented in the following paragraphs.

\section{Central Heat Pump}

The central heat pump will be specified to deliver the estimated average daily heating requirement during the peak heating month of January. The equivalent load on the central heat pump is determined by first calculating the heat to be extracted from the wastewater flow through the following equation:

$$
\begin{aligned}
Q_{\text {wastewater }}=\left\{\left[Q_{\text {heat req'd }}\left(1-\frac{1}{C .0 . P \cdot \text { end-user }}\right)\right]\right. \\
\\
\times \frac{\left.\left(1-\frac{1}{C .0 . P \text { central heat pump }}\right)\right\}}{\text { DAYS IN PERIOD }}
\end{aligned}
$$


Substituting the following values:

$$
\begin{aligned}
& Q_{\text {heat req'd }}=2.915 \times 10^{9} \text { BEu-from Table } 8-2 \\
& \text { C.0.P. end-user }=2.9- \begin{array}{l}
\text { selected as a median value for the heating } \\
\text { performance of the hydronic units assessed } \\
\text { in Reference } 7
\end{array}
\end{aligned}
$$

C.0.P. central heat pump $=4.5$-from the C.O.P. vs. Capacity Curve of Reference 5

Thus,

$$
\begin{aligned}
Q_{\text {wastewater }} & =\frac{\left[2.915 \times 10^{9}\left(1-\frac{1}{2.9}\right)\right]\left(1-\frac{1}{4.5}\right)}{31} \\
& =47.92 \times 10^{6} \mathrm{Btu} / \text { day }
\end{aligned}
$$

Thermal storage will be provided in the system in order to lower the nominal peak load seen by the central station equipment. Thus, the central heat pump will be sized to provide the above heating requirement over 18 hours, operating at nominal full load. Operation on this basis yields:

$$
\begin{aligned}
\text { Heat Extraction Rate } & =\frac{47.92 \times 10^{6}}{18} \\
& =2.66 \times 10^{6} \mathrm{Btu} / \mathrm{hr}
\end{aligned}
$$

Conditions at the central heat pump evaporator dictate wastewater intake at $62^{\circ} \mathrm{F}$ (from section 8.2 .8 ) and a $\Delta \mathrm{T}$ drop of $10^{\circ} \mathrm{F}$. Thus, the required wastewater flow rate is determined by the equation below:

$$
\begin{aligned}
\text { Flow Rate } & =\frac{\mathrm{HER}}{\left(8.33 \frac{\mathrm{lbm}}{\mathrm{gal}}\right)\left(60 \frac{\mathrm{min}}{\mathrm{hr}}\right)\left(10^{\circ} \mathrm{F}\right)\left(1.0 \frac{\mathrm{Btu}}{1 \mathrm{bm}-{ }^{\circ} \mathrm{F}}\right)} \\
& =\frac{2.66 \times 10^{6}}{(8.33)(60)(10)(1.0)} \\
& =532 \mathrm{GPM}
\end{aligned}
$$


At this point it may be noted that the required wastewater flow rate exceeds the average instantaneous flow through the treatment plant - 432 GPM $(0.623 \mathrm{MGD} /(24)(60))$. However, it should be reiterated that central heat pump operation is specified to provide the average daily load over an 18 hour period and that the resulting daily required flow is then 0.574 MGD (532 GPM $x$ $60 \times 18)$. The additional flow - 100 GPM average during central heat pump operation - can be obtained when necessary through pulldown of the thermal supply medium - wastewater - from the retention capacity of the oxidation ditch components of the wastewater treatment facility.

Two other options for central heat pump operation also exist which would alleviate the apparent flow rate mismatch. The first option would require supplying the estimated average daily heating requirement over a longer period of operation. If the design flow rate of wastewater through the central heat pump evaporator is reduced to the average flow figure of $432 \mathrm{GPM}$, the necessary heat extraction rate would be reduced to $2.16 \times 10^{6} \mathrm{Btu} / \mathrm{hr}$, and the time of operation would be increased to approximately 22 hours.

The second option would involve specifying a slightly larger $\Delta \mathrm{T}$ across the evaporator. At the calculated heat extraction rate of $2.66 \times 10^{6} \mathrm{Btu} / \mathrm{hr}$ (for 18 hour operation) and utilizing the average flow figure of 432 GPM, the required $\Delta \mathrm{T}$ is found to be $12.3^{\circ} \mathrm{F}$, obviously within the range of reasonable operation for the type machine being considered for: service.

It is expected, however, that specifying the central heat pump evaporator for the extraction rate of $2.66 \times 10^{6} \mathrm{Btu} / \mathrm{hr}$ and flow rate of $532 \mathrm{GPM}$ will provide an appropriately conservative design.

The operating parameters at the condenser can be defined through similar calculations : 


$$
\begin{aligned}
\text { Heat Rejection Rate } & =\text { HER }\left(1+\frac{1}{\text { C.0.P. }}\right) \\
& =2.66 \times 10^{6}\left(1+\frac{1}{4.5}\right) \\
& =3.25 \times 10^{6} \mathrm{Btu} / \mathrm{hr}
\end{aligned}
$$

System circulating water intake to the condenser will be at $80^{\circ} \mathrm{F}$ and a rise of $10^{\circ} \mathrm{F}$ will be achieved across the heat exchanger.

$$
\begin{aligned}
\text { Flow Rate } & =\frac{\mathrm{HRR}}{(8.33)(60)(10)(1.0)} \\
& =\frac{3.25 \times 10^{6}}{(8.33)(60)(10)(1.0)} \\
& =650 \mathrm{GPM}
\end{aligned}
$$

The compressor for the central station unit will receive shaft power from an electric motor drive; performance will be on the following basis:

$$
\begin{aligned}
W_{c} & =\frac{(\text { HER })\left(\frac{1}{C .0 . P} \cdot\right. \text { central heat pump }}{3413 \frac{\text { Btu }}{\mathrm{KWH}}} \\
& =\frac{\left(2.66 \times 10^{6}\right)}{(4.5)(3413)} \\
& =173 \mathrm{KW}
\end{aligned}
$$

The central heat pump will be constructed with shell-and-tube condenser and evaporator and a centrifugal compressor. The heat pump will have approximately thë'same physical dimensions and appearance as a nominal 250 ton centrifugal water chiller used in air conditioning applications. Due to the comparatively low capacity requirement for the central station machine, one unit will be specified to serve the full requirements of the HP-WHR system. The reliability of this type machine is typically high; however, thermal storag 
will be appropriately sized to provide effective back-up capacity in the event of central heat pump failure.

\section{Thermal Storage}

Inspection of the wastewater flow cycle at the subject Conyers treatment plant (presented in section 8.2.8) reveals that the characteristic low flow period during the seven-day flow cycle had an approximate 60 hour duration. In order to provide adequate thermal energy supply capacity for the system during these low flow periods, the thermal 'storage component will be sized for a nominal 72 hour period (making an allowance for a $+20 \%$ variance in duration from the flow cycle documented in section 8.2 .8 ) under January heating demand conditions. The nominal 72 hour capacity will also provide an adequate downtime "window" for the central heat pump in the event of a failure requiring emergency repairs or for necessary scheduled maintenance.

Allowable temperature pulldown within the vessel will be designed at $40^{\circ} \mathrm{F}$. The primary consideration in defining this range is the effect on end-user heat pump performance. According to the equipment assessment of Reference 7 , the performance of a hydronic heat pump, with nominal C.0.P. of 2.910 at Standard ARI rating conditions (the figure previously utilized in assessing central heat pump thermal loads) improves to a C.0.P. of 3.084 at the HY-WHR design condition of $90^{\circ} \mathrm{F}$ supply water. Conversely, as supply water temperature drops to the design lower limit of $50^{\circ} \mathrm{F}, \mathrm{C} .0 . \mathrm{P}$. drops only to 2.852 . Therefore, it is expected that the $40^{\circ} \mathrm{F}$ pulldown will provide more than adequate thermal storage capacity, and that during all but the peak heating period, end-user heat pump performance will equal or exceed the nominal 2.91 C.0.P. The physical capacity of the thermal storage component is computed as 
follows:

$$
\begin{aligned}
Q_{\text {thermal storage }} & =\frac{\left(2.915 \times 10^{9} \mathrm{Btu}\right)\left(1-\frac{1}{2.9}\right)}{744 \mathrm{hrs}} \times 72 \mathrm{hrs} \\
& =185.16 \times 10^{6} \mathrm{Btu} \\
M_{\text {water storage }} & =\frac{185.16 \times 10^{6} \mathrm{Btu}}{\left(40^{\circ} \mathrm{F}\right)\left(1.0 \frac{\mathrm{Btu}}{\mathrm{Lbm}-{ }_{\mathrm{F}}}\right)} \\
& =4,628,908 \mathrm{Lbm} \\
& =555,691 \mathrm{GALLONS} \\
& =74,300 \mathrm{FT}^{3}
\end{aligned}
$$

This necessary capacity will be provided in the form of two square tanks with dimensions of $45^{\prime} \times 45^{\prime} \times 20^{\prime}$ (depth). The vessels will be field constructed of steel reinforced concrete. Installation will be partially below grade with the exposed vertical surfaces being earth bermed for improved heat retention.

\section{Cooling Tower}

The cooling tower component of the Conyers HP-WHR system will be specified to dissipate the average daily heat gain on the system during the peak cooling month of July, as determined below:

$$
\begin{aligned}
& Q_{\text {avg clg load }}=\frac{Q_{\text {monthly }}\left(1+\frac{1}{C .0 . P} \text { end-user }_{\text {cooling }}\right)}{\text { DAYS IN MONTH }} \\
& =\frac{\left(2.184 \times 10^{9}\right)\left(1+\frac{1}{2 \cdot 5^{\star}}\right)}{31} \\
& =98.28 \times 10^{6} \mathrm{BTU} / \mathrm{DAY}
\end{aligned}
$$


The required heat rejection rate will be determined on the basis of 18 hours operation per day at nominal full load, thus:

$$
\begin{aligned}
\mathrm{HRR} & =\frac{98.28 \times 10^{6}}{18} \\
& =5.46 \times 10^{6} \mathrm{Bcu} / \mathrm{hr}
\end{aligned}
$$

System operating parameters dictate a $10^{\circ} \mathrm{F}$ temperature drop in the circulating water. Required cooling tower flow is then determined as:

$$
\begin{aligned}
\dot{\mathrm{M}}_{\text {cooling tower }} & \left.=\frac{5.46 \times 10^{6} \frac{\mathrm{Btu}}{\mathrm{hr}}}{\left(8.33 \frac{\mathrm{LBM}}{\mathrm{GAL}}\right)\left(60 \frac{\mathrm{MIN}}{\mathrm{HR}}\right)\left(10^{\circ} \mathrm{F}\right)\left(1.0 \frac{\mathrm{BTU}}{\mathrm{LBM}}-{ }^{\circ} \mathrm{F}\right.}\right) \\
& =1092 \mathrm{GPM}
\end{aligned}
$$

A modular, pre-constructed tower with a nominal flow rating of $1200 \mathrm{GPM}$ at the required $10^{\circ} \mathrm{F}$ TD will be selected. Fan horsepower will be $30 \mathrm{HP}$.

\section{Auxiliary Pumps}

The three pump functions on the HP-WHR system will be specified as discussed below:

Wastewater pumps will be variable speed types, each capable of delivering total required flow at design pressure drops. The flow rate required for each pump is 535 GPM at an estimated dynamic head of $60 \mathrm{ft}$. of water. This head rating makes adequate allowance for piping and central station heat exchanger pressure drops.

Circulating pumps will each be sized for one half of the total required flow of 600 GPM. Pump head required will be approximately $90 \mathrm{ft}$. of water. Distribution pumps will each be sized for one half of the total required 
flow to the end-users. One pump will be a variable speed type. The total flow through the distribution system will be based on serving the heat dissipation requirements at peak conditions with a $10^{\circ} \mathrm{F}$ temperature rise. Based on a nominal heat rejection requirement of 16,740 Btu per ton of air conditioning, the required flow rate for a 782 ton peak load is 2618 GPM. (Heating season peak flow requirement is approximately 1350 GPM.) Total pumping head at peak flow will be $500 \mathrm{ft}$. of water. This head includes allowances for end-user system and distribution system piping pressure drops.

\section{Distribution Piping}

The required circulating water flow rates at peak load will determine distribution pipeline sizing. Peak heating and cooling loads for each zone are first determined through the procedures outlined in section 8.2 .7 and utilizing the appropriate zonal data from the computer analysis. The required flow rates per zone are then calculated and piping sizes are selected to yield proper line velocities and acceptable pressure drops.

\section{$\underline{\text { ZONE R-1 }}$}

$$
\begin{aligned}
\text { PEAK HEATING LOAD } & =\frac{\left[\left(3.729 \times 10^{6}\right)\left(1-\frac{1}{2.9}\right)\right](53)}{(701)} \\
& =0.77 \times 10^{6} \mathrm{Btu} / \mathrm{hr} \\
\text { PEAK COOLING LOAD } & =\frac{\left(55,000 \mathrm{ft}^{2}\right)(16,740 \mathrm{Btu} / \mathrm{hr}) *}{550 \mathrm{ft}^{2} / \mathrm{PEAK} \mathrm{A-C} \mathrm{TON}} \\
& =1.67 \times 10^{6} \mathrm{Btu} / \mathrm{hr} \quad \begin{array}{l}
\text { *Heat Rejection Rate based } \\
\text { on the } 2.53 \text { cooling C.0.P. } \\
\text { of the subject hydronic } \\
\text { unit. }
\end{array}
\end{aligned}
$$




$$
\begin{aligned}
\dot{M}_{\text {heating }} & =\frac{\left(0.77 \times 10^{6}\right)}{(8.33)(60)(10)(1.0)} \\
& =154 \mathrm{GPM} \\
\dot{M}_{\text {cooling }} & =\frac{1.67 \times 10^{6}}{4998} \\
& =334 \mathrm{GPM}
\end{aligned}
$$

ZONE R-2

$$
\begin{aligned}
\text { PEAK HEATING LOAD } & =\frac{\left[\left(1.22 \times 10^{9}\right)\left(1-\frac{1}{2.9}\right)\right](53)}{(701)(24)} \\
& =2.52 \times 10^{6} \mathrm{Btu} / \mathrm{hr} \\
\text { PEAK COOLING LOAD } & =\frac{(180,000)(16,740)}{550} \\
& =4.58 \times 10^{6} \mathrm{Btu} / \mathrm{hr} \\
\dot{\mathrm{M}}_{\text {heating }} & =\frac{\left(2.52 \times 10^{6}\right)}{4998} \\
& =504 \mathrm{GPM} \\
\dot{M}_{\text {cooling }} & =\frac{\left(5.48 \times 10^{6}\right)}{4998} \\
& =1096 \mathrm{GPM}
\end{aligned}
$$

\section{ZONE R-3}

$$
\begin{aligned}
\text { PEAK * HEATING LOAD } & =\frac{\left[\left(1.32 \times 10^{9}\right)\left(1-\frac{1}{2.9}\right)\right](53)}{(701)(24)} \\
& =2.72 \times 10^{6} \mathrm{Btu} / \mathrm{hr} \\
\text { PEAK COOLING LOAD } & =\frac{(195,000)(16,740)}{550} \\
& =5.94 \times 10^{6} \mathrm{Btu} / \mathrm{hr}
\end{aligned}
$$




$$
\begin{aligned}
\dot{M}_{\text {heating }} & =\frac{\left(2.72 \times 10^{6} \cdot\right)}{4998} \\
& =544 \mathrm{GPM} \\
\dot{M}_{\text {cooling }} & =\frac{\left(5.94 \times 10^{6}\right)}{4998} \\
& =1188 \mathrm{GPM}
\end{aligned}
$$

Obviously, the circulating water flow rates into each zone during the cooling mode will be the governing criteria in distribution pipe size selection, Pipe sizes and the corresponding flow rates, velocities, and pressure drops for each distribution system piping segment are presented in Table 8-5.

TABLE 8-5:

DISTRIBUTION PIPING SPECIFICATIONS

$\begin{array}{lcccc}\text { LOCATION } & \frac{\text { FLOW RATE }}{(G P M)} & \frac{\text { PIPE SIZE }}{(\text { INCHES })} & \frac{\text { VELOCITY }}{\text { FPS }} & \frac{\text { PRESSURE DROP }}{(\text { PSI } / 100 \text { FT })} \\ \text { Trunk Line } & 2618 & 14^{\prime \prime} & 5.46 & .25 \\ \begin{array}{l}\text { Zone R-2 \& R-3 } \\ \text { Trunk }\end{array} & 2284 & 12^{\prime \prime} & 6.48 & .40 \\ \text { Zone R-2 Feeder } & 1096 & 10^{\prime \prime} & 4.47 & .25 \\ \text { Zone R-3 Feeder } & 1188 & 10^{\prime \prime} & 4.85 & .30 \\ \text { Zone R-1 Feeder } & 334 & 5^{\prime \prime} & 5.46 & .90\end{array}$

\subsubsection{SYSTEM COMPONENT DESCRIPTIONS}

1! :

The Heat Pump Waste Heat Recovery Systems analyzed in this report are composed of standard HVAC components commonly used by the residential, commercial and industrial sectors. Some special testing and performance rating may be necessary where the intended HP-WHR application parameters exceed the normal 
operating range of the specific equipment involved. A brief description of each component follows:

Central Heat Pump

The central heat pump is a package unit including compressor and electric drive, heat exchangers, operating and safety controls, interconnecting piping and refrigerant charge. Unit construction and performance will conform to the ARI Standard for centrifugal water chillers accepted by the air conditioning industry.

The evaporator and condenser will each be of shell and tube construction. Water box covers should be of the "marine" type so that removal for tube cleaning and replacement may be easily accomplished. The heat exchanger tubes should be seamless copper and will be individually replaceabile. The compressor selected for service is of centrifugal design with hermetic electric motor drive. Variable inlet guide vanes at the compressor inlet are used to modulate unit capacity by varying refrigerant flow. Screw or reciprocating compressors may be considered for other applications. The motor used for the compressor drive is a squirrel-cage induction type operating at constant speed. The motor will be refrigerant cooled.

Cooling Tower

The cooling towers chosen are of the induced draft, prefabricated type. They will be mounted on field erected structural steel supports installed over the thermal storage basins. The tower design will include non-combustible casing and fill, lower collection basin, distribution headers and an electricdrive fan assembly. 
Pumps

Distribution system pumps will be the horizontal, split-case type. Pump components should be selected for long lasting service. Recommended materials are bronze and steel alloys commonly used for water pumping service. The pumps will be driven by variable speed electric motors:

Circulating pumps used within the central heat recovery plant will be the horizontal, split-case type or end-suction type depending on the manufacturer. Pumps for this service would be similar to pumps used for condenser water service in typical heating and air conditioning applications.

Pumps delivering wastewater effluent to the central heat recovery system should be of the vertical turbine type for sewage pumping service. A non-clogging impeller should be specified and the inlet to the suction of the pump should be protected by a suction strainer. In some cases the pump will require variable speed motor drive.

\section{Thermal Storage}

The thermal storage device will consist of a cylindrical or rectangular tank located schematically between the central heat pump and the distribution system. It will be constructed of steel reinforced concrete and be located partially below ground level. The portions above ground will be earth bermed for structural support and to retard heat loss. The vessel will be insulated with $3 / 4$ inch styrofoam sheathing and will be covered to retard water surface heat loss and evaporation. A piping and valve arrangement within the vessel will serve to make use of temperature stratification within the vessel to provide appropriate temperature supply water to the distribution system or 
return water to the central heat pump unit.

\section{Control Systems}

Automatic controls for the Heat Pump-Wastewater Heat Recovery Systems will be pneumatic or electric types commonly found in industriạl and commercial use for temperature and pressure measurement and valve operation. The limited number of operator functions involved will probably make an electric control system the most economic choice.

\section{Water Treatment System}

A water treatment system to eliminate scale build-up and control bacteriological growth will be incorporated into the distribution water system. Packaged systems for proportional chemical feeding and periodic conductivity analysis are commonly used with refrigeration condenser systems and are similar to the type which will be used with the HP-WHR system.

\section{Piping System (at Central Plant)}

System piping within the central heat recovery plant will be seamless black steel. Connections to equipment will be made with flanges or removable ring type connectors. Valves and piping accessories will be iron-bodied types for the appropriate service classification.

\section{Piping System (Distribution)}

The distribution system piping will be constructed of PVC pressure pipe similar to the types used in potable water distribution systems. Joints will be made by solvent cementing or a mechanical bell and gasket connection. The 
use of plastic piping material will eliminate galvanic corrosion problems and simplify installation. Additionally, the plastic system should offer lower pumping resistance than other materials.

\subsubsection{EXPECTED PERFORMANCE}

In order to develop an estimate of overall system performance which would also take into account the variances in C.O.P. which result from serving the continually changing thermal loads during an annual cycle, an estimate of system performance for each month of a typical year was made. The estimating procedure involved tallying all energy inputs to the system, including central heat pump power, pump work, cooling tower fan work, system auxiliaries power, and end-user heat pump power, and comparing that total (in Btu equivalents) to the net heating or cooling effect provided to the structures within the system service area. Estimating the monthly performance in this manner revealed system performance in the peak heating, peak cooling, and simultaneous heating and cooling modes. Estimates of instantaneous performance were not attempted since thermal storage within the system allows for averaging of absolute peak conditions. The energy consumption figures presented in the performance analysis are considered to be conservative since the level of analysis appropriate to a preliminary study could not take into account operating variables such as the effects of varying condenser water temperature below design conditions or : higher than average temperatures at the thermal source during the heating season. The general assumptions in effect for the performance analysis are as follows: Distribution Media Temperatures

HEATING MODE

Supply

Return

$$
90^{\circ} \mathrm{F}
$$

$80^{\circ} \mathrm{F}$
COOLING MODE

$$
80^{\circ} \mathrm{F}
$$$$
90^{\circ} \mathrm{F}
$$ 
Pump Work

Pump work for all subsystems was estimated as the work required to transfer the necessary quantities of thermal energy at the appropriate temperatures and pressures. Distribution pump work was estimated on the basis of supplying the required heating or cooling effects at the specified $\Delta \mathrm{T}$ of $10^{\circ} \mathrm{F}$ by maintaining

a constant head on the system and varying flow proportionately with thermal load. All pump efficiencies were assumed to be $65 \%$.

\section{Cooling Tower Work}

The cooling tower was assumed to operate at full load (as per design specifications) to dissipate the estimated monthly heat gain. No allowance was made for improved tower performance due to decreased ambient wet bulb temperature.

\section{End-User Heat Pumps}

End-user equipment was assumed to operate at the nominal heating and cooling C.0.P.'s of 2.91 and 2.53, respectively (from Reference 7 ).

The results of the monthly performance analysis are summarized in Table 8-6 below. The full analysis and calculational procedures are presented in Appendix C.

TABLE 8-6

CONYERS HP-WHR SYSTEM PERFORMANCE

Heating Btu Delivered to Space Delivered to Space $\times 10^{9}$

Jan.

Feb.

March

April

May

June
2.915

2.335

1.845

0.593

0.116

0
Cooling Btu $\times 10^{9}$

$$
\begin{array}{r}
0 \\
0 \\
0.060 \\
0.146 \\
0.834 \\
1.737
\end{array}
$$

End-User

Energy Input Energy Input SYSTEM KWH

$$
\begin{array}{r}
125,411 \\
98,856 \\
92,247 \\
17,742 \\
21,090
\end{array}
$$$$
44,092
$$
$\mathrm{KWH}$ C.0.P.

$\begin{array}{rr}294,512 & 2.034 \\ 235,913 & 2.044 \\ 193.439 & 1.954 \\ 77,924 & 2.285 \\ 109,464 & 2.132 \\ 203,574 & 2.055\end{array}$

(Table 8-6 Cont'd) 
TABLE 8-6 (Cont'd)

\begin{tabular}{|c|c|c|c|c|c|}
\hline & $\begin{array}{c}\text { Heating Btu } \\
\text { Delivered to Space } \\
\times 10^{9}\end{array}$ & $\begin{array}{r}\text { Cooling Btu } \\
\text { Delivered to Space } \\
\times 10^{9} \\
\end{array}$ & $\begin{array}{c}\text { Central Plant } \\
\text { Energy Input } \\
\text { KWH } \\
\end{array}$ & $\begin{array}{c}\text { End-User } \\
\text { Energy Input } \\
\text { KWH } \\
\end{array}$ & $\begin{array}{l}\text { System } \\
\text { C.0.P. }\end{array}$ \\
\hline July & 0 & 2.184 & 57,236 & 255,962 & 2.043 \\
\hline Aug. & 0 & 2.098 & 80,560 & 245,883 & 1.883 \\
\hline Sept. & 0.039 & 1.230 & 31,930 & 148,095 & 2.065 \\
\hline Oct. & 0.568 & 0.310 & 3,679 & 93,719 & 2.641 \\
\hline Nov. & 1.703 & 0 & 71,825 & 172,060 & 2.046 \\
\hline Dec. & 2.786 & 0 & 118,260 & 281,479 & 2.042 \\
\hline TOTAL & 12.900 & 8.599 & 762,928 & $2,311,124$ & \\
\hline
\end{tabular}

With the monthly system performance thus defined for each month during the annual cycle, the overall system C.O.P. can be easily derived. Considering the system as a "black-box," its performance can be determined by the expression

$$
\text { C.0.P. }=\frac{Q_{\text {out }}}{W_{\text {in }} \times 3413}
$$

where

$$
\begin{aligned}
& \mathrm{Q}_{\text {out }}=\text { heating or cooling effect provided by the system, Btu } \\
& \mathrm{W}_{\text {in }}=\text { work input to the system, KWH }
\end{aligned}
$$

Thus, substituting from Table 8-6:

$$
\begin{aligned}
\text { C.0.P. } & \left.=\frac{\left(12.900 \times 10^{9}+8.599\right.}{(762,928+2,311,124)} \times 10^{9}\right) \\
& =2.049
\end{aligned}
$$


In order to identify the areas of energy usage on the HP-WHR system which would benefit system performance the most through decreased consumption, the performance analysis also included a breakdown of individual component energy usage. Overall central plant power consumption was first analyzed and plotted as illustrated in Table 8-7 and Figure 8-11. Consumption was then further broken down according to individual components, as summarized in Table 8-8.

It is apparent from the component analysis and from the monthly consumption figures presented in Appendix $C$ that system performance is severely penalized by auxiliaries such as pumps and cooling towers. Obviously then, this area of energy consumption exhibits the potential for improvement if equipment offering better than average operating efficiencies can be economically specified.

By far the largest energy user on the system is the collective end-user heat pump. Prototype hydronic heat pumps which offer nominal C.0.P.'s in the 4.0 - 5.0 range (as opposed to the 2.91 assumed for the analysis) are currently under development and show vast potential, if incorporated into the HP-WHR system, to improve system performance by decreasing end-user heat pump energy consumption while delivering the same thermal load.

Finally, in actual practice some improvement in performance may be gained through operating practices such as producing water at higher or lower than destini lemperatures at nominal central heat pump full loads during off-peak hours in order to "charge" the thermal storage component of the system. 
TABLE 8-7

ELECTFICITY USAGE ANALI..YSIS

FOF: CONYERS HF-TCES

IN COOFEFATION WTTH THE TECHNOLOGY REVELOPMENT LAD

GEOFE'TIA TECH ENGINEEFTNG EXFEFIMENT STATTON

ATLANTA, GEOFGTA 30332

I $N F U T$ I A $r$ A

\begin{tabular}{|c|c|c|c|c|c|}
\hline EILLING FEFIOI & ACTUAL IIEMANII & ETLLING IEMAND & CONSUMFTION & FUEL AIIJUSTKENT & LOAD FACTOF \\
\hline 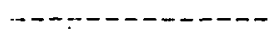 & $---\infty-\infty-1-\infty$ & - & $-\infty-\infty-m$ & $-1-1$ & $-\ldots$ \\
\hline JAYUUAFY, 1979 & 680 & 523 & 12511.1 & .000 & .25 \\
\hline FEEFUAFYY, 1979 & 630 & 523 & 98856 & .000 & .22 \\
\hline MAF:CH, 1979 & 680 & 523 & 92247 & .000 & .18 \\
\hline VIFEIL, 1979 & 630 & 523 & 17742 & .000 & .04 \\
\hline IAAY, 1979 & 600 & 523 & 21090 & .000 & .05 \\
\hline JUNE, $197 \%$ & 550 & 550 & 44092 & .000 & .11 \\
\hline JULY, 1979 & 550 & 550 & 57236 & .000 & .14 \\
\hline ALUGUST, 1979 & 550 & 550 & 80560 & .000 & .20 \\
\hline SEFTEMAEF, 1979 & 550 & 550 & 31930 & .000 & .08 \\
\hline OCTUBEF : 1979 & 630 & 523 & 3679 & .000 & .01 \\
\hline NOUEMBEK, 1979 & 680 & 523 & 71825 & .000 & .15 \\
\hline DEECEMEEK, 1979 & 680 & 523 & 118260 & .000 & .23 \\
\hline
\end{tabular}

LOCAL TAX IS $\$ .03$

F F O JE C T E D ELE C T F J C I I $T$ Y C C O S

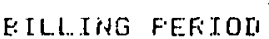

HILLING AMOUNT

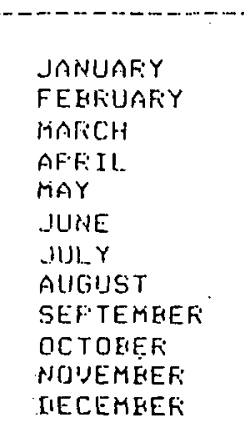

TOTAL

HILLING ANOUNT
5658.20
4994.70
4670.23
1012.41
1176.78
2306.06
2951.37
4096.46
1708.97
250.37
3667.61
5520.72
$-301 .-07$


FLOT OF CONSUMFTION FIG. $8-11$

CONSUMF TON (NWH)

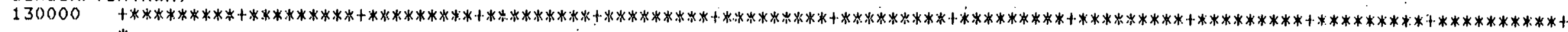

$*$

$* x$

$* x$

* $x$

$x$

${ }_{x}^{x}$

$x \times x$

98250

$x \times x \times x$

$x \times x x$

$x$

$x$

$\infty$

66500

3000 
TABLE 8-8

CONYERS HP-WHR SYSTEM

ANNUAL COMPONENT ENERGY USE

ITEM

$$
\begin{array}{ll}
\text { PENERGY USE } & \text { PERCENT OF } \\
\hline
\end{array}
$$

PERCENT OF

KWH

SYSTEM

Distribution Pumps

141,056

18.5

4.6

Circulating Pumps

128,812

16.9

4.2

Sewage Pumps

24,011

3.1

0.8

Cooling Tower

48,807

6.4

1.6

Misc. Electrical

12,000

1.6

0.4

Central Heat Pump

408,242

53.5

$\underline{13.3}$

Central Plant Total

762,928

100.0

24.9

End-user Heat Pumps

$2,311,124$

$\underline{\underline{75.1}}$

System Total

3,074,052 KWH

100.0 


\section{ENERGY CONSERVATION POTENTIAL}

The Heat Pump-Wastewater Heat Recovery System shows the potential to favorably alter the existing energy use patterns within a community and to promote the overall conservation of primary energy sources. In the case of the Conyers community, the existing energy use pattern shows a reliance on electric energy for cooling and natural gas for heating. Essentially all endusers within the proposed HP-WHR system service area now exhibit this energy usage pattern.

The energy consumed on-site by the conventional space conditioning systems in meeting the heating and cooling requirements projected by the computerized load estimate was first calculated. The assumptions were that heating requirements were met with natural gas fired furnaces operating at a $65 \%$ driven efficiency and that cooling requirements were met with electrically driven air-conditioning units with C.O.P.'s of 2.0. Based on these assumptions the conventional systems consume annually the following amounts of energy:

\begin{tabular}{lcc} 
& \multicolumn{1}{c}{ Cooling } & Heating \\
Zone R-1 & $161,148 \mathrm{KWH}$ & 25,385 THERMS \\
Zone R-2 & $527,395 \mathrm{KWH}$ & 83,077 THERMS \\
Zone R-3 & $571,345 \mathrm{KWH}$ & 90,000 THERMS \\
TOTAL & $1,259,888 \mathrm{KWH}$ & $\frac{900}{198,462 \mathrm{THERMS}}$
\end{tabular}

The above totals compare to the annual total HP-WHR system energy requirement of 3,074,052 KWH (from Table 8-8). It is duly noted that the HP-WHR system consumption represents an approximate $144 \%$ increase in electrical energy consumption. However, on-site consumption of natural gas 1 s reduced lo zero. The rise in electrical energy consumption is attributable to two factors: 
1) the demand for natural gas in satisfying heating requirements is effectively displaced with the electrical demand of the heat pump system, and 2) the overal1 heat pump system operates at a slightly. lower efficiency (lower C.0.P.) than the conventional electrically driven air conditioning units in meeting cooling requirements.

In order to compare the projected primary energy resource consumption of the HP-WHR system to that of the conventional space conditioning systems, the procedures for determining annual tuel and resource energy utilization, as outlined in ASHRAE Standard 90-75, ENERGY CONSERVATION IN NEW BUILDING DESIGN, 58 were followed. As can be seen from the results of this assessment as illustrated on the following pages, the primary effect of the HP-WHR system operation would be to displace the consumption of natural gas with that of coal and nuclear energy. A minor increase will also be noted in the consumption of hydro-power and crude oil. A secondary, but desirable, effect would be to free the additional quantities of natural gas for use in satisfying other, less flexible energy requirements. 
ANNUAL FUEL AND ENERGY CALCULATION FORM 12-1

\begin{tabular}{|c|c|c|c|c|c|c|c|c|c|c|c|c|}
\hline \multirow[b]{2}{*}{ ine } & \multirow[b]{2}{*}{ Column } & \multicolumn{2}{|c|}{$\begin{array}{c}\text { Building/Project } \\
\text { Energy Req'inents } \\
\end{array}$} & \multicolumn{9}{|c|}{ Fuel and Energy Supplied to Sile } \\
\hline & & A1 & A2 & B1 & B2 & B3 & B4 & B5 & B6 & B7 & B8 & B9 \\
\hline & Function & $\begin{array}{c}\text { Thermal } \\
10^{6} \mathrm{Btu}\end{array}$ & $\begin{array}{l}\text { Electric } \\
10^{3} \mathrm{KWH}\end{array}$ & $\begin{array}{c}\text { Coal } \\
10^{6} \text { BIU }\end{array}$ & $\begin{array}{c}\text { Gas } \\
10^{6} \mathrm{Blu} \\
\end{array}$ & $\begin{array}{c}\text { Light Oil } \\
10^{\circ} \mathrm{Btu}\end{array}$ & $\begin{array}{c}\text { Heavy Oil } \\
10^{6} \text { Btu }\end{array}$ & $\begin{array}{l}\text { Elec. Win. } \\
10^{3} \mathrm{KWH}\end{array}$ & $\begin{array}{l}\text { Elec. Sum. } \\
10^{3} \mathrm{KWH}\end{array}$ & $\begin{array}{c}\text { Elec. Ann. } \\
10^{3} \mathbf{K W H} \\
\end{array}$ & Other & Other \\
\hline 1 & Heating & 12,900 & & & 19,846 & & & & & & & \\
\hline 2 & Cooling & 8599 & & & & & & & 1259.8 & & & \\
\hline 3 & Water Heating. & & & & & & & & & & & \\
\hline 4 & IIVAC Auxiliaries & & & & & & & & & & & \\
\hline 5 & Lighting & & & & & & & & & & & \\
\hline 6 & Elevators & & & . & & & & & & & & \\
\hline$\underline{7}$ & Computers & & & & & & & & & & & \\
\hline 8 & Cooking & & & & & & & & & & & \\
\hline 9 & Process & & & & & & & & & & & \\
\hline 10 & Other & & & & & & & & & & & \\
\hline 11 & Other & & & & & & & & & & & \\
\hline 12 & Other & & & & & & & & & & & \\
\hline 13 & Total Carry Fwd. t & Form 12-2 & & & $19 ; 846$ & & & & 1259.8 & & & \\
\hline
\end{tabular}

\section{CONYERS-CONVENTIONAL SYSTEMS}

\begin{tabular}{|c|c|c|c|c|c|c|c|c|c|c|c|c|}
\hline \multicolumn{4}{|c|}{$\begin{array}{c}\text { Annual Fuel and Energy } \\
\text { Calculation Form 12-2 }\end{array}$} & \multirow{3}{*}{$\begin{array}{c}\text { C.o. } \\
\text { Total } \\
\text { From } \\
\text { Form } \\
12.1 \\
\text { Line 13 } \\
\end{array}$} & \multirow{3}{*}{$\begin{array}{c}\text { RUF } \\
\text { From } \\
\text { Supplier } \\
\text { or From } \\
\text { Tables }\end{array}$} & \multicolumn{7}{|c|}{$\begin{array}{l}\text { Fuel and Energy Resources Used on Site and Off Sire } \\
\text { To Meet Energy Requirements of Building/Project }\end{array}$} \\
\hline \multirow[t]{2}{*}{ Lind } & \multirow{2}{*}{\multicolumn{3}{|c|}{$\begin{array}{l}\text { Fuel and Energy } \\
\text { Supplied to Site }\end{array}$}} & & & C1 & C2 & C3 & CA & Cs & C6 & C7 \\
\hline & & & & & & $\begin{array}{l}\text { S. Tons } \\
\text { Cosl }\end{array}$ & $\begin{array}{l}\text { MCF } \\
\text { Nat'I }\end{array}$ & $\begin{array}{c}\text { BBL } \\
\text { Crude Oil }\end{array}$ & $\begin{array}{l}\text { Grams } \\
\text { U-235 }\end{array}$ & $\begin{array}{l}10^{3} \mathrm{KWH} \\
\text { Hydro }\end{array}$ & Other & Other \\
\hline 14 & \multicolumn{3}{|c|}{ Fuel Oil, Light } & & & & & & & & & \\
\hline 15 & \multicolumn{3}{|c|}{ Fuel Oil, Heavy } & & & & & & & & & \\
\hline \multirow[t]{2}{*}{16} & \multirow[t]{2}{*}{ Gas } & Nai'l & $\mathrm{MCF}$ & \multirow[t]{2}{*}{19,846} & \multirow[t]{2}{*}{1.16} & & \multirow[t]{2}{*}{23,021} & & & $\dot{2}$ & & \\
\hline & & Oil & $\mathrm{BBL}$ & & & & & & & & & \\
\hline 17 & \multicolumn{3}{|c|}{ Coal } & & & & & & & & & \\
\hline \multirow[t]{7}{*}{18} & \multicolumn{3}{|c|}{ Elec. Winter } & $-0-$ & & & & & & & & \\
\hline & & coal & S. Tons & & .22 & & & & & & & \\
\hline & & Gas & MCF & & .56 & & & & & & & \\
\hline & & Oil & $B B L$ & & .53 & & & & & & & \\
\hline & & Nuc & Grams & & 3.84 & & & & & & & \\
\hline & & Hydro & $\overline{10^{3} \mathrm{KWH}}$ & & .07 & & & & & & & \\
\hline & & Other & & & & & & & & & & \\
\hline \multirow[t]{7}{*}{19} & \multicolumn{3}{|c|}{ Elec. Summer } & 1259.8 & & & & & & & & \\
\hline & . & Coal & S. Tons & & .26 & 327.5 & & & & & & \\
\hline & & Gas & MCF & & 1.04 & & 1310.2 & & & & & \\
\hline & & Oil & BBL & & .56 & & & 705.5 & & & & \\
\hline & & Nuc & Grams & & 3.84 & & & & 4837.6 & & & \\
\hline & & Hydro & $10^{3} \mathrm{KWH}$ & & .04 & & & & & 50.39 & & \\
\hline & & Other & & & & & & & & & & \\
\hline \multirow[t]{7}{*}{20} & \multicolumn{3}{|c|}{ Elec. Allliual } & & & & & & & & & \\
\hline & & Coal & S. Tons & & & & & & & & & \\
\hline & & Gas & MCF & & & & & & & & & \\
\hline & & Oil & BBL & & & & & & & & & \\
\hline & & Nuc & Grams & & & & & & & & & \\
\hline & & Hydro & $10^{3} \mathrm{KWH}$ & & & & & & & & & \\
\hline & & Oiher & & & & & & & & & & \\
\hline 21 & (Other) & & & & & & & & & & & \\
\hline 22 & & & & & tal Resourc & 327.5 & 24.331 .2 & 705.5 & 4837.6 & 50.39 & & \\
\hline
\end{tabular}


ANNUAL FUEL AND ENERGY CALCULATION FORM 12-1

\begin{tabular}{|c|c|c|c|c|c|c|c|c|c|c|c|c|}
\hline \multirow[b]{2}{*}{ Line } & \multirow[b]{2}{*}{ Column } & \multicolumn{2}{|c|}{$\begin{array}{l}\text { Building/Project } \\
\text { Energy Req'ments } \\
\end{array}$} & \multicolumn{9}{|c|}{ Fuet and Energy Supplied to Site } \\
\hline & & A1 & $\mathbf{A 2}$ & B1 & B2 & B3 & B4 & BS & $\mathbf{B 6}$ & B7 & B8 & B9 \\
\hline & Function & \begin{tabular}{|c|} 
Thermal \\
$10^{\circ} \mathrm{Btu}$ \\
\end{tabular} & $\begin{array}{c}\text { Electric } \\
10^{3} \mathrm{KWH}\end{array}$ & $\begin{array}{c}\text { Cosl } \\
10^{6} \text { Btu }\end{array}$ & $\begin{array}{c}\text { Gas } \\
10^{6} \text { Biu }\end{array}$ & $\begin{array}{c}\text { Light Oil } \\
10^{6} \text { Btu }\end{array}$ & $\begin{array}{c}\text { Heavy Oil } \\
10^{6} \mathrm{Btu}\end{array}$ & $\begin{array}{r}\text { Elec. Win. } \\
10^{3} \mathrm{KWH} \\
\end{array}$ & $\begin{array}{l}\text { Elec. Sum. } \\
10^{3} \mathrm{KWH}\end{array}$ & $\begin{array}{l}\text { Elec. Ann. } \\
10^{3} \mathrm{KWH}\end{array}$ & Other & $\overline{\text { Oth }}$ \\
\hline 1 & Heating & 12,900 & & & & & & 1876.2 & & & & \\
\hline 2 & Cooling & 8599 & & & & & & MIMIMII & 1197.9 & & & \\
\hline 3 & Water Heating & & & & & & & & & & & \\
\hline 4 & HVAC Auxiliaries & & & & & & & & & & & \\
\hline$s$ & Lighting & & & & & & & & & & & \\
\hline 6 & Elevators & & & & & & & & & & & \\
\hline 7 & Computers & & & & & & & & & & & \\
\hline 8 & Cooking & & & & & & & & & & & \\
\hline 9 & Process & & & & & & & & & & & \\
\hline 10 & Other & & & & & & & & & & & \\
\hline 11 & Other & & & & & & & & & & & \\
\hline 12 & Other & & & & & & & & & & & \\
\hline 13 & Total Carry Fwd. I & Form 12-2 & & & & & & 1876.2 & 119.7 .9 & & & \\
\hline
\end{tabular}

\section{CONYERS-HP-WHR SYSTEM}

\begin{tabular}{|c|c|c|c|c|c|c|c|c|c|c|c|c|}
\hline \multicolumn{4}{|c|}{$\begin{array}{l}\text { Annual Fuel and Energy } \\
\text { Calculation Form 12-2 }\end{array}$} & $\begin{array}{l}\text { C.o. } \\
\text { Total }\end{array}$ & $\begin{array}{l}\text { RUF } \\
\text { From }\end{array}$ & & $\begin{array}{l}\text { Fuel and } \\
\text { To Mee }\end{array}$ & $\begin{array}{l}\text { Energy Reso } \\
\text { I Energy Req }\end{array}$ & $\begin{array}{l}\text { urces Used } \\
\text { uirements o }\end{array}$ & $\begin{array}{l}\text { on Site and } \mathrm{O} \\
\text { Building/Pr }\end{array}$ & $\begin{array}{l}\text { Sile } \\
\text { ect }\end{array}$ & \\
\hline \multirow[t]{2}{*}{ Ling } & \multirow{2}{*}{\multicolumn{3}{|c|}{$\begin{array}{l}\text { Fuel and Energy } \\
\text { Supplied to Site }\end{array}$}} & From & Supplier & C1 & C2 & $\mathrm{C}_{3}$ & $\mathrm{C}$ & Cs & co & $\mathrm{C} 7$ \\
\hline & & & & $\begin{array}{c}\text { Form } \\
12-1 \\
\text { Line } 13\end{array}$ & $\begin{array}{c}\text { or From } \\
\text { Tables }\end{array}$ & $\begin{array}{l}\text { S. Tons } \\
\text { Coal }\end{array}$ & $\begin{array}{l}\text { MCF } \\
\text { Nat'I }\end{array}$ & $\begin{array}{c}\text { BBL } \\
\text { Crude Oid }\end{array}$ & $\begin{array}{l}\text { Grams } \\
\text { U.235 }\end{array}$ & $\begin{array}{c}10^{3} \mathrm{KWH} \\
\text { Hydro }\end{array}$ & Orher & Other \\
\hline 14 & \multicolumn{3}{|c|}{ Fuel Oil, Light } & & & & & & & & & \\
\hline 15 & \multicolumn{3}{|c|}{ Fuel Oil, Heavy } & & & & & & & & & \\
\hline \multirow[t]{2}{*}{16} & \multirow[t]{2}{*}{ Gas } & Nat'l & MCF & $-0-$ & 1.16 & & & & & . & & \\
\hline & & Oil & BBL & & & & & & & & & \\
\hline 17 & \multicolumn{3}{|c|}{ Coal } & & & & & & & & & \\
\hline \multirow[t]{7}{*}{18} & \multicolumn{3}{|c|}{ Elec. Winter } & 1876.2 & & & & & & & & \\
\hline & & Coal & S. Tons & & .27 & 506.6 & & & & & & \\
\hline & & Gas & MCF & & .56 & & 1050.7 & & & & & \\
\hline & & Oil & BBL & & .53 & & & 994.4 & & & & \\
\hline & & Nuc & Grams & & 3.84 & & & & 7205 & & & \\
\hline & & Hydro & $10^{3} \mathrm{KWH}$ & & .07 & & & & & 131.3 & & \\
\hline & & Other & & & & & & & & & & \\
\hline \multirow[t]{7}{*}{19} & \multicolumn{3}{|c|}{ Elec. Summer } & 1197.9 & & . & & & & & & \\
\hline & & Coal & S. Tons & & .26 & 311.5 & & & & & & \\
\hline & & Gas & MCF & & 1.04 & & 1245.8 & & & & & \\
\hline & & Oil & BBL & & .56 & & & 670.8 & & & & \\
\hline & & Nuc & Grams & & 3.84 & & & & 4600 . & & & \\
\hline & & Hydro & $10^{3} \mathrm{KWH}$ & & .04 & & & & & 47.9 & & \\
\hline & & Other & & & & & & & & & & \\
\hline \multirow[t]{7}{*}{20} & \multicolumn{3}{|c|}{ Elec. Annual } & & & & & & & & & \\
\hline & & Coa! & S. Tons & & & & & & & & & \\
\hline & & Gas & MCF & & & & & & & & & \\
\hline & & Dil & BBL & & & & & & & & & \\
\hline & & Nuc & Grams & & & & & & & & & \\
\hline & & Hydro & $10^{3} \mathrm{KWH}$ & & & & & & & & & \\
\hline & & Other & & & & & & & & & & \\
\hline 21 & (Other) & & & & & & & & & & & \\
\hline 22 & & & & & tal Resourc & 8.8 .1 & 2296.5 & 1665.2 & 11,805 & $179.2^{\circ}$ & & \\
\hline
\end{tabular}




\section{SECOND LAW PERFORMANCE ANALYSIS}

A second law performance analysis was performed for the Conyers HP-WHR system during peak heating season, peak cooling season and a period when both heating and cooling was required. The analysis was conducted on a monthly basis.

Heating was accomplished by heating air from $75^{\circ} \mathrm{F}$ to $120^{\circ} \mathrm{F}$ and cooling was provided by cooling air from $75^{\circ} \mathrm{F}$ to $55^{\circ} \mathrm{F}$. The reference state for the air stream availabilities was $75^{\circ} \mathrm{F}$. In determining the primary resource utilization of electric energy a second law efficiency of .33 was used. The results are tabulated :below.

\begin{tabular}{|c|c|c|c|c|c|c|c|}
\hline SEASON & $\begin{array}{r}\text { HEATING } \\
\text { SUPPLIED } \\
\end{array}$ & $\begin{array}{r}\text { COOLING } \\
\text { SUPPLIED } \\
\end{array}$ & $\begin{array}{c}\text { AVAILABILITY OF } \\
\text { HEATING \& COOLING } \\
\text { SUPPLIED } \\
\end{array}$ & $\begin{array}{c}\text { AVAILABILITY OF } \\
\text { ENERGY SUPPLIED } \\
\text { TO SYSTEM } \\
\end{array}$ & $\begin{array}{c}\text { SECOND } \\
\text { LAW } \\
\text { EFFICIENCY } \\
\end{array}$ & $\begin{array}{l}\text { AVAILABILITY OF } \\
\text { ENERGY SUPPLIED } \\
\text { TO SYSTEM } \\
\end{array}$ & $\begin{array}{c}\text { SECOND } \\
\text { LAW } \\
\text { EFFICIENCY } \\
\end{array}$ \\
\hline $\begin{array}{c}\text { January } \\
\text { (Heating) }\end{array}$ & $\begin{array}{c}2.915 \times 10^{9} \\
.\end{array}$ & $-0-$ & $1.161 \times 10^{8}$ & $4.34 \times 10^{9}$ & .02670 & $4.484 \times 10^{9}$ & .0258 \\
\hline $\begin{array}{c}\text { July } \\
\text { (Cooling) }\end{array}$ & $-0-$ & $2.184 \times 10^{9}$ & $4.186 \times 10^{7}$ & $3.23 \times 10^{9}$ & .01296 & $\times 10^{9}$ & .01391 \\
\hline $\begin{array}{l}\text { October } \\
\text { (Mixed) }\end{array}$ & $.568 \times 10^{9}$ & $.310 \times 10^{9}$ & $2.854 \times 10^{7}$ & $9.69 \times 10^{8}$ & .0294 & $1.3009 \times 10^{9}$ & .0219 \\
\hline
\end{tabular}




\subsubsection{EXPECTED ECONOMICS}

This report section evaluates the expected economic performance of the HP-WHR system as compared to conventional heating and cooling systems in the Conyers area. First costs, operating costs and maintenance costs for each of the compared systems are estimated in order to determine annualized costs to consumers. A life cycle cost comparison for the system is also made.

System design and performance has been presented in previous sections nf this report. For the purposes of this analysis it is assumed that some form of government entity will own and operate the central utility and distribution system. End-users will own and operate their own heat pump systems and purchase thermal energy from the central plant. The purchase price for the thermal energy will be determined by the cost to produce and deliver the energy plus maintenance costs, personnel costs, administrative costs and debt service.

It is anticipated that the thermal utility would provide distribution and metering equipment to the property line of the customer. Piping and equipment installed on the user's property would be paid for and become the property of that user.

Debt service for the central plant was based on a 7 percent per year interest rate with payments over a 25 year period. This rate appeared to be :to be approximately mid-range for rates that could be expected for Conyers.

The following cost analysis is broken into three parts: first costs, operating costs, life cycle costs. A summary of results is presented in the latter part of the section.

\section{FIRST COSTS}

First costs are categorized as costs incurred by the central utility or 
costs incurred by the end-users. In Conyers' case, it is anticipated that the central utility's costs will be those associated with the central plant, distribution system and metering. End-users will be responsible. for the retrofit or initial installation of their own HVAC system and for piping from their heat pump unit to the lileter connection,

Central plant first costs were based on the equipment sizes and types presented in the system design section. A detailed cost breakdown is presented in Appendix C. A summary of these costs follows:

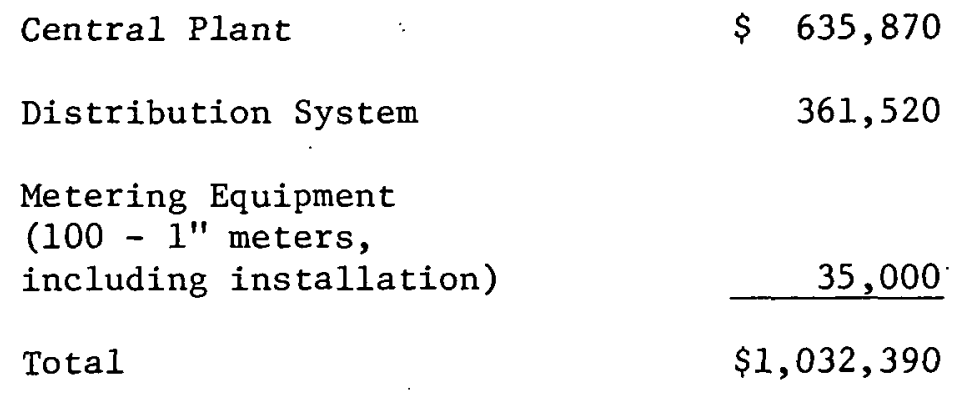

Total

$\$ 1,032,390$

End-user system costs were computed on the basis of $175 \mathrm{ft}$. of 1 " pipe per end-user to connect to the distribution system and $\$ 600$ per installed ton of air conditioning capacity for retrofit situations. The $\$ 600$ per ton is for installation of hydronic heat pump units only, with connection to existing duct systems, and is assumed to include any salvage value of equipment removed from the end-user buildings. New ingtallations were assumed to involve no differential cost over the standard HVAC system. For Conyers the end-user cost is approximately:

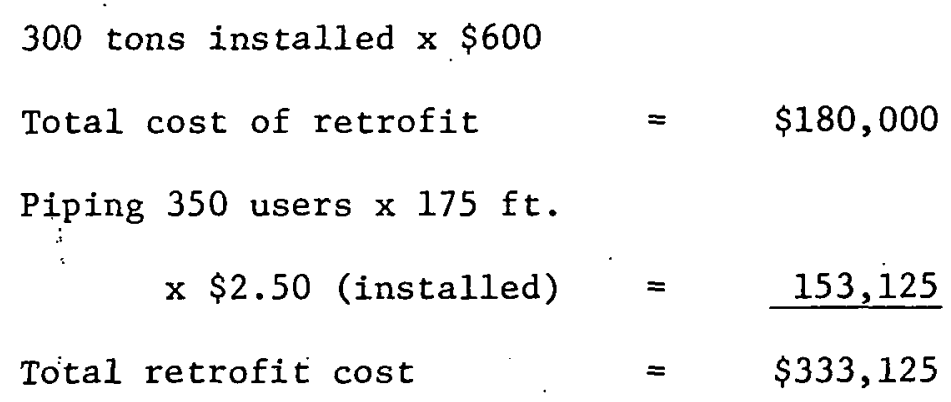


The retrofit costs are based on the individual prices each end-user would be required to pay if the work were contracted on an individual basis.

OPERATING COSTS

Operating costs were based on the results of the performance analysis presented in section 8.3.3. The cost of electric power for the central plant was computed from Georgia Power Company's PL-1 rate schedule. Power for endusers was assumed to cost $5.00 \mathrm{c} / \mathrm{KWH}$. The cost of thermal energy delivered to end-users by the HP-WHR system will be discussed in a subsequent section: From Table 8-7 of the performance analysis, the annualized cost for power to the central plant will be approximately $\$ 38,015$.

The end-users on the HP-WHR system will use approximately $2,311,124 \mathrm{KWH}$ per year. This electricity will cost approximately $\$ 115,556$ under individual billings.

Maintenance costs for the HP-WHR central station are estimated at 5 percent per year of the installed cost of the station and 0.5 percent per year for the distribution system. These maintenance costs are:

\section{$\underline{\text { Item }}$}

Central Station Equipment

Distribution System \& Meters

Total
Annual

Maintenance Cost

$\$ 31,793$

1,982

$\$ 33,77.5$

End-úser maintenance costs were assumed to be $\$ 20$ higher per installed ton of air conditioning capacity than would comparable system maintenance on conventional systems. This figure is:

$$
782 \times 20=\$ 15,640 \text { per year }
$$


HP-WHR SYSTEM OPERATION AS A THERMAL UTILITY.

In order to compare the HP-WHR scheme to conventional utility supplied schemes, it is necessary to perform an analysis from the end-user's viewpoint. To account for thermal energy distributed from the central plant, it is anticipated that the system will bc operated as a thermal utility. The charges to the end-users will be based on meter readings and will be sufficient to cover the central plant's operating and maintenance costs, debt service, and administrative costs associated with operation of the system.

The cost figures contained in this report were generated for the cornelia system using the stated electric energy costs, an administrative cost of 10 percent of total owning and operating costs, and debt service based on an interest rate of 7 percent per year over 25 years. It is recognized that the seven percent interest rate is somewhat arbitrary and will vary with the type of financing arrangements actually implemented; however, it was selected as a compromise between typical 1977 yields for Municipal Class A bonds and Utility bonds issued by private companies.

The total annual cost to the end-users for thermal service was computed as follows:

CONYERS - HP-WHR SYSTEM

ANNUAL THERMAL UTILITY CHARGES

(COMPONENT COSTS IN 1979 DOLLARS)

Energy Cost

Maintenance on Central Plant

and Distribution System
$\$ 38,015$

$33,7 / 5$

(UTILITY CHARGES - cont'd) 


\section{ANNUAL THERMAL UTILITY CHARGES}

(cont'd)

Debt Service on Total System

Cost (7\%, 25 years)

$(\$ 1,032,390 \times .0858)$

88,580

Subtotal

$\$ 160,370$

10\% Administrative fee (Including

Insurance \& Contingencies)

16,035

Total

$\$ 1.76 ; 405$

Based on the above total, the necessary cash flow for the system will be as projected in Table 8-9.

\section{LIFE CYCLE COSTS}

A life cycle cost analysis was prepared for the Cornelia HP-WHR system and the existing conventional systems. The analysis was performed from the end-user point of view, since the consumer will ultimately pay all costs associated with each system. In the case of thermal energy distributed by the HP-WHR system, central plant capital and energy costs are embedded in the cost of service to the end-user.

The present value of the cash flow for each alternative was determined for a twenty-five year period at the stated discount factor. The following general formula was used:

$$
P V_{i}=F C_{i}+\sum_{\dot{y}=1}^{25}\left[f(j, y) \times\left(A D C_{i}+A M C_{i}\right)\right]
$$


TABLE 8-9

CONYERS HP-WHR SYSTEM

THERMAL UTILITY CHARGES

CASH FLOW

THE FOLLOWJNG ASSUPFTTONS WEFI: USET

ANALYSIS FEFIOT OF 25 YEAFG TNTEFEST FATE OF OO WEOENT SAL/COST ESCALATTON=.000 MATRT. ESCALATTON= .080 AUEFAGE UTILTTY ESCALATION:E: D IO TNCOME ESCALATTONW:OOO

\begin{tabular}{|c|c|c|c|c|c|}
\hline \multicolumn{2}{|c|}{ IIEET S. } & ANNUAL & $: \cos \theta$ & AlMTN. & \multirow[t]{2}{*}{$006 \%$} \\
\hline YFi & OF COST & MATN YEYC & UTHLTTEs & di Facr & \\
\hline 0 & 88580. & 0. & 0 & $0 . * 1.000$ & $-30 \operatorname{sos}$ \\
\hline 1. & 88580 & 36477 & $4219 \%$ & $10 \% 29 . * 1.000$ & $1839 \%$ \\
\hline 2 & 88380 & 39395. & 46033. & $1 \% 481 . * 1.000$ & 19220 \\
\hline 3 & 88380 & 421047 & 51900 & $183 \mathrm{~L} \%$ * 2.000 & $20] 42$ \\
\hline 4 & 38380 & 45951. & 57709 & $19204 .+1.000$ & \\
\hline 5 & $80 \% 30$ & 49627 & $640 \%: \%$ & $20226, * 1.000$ & \\
\hline 6 & 88580 & 53597 & 71.04 & $21328, * 1.000$ & 23460 \\
\hline 7 & 88580 & 37884 & 79929. & $2253 \% .41 .000$ & 24792 \\
\hline 8 & 88580 & 62513. & 87607 & $238 \% 0 . * 1.000$ & 26257 \\
\hline$\varphi$ & 83530 & 67516. & 97244 & $29334 . * 1.000$ & 278676 \\
\hline 10 & 89580 & 72918 & $1.0794 \mathrm{l}$ & $\therefore 6944 . * 1.000$ & 29638 \\
\hline L L L & 83580 & $797 \% 1$ & 119814. & $2971 \%, * 1.000$ & 366 \\
\hline 12 & 80580 & $8505 \mathrm{l}$ & 132994 & $30662, * 1.000$ & 36728 \\
\hline 1.3 & 88580 & $9185 \%$ & 147623 & $32006 . * 1.000$ & .360 \\
\hline 14 & 8830 & 99204 & 163861 & 39165.41 .000 & \\
\hline 15 & 88580 & 1071.10 & .181 .886$. & $37761 . * 1.000$ & 415367 \\
\hline 16 & 88580 & $11: 371$. & 201894 & $40618 . * 1.000$ & 446803 \\
\hline 17 & 88530 & 124968 & 224102 & $43765 .+21.000$ & 401815 \\
\hline 18 & 88580 & 134966. & $248 \% 53$ & $47230 . * 1.000$ & $\because 1959 \%$ \\
\hline 29 & 83680 & 1.9676 .3 & 27011.6. & $\because 1046 . * 1.000$ & $\because 6100$ \\
\hline 20 & 88580 & 197424. & 306489 & $3199 . \times 1.000$ & $60 \% \%$ \\
\hline $2 \mathrm{~L}$ & 88030 & 170018 & 340203 & $59000+x 1+000$ & 61680 \\
\hline 22 & 88380 & 133619 & 377525 & $* 1.000$ & 71.9308 \\
\hline 2.3 & 83080 & $19830 \%$ & 41.164. & $70609 .+1.000$ & $9766 \%$ \\
\hline 24 & 88030 & 214173. & $46 \% 2 \% 2$ & $70002 . * 1.000$ & $84482 \%$ \\
\hline 25 & $88 \cdots 80$ & 231307 & ‥ & 83634.21 .000 & $9199 \%$ \\
\hline
\end{tabular}


Where:

$$
\begin{aligned}
\mathrm{PV}_{i} & =\text { Present value of the } i^{\text {th }} \text { alternative } \\
\mathrm{FC}_{i}= & \text { First cost of the } i^{\text {th }} \text { alternative } \\
\mathrm{f}(j, \mathrm{y})= & \begin{array}{l}
\text { The present worth factor at } j \text { percent interest for } \\
\end{array} \\
\mathrm{ADC}_{i}= & \text { Annual operating costs of the } i^{\text {th }} \text { alternative } \\
\mathrm{AMC}_{i}= & \text { Annual maintenance costs of the } i^{\text {th }} \text { alternative }
\end{aligned}
$$

The results of the life cycle cost analysis are presented in Table $8-10$ for. the conventional systems as the base case and Table 8-11 for the HP-WHR system alternative. The present value figure is given as a positive number; however, in actuality it should be realized that the number is a present value of present and future costs.

\section{SUMMARY OF EXPECTED ECONOMICS}

The results of the life cycle economic analysis indicate that the HP-WHR system as proposed for the Conyers community is more costly to the end-users than the conventional space conditioning system alternative. On the basis of the results presented in Tables 8-10 and 11, implementation of the HP-WHR system would result in a net additional cost to the end-users of $\$ 2,274,520$. Several factors detract from the comparative system economics. The arduous retrofit costs for portions of the proposed service area, even though borne by the individual system subscribers, increase the capital investment necessary to implement the system and thus penalize the economic attractiveness from the end-users' point of view. System performance during the cooling mode is comparable, on a C.O.P. basis, to the standard electric air conditioning systems typically in residential service in the proposed service area. 
TABLE 8-10

CONYERS CONVENTIONAL SYSTEMS (BASE CASE)

LIFE CYCLE COST ANALYSIS

\begin{tabular}{|c|c|c|c|c|c|c|c|c|}
\hline & $\underline{\mathrm{YR}}$ & $\begin{array}{c}\text { DEBT SERVICE } \\
\text { OR COST } \\
\end{array}$ & $\begin{array}{c}\text { BASE } \\
\text { YAINTENANCE }\end{array}$ & $\begin{array}{l}\text { UTILITY } \\
\text { N.GAS }\end{array}$ & $\begin{array}{l}\text { COSTS } \\
\text { ELECT. }\end{array}$ & $\begin{array}{l}\text { TOTAL } \\
\text { COSTS } \\
\end{array}$ & $\begin{array}{l}\text { DISCOUNT } \\
\text { FACTOR } \\
\end{array}$ & $\begin{array}{l}\text { DISCOUNTED } \\
\therefore \quad \text { COSTS } \\
\end{array}$ \\
\hline & 0 & 0. & 0. & $\begin{array}{r}0 \\
0179\end{array}$ & $\begin{array}{r}0 . \\
\end{array}$ & $\begin{array}{l}0 . \\
07\end{array}$ & 1.000 & 0. \\
\hline $1980=$ & $\begin{array}{l}1 \\
2\end{array}$ & 0. & 0. & 71,179 . & $71,595$. & $\begin{array}{l}142,774 \text {. } \\
159902\end{array}$ & $\begin{array}{r}.090 \\
826\end{array}$ & 129,782 . \\
\hline : & 3 & 0. & 0 & 90,888 & 88,212 . & $\begin{array}{l}139,902 . \\
179,100 .\end{array}$ & $\begin{array}{l}.826 \\
.751\end{array}$ & 134,504 . \\
\hline & 4 & 0 . & 0 . & 102,704 . & 97,916 . & 200,620 . & .683 & 137,023 . \\
\hline & 5 & 0 . & 0 . & 116,055 . & 108,686 . & 224,741 . & .621 & 139,564 . \\
\hline & 6 & 0 . & 0 . & 131,142 . & 120,642 . & 251,784 . & .564 & 142,006 . \\
\hline & 7 & 0 . & 0 . & 148,191 . & 133,912 . & 282,103 & .513 & 144,719 . \\
\hline & 8 & 0 . & 0 . & 167,455 . & 148,643 & 316,098 . & .467 & 147,617 . \\
\hline & 9 & 0 . & 0 . & 189,225 . & 164,993 . & 354,218 . & .424 & 150,188 \\
\hline & 10 & 0 . & 0. & 213,824 . & 183,143 & 396,967 . & .386 & 153,229 . \\
\hline & 11 & 0 . & 0 . & 241,621 . & 203,288 . & 444,909. & .350 & 155,718 . \\
\hline & 12 & 0 . & 0 . & 273,032 . & 225,650 & 498,682 . & .319 & 159,080 . \\
\hline & 13 & 0 . & 0 . & 308,526 . & 250,472 . & 558,998 . & .290 & 162,109 . \\
\hline & 14 & 0 . & 0 . & 348,634 . & 278,023 . & 626,657 . & .263 & 164,811 . \\
\hline & 15 & 0 . & 0. & 393,956 . & 308,606 . & 702,562 . & .239 & 167,912 . \\
\hline & 16 & 0 . & 0 . & 445,171 & 342,553 . & 787,724 . & .218 & 171,724 . \\
\hline & 17 & 0 & 0 . & 503,043 . & 380,233 . & 883,276 . & .198 & 174,889 . \\
\hline & 18 & 0 . & 0. & 568,439 . & 422,059 & 990,498 . & .180 & 178,290 . \\
\hline & 19 & 0. & 0 . & 642,336 & 468,486 . & $1,110,822$. & .164 & 182,175 . \\
\hline & 20 & 0 . & 0 . & 725,839 . & 520,019 . & $1,245,858$. & .149 & 185,633 . \\
\hline & 21 & 0 . & 0 . & 820,198 . & 577,221 . & $1,397,419$. & .135 & 188,652 . \\
\hline & 22 & 0 . & 0. & 926,824 . & 640,716 . & $1,567,540$. & .123 & 192,807 . \\
\hline & 23 & 0 . & 0. & $1,047,311$ & 711,194 . & $1,758,505$ & .112 & 196,953 . \\
\hline & 24 & 0 . & 0 . & $1,183,462$ & 789,426 . & $1,972,888$ & .102 & 201,235 . \\
\hline & 25 & 0. & 0. & $1,337,312$. & 876,262 . & $2,213,574$. & .092 & 203,649 . \\
\hline 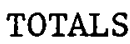 & & & & $, 076,799$ & $, 191,420$. & $9,268,219$. & & $4,096,348$. \\
\hline
\end{tabular}

\section{ASSUMPTIONS:}

1) Natural Gas Cost Escalation - $8 \%$

2) Electric Energy Cost Escalation - 11\% (3\% Over Base Inflation Rate)

3) Discount Rate - $10 \%$ 
TABLE 8-11

CONYERS HP-WHR SYSTEM

LIFE CYCLE COST ANALYSIS

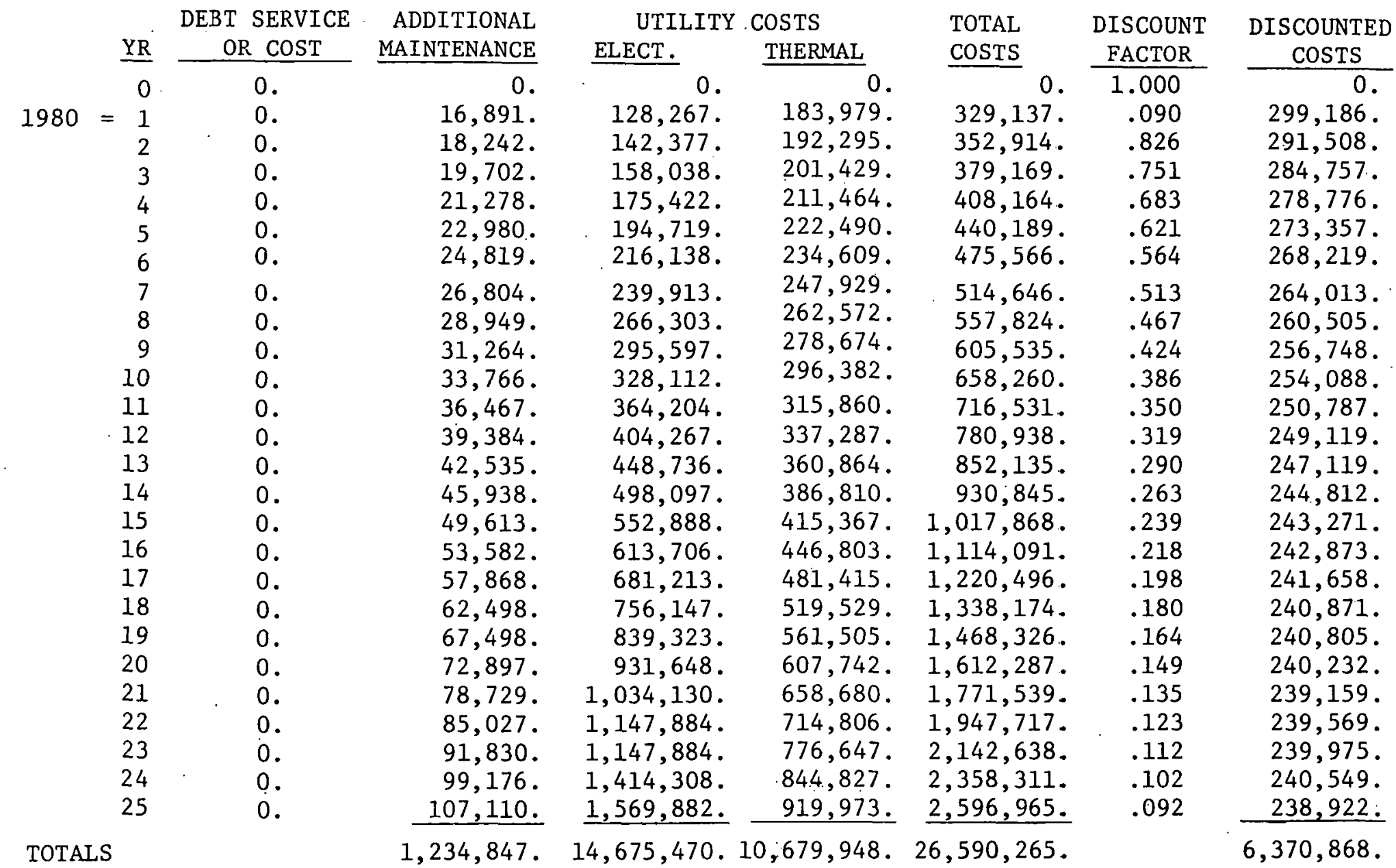

ASSUMPTIONS :

1) Maintenance and Replacement Cost Escalation - 8\%

2) Electric Energy Cost Escalation - 11\% (3\% Over Base Inflation Rate)

3) Thermal Utility Charge Escalation - 11\% (From Table 3-9)

4) Discount Rate - $10 \%$ 
Thus no performance or economic benefit in favor of the HP-WHR system is presented. Finally, the current low energy costs for natural gas, the heating resource of choice in the proposed service area, make the gas-fired furnace option the most cost effective heating syștem alternative. This last factor, combined with the fact that the proposed system is essentially cooling dominated, is perhaps the most critical detriment to system economics. It is anticipated that, if the system were located at heating dominated sites-of-application, or if (and when) natural gas prices escalate, the system will approach the threshold of economic viability. 


\subsubsection{PLAN FOR HP-WHR SYSTEM PHASING - CONYERS, GEORGIA}

An HP-ICES will operate in its community as a form of public utility which will provide a needed and potentially widespread (in relation to the overall community) service. Serving in this capacity, the system is subject to the need for long-range planning in order to provide its service in a manner most beneficial, service-wise and cost-wise, to the end-user. The primary concern is that the system be designed and constructed to fulfill the needs of the existing viable service areas. However, consideration must also be given to expanding the system in the most efficient manner and at the most advantageous time to accommodate future growth within the community. Chaper 6.0 - PROJECTED GROWTH discusses methods of projecting growth within a specific community and addresses construction phasing of central plant facilities and the distribution system for ranges of growth rate situations. The following paragraphs apply the general approaches outlined in the earlier chapter to the Conyers demonstration community situation.

The initial approach of the Conyers - based HP-WHR system will be to provide thermal utility services to a compact area of residential subdivisions just outside the corporate city limits on Stanton Road. The first candidate subdivision is located adjacent to the Almand Branch sewage treatment facility in the vicinity of the intersection of Stockbridge Highway 138 and Stanton Road. This subdivision is currently under development with several structures already completed and an ultimate build-out potential of 40 to 50 houses. A second subdivision approximately one mile down Stanton Road from the first is at a comparable degree of development with 60 to 75 houses completed and a build-out potential of 100 to 150 houses. Additionally, there is a parcel of land directly between the two subdivisions and roughly equivalent in land area to the second which is considered a likely candidate for development if the Conyers community continues its trend of rapid growth. Ultimate build-out. 
potential of this parcel of land, if developed, is approximately 150 houses. Accounting.for the total build-out potential of each of the three areas, this compact residential community would show a viable service area of approximately 120 houses within a one and one half mfle corridor around the sewage treatment plant. Since the current building inventory is approximately $30 \%$ of ultimate potential, and since it is estimated that the area, at its present rate of growth, will reach its build-out potential within five to ten years, this community will offer opportunities for phased system construction and a combination of residential retrofits and new home system installation. CENTRAL PLANT PHASING -- In general, it is advisable to plan and construct central plant facilities for a high growth area (such as this residential community) in several stages over a given planning period (usually 20 years). This procedure avoids committing large sums of money for excess capacity at the central plant which may not be needed until much later in the planning period. However, the Conyers demonstration community is an interesting mix of aspects of high growth and low growth areas. The growth potential of the subject area can be shown to be approximately $200 \%$ of the existing number of structures in the area over a 20 year planning period. The limited land area in the community, however, puts an effective ceiling on the ultimate expansion in the immediate area. The combination of the above two factors results in the estimate that the area may reach its potential in five to ten years. Considering this estimate and considering the fact that central station capacity may be limited somewhat by the relatively low capacity of the sewage treatment plant, it is deemed advisable to plan for installation of the bulk of central station capacity during the initial construction. A minor plant expansion would then be planned to finalize central station capacity in approximately five years. The pipe lines; sumps, and pumps which serve on the sewer tic-in subsystem will be constructed initially to handle 
100 to $110 \%$ of the ultimate wastewater flow which could be accommodated at the sewage treatment facility. The major building structure will be constructed to accommodate all equipment which would be necessary to serve the ultimate build-out potential of the system. Since the total quantity of thermal energy available from the wastewater could reasonably be handled by one central station heat pump, it is likely that full capacity will be installed. Installation of the auxiliary equipment (circulating pumps, distribution pumps, thermal storage, and cooling tower) will be based on estimated system requirements during the first five year period. At the time when additional. capacity is required, a minor plant expansion would involve the installation of an additional circulating pump, distribution pump, cooling tower cell, and if required, thermal storage. All equipment installation could be handled with little or no major modification to the in-plant piping system or structure. Costs for system expansion within the central plant should thus be minimized. DISTRIBUTION SYSTEM PHASING - There are several characteristics of the design and construction of high-volume water distribution (and return) lines which will influence the manner in which such systems will be constructed and expanded. First, water and sewer and, in this case, thermal utility lines have a useful life of approximately 50 years. Secondly, a major portion of the cost of constructing such lines is not in material costs but in manpower and equipment expenditures for the construction process. Hence, the most economical way to provide additional capacity generally is to construct a larger line initially rather than a parallel line at a later date.

The first phase of distribution system construction will involve installation of a distribution trunk line into the subdivision adjacent to the sewage treatment facility site. Due to the layout of the subdivision and to housing construction patterns, construction of the distribution system within this area can also be phased. The main trunk line would first be constructed along Morris Drive and Cindy Drive, with tributary 
lines along Rodgers Drive and into the as yet unnamed northern section of the subdivision to be installed at later dates. In all cases, line sizing and construction would be based on estimated ultimate requirements for the area so that the expense and inconvenience of constructing parallel 1ines at different stages of development could be avoided.

The second phase of distribution system construction would involve installation of a separate distribution trunk line into the second subdivision now under development. The main trunk line of this leg would run in a generally southerly direction from the plant, over to stanton Road, and into the subdivision along Almand Branch Road. Several structures could be served directly from this main trunk line, and as the degree of development in the area warrants, tributary lines could be constructed in a manner similar to the first pahse construction. It should be noted that construction of distribution lines for service into this area would quite likely coincide with the central station expansion discussed in the preceeding section.

The third phase of construction, involving the development of the vacant parcel of land between the two subdivisions, is very tentative. Discussion of this phase is only to identify the potential of the area if current housing and growth trends continue. There are two options for providing service into this area. Depending upon the layout and developuent partern of this zone, a main distribution trunk could be constructed off of the bulk transmission trunk line located along Stanton Road, or a separate trunk line could be constructed from the central station for service to the area.

Due to the development patterns in the three relatively segregated zones in the community adjacent to the Conyers sewage treatment facility, it is apparent that there is ample opportunity to demonstrate the options for phased construction of the central plant, distribution system, and end-user systems in an HP-WHR system. 


\subsection{INSTITUTIONAL CONSIDERATIONS}

As with any undertaking that proposes to provide a public service in some form to the members of a community, the implementation of a Heat Pump CenteredIntegrated Community Energy System will encounter significant institutional barriers. In order to impose a priority for consideration, however, these barriers can be classified into three fairly definitive categories. The first category involves the institutional considerations typical in the implementation of any large scale venture such as ownership, opcratioü, and financing alternatives. Categories two and three involve consideration of the effects upon implementation of the existing state and local laws, respectively. The following sections of this chapter discuss these institutional considerations with regard to their effect upon the implementation of the HP-WHR concept.

\subsubsection{OWNERSHIP AND OPERATION OF A HEAT PUMP CENTERED-INTEGRATED COMMUNITY ENERGY SYSTEM} $\underline{(\text { HP-ICES) }}$

There would be several alternative approaches to the ownership and operation of a Heat Pump Centered-Integrated Community Energy System. Such a system would be very similar to a public utility that provides water supply, wastewater collection and treatment, electrical power, or natural gas. Consequently, the alternative methods for ownership and operation would be similar to the types of institutions which provide the public utilities just listed. The three basic types of institutions that could serve as the owner and operator of a Heat Pump Centered-Integrated Community Energy System are as follows:

1. A privately-owned public utility company

2. A municipal-owned public utility

3. A special purpose authority 
The privately-owned public utility company would be similar to Georgia Power Company or the Atlanta Gas Light Company. Such companies are generally profit making corporations that are owned by the individual stockholders who have invested in the corporation.

An example of a municipal-owned public utility would be a city or county water system which is operated as a part of the city or county government. Some municipal governments also operate electrical distribution systems and natural gas distribution systems within their jurisdictions as a part of the utilities provided by the local government.

The third type of institution would be a special purpose authority created solely for the purpose of owning and operating a Heat Pump Centered-Integrated Community Energy System. In Georgia such authorities can be created by an act of the State Legislature. Such authorities are non-profit organizations created for a single purpose and having jurisdiction over a limited and clearly defined area. The most common special-purpose authorities in Georgia are water authorities whose jurisdiction usually covers all or part of a county. Speical purpose authorities can build, own and operate the specified facilities within their jurisdiction. Such authorities can enter Into the necessary financial arrangements needed for constructing and operating their facilities. However, the revenues for the authority are limited strictly to those revenues that can be generated from the operation of the facilities which the authority has constructed. In most cases, these revenues come from the service charges billed to individual residential and commercial customers of the system. The main difference between a special-purpose authority and a municipal-owned public utility is found in the available means of financing. A special-purpose authority is generally a separate entity from 
the municipal or county government, both financially and organizationally. The authority is generally independent and financially self-supporting from the municipal or county government. However, a municipal-owned public utility can be operated as a part of a municipal or county government and may not be financially self-supporting. This means that a municipal-owned public utility may be financed in part by general obligation bonds, ad 'valorem taxes, or other sources of revenue which the municipal or county government may have. The revenues that are derived from the operation of a municipal-owned public utility do not have to provide the total financing for the operation and maintenance of the utility.

The special-purpose authority is further defined in the Georgia Code as follows:

"The 'authority system of finance' is a system whereby the state or a municipality can carry out a function of a public or charitable nature through an agency created by the legislature and designated by the creating statute as an 'authority.' Such an authority has the power to borrow funds for its establishment and early operation through the issuance of revenue bonds, which, for their retirement and for the payment of interest thereon, may only pledge funds arising from the operation of the authorized project. In no event may such bonds pledge the credit of the municipality, create any lien on public property, nor give the bondholder any right to compel the exercising of the taxing power." 


\section{4 .2 FINANCING ALTERNATIVES FOR AN HP-ICES}

The alternative means for financing a Heat Pump Centered-Integrated Communtiy Energy System can be best described by the different categories of ownership which have been previously presented.

A privately-owned public utility company is a profit making corporation and generally can use the same methods of financing that are available to other corporations and businesses. Short-term financing can generally be obtained from banks and other lending institutions and long-term financing can be obtained by issuing stocks, bonds, or warrants.

A municipal-owned public utility can usually obtain short-term financing from banks or other lending institutions. Long-term financing is generally obtained by selling revenue bonds or general obligation bonds to private investors, banks, or other financial institutions. Municipal-owned public utilities in recent years have been able to obtain significant money for improvements or expansions through Federal or State grant or loan programs. The Federal Environmental Protection Agency has a significant grant program to assist local governments in the construction of interceptor sewers and wastewater treatment facilities. The Farmers Home Administration within the Jepartment of Agı liculluse lias löth a loan and grant program to holp emall communities in the construction of water and sewer systems. The Department of Housing and Urban Development has provided significant sums of grant monies to urban areas for the construction of water and sewer facilities, in addition to other public facilities that would not be categorized as utilities. The Economic Development Administration has also provided Federal grant funds to construct or expand utilities to serve industrial growth areas.

A special-purpose authority could obtain short-term financing from banks 
or other lending institutions if sufficient collateral could be provided or adequate assurance that the loan could repaid. The principal means for longterm financing of a special-purpose authority would be through the sale of revenue bonds which would be repaid from the annual revenues of the authority. Therefore, the strength and potential for growth would determine the rating for the revenue bonds and the difficulty that might be encountered in selling the revenue bonds. Special-purpose authorities are generally eligible for Federal and State grant loan funds as previously described for municipal-owned public utilities.

\subsubsection{COMPARISON OF ALTERNATIVE METHODS OF OWNERSHIP, OPERATION AND FINANCING OF} AN HP-ICES

The two previous sections have discussed the alternative methods available for the ownership, operation and financing of a Heat Pump Centered-Integrated Community Energy System. This section will provide a comparative discussion of the alternative means for ownership, operation and financing of a Heat Pump Centered-Integrated Community Energy System.

The alternative of a privately-owned public utility company has two significant drawbacks. The first drawback is that such companies would not generally desire to take on the responsibility for such a project until its feasibility and profit potential had been fully established. An exception to this might be that if massive Federal grant funds were involved in the initial demonstration and there was little financial risk to the utility company, then the company might be willing to be involved. The preceding statements assume that the public utility company concerned was already in existence and providing other services prior to being approached about involvement with a Heat Pump Centered-Integrated Community Energy System. At this 
stage in the development of the HP-ICES concept, it would be virtually impossible to consider creating a new public utility company solely for the purpose of owning and operating the HP-ICES. Because of the uncertainties involved with the initial capital cost, operating cost, and profit potential, it would be highly unlikely that such a company could successfully self the necessary stock that would be required for initial financing and operation.

The alternative of a municipal-owned public utility offers several advantages and disadvantages. One of the main advantages, as previously mentioned, is that a municipal-owned public utility has several alternative means of financing available to it. Long-term financing through the sale of municipal bonds offers an attractive means of financing construction since the interest rates on municipal bonds are often lower due to the tax-free status which they offer investors. Since a municipal-owned public utility does not have to make a profit, the utility rates which must be charged to customers are generally lower than might be charged by privately-owned utility companies. There are several disadvantages which are posed by municipal-owned public utilites. One disadvantage is that municipal-owned public utilities usually try to provide service to the entire community or municipality. However, with the HP-ICES concept, it may be that only a portion of the community can be served. Another disadvantage to a municipa1-owned public utility is that in recent years many small to medium sized towns have come to depend heavily on Federal grant and loan funds to improve and expand their public utilities (primarily water and sewer). Because of this trend, local officials will often postpone needed construction or improvements until massive Federal grant funds can be obtained which will pay, in some cases, 100 percent of the total cost involved. Because of this trend and because of the 
uncertainties involved in the initial construction of a demonstration project for an HP-ICES it is highly unlikely that a municipality would undertake such a system without significant Federal grant funds being involved in both the initial construction and operation of the system.

The last alternative is the creation of a special-purpose authority. An advantage to the special-purpose authority is that the area covered by the authority could be limited solely to the area which would be served by the Heat Pump Centered-Integrated Community Energy System. Therefore, local officials could not be criticized for operating a municipal utility which served only a limited portion of the total community. The main disadvantage to a special-purpose authority are the inherent limitations in financing construction with local funds. Special-purpose authorities are limited almost totally to revenue bonds for long-term financing. It is also difficult to issue revenue bonds for new authorities who do not have established customers and a past history of revenue collections. For a new type of utility such as the HP-ICES which has not been fully proven and demonstrated, it would be even more difficult to issue revenue bonds to finance the construction of such a system. Consequently, a special-purpose authority would also require significant Federal grant funds to help pay for the initial construction and operation of the system.

of the three alternative methods that have been considered for ownership, operation and financing of the HP-ICES, only two appear to be viable alternatives. These are the municipal-owned public utility and the special-purpose authority. The initial construction and operation of such a system under either of these alternatives would definitely require significant Federal grant funds and future availability of Federal grant or low interest loan funds. 
$0.4 .4^{\circ}$ STATE OF GEORGIA-REVIEW OF LEGAL AND REGULATORY FACTORS OF CONCERN IN THE DEVELOPMENT OF AN HP-ICES

In the development and implementation of any new concept, it is important that existing laws and regulations be reviewed to determine what legal constraints may impede or affect actual implementation. In this regard, state and local laws, regulations, codes and ordinances have been reviewed to determine what impact they might have on the construction and operation of a Heat Pump Centered-Integrated Community Energy System. In order for this review to be applicable to the two application communities, the review has been limited to laws and regulations of the State of Georgia and to codes and ordinances for the cities of Cornelia and Conyers, Georgia. Existing statutory law for the State of Georgia was review in the form of The Code of Georgia, Unannotated, 1978 edition. Statutory laws for the State of Georgia are organized and presented in this publication by subject matter which include Titles 1 through 114. A review of these titles indicated only three titles which might have application to a Heat Pump Centered-Integrated Community Energy System. These titles were "Title 17, Canals, Waters and Navigations," "Title 88, Public Health," and "Title 92A, Public Safety".

In reviewing Title 1.7, Canals, Waters and Navigation, one chapter in particular was found to have a potential effect on the construction of a Heat Pump Centered-Integrated Community Energy System. This was Chapter 17-5, "The Georgia Water Quality Control Act". This chapter establishes certain . laws and regulations concerning water quality of the streams, rivers and lakes within the State of Georgia. The chapter designates the Environmental Protection Division of the Georgia Department of Natural Resources as the state agency with the responsibility for implementing and enforcing the water quality 
laws and regulations of the state. One of the requirements of this chapter is that municipalities and industries must obtain permits from the state in order to construct and operate wastewater treatment facilities. These permits are also required for expanding or modifying existing wastewater treatment facilities. The permits which are issued by the Environmental Protection Division constitute both a Federal and State permit under the Federal Water Pollution Control Act of 1972 and these permits establish treatment requirements and effluent limitations which must be achieved by the wastewater trcatment facility. Consequently, the planning and design of a Heat Pump Centered-. Integrated Community Energy System must evaluate what effect the operation of such a system will have on the municipal wastewater treatment plant and its ability to operate within the limits established by its permit.

Another chapter which may have indirect implication is Chapter 17-13, The Georgia Safe Drinking Water Act of 1977. This chapter creates the necessary laws and regulations needed for the establishment of a safe drinking water program for the State of Georgia. One aspect of such a program is to prevent improper connections being made between potable water systems and non-potable water sources or wastewater sources. One of the potential dangers of a Heat Pump Centered-Integrated Community Energy System is the possibility that someone will mistakenly make a connection to the HP-ICES distribution system, thinking that it is a potable water distribution main. For this reason, it will be important that the pipe, network in the HP-ICES be adequately marked to. avoid improper cross connections with potable water systems.

Title 88, Public Health, assigns specific responsibilities to the Georgia Department of Human Resources and to County Boards of Health for the protection of the public health. These responsibilities include protection 
to the water quality public water supplies. This responsibility would include the responsibility to prevent and minimize the potential for cross connections between potable and non-potable water supplies.

\subsubsection{CITY OF CONYERS GEORGIA - REVIEW OF LOCAL ORDINANCES AND CODES}

The local codes and ordinances of the City of Conyers and Rockdale County were reviewed to determine what impacts or restrictions they might impose. on the development of a. Heat Pump Centered-Integrated Community Energy System. This review indicated that there were several local building codes which would require an in depth review in conjunction with the design and construction of a Heat Pump Centered-Integrated Community Energy System. The local building codes which have been adopted for the Conyers-Rockdale County area are as follows:

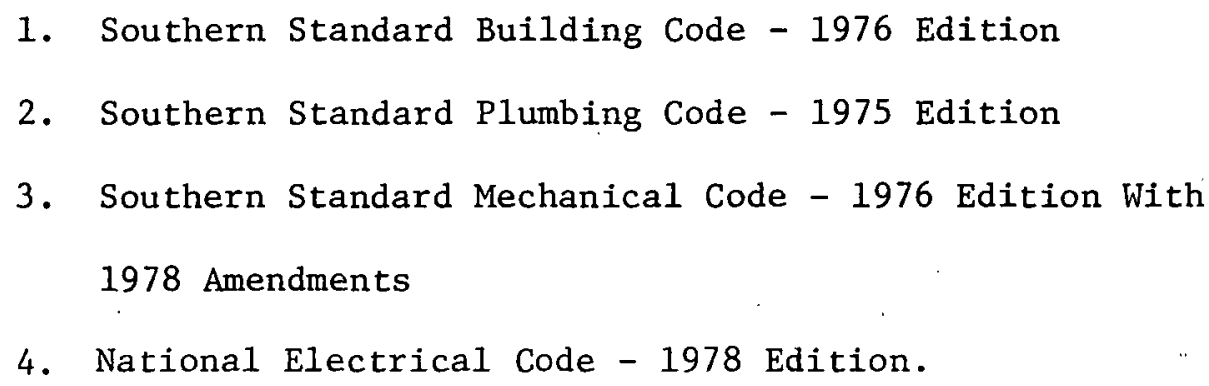

Thie first three (3) are published by the Southern Building Code Congress International, Inc., located in Birmingham, Alabama. These building codes are widely used by local governments both in Georgia and other parts of the United States. These codes establish minimum construction standards, which must be followed in the construction of residential, commercial and industrial building. In reviewing the codes noted above, there were not requirements or specifications found that would severly restrict the development of an HP-ICES. There were, however, several aspects of the codes which would need to be considered in the planning and design of the system. 
Some of the requirements of the codes are as follows:

1. Pipes used for transporting non-potable water must be clearly identified to avoid accidential tie-ins or connections to the potable water system of a home or commercial establishment.

2. The plumbing code establishes other restrictions that are needed to prevent cross-connections and backflow from the non-potable HP-ICES piping to the potable water system.

3. The plumbing code also establishes minimum criteria and specifications for piping materials and related appurtenances to be used within residential and commercial buildings.

4. The plumbing code may also include additional specifications or requirements for the HP-ICES piping as a result of the higher pressures which may be involved with this piping as compared with normal water distribution systems.

5. At the present time there is only limited reference to heat pump type heating systems within the various codes. However, as heat pumps become more widely used, future revisions of the codes will probably contain more specific provisions and criteria related to heat pump specifications and installation requirements.

There were no other local ordinances or codes that would affect or restrict the construction of a Heat Pump Centered-Integrated Community Energy System within the Conyers, Georgia-Rockdale County area. 


\subsection{SITE-SPECIFIC FEASIBILITY STUDY FOR CORNELIA, GEORGIA}

\subsection{COMMUNITY DESCRIPTION - CORNELIA, GEORGIA}

The City of Cornelia is located in the southeastern corner of Habersham County, which lies in the Piedmont Plateau Region of northeast Georgia in the foothills of the Blue Ridge Mountains. Cornelia lies along U. S. Highway 441, a major north-south highway, which carries a high volume of tourist traffic. Cornelia is located 80 miles northeast of Atlanta, 27 miles northeast of Gainesville, 46 miles north of Athens and 84 miles west of Greenville, South Carolina.

The topography of Cornelia ranges from fairly broad, level land along streams and branches to gently rolling hills in the higher elevations. Elevation ranges from approximately 1,400 feet to 1,680 feet above sea leve1.

\section{1 .1 POPULATION GROWTH}

According to published population data, Cornelia was the second fastest growing city in Habersham County for the decade 1950 - 1960, the slowest growing city in the county for the decade 1960 - 1970, and grew at approximately the same rate as the other six towns in the county for the period 1970 - 1977. Population projections for Cornelia through 1995 are as shown in Table 9-1. These projections are based on the assumption that growth in Cornelia will represent a fixed percentage of the estimated population increase of Habersham County: as included in the Georgia Mountains Future Land Use Plan, March 1973. 
TABLE 9-1

POPULATION AND PROJECTIONS FOR CORNELIA (1970-1995)

$\begin{array}{lccc}\text { Years } & \text { Population } & \begin{array}{c}\text { Projected } \\ \text { Population }\end{array} & \begin{array}{c}\text { Percent } \\ \text { of Increase }\end{array} \\ 1970 & 3,014 & & \\ 1977 & & 3,404 & 12.9 \\ 1980 & 3,571 & 4.9 \\ 1985 & 4,017 & 12.4 \\ 1990 & & 4,463 & 11.1 \\ 1995 & & 5,578 & 24.9\end{array}$

Source: Cornelia Community Development Concept Plan, Georgia Mountains Planning and Development Commission, 197. 57

\subsubsection{ECONOMIC CHARACTERISTICS}

Accelerated growth is greatly changing the economy of Cornelia and Habersham County. The region is in transition from an agricultural-oriented base to a rapidly-growing manufacturing base. Cornelia has in the past received most of its economic benefits from agricultural products. But in the past two decades the city and county have received benefits from increasing industrial development and commercial activity. Cornelia presently has a somewhat balanced economy with respect to industrial employment, agricultural production and retail sales volume.

Due to Cornelia's size, data conerning Cornelia's economy is not available except as a part of Habersham County. The economy of Habersham County is diversified with the largest part of the labor force employed in manufacturing, trade, finance, insurance, real estate, and services. Manufacturing, which accounts for the largest number of jobs in the county, comprises $43.7 \%$ of the 
county's employment. Finance, insurance, real estate, and services comprise the second largest category of employment in the county with $26.1 \%$. Jobs in wholesale and retail trade comprise another $16.3 \%$ of the county work force. The balance of employemnt is in the areas of construction with $8.1 \%$, agriculture with $5.2 \%$, or transportation and public utilities employment with $3.5 \%$ of the work force.

Projections of economic growth in Georgia from 1975 to 1985 have been made by the Georgia Economic Forecasting Project under the direction of Dr. John Legler at the University of Georgia. Using these projections as an indication of Cornelia's economic growth for the next ten years, the town can expect per capita income to increase faster than consumer prices, total employment to increase approximately two and one-half percent annually, a steady increase in manufacturing employment and earnings, and a concomitant increase in the dollar volume of retail sales.

\section{1 .3 LAND USE}

The City of Cornelia encompasses 1,158 acres within its corporate limits. Residential acreage accounts for the bulk of the land usage with $62.7 \%$ or 726 acres. Agricultural usage and open space comprise the second largest land usage category with 164 acres or $14.2 \%$. Commercial land usage is a comparable 131 acres or $11.3 \%$. Public and semi-public land usage and industrial usage are the smallest categories with $7.8 \%$ (90 acres) and 4\% (47 acres), respectively. The average population density is 2.5 persons per acre.

The land use pattern in Cornelia is similar in most respects to that found in cities of the same size. The core, the oldest section of the city, is exclusively in retail stores, business establishments, offices, banks and similar uses. Immediately surrounding the core area and along both sides of 
the railroad tracks are located commercial and wholesale establishments includ hardware, gasoline stations, restaurants, farm sales and services and automobile dealers. Slightly to the southeast of the core, most of the local government functions are concentrated.

Away from the core area of Cornelia are found other commercial uses. Such businesses are mainly neighborhood oriented such as grocery stores, auto repair. shops, service stations, and restaurants. Most of the highway oriented businesses which cater to automobile services are found along U. S. Highway 441,23 , and 123 .

The majority of industrial development in Cornelia has occurred in the southwest section of the city, while residential. development has occurred throughout with concentrations occurring to the northeast and southeast.

The City of Cornelia, its attending municipal wastewater treatment facility, and the city's contiguous areas to be considered for service with the proposed HP-WHR system are illustrated in Figure 9-1.

\section{1 .4 CLIMATE}

The climate of Cornelia is relatively mild with mild summers and moderate winters. The average annual precipitation is approximately 50 inches. This precipitation is nearly always in the form of rain with snow falling only occasionally in winter. Temperature averages for summer months range from 70 to:80 degrees while averages for winter months range from 40 to 45 degrees Fahrenheit. Periodic blasts of wintry Arctic air are felt by the city with the average number of freezing days being 45 to 60 . The frost-free season is long and usually averages around 215 days. Frosts can occur in late October and the danger of frosts normally passes by mid or late April. 


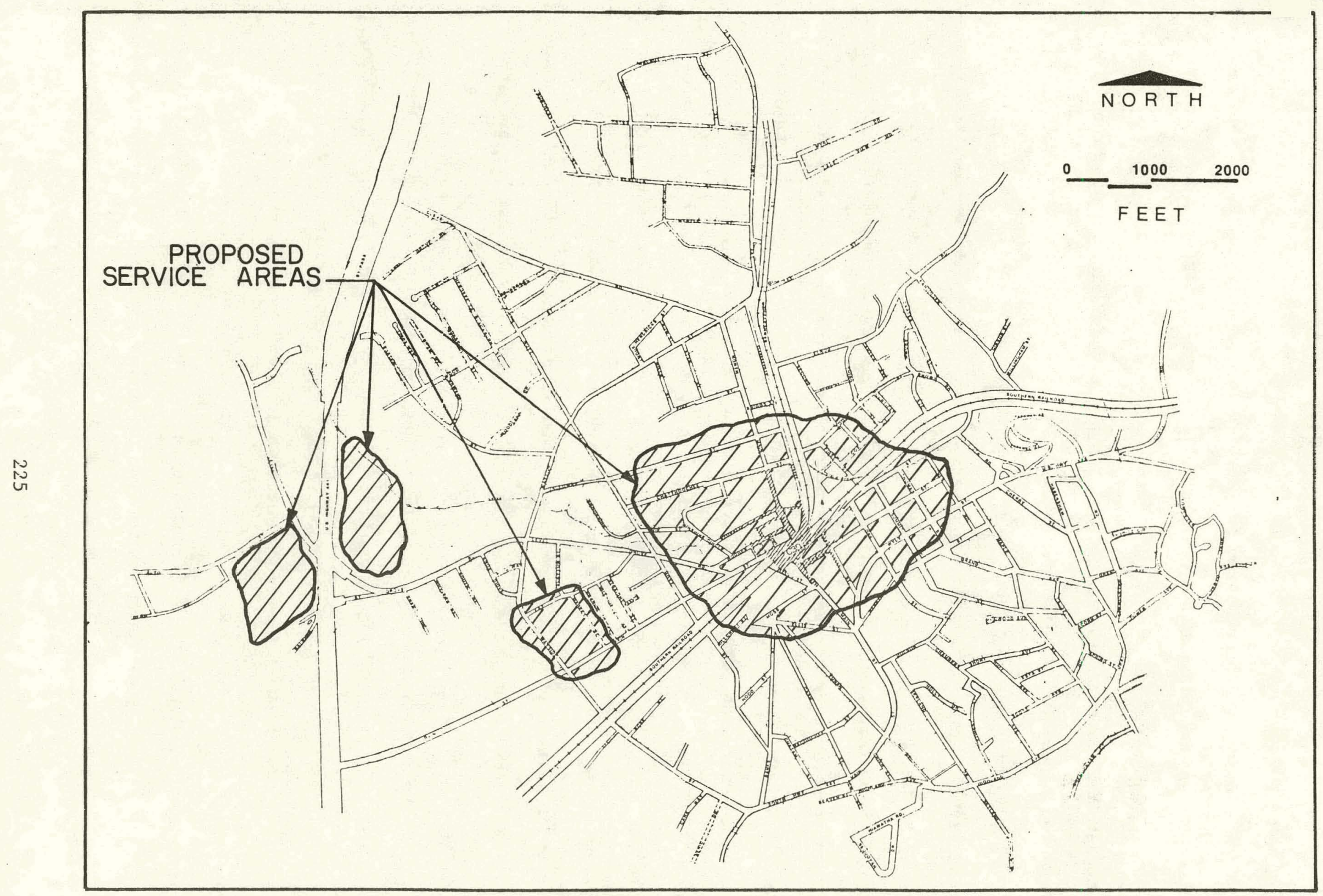

CITY OF CORNELIA

HP-WHR SYSTEM SERVICE AREAS

FIGURE 9-I 


\subsubsection{PROPOSED SERVICE AREA}

The community area proposed for service by the Cornelia Heat Pump - Wastewater Heat Recovery System is restricted to a fairly close group of commercial establishments, an industrial plant and the central business district. This somewhat limited service group was chosen after consideration of the points presented in the following paragraphs.

The initial consideration when determining the Cornelia service area was proximity of thermal loads to the energy source. As is the case with many waste treatment facilities, Cornelia's is located remote from the town core and is significantly removed from most residential groupings. Residential growth has tended to move away from the treatment plant area due to more favorable access to Gainesville, Georgia (the nearest town of significant size) and because of the unpleasant side effects of the treatment plant itself - i.e. odors from incomplete waste treatment. For this reason, the newer, larger residences offering the greatest potential for using the thermal media provided by the system are furthest from the thermal source. Those residences nearest the treatment plant are 30 to 40 years old, small and generally in need of weatherization. These older houses are typically heated with natural gas and are not air conditioned.

Another significant factor influencing the decision not to deal specifically with residential service is a lack of predictable residential growth. Community development studies for Cornelia predict small population increases over the next 20 years with no trends which would indicate housing growth in a particular area convenient to serve from the HP-WHR system. Accordingly, it was determined that Cornelia's residential sector did not offer an attractive market for thermal energy services from a central wastewater heat recovery plant. 
The commercial sector of Cornelia is primarily "Highway-oriented" or located in the central business district in the heart of town. This group would appear to offer the highest potential for thermal energy use in the shopping center area located west of town along the Rt. 441 Cornelia Bypass and in the central business district. Factors favoring the use of thermal energy through heat pump retrofit are: heavy use of space air conditioning, trend toward remodeling some of the central business district shops, and a significant number of commercial shops using electric resistance heating.

The only significant industrial customer present within the service area is the Fieldale Poultry Processing Plant. This plant is also the supplier of most of the thermal effluent contained in the wastewater stream. It is envisioned that a nearly continuous supply of $70-80^{\circ} \mathrm{F}$ water could be utilized by Fieldale for their ice-making and process refrigeration requirements, thus eliminating their need for evaporative coolers. This arrangement would also benefit the system performance since the additional heat input during winter operation could be used by other buildings.

\subsubsection{BUILDING CONSTRUCTION}

As shown in Figure 9-2, three zones, categorized by locality and building type, were identified within the proposed service area.

Zone $\mathrm{C}-1$ is the central business district located in the heart of the City of Cornelia. It is an extremely dense building area for this size town with an inventoried 73 commercial structures, composed of one and two story brick buildings, most of which have adjoining walls. In most cases the building shells are 30 to 40 years old. Many buildings have had interior remodeling to serve the current occupants. As is typical of older commercial structures, little or no insulation is present except where added during remodeling. There 
are also some newer structures ranging in age from 3 to 20 years. Most buildings in this zone are heated and cooled with forced air systems. The heating requirements are provided by natural gas furnaces or electric resistance heaters. Cooling is accomplished by direct refrigerant expansion systems using air cooled condensers.

Zone C-2 is a new strip shopping center located on the Highway 441 Bypass. When ultimate build-out potential is reached, an estimated 10 commercial structures will be located on this site. The center is typical of current commercial construction and consists of masonry walls, glass storefront and a metal deck, insulating board and built up roof assembly. Insulation is included in the ceilings and walls. The stores within the shopping center will be heated by electric resistance heat and cooled by roof mounted packaged air conditioning units. Each store has its own individual HVAC system.

Zone $\mathrm{C}-3$ is an existing strip type shopping center located on the Highway 441 Bypass. An estimated 8 commercial establishments will be located at this site, upon completion. The center is approximately three years old and is constructed with masonry walls, glass storefront and a metal deck, insulating board and built-up roof assembly. Typically, only the roof is thermally insulated. The stores within the shopping center are heated and cooled by roof mounted packaged air conditioning units which utilize electric resistance heat. Each store has its own individual HVAC system.

Total commercial structure square footage in the three proposed service zones is estimated at 434,709 . The estimate is based upon actual inventories of the existing structures in the central business district (Zone C-1) and upon estimates of the completed square footage of the commercial establishments to be located in the two shopping centers (Zones $\mathrm{C}-2$ and $\mathrm{C}-3$ ). 


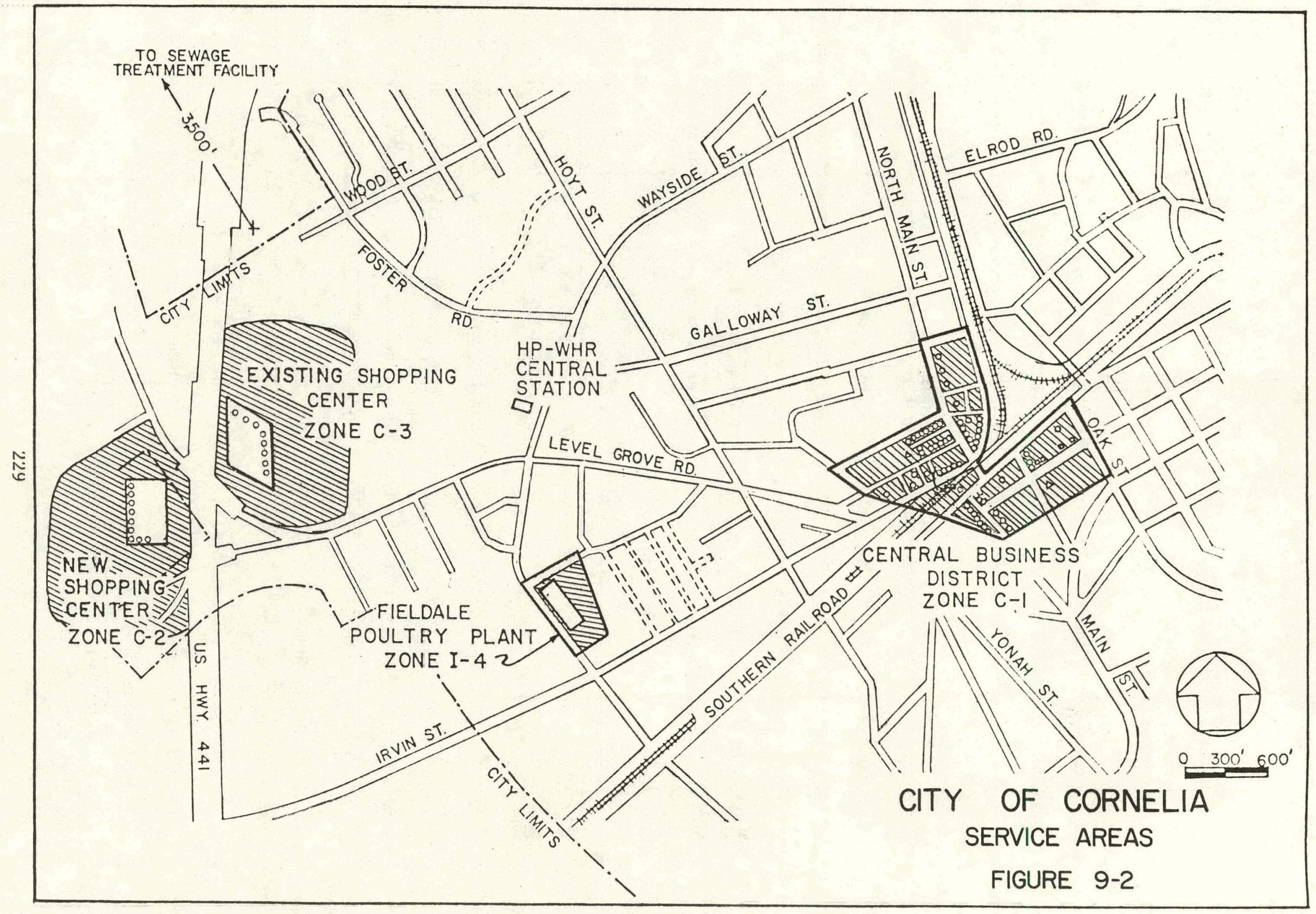




\subsubsection{HEATING AND COOLING LOADS}

\section{Monthly Loads}

Heating and cooling loads for the Cornelia study area were estimated on a monthly basis for those building structures served within the projected service area. The primary emphasis in load development was placed on monthly figures since no greater degree of detail could be justified in a preliminary study of this type. Peak loads were also developed using design conditions from the 1977 Fundamentals volume of . ASHRAE Handbook and Product Directory. 50

The estimation of monthly heating and cooling requirements was calculated by the computer program discussed previously in Chapter 8.0 of this report. The input to the calculation procedure takes into account building area served and unit building energy requirements determined by the program user for building type and climatological zone.

The service area under consideration for Cornelia contains only commercial establishments and an industrial plant located close to the proposed central heat recovery plant. Building count and area were estimated from field surveys and data excerpt from the Cornelia Community Development Plan ${ }^{57}$ prepared by the Georgia Mountains Area Planning and Development Commission. Experience with commercial building energy use patterns in the southeast indicates that annual heat losses will total approximately $50 \mathrm{MBtu} / \mathrm{ft}^{2}$ and that cooling requirements will be in the range of $32 \mathrm{MBtu} / \mathrm{ft}^{2}$ for the type buildings found in the Cornelia service area.

Monthly heating and cooling loads were determined by apportioning the annual requirement according to the percentage of heating or cooling degree days occurring in a particular month. Heating and cooling degree days were 
taken from "Monthly Normals of Heating and Cooling Degree Days 1941 - 1970", published by the National Climatic Center, Asheville, North Carolina. ${ }^{55}$ Table 9-2 is a summary of the percentage figures utilized in apportioning the annual load estimates.

TABLE 9-2

Annual Heating and Cooling Degree Days

Cornelia, Georgia

\begin{tabular}{|c|c|c|c|c|}
\hline \multirow[b]{2}{*}{ Month } & \multicolumn{2}{|c|}{ Heating } & \multicolumn{2}{|c|}{ Cooling } \\
\hline & Degree Days & $\%$ Total & Degree Days & $\%$ Total \\
\hline Jan. & 732 & 21.0 & 0 & 0.0 \\
\hline Feb. & 605 & 17.3 & 0 & 0.0 \\
\hline March & 492 & 14.1 & 12 & 1.0 \\
\hline April & 188 & 5.4 & 20 & 1.7 \\
\hline May - & 61 & 1.7 & 108 & 9.0 \\
\hline June & 10 & 0.3 & 244 & 20.3 \\
\hline July & 0 & 0.0 & 322 & 26.8 \\
\hline August & 0 & 0.0 & 310 & 25.6 \\
\hline Sept. & 29 & 0.8 & 155 & 12.9 \\
\hline Oct. & 196 & 5.6 & 32 & 2.7 \\
\hline Nov. & 468 & 13.3 & 0 & 0.0 \\
\hline Dec. & 716. & $20: 5$ & 0 & 0.0 \\
\hline & 3497 & 100.0 & 1203 & 100.0 \\
\hline
\end{tabular}

Industrial energy requirements are significantly more difficult to estimate without a detailed analysis of process and environmental constraints. However, to account for a potential energy credit from the industrial concern included in the service area, a constant monthly cooling requirement of 230 MBtu/month was allowed. This cooling requirement represents a constant demand 
at the subject plant for condenser water service for ice-making equipment.

Table 9-3 presents a month-by-month summary of the total projected thermal load on the HP-WHR system. The results of the computerized load calculations and peak load determinations are presented in Appendix D.

TABLE 9-3

CORNELIA HP-WHR SYSTEM LOADS

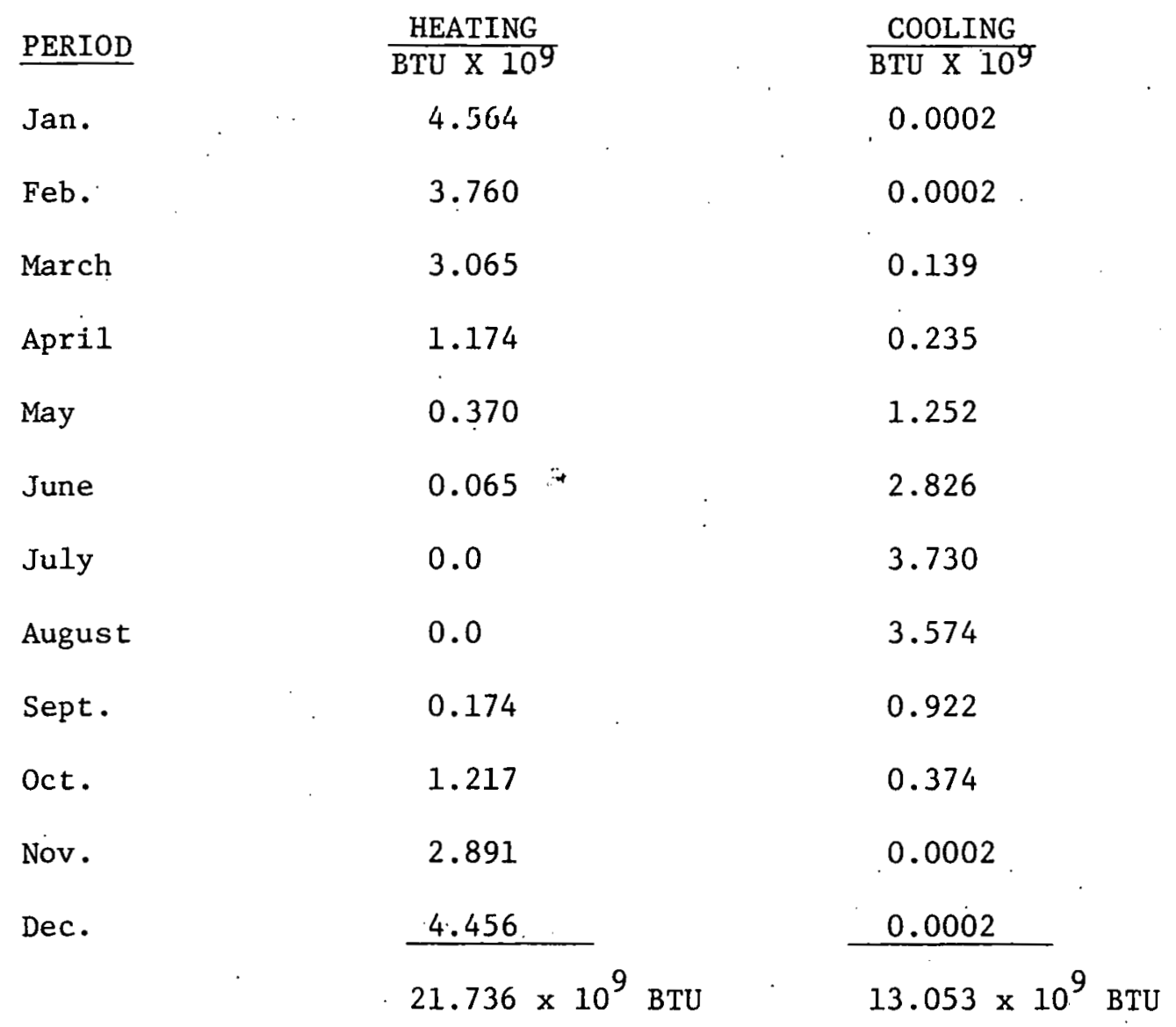

Peak Heating Load

As mentioned above, peak loads were estimated using the procedures and design conditions from the ASHRAE Handbook. ${ }^{50}$ The degree day formula, with terms rearranged to solve for the peak load, $P$, was utilized as shown below: 


$$
P=\frac{(E) \times(T D)}{(D D) \times(24)}
$$

Where:

$$
\begin{aligned}
& P: \text { - Design heating load per hour } \\
& E=\text { Heat energy required } \\
& T D=\text { Design temperature difference } \\
& D D=\text { Heating degree days }
\end{aligned}
$$

For this estimate:

$$
\begin{aligned}
E=4.564 \times 10^{9} \mathrm{Btu}-\text { from the computer load estimate for January } \\
\mathrm{TD}=70^{\circ}-17^{\circ}=53^{\circ} \mathrm{F}-\text { desired inside temperature minus the } 99 \% \text { design } \\
\text { temperature for Cornelia. } \\
\mathrm{DD}=732-\text { from Table } 9-2 .
\end{aligned}
$$

Thus

$$
\begin{aligned}
P & =\frac{\left(4.564 \times 10^{9}\right) \times\left(53^{\circ}\right)}{(732) \times(24)} \\
& =13.77 \times 10^{6} \mathrm{Btu} / \mathrm{hr}
\end{aligned}
$$

\section{Peak Cooling Load}

Utillzlng the design figures of an average 350 square feet per peak ton of refrigeration for commercial structures, the peak cooling load for the proposed Cornelia service area was estimated as follows:

$$
\begin{aligned}
\text { Peak Cooling Load } & =\frac{434,709 \mathrm{ft}^{2} \text { (building area served) }}{350 \mathrm{ft} / \mathrm{ton}} \\
& =1242 \text { Tons }
\end{aligned}
$$




\section{1 .8 THERMAL ENERGY RESOURCES}

As noted in earlier chapters of this report, the low-grade heat in a community.'s wastewater will be utilized as the thermal energy source in an HP-WHR based HP-ICES. Also as explained earlier, many site-specific variables affect the amounts and availability of thermal energy from this source at any particular point of application. To determine the quantities of thermal energy available at a spectic dcmonstration community necessarily involves examination and analysis of the community's wastewaler.collection and treatment facilities along with any appropriate documentation of operating conditions, performance, etc. The following sections examine the wastewater facilities of the Cornelia, Georgia community and develop estimates of the thermal energy available to an HP-WHR installation at a proposed location in Cornelia. CITY OF CORNELIA, GEORGIA WASTEWATER FACILITIES

The City of Cornelia completed in July 1977 a comprehensive review of its wastewater collection and treatment facilities in the form of a 201 Facilities Plan under E.P.A. Pröject \# $130585-01-0 .{ }^{60}$ Pertinent data and descriptions from this report will be adopted as the basis for the evaluation of thermal energy availability at the Cornelia community.

The layout of the wastewater system, detailing location of lines, sizes, manholes, pump stations, and force mains, is depicted on Figure 9-3, reproduced from the 201 Plan. Also shown on this layout are the major division lines between the flow metering areas employed for the 201 Study Analysis. Sections 
of the system vary in age from one year to 65 years. The older portion of the system is composed of concrete pipes with concrete joints and is located principally in the downtown area, located in flow metering area 3 and the western portion of area 4. The most recently constructed sewers are located in flow metering areas 2 and 6 , and the outskirts of area 7 . Sewer construction in these areas incorporates terra cotta pipe with rubber 0-ring sealed joints. The general condition of the entire sewer system is good relative to deterioration of existing pipes and manholes.

The original Cornelia Treatment Plant was built at its present location in 1963. The original plant consisted of coarse screening, grit removal, fine screening (1/4"), primary clarification, low rate trickling filter, polishing pond, anaerobic sludge digestion (uncovered), and sand drying beds. The facility was expanded in 1967 with the following additions: a second primary clarifier, a large high rate trickling filter, a secondary clarifier, and a second anaerobic sludge digestor (uncovered). More recently, and in response to the NPDES permit requirements for fecal coliform removal and post-treatment aeration, a chlorine feed system and contact basin with cascading outfall were added to the process. The chlorination system and cascading outfall became operational in mid-July 1976. The plant as it exists today is shown in Figure 9-4.

FLOW AND TEMPERATURE DATA - CORNELIA, GEORCIA

As discussed in Chapter 10.0 - COMPONENT TESTING, site-specific temperature and flow measurements are the necessary first step in developing a data base for determining the thermal energy available at any particular site of application. Measurement of these parameters at the Cornelia sewage treatment facility were performed during the period $10 / 13 / 78$ to $10 / 20 / 78$. Temperature measurement was with a Simpson Type 23103 portable strip-chart recorder with 


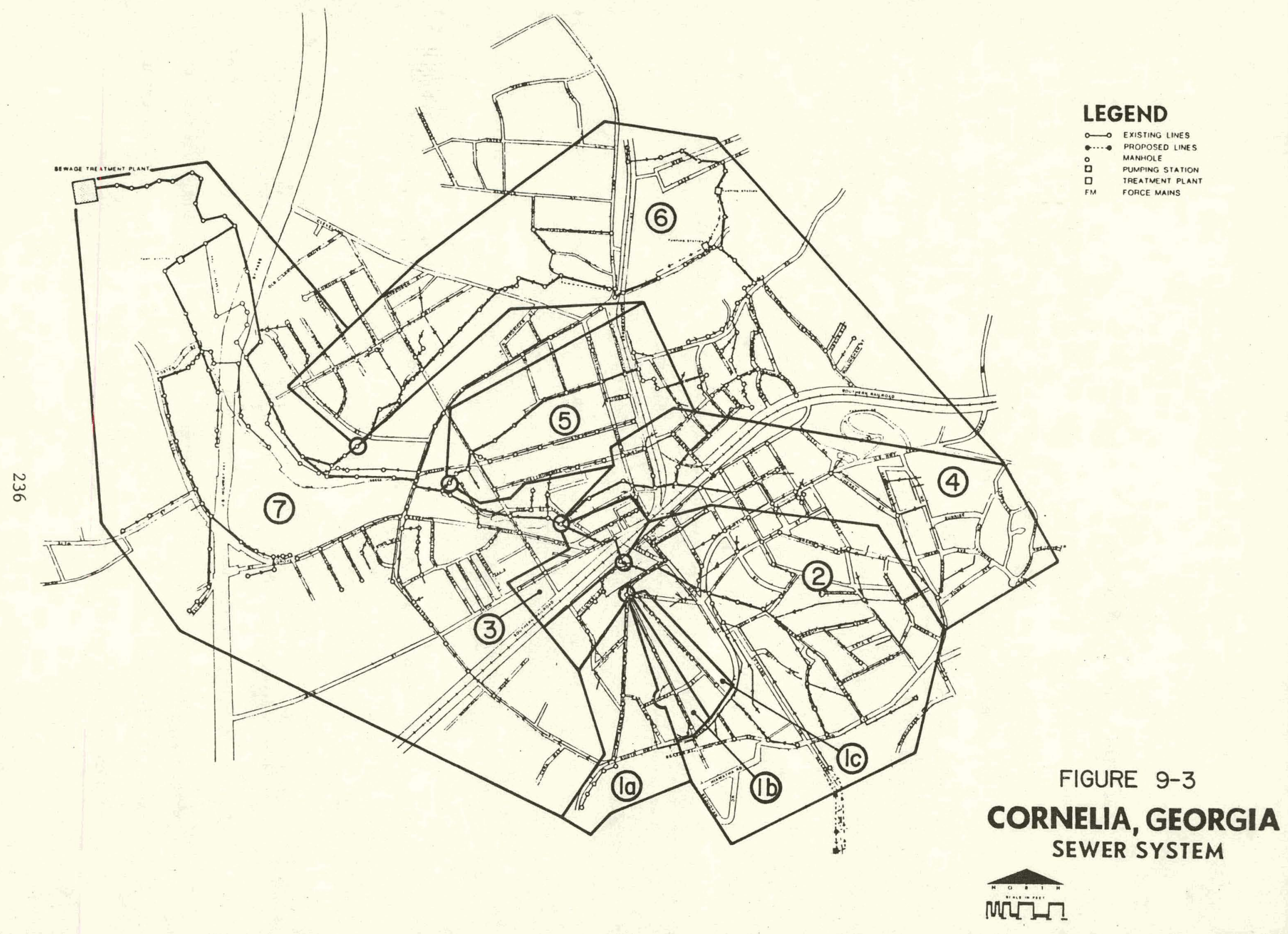




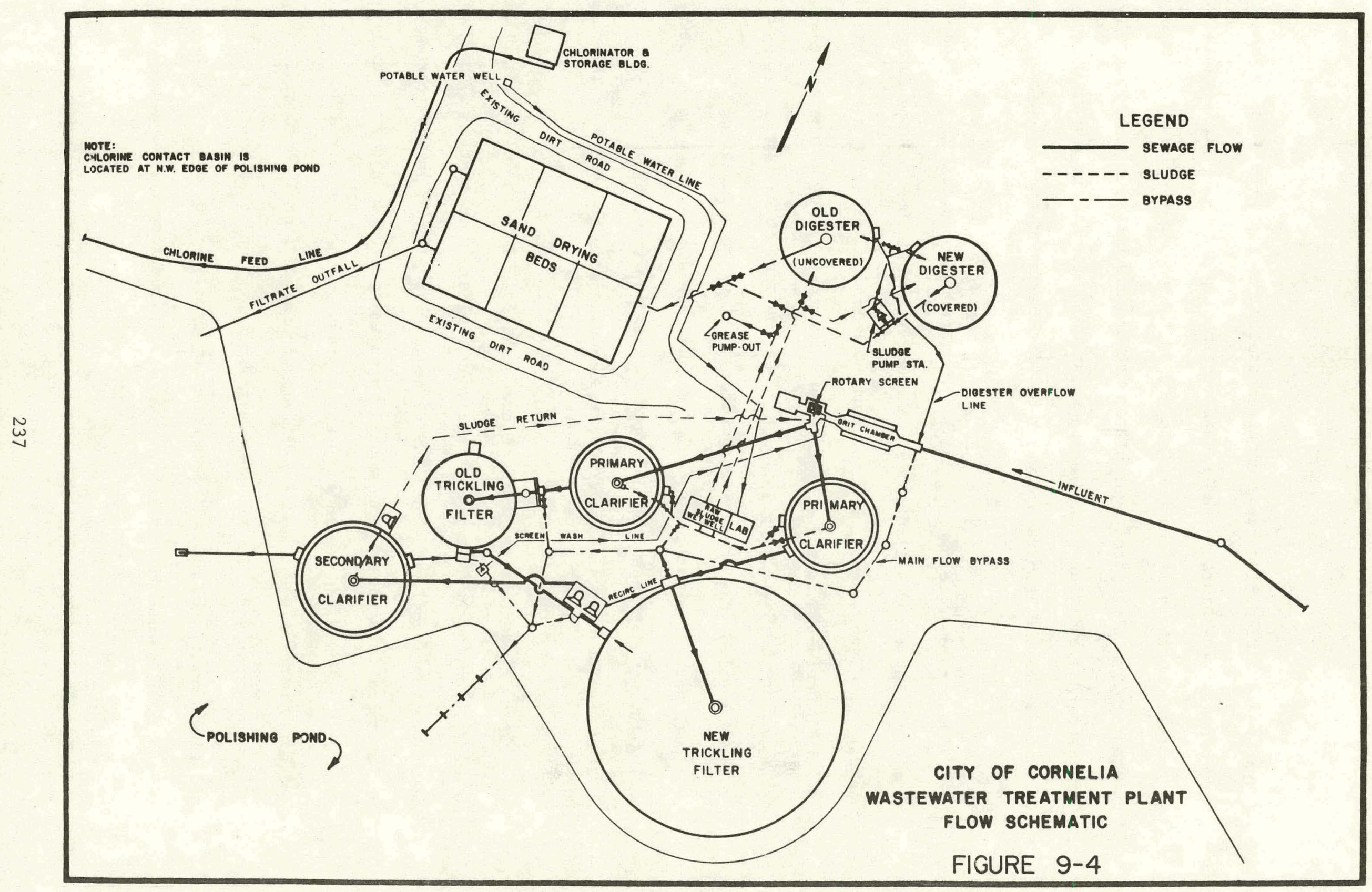


a type $\mathrm{R}-22,3-\mathrm{SE} 100-120$ resistance temperature device (RTD). Measurements were made at two-points in the sewage treatment plant: 1.) plant influent at the head of the grit chamber, and 2.) at the secondary clarifier (essentially the last point in the treatment process before discharge). Flow measurement was taken from existing plant instrumentation. Results are presented graphically (Flow vs. Time and Temperature vs. Time) in Figure 9-5 and summarized in Table $9-4$.

F1nw was found to be on a daily cycle, as expected, with significant peaks at mid-morning ( $9: 30-11: 00 \mathrm{am})$ and mid-afternoon (1:30 - 3:0Upm) dusing the weekdays (no doubt due to the Monday through Friday operation of the Fieldale poultry processing plant which produces approximately $72 \%$ of the wastewater processed at the Cornelia plant). Flow was noticed to be fairly constant and at a low level on the weekend with Saturday flows at a relatively higher level (and with several significant peaks) than on Sunday. Average Daily Flow (ADF) during the weekdays was $1,640,000$ gallons per day (1.65 MGD). ADF during the weekend was 350,000 gallons per day (.35 MGD). Weighted ADF over the entire week is 1.25 MGD.

Plant influent temperature on the weekdays seemed to follow with the level of flow (again likely contingent on Fieldale's discharge) with high temperatures ranging from $95^{\circ} \mathrm{F}$ to $109^{\circ} \mathrm{F}$, peaking usually in late afternoon (4:00pm or later) or into the evening hours. High temperatures on the weekend ranged from $82^{\circ} \mathrm{F}$ to $900 \mathrm{~F}$. Low temperatures on plant influent occurred usually during the early morning hours $(7: 00-9: 00 \mathrm{am})$ and ranged from $70^{\circ} \mathrm{F}$ to $820 \mathrm{~F}$.

Temperatures at the secondary clarifier remained relatively constant at all times during the day and week, ranging from $68{ }^{\circ} \mathrm{F}$ to $82^{\circ} \mathrm{F}$. Slightly higher temperatures seemed to prevail in the clarifier during the weekend (perhaps due 
SEWAGE TREATMENT PLANT

10-14-78-10-19-78
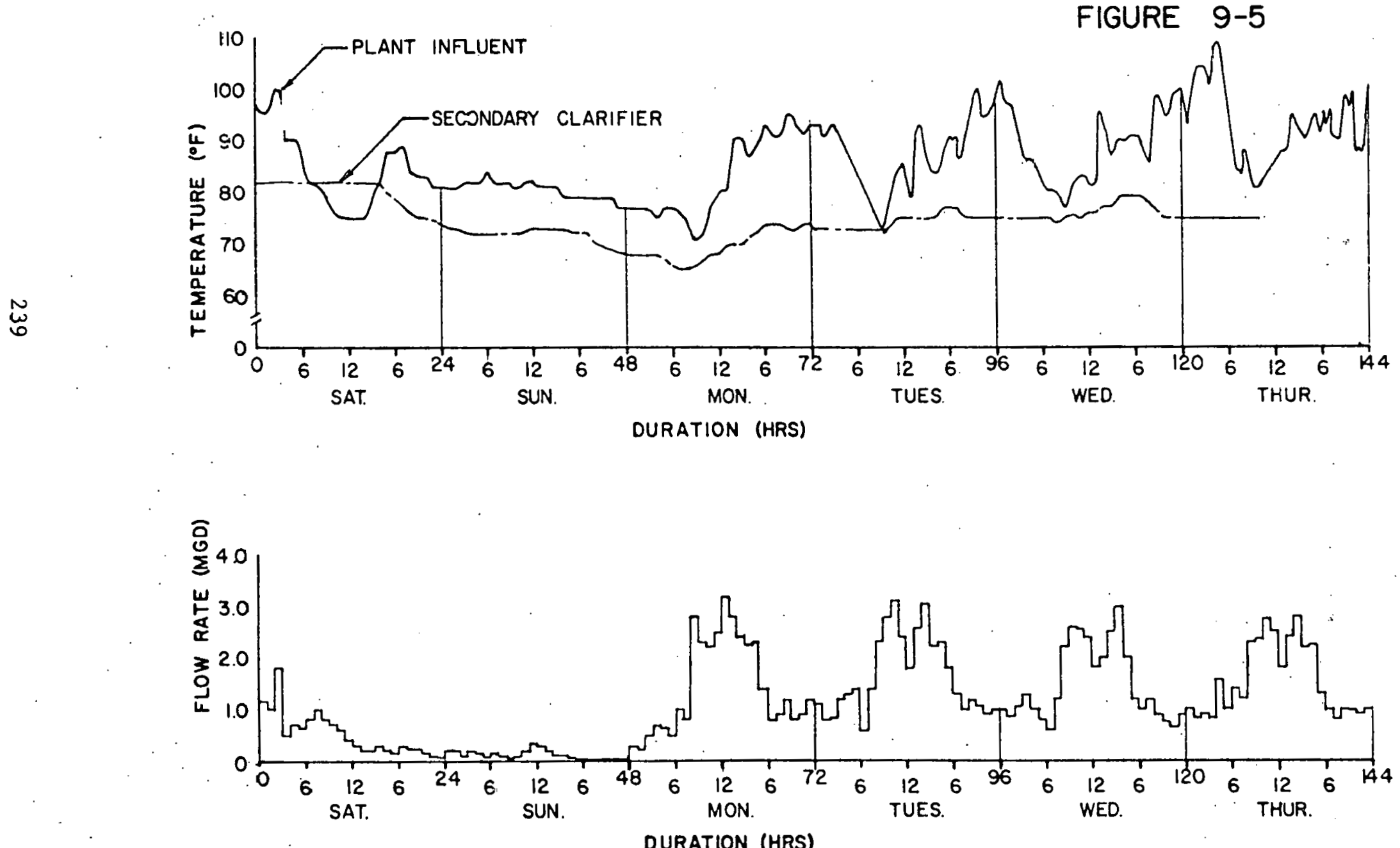
to the extended retention time - up to 15 hours - made necessary by the low weekend flow levels).

It is expected that, for the Cornelia wastewater system, sewage flows will continue to show a daily pattern of high flows during normal. working hours due to the continuing presence of the Fieldale plant, and lower flows during evening and early morning hours. The weekend pattern of proportionately lower flows will also likely continue.

It is also expected that the temperature of the plant influent will continue to exhibit daily peaks of approximately $104^{\circ} \mathrm{H}^{\prime}$ durlng the latc afternoon hours of the weekdays, due to the relatively constant temperature discharge of Fieldale's processes. Temperatures at the secondary clarifier will continue on their relatively constant trend. Extreme seasonal influences may reduce the operating temperatures somewhat, but will not significantly affect the availability of the thermal energy at this source.

From the above characterization of the Cornelia wastewater conditions it is apparent that signficant amounts of thermal energy are available for reclaim with an HP-WHR system. The next report section will discuss briefly the factors pertinent to the wastewater system which will affect the location of the HP-WHR central station and will develop estimates of the quantities of thermal energy available at the proposed location.

\section{CENTRAL PLANT LOCATION \& THERMAL ENERGY ESTIMATE}

As explained in the discussion of the proposed service area, primarily commercial customers will be served from the initial system. The most attractive service areas, therefore, will be the central business district and the two shopping centers developing along the newly constructed Cornelia By-pass. Inspection of the sewer system layout reveals that a central station sited in 
TABLE 9-4

CORNELIA, GA. WASTEWATER SYSTEM

SEWAGE TREATMENT PLANT DATA

TEMPERATURES

\section{PLANT INFLUENT}

Day

$10 / 13$

$10 / 1 \dot{4}$

$10 / 15$

MON $10 / 16$

TUE $10 / 1$

WED $-0 / 18$

THUR $\quad 10 / 19$

FRI $10 / 2 C$

$\stackrel{N}{\lessgtr}$

\begin{tabular}{cc} 
Low $\left({ }^{\circ} \mathrm{C} /{ }^{\circ} \mathrm{F}\right)$ & High $\left({ }^{\circ} \mathrm{C} /{ }^{\circ} \mathrm{F}\right)$ \\
\hline $28 / 82$ & $36 / 97$ \\
$24 / 75$ & $32 / 90$ \\
$25 / 77$ & $28 / 82$ \\
$21 / 70$ & $35 / 95$ \\
$23 / 73$ & $39 / 102$ \\
$25 / 77$ & $40 / 104$ \\
$26 / 79$ & $43 / 109$ \\
$26 / 79$ & $40 / 104$
\end{tabular}

\section{$\underline{\text { FLCW }}$}

Low :

$4167 \frac{\mathrm{gal}}{\mathrm{hr}}(\simeq 0.1 \mathrm{MGD})$ SUN 10/15 $5: 00 \mathrm{pm}$ $154,167 \frac{\mathrm{gal}}{\mathrm{hr}}(\simeq 3.7 \mathrm{MGD})$ MON 10/16 12:15pm

Weekday Avg:

Weekend Avg:

$1,640,000 \mathrm{GPD}^{*}$

$350,000 \mathrm{GPD} *$
SECONDARY CLARIFIER

\begin{tabular}{cc} 
Low $\left({ }^{\circ} \mathrm{C} /{ }^{\circ} \mathrm{F}\right)$ & High $\left({ }^{\circ} \mathrm{C} /{ }^{\circ} \mathrm{F}\right)$ \\
\hline $28 / 82$ & $30 / 86$ \\
$28 / 82$ & $28 / 82$ \\
$20 / 68$ & $23 / 73$ \\
$19 / 66$ & $23 / 73$ \\
$22 / 72$ & $25 / 77$ \\
$24 / 75$ & $25 / 77$ \\
$24 / 75$ & $24 / 75$ \\
- & -
\end{tabular}

* FRGM E.P.A. 201 FACILITIES PLAN 60 
the vacant area bordered by Foster Street, Wayside Street, and Level Grove Road would have access to the parallel sewer mains which carry the bulk of the community wastewater effluent, including the discharge from the Fieldale plant, to the sewage treatment plant. Thus, the wastewater flows from flow metering areas $1 \mathrm{~A}-\mathrm{C}, 2,3,4,5$, and Fieldale would be available for heat reclaim at the central station. A station sited at this location would also be central to a distribution system serving the two main service areas, being approximately mid-way on a line between the central business district and the new shopping centers.

From Chapter 2.0 - POTENTIAL APPLICATIONS, the total amount of heat available from the thermal supply (wastewater) can be calculated from equation (2-2). shown below:

$$
Q=W C(\Delta T)
$$

Where:

$Q=$ total heat, Btu

$\mathrm{W}=$ flow of wastewater, $1 \mathrm{bm}$

$\mathrm{C}=$ specific heat of wastewater (assumed to be $1.0 \mathrm{Btu} / 1 \mathrm{bm}-{ }^{\circ} \mathrm{F}$ )

$\Delta \mathrm{T}=$ change in temperature of supply medium across the central station equipment heat exchanger, $O F$

For the purpose of making nationwide projections on available thermal energy from wastewater, flow was defined as a function of national population, and industrial wastewater discharges (a significant source of reject thermal energy) were ignored due to insufficient data. However, due to the availability of the 201 Facilities Plan for the Cornelia community and sewage system, actual flow data for the various flow metering areas in the community will be used as the basis for the estimates for available thermal energy. It should be noted that these figures also include industrial discharges.

Flow data from the 201 study is presented in tabular form as Table 9-5, 
TABLE 9-5

CORNELIA, GA. WASTEWATER SYSTEM

GENERAL FLOW METERING AREA DATA

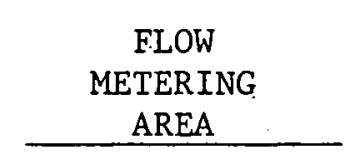

IA

$1 B$

$1 \mathrm{C}$

2

3

4

5

6

7 (W/O FIELDALE)

FIELDALE

TOTAL

*WEEKDAY

*WEEKEND

*SOURCE: EPA 201 FACILITIES PLAN
SENER

DIAMETER

(INCHES)

8

8

6

10

10

10

12

10

18

38,600

$$
141,900 \text { FT. }
$$

AVERAGE DAILY FLOW (GPD)

$$
9,000
$$

4,300

4,300

60,000

14,000

46,000

38,000

83,000

93,000

920,000

$1,271,600 \mathrm{GPD}$

$1,640,00$

350,000 
and schematically as Figure 9-6. Figure 9-6 also displays schematically the proposed location of the HP-WHR central station fiacility in relation to the overall sewer system. Thus, the central station, installed at this proposed location with the necessary storage capacities to absorb the diurnal fluctuations in flow and take advantage of the full available wastewater flow, would have access. to an average flow (ADF) of $1,095,600$ gallons per day (1.096. MGD -. the sum of flows from metering areas $1 \mathrm{~A}, 1 \mathrm{~B}, 1 \mathrm{C}, 2,3,4,5$, and Fieldale). Note that this figure is a weighted daily average of flows over a one week period. Weekend flows may be significantly less than this weighted average, thus the necessity of incorporating some form of storage capacity into the central station design.

Temperature data from the sewage treatment facility will also be utilized in developing estimates of available thermal energy. It is duly noted that the conditions documented herein are from a somewhat arbitrarily selected oneweek period which may or may not have been representative of conditions to be expected over an annual cycle. However, inspection of the seven-day flow cycle reveals no characteristics which would indicate it to be atypical. Further, since the flow pattern documented in this effort coincides quite accurately with that found during the E.P.A. 201 Facilities Plan analysis, it is anticipated that the documented weekly flow cycle can indeed be taken as typical. The temperatures of the wastewater, on the other hand, will likely exhibit more significant variations due to seasonal influences. However, due to the fact that the major controlling factor on wastewater temperature (at least during the five weekdays) is the temperature of Fieldale's process.discharge, it is anticipated that the affect of ambient temperature changes on the wastewater temperature will be moderated somewhat. The temperature and 


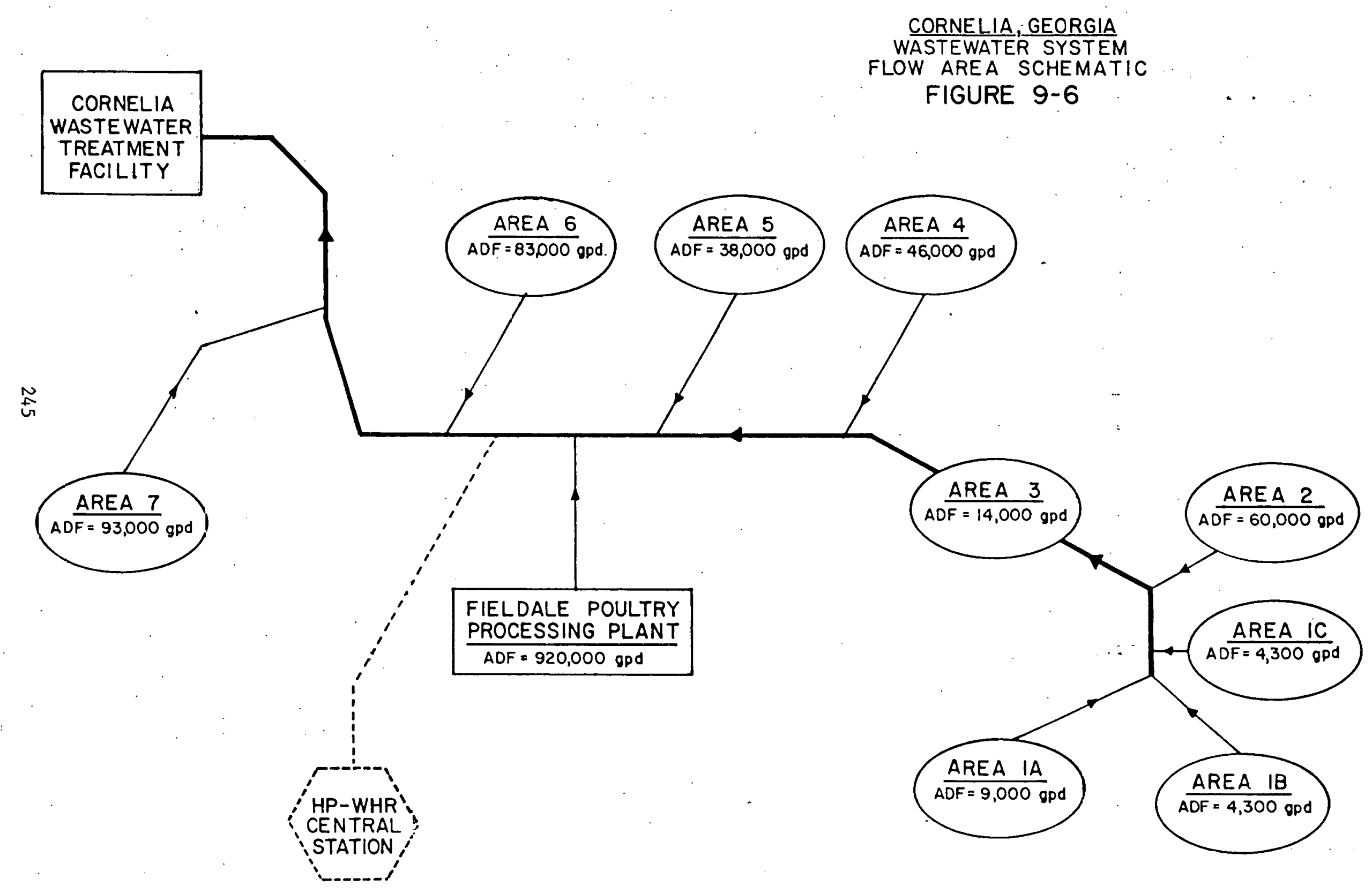


flow data presented here and utilized in the following estimate of available thermal energy are presented primarily to provide a firm base for this "ballpark" estimate. Figure 9-7 is a Temperature vs. Duration curve for plant influent temperature during the period $10 / 13 / 78$ through $10 / 20 / 78$, developed from the strip-chart temperature plot. A weighted average of the data shows the average temperature to be $86^{\circ} \mathrm{F}$.

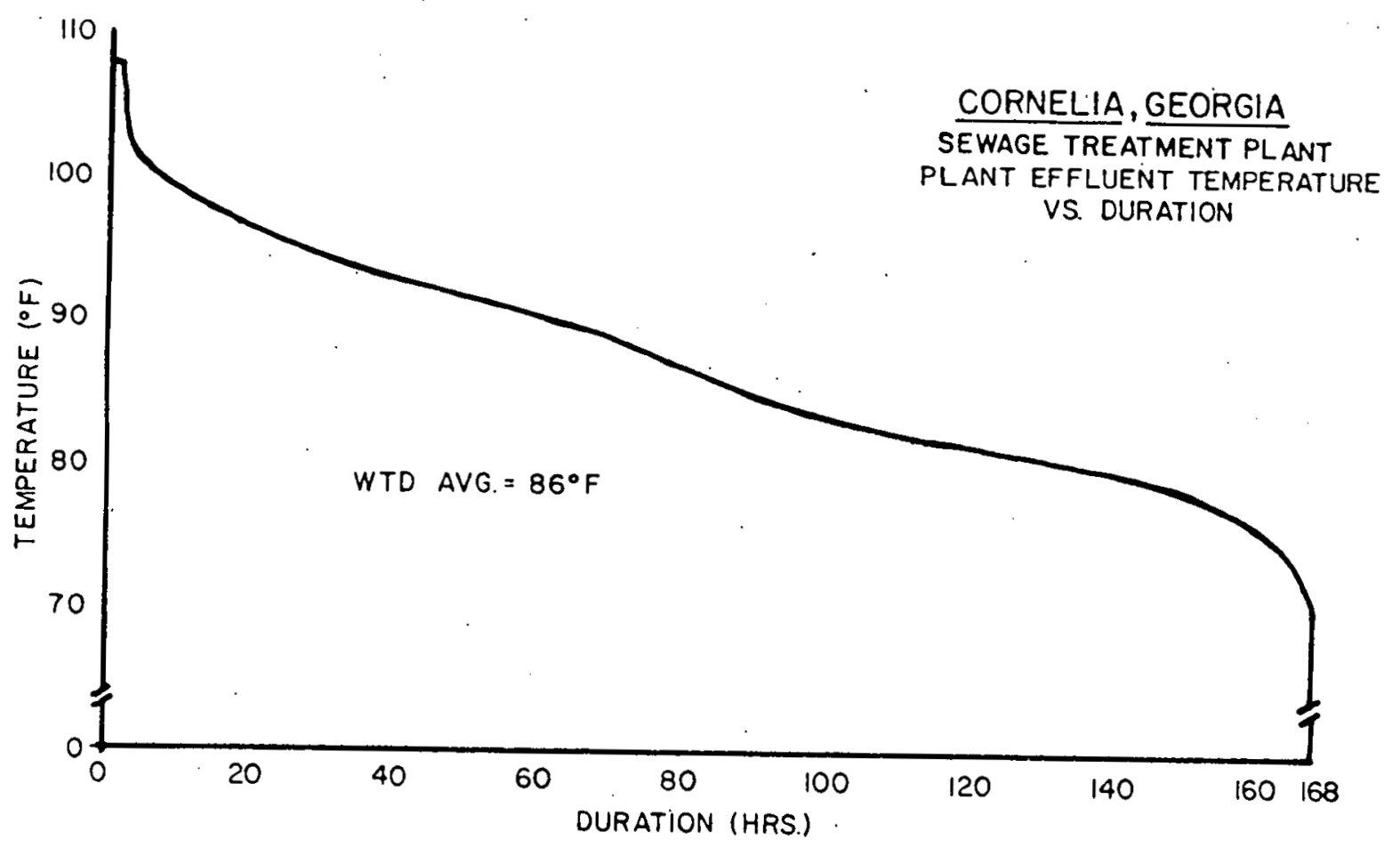

Figure 9-7 
A third condition to be defined for the thermal energy estimate is the change in temperature of the heat supply medium, $\Delta \mathrm{T}$ in equation (2-2), which could be achieved across the central station equipment heat exchanger. Essentially this would represent the heat transferred out of the wastewater flow. Theoretically, heat could be removed from a water source down to approximately $32 \circ \mathrm{F}$. However, due to equipment operating characteristics, a practical limit of $30^{\circ} \mathrm{F}$ can be set for $\Delta \mathrm{T}$.

Inspection of equation (2-2) reveals that the greatest quantity of heat would be reclaimed with the largest $\Delta \mathrm{T}$ possible, in this case $\Delta \mathrm{T}=30^{\circ} \mathrm{F}$. General HVAC system design practice dictates a $\Delta \mathrm{T} \simeq 10^{\circ} \mathrm{F}$. However, in this particular application, larger $\Delta T^{\prime}$ 's may be necessary or desirable. Therefore, in order to bracket the operating conditions which may be in effect at the central station, $\Delta \mathrm{T}^{\prime} \mathrm{s}$ of $100 \mathrm{~F}, 20^{\circ} \mathrm{F}$, and $30^{\circ} \mathrm{F}$ will be considered. Estimates of the thermal energy available for reclaim from Cornelia's wastewater can now be calculated.

- As an example, and utilizing equation (2-2), the energy reclaimed from community wastewater would be calculated thusly:

$$
\begin{aligned}
\text { AVG. DAILY FLOW }-1,095,600 \text { gallons } \\
\Delta T-300 \mathrm{~F} \\
\begin{aligned}
Q_{\text {DAILY }}= & 1,095,600 \frac{\mathrm{gal}}{\mathrm{day}} \times\left(8.33 \frac{1 \mathrm{bm}}{\mathrm{gal}}\right) \times\left(1.0 \frac{\mathrm{Btu}}{1 \mathrm{bm}-0 \mathrm{~F}}\right) \times\left(30^{\circ} \mathrm{F}\right) \\
= & 273,790,440 \frac{\mathrm{Btu}}{\mathrm{day}}
\end{aligned}
\end{aligned}
$$

Derived through this estimative methodology, Table 9-6 summarizes the quantities of thermal energy potentially available, on a daily basis, to an HP-WHR system installed at the proposed location in Cornelia and operating at the various conditions discussed in the foregoing paragraphs. 
TABLE 9-6

HEAT AVAILABLE FROM WASTEWATER

CORNELIA, GEORGIA

\begin{tabular}{|c|c|c|c|}
\hline$\Delta \mathrm{T}\left({ }^{\circ} \mathrm{F}\right)$ & $\begin{array}{l}\text { WASTEWATER } \\
\text { IN(OF) }\end{array}$ & $\begin{array}{l}\text { CONDITIONS } \\
\text { OUT }\left({ }^{\circ}\right) \\
\end{array}$ & $\begin{array}{l}\text { AVG. DAILY } \\
\text { HEAT RECOVERY } \\
\end{array}$ \\
\hline & & & (Btu/day) \\
\hline 10 & 86 & 76 & $91.26 \times 10^{6}$ \\
\hline 20 & 86 & 66 & $182.53 \times 10^{6}$ \\
\hline 30 & 86 & 56 & $273.79 \times 10^{6}$ \\
\hline
\end{tabular}

An important consideration in the application of an HP-WHR system to a community is the balance between the portions of the community served by the wastewater collection and treatment system and the portion of the community proposed for service by the heat pump system. Based upon the above estimate of thermal energy available at the Cornelia HP-WHR central plant and upon the assessment of the proposed service areas, the space conditioning requirements of the 73 commercial structures in the central business district and of the approximate 18 structures which will ultimately be constructed in the two shopping centers, and a portion of Fieldale's process requirements can be served under this system application. Examination of the wastewater collection system layout and of existing land use patterns and building locations reveals that, due to the proposed location of the HP-WHR central plant and its attendant take-off from the sewer trunk lines, only a portion of the community will serve to supply wastewater/thermal energy to the heat pump system. A field inventory of Cornelia and contiguous areas performed for the Cornelia Community Development Concept Plan ${ }^{57}$ indicates that 868 residential structures, 194 commercial and public structures, and 11 industrial structures are served by the wastewater collection system prior to the HP-WHR system tie-in. Of 
primary consequence is the fact that the wastewater effluent from Fieldale, which comprises approximately $72 \%$ of the total average daily wastewater flow from the community, is available at the proposed central plant location. Obviously, with this composite service area (residential, commercial, and industrial discharges) on the wastewater system, a concise balance ratio cannot be drawil as cuuld be for the purely residential service Conyers system. However, the above figures detailing the respective service areas of the wastewater and heat pump systems should serve to illustrate the balance between the two. 


\subsection{CORNELIA SYSTEM DESCRIPTION}

The wastewater heat recovery system for the Cornelia community will intercept warm sewage effluent from community industries and the majority of community residential buildings and extract heat ultimately to be used by selected commercial and industrial customers. The Cornelia system concept, while not different from the concept of extracting low-grade heat from sewage, differs from the original Heat Pump-Wastewater Heat Recovery System concept of rascaded heat pumps in several areas. These aleas are briefly outlined in following discussions.

The relatively high temperature of the sewage effluent encountered in the Cornelia community wastewater collection system $\left(86^{\circ} \mathrm{F}\right)$ suggests that a water-to-water heat exchanger might be more practical for extracting the waste heat contained in the sewage effluent than using a centrifugal heat pump: With this system modification, distribution system water temperatures of approximately $70^{\circ} \mathrm{F}$ should be obtainable for use by end-user heat pump systems throughout the community. In the event that wastewater temperatures were lowered due to dilution or unforeseen curtailment of thermal discharges into the sewer system, the heat exchanger component could be easily replaced with a central heat pump of the type envisioned for the basic HP-WHR System.

Another variation from the original Heat Pump-Wastewater Heat Recovery System concept is the use of an evaporative cooling tower to dissipate building heat in the summer rather than direct heat rejection to the wastewater stream. As demonstrated in the earlier concepts, the evaporative cooling component offers a significant energy conservation potential especially when one considers the high temperature of the wastewater stream into which the central heat pump would have to reject building heat. Figure 9-8 is a single 


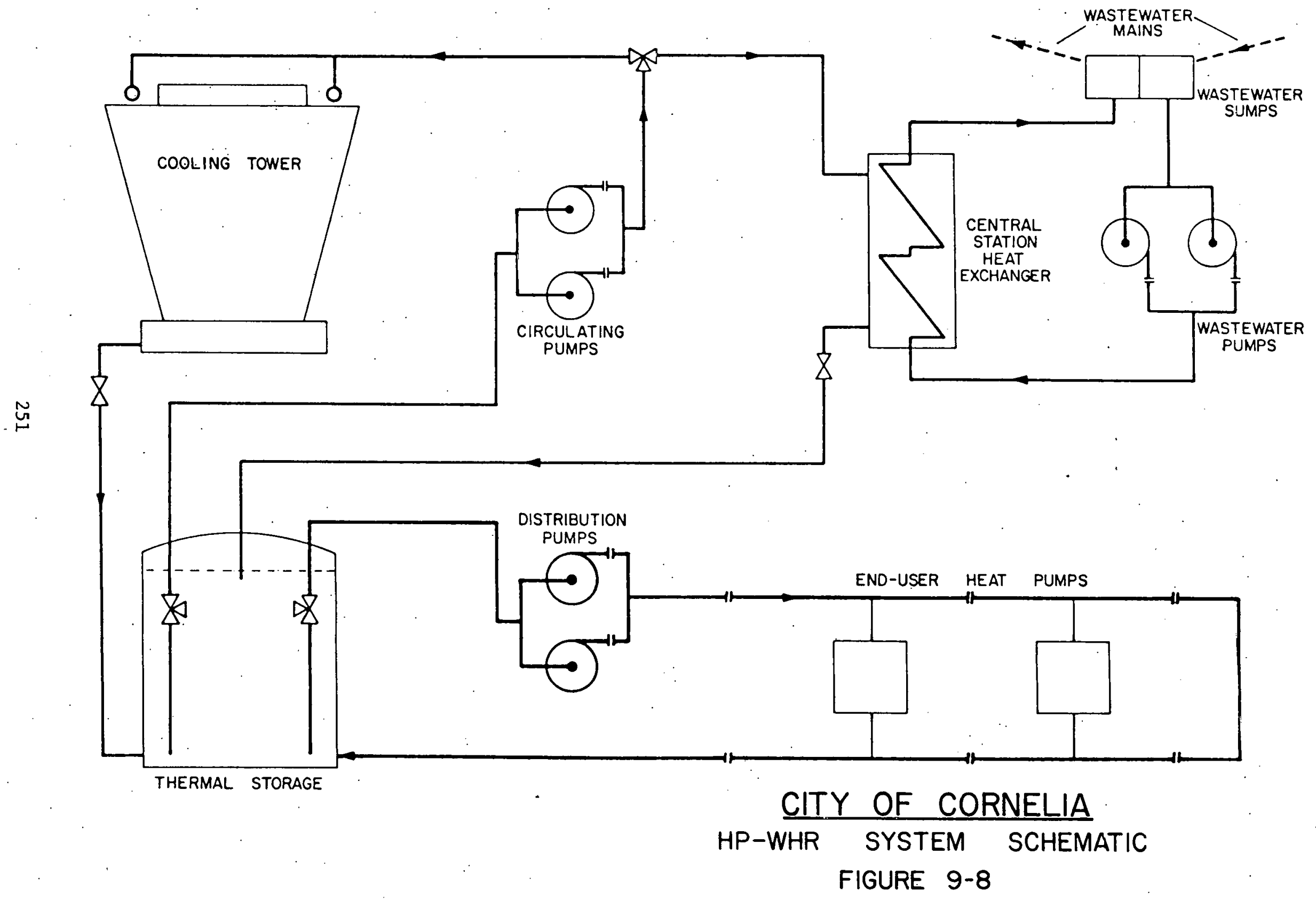


line schematic diagram for the Cornelia HP-WHR system.

The end-users served by the Heat Pump-Wastewater Heat Recovery System will be a subset of the Cornelia community composed of selected industrial and commercial establishments and the central business district. This subset was chosen because of its proximity to the thermal energy source, its high dependence on electric resistance heating as a current energy source, and the perception that these segments of the community would better be able to retrofit thcir buildings and establishments to use the recovered heat than would the typical residential consumer in the City of Cornelia.

The HP-WHR central station will be sited on a parcel of land centrally located and in close proximity to the four proposed service zones. Interconnection with the existing. wastewater collection system will be at a point on the main trunk line crossing the selected central plant site. The central plant layout and piping interconnection will be as illustrated in Figure 9-9: The warm water distribution system for the selected service areas will be designed and routed as illustrated in Figure 9-10.

The HP-WHR system application in the Cornelia community offers the unique opportunity to evaluate heat recovery from wastewater effluent through direct heat exchange techniques, thermal energy distribution to end-users, and the ultimate use of that low-grade thermal energy by commercial and industrial consumers. It is felt that the proposed system concept offers the greatest potential for implementation by the Cornelia community.

\subsubsection{SYSTEM DESIGN CALCULATIONS}

The major components comprising the HP-WHR system which are to be specified in a system development study include the central heat pump, the thermal storage vessel, the cooling tower, auxiliary pumps, and end-user heat pumps. 

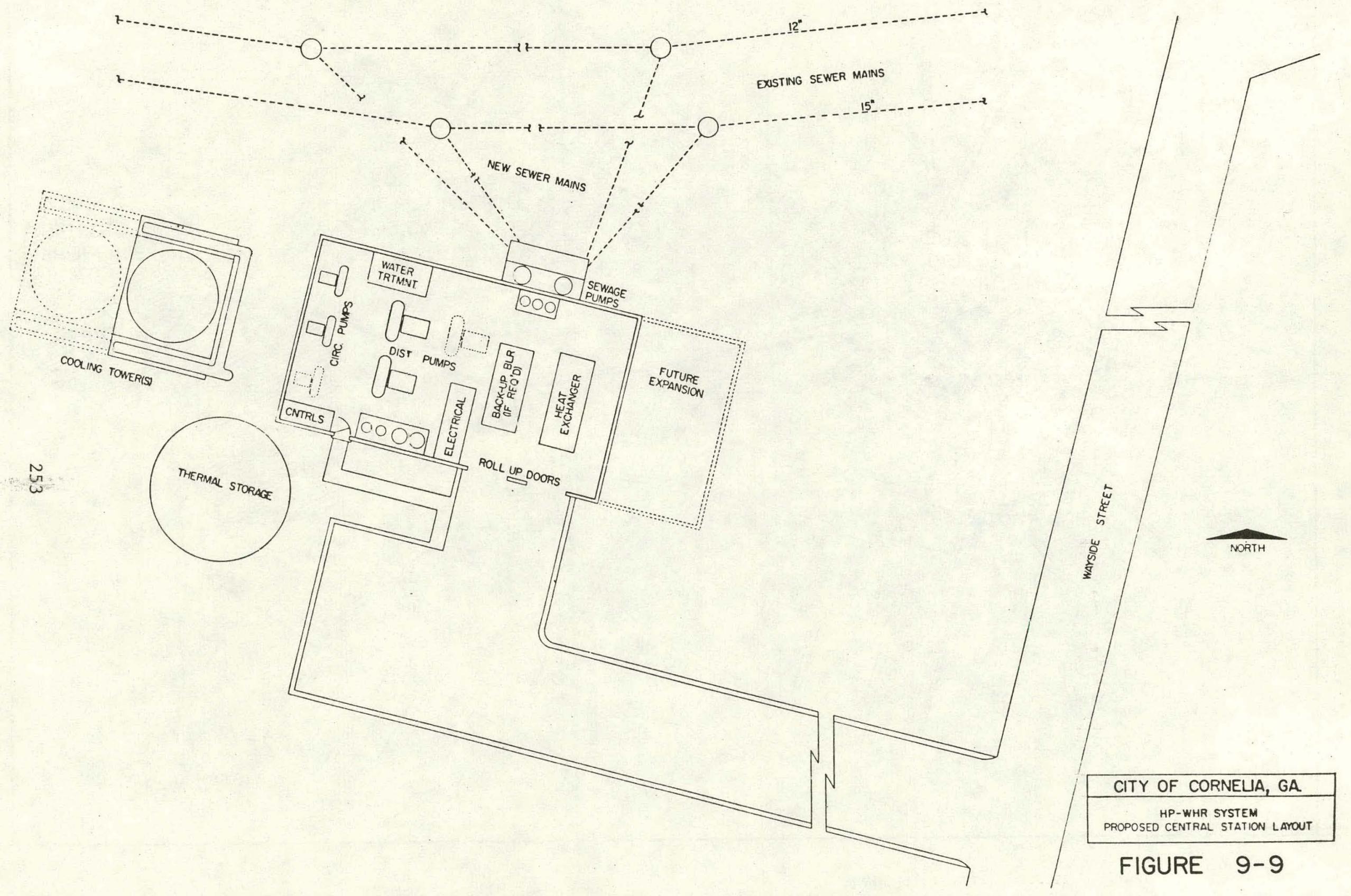


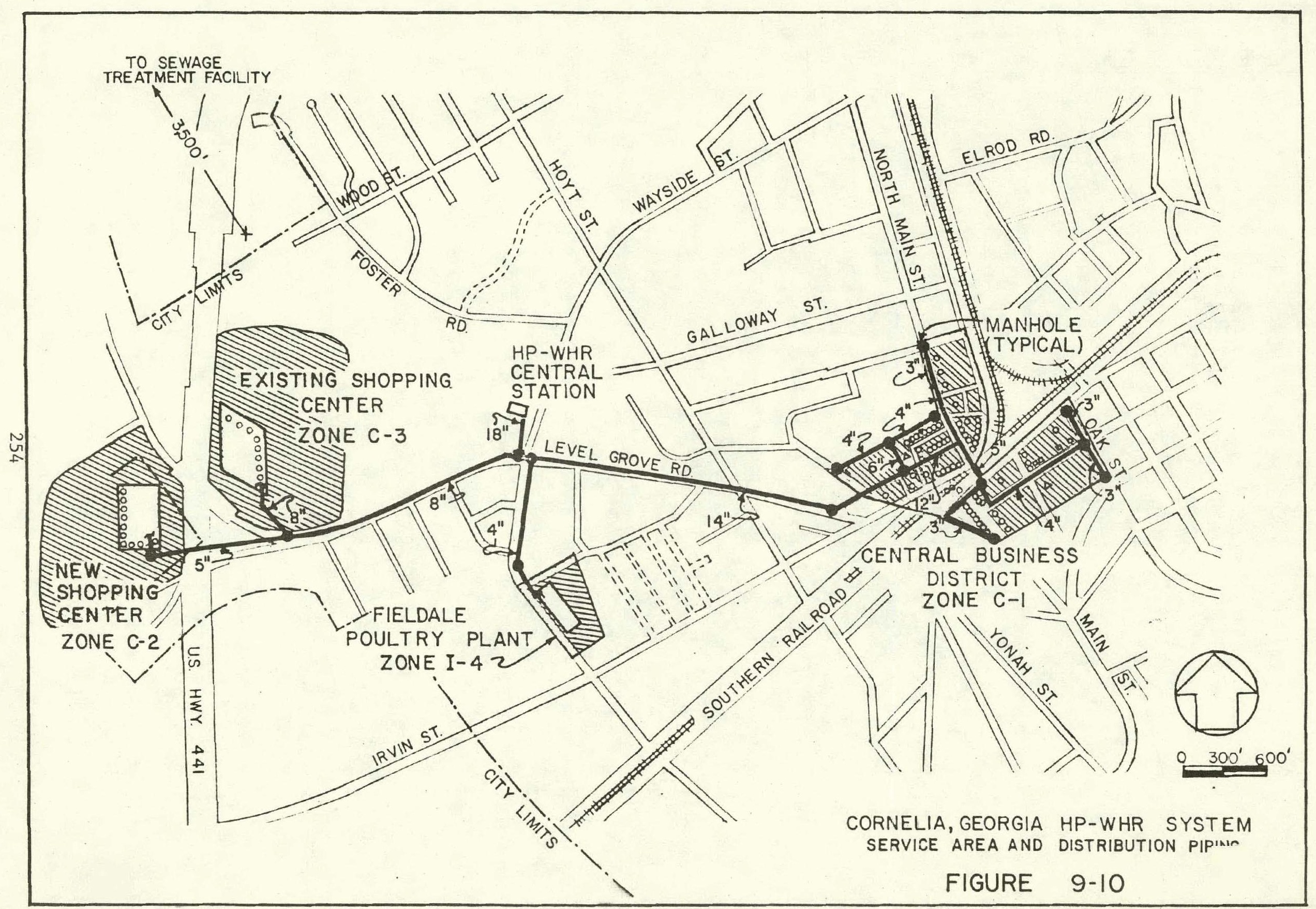


However, since for any system the end-user heat pump specification.will be necessarily structure-specific, sizing of those components will not be addressed in this report section. The remainder of the major component design calculations are presented in the following paragraphs.

\section{Central Heat Exchanger}

The central heat exchanger will serve in lieu of a central heat pump to transfer the low-grade thermal energy in Cornelia's wastewater to the HP-WHR system transport media, Due to the fact that the central station is located on a site away from the sewage treatment facility, the potential for warm wastewater storage in the facilities clarifiers will not be available. Thus the central heat exchanger must be of sufficient size to take advantage of the peak wastewater flows during a daily cycle. Peak flow during the documented period was $154,167 \mathrm{gal} / \mathrm{hr}$. The heat exchanger will be sized to handle approximately $80 \%$ of this peak flow, or 2100 GPM. An entering wastewater temperature of $80^{\circ} \mathrm{F}$ will be assumed with a $\Delta \mathrm{T}$ drop of $20^{\circ} \mathrm{F}$ across the heat exchanger. $\left(80^{\circ} \mathrm{F}\right.$ is assumed rather than the documented $86^{\circ} \mathrm{F}$ in order to produce an appropriately conservative design.) The circulating water system between the heat exchanger and thermal storage will consequently be designed to accommodate a flow rate of $4200 \mathrm{GPM}$ entering at $55^{\circ} \mathrm{F}$ and leaving at $65^{\circ} \mathrm{F}$ (the $10^{\circ} \mathrm{F}$ $\Delta \mathrm{T}$ rise which will be necessary for thermal energy distribution 1nto the community). Operation will be on a 24 hour basis.

Based on the above noted operating conditions, the Log Mean Temperature Difference across the central heat exchanger would be: 


$$
\begin{aligned}
\text { LMTD } & =\frac{(60-55)-(80-65)}{L_{\mathrm{n}}\left[\frac{(60-55)}{80-65}\right]} \\
& =9.10^{\circ} \mathrm{F}
\end{aligned}
$$

Assuming an overall heat transfer coefficient, $\mathrm{U}_{\mathrm{O}}$, of $250 \mathrm{Btu} / \mathrm{hr}-\mathrm{ft}{ }^{2}-{ }^{\circ} \mathrm{F}$ typical in heat exchangers of this type 59 , the heat exchanger area required is determined as follows:

$$
\begin{aligned}
A & =\frac{G P M \times\left(8.33 \frac{\mathrm{LBM}}{G \mathrm{~T}}\right)\left(60 \frac{\mathrm{MIN}}{\mathrm{HR}}\right) \times \Delta \mathrm{T}}{\left(\mathrm{U}_{0}\right) \times \mathrm{LMTD}} \\
& =\frac{(2100)(8.33)(60)(20)}{(250)(9.1)} \\
& =9227 \mathrm{ft}^{2}
\end{aligned}
$$

The external dimensions of a heat exchanger with this amount of heat transfer surface will be approximately $26^{\prime}$ length by $8^{\prime}$ diameter.

The applicability of the central heat exchanger is verified when the effective load on the central station is compared to its potential performance. Since the thermal storage component will allow the system to moderate somewhat the peak thermal demand, the quantity of heat which must be extracted from the wastewater flow during an average day of the peak heating month of January can be used as the basis of the comparison. The average daily heat requirement is calculated as follows:

$$
\begin{aligned}
Q_{\text {wastewater }} & =\frac{Q_{\text {heat req'd }}\left(1-\frac{1}{\text { C.0.P. }}\right. \text { end-user }}{\text { DAYS IN PERIOD }} \\
& =\frac{\left(4.564 \times 10^{9}\right)\left(1-\frac{1}{2.9}\right)}{31} \\
& =96.46 \times 10^{6} \mathrm{Btu} / \text { day }
\end{aligned}
$$


For comparison, the potential for heat reclaim at the central heat exchanger can be calculated, based on the available wastewater flow at the central station site. Inspection of the flow vs. time plots from section 9.1.8 reveals that the absolute peak flow at the sewage treatment facility exceeds the specified flow capacity of the central heat exchanger 3.02 MGD (2100 GPM $\times 60 \times 24$ ) - for just 2 hours of the 144 hour test period. Therefore, since no inordinate amount of the daily flow is received at rates exceeding the heat exchanger capacity, the average daily flow figures for the central station site can be utilized as the basis for the heat available calculation. Thus:

$$
\begin{aligned}
Q_{\text {available }} & =1,095,600 \frac{\mathrm{Gal}}{\mathrm{day}} \times\left(8.33 \frac{1 \mathrm{bm}}{\mathrm{gal}}\right) \times\left(1.0 \frac{\mathrm{Btu}}{1 \mathrm{bm}-{ }^{\circ} \mathrm{F}}\right) \times\left(20^{\circ} \mathrm{F}\right) \\
& =182.53 \times 10^{6} \frac{\mathrm{Btu}}{\mathrm{day}}
\end{aligned}
$$

The specified capacity of the central heat exchanger is thus compatible with the flow and temperature conditions to be expected on the Cornelia wastewater system and provides adequate capacity for serving the projected loads on the HP-WHR system.

\section{Therma1: Storage}

Inspection of the wastewater flow cycle at the Cornelia treatment plant (presented in section 9.1 .8 ) reveals that the characteristic low flow period during the seven-day flow cycle had an approximate 60 hour duration. In order to pluvlde adequate thermal energy supply capacity for the system during thcse low flow periods, the thermal storage component will be sized for a nominal 72 hour period (making an allowance for a $+20 \%$ variance in duration 
from the flow cycle documented in section 8.2.8) under January heating demand conditions. The nominal 72 hour capacity will also provide an adequate downtime "window" for the central heat exchanger for necessary scheduled maintenance such as tube cleaning.

Allowable temperature pulldown within the vessel will be designed at $25^{\circ} \mathrm{F}$. As in the Conyers system design, the primary consideration in defining this range is the effect on end-user heat pump performance. According to the equipmenl asscesment of Reference 7 , the performance of the selected hydronic heat pump at the upper design temperature of $65^{\circ} \mathrm{F}$ is very close to the nominal C.O.P. of 2.91. Heating C.O.P. deteriorates to 2.79, however, as the lower limit of $40^{\circ} \mathrm{F}$ is reached. This lower temperature also approaches what is generally considered to be the lower acceptable limit on entering water temperature for hydronic units.

The physical capacity of the thermal storage component is computed as follows:

$$
\begin{aligned}
Q_{\text {thermal storage }} & =\frac{\left(4.56 \times 10^{9} \mathrm{Btu}\right)\left(1-\frac{1}{2.9}\right) \times 72 \mathrm{hrs}:}{744 \mathrm{hrs}} \\
& =289.40 \times 10^{6} \mathrm{Btu} \\
M_{\text {water storage }} & =\frac{289.40 \times 10^{6} \mathrm{Btu}}{\left(25^{\circ} \mathrm{F}\right)\left(1.0 \frac{\mathrm{Btu}}{\mathrm{LBM}-\mathrm{OF}}\right)} \\
& =11,576,009 \mathrm{LBM} \\
& =1,389,677 \mathrm{GALLONS} \\
& =185,811 \mathrm{FT}^{3}
\end{aligned}
$$

This necessary capacity will be provided in the form of two rectangular tanks with dimensions of $50^{\prime} \times 60^{\prime} \times 35^{\prime}$ (depth). The vessels will be field 
constructed of steel reinforced concrete. Installation will be partially below grade with the exposed vertical surfaces being earth bermed for improved heat retention.

\section{Cooling Tower}

The cooling tower component of the Conyers HP-WHR system will be specified to dissipate the average daily heat gain on the system during the peak cooling month of July, as determined below:

$$
\begin{aligned}
Q_{\text {avg clg load }} & =\frac{Q_{\text {monthly }}\left(1+\frac{1}{C .0 . P} \text { end-user }_{\text {cooling }}\right)}{\text { DAYS IN MONTH }} \\
& =\frac{\left(3.73 \times 10^{9}\right)\left(1+\frac{1}{2.5^{*}}\right)}{31} \\
& =168.45 \times 10^{6} \mathrm{Btu} / \text { day }
\end{aligned}
$$

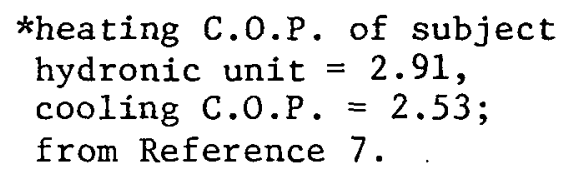

The required heat rejection rate will be determined on the basis of 18 hours operation per day at nominal full load, thus:

$$
\begin{aligned}
\mathrm{HRR} & =\frac{168.45 \times 10^{6}}{18} \\
& =9.36 \times 10^{6} \mathrm{Btu} / \mathrm{hr}
\end{aligned}
$$

System operating parameters dictate a $10^{\circ} \mathrm{F}$ temperature drop in the circulating water. Required cooling tower flow is then determined as:

$$
\begin{aligned}
\dot{\mathrm{M}}_{\text {cooling tower }} & =\frac{9.36 \times 10^{6 \frac{\mathrm{Btu}}{\mathrm{hr}}}}{\left(8.33 \frac{\mathrm{Lbm}}{\mathrm{gal}}\right)\left(60 \frac{\mathrm{min}}{\mathrm{hr}}\right)\left(10^{\circ} \mathrm{F}\right)\left(1.0 \frac{\mathrm{Btu}}{\mathrm{Lbm}-}{ }^{\circ} \mathrm{F}\right.} \\
& =1873 \mathrm{GPM}
\end{aligned}
$$


A modular, pre-constructed tower with a nominal flow rating of 2000 GPM at the required $10^{\circ} \mathrm{F}$ TD will be selected. Fan horsepower will be $50 \mathrm{HP}$.

\section{Auxiliary Pumps}

The three pump functions on the HP-WHR system will be specified as discussed below:

Wastewater pumps will be variable speed types, each capable of delivering $2 / 3$ of required flow at design pressure drop. The fluw rate requj.red for each pump is 1400 GPM at an estimated dynamic head of $50 \mathrm{ft}$. of water. This head rating makes adequate allowance for piping and central heat exchanger pressure drops.

Circulating pumps will each be sized for one half of the total required flow of 4200 GPM. Pump head required will be approximately $80 \mathrm{ft}$. of water. Distribution pumps will each be sized for one half of the total required flow to the end-users. One pump will be a variable speed type. The total flow through the distribution system will be based on serving the heat dissipation requirements at peak conditions with a $10^{\circ} \mathrm{F}$ temperature rise. Based on a nominal heat rejection requirement of 16,740 Btu per ton of air conditioning, the required flow rate for a 1250 ton peak load is 4187 GPM. (Heating season peak flow requirement is approximately 2400 GPM.) Total pumping head at peak flow will be $325 \mathrm{ft}$. of water. This head includes allowances for end-user system and distribution system piping pressure drops.

\section{DISTRIBUTION PIPING}

The required circulating water flow rates at peak load will determine distribution pipeline sizing. Peak heating and cooling loads for each zone 
are first determined through the procedures outlined in section 9.1 .7 and utilizing the appropriate zonal data from the computer analysis. The required flow rates per zone are then calculated and piping sizes are selected to yield proper line velocities and acceptabḷe pressure drops.

ZONE C-1

$$
\begin{aligned}
\text { PEAK HEATING LOAD } & =\frac{\left[\left(3.488 \times 10^{9}\right)\left(1-\frac{1}{2.9}\right)\right](53)}{(732)} \\
& =6.89 \times 10^{6} \mathrm{Btu} \\
\text { PEAK COOLING LOAD } & =\frac{\left(332,208 \mathrm{ft}^{2}\right)\left(16,740 \mathrm{Btu} / \mathrm{hr}^{*}\right)}{350 \mathrm{ft}^{2} / \mathrm{PEAK} \mathrm{A-C} \mathrm{ton}} \\
& =15.89 \times 10^{6} \mathrm{Btu}
\end{aligned}
$$

*Heat Rejection Rate based on the 2.53 cooling C.O.P. of the subject hydronic unit.

$$
\begin{aligned}
\dot{M}_{\text {heating }} & =\frac{6.89 \times 10^{6}}{(8.33)(60)(10)(1.0)} \\
& =1378 \mathrm{GPM} \\
\therefore & \\
\therefore \text { cooling } & =\frac{15.89 \times 10^{6}}{4998} \\
& =3178 \mathrm{GPM}
\end{aligned}
$$

\section{ZONE C-2}

$$
\begin{aligned}
\text { PEAK HEATING LOAD } & =\frac{\left[\left(0.3675 \times 10^{9}\right)\left(1-\frac{1}{2.9}\right)\right](53)}{(732)} \\
& =0.73 \times 10^{6} \mathrm{Btu} \\
\text { PEAK COOLING LOAD } & =\frac{(35,000)(16,740)}{(350)} \\
& =1.67 \times 10^{6} \mathrm{Btu}
\end{aligned}
$$




$$
\begin{aligned}
\dot{\mathrm{M}}_{\text {heating }} & =\frac{0.73 \times 10^{6}}{4998} \\
& =146 \mathrm{GPM} \\
\therefore \quad \because \because & =\frac{1.67 \times 10^{6}}{4998} \\
\dot{M}_{\text {cooling }} & =334 \mathrm{GPM}
\end{aligned}
$$

ZONE C-3

$$
\begin{aligned}
\text { PEAK HEATING LOAD } & =\frac{\left[\left(0.708 \times 10^{9}\right)\left(1-\frac{1}{2.9}\right)\right](53)}{(732)} \\
& =1.40 \times 10^{6} \mathrm{Btu}
\end{aligned}
$$

PEAK COOLING LOAD $=\frac{(67,500)(16,740)}{350}$

$$
\begin{aligned}
& =3.23 \times 10^{6} \mathrm{Btu} \\
\dot{\mathrm{M}}_{\text {heating }} & =\frac{1.40 \times 10^{6}}{4998} \\
& =280 \mathrm{GPM} \\
\dot{\mathrm{M}}_{\text {cooling }} & =\frac{3.23 \times 10^{6}}{4998} \\
& =646 \mathrm{GPM}
\end{aligned}
$$

$\underline{\text { ZONE I-4 }}$

PEAK HEATING LOAD $=0.0$

PEAK COOLING LOAD $=230.0 \times 10^{9} \mathrm{Btu}$

$$
\dot{\mathrm{M}}_{\text {cooling }}=130 \mathrm{GPM}
$$

Obviously, the circulating water flow rates into each zone during the cooling mode will be the governing criteria in distribution pipe size selection. Pipe sizes and the corresponding flow rates, velocities, and 
pressure drops for each distribution system piping segment are presented in Table 9-7.

TABLE 9-7

DISTRIBUTION PIPING SPECIFICATIONS

\begin{tabular}{|c|c|c|c|c|}
\hline LOCATION & $\frac{\text { FLOW RATE }}{\text { (GPM) }}$ & $\frac{\text { PIPE SIZE }}{\text { (INCHES) }}$ & $\frac{\text { VELOCITY }}{\text { FPS }}$ & $\frac{\text { PRESSURE DROP }}{(\mathrm{PSI} / 100 \mathrm{FT})}$ \\
\hline Trunk Line & 4309 & $18^{\prime \prime}$ & 5.43 & .20 \\
\hline $\begin{array}{l}\text { Zone C-1 } \\
\text { Trunk }\end{array}$ & 3179 & $14^{\prime \prime}$ & 6.63 & .35 \\
\hline $\begin{array}{c}\text { Zones } \mathrm{C}-2 \& \mathrm{C}-3 \\
\text { Trunk }\end{array}$ & 980 & $8 "$ & 6.26 & .60 \\
\hline $\begin{array}{l}\text { Zone } C-3 \\
\text { Feeder }\end{array}$ & 646 & $8^{\prime \prime}$ & 4.12 & .30 \\
\hline $\begin{array}{l}\text { Zone C-2 } \\
\text { Feeder }\end{array}$ & 334 & $5^{\prime \prime}$ & 5.46 & .85 \\
\hline $\begin{array}{l}\text { Znne I-4 } \\
\text { Feeder }\end{array}$ & 150 & 4" & 3.83 & .55 \\
\hline
\end{tabular}

\subsubsection{SYSTEM COMPONENT DESCRIPTIONS}

The components used in the Heat Pump Wastewater Heat Recovery Scheme for Cornelia are essentially identical to those used in the Conyers system. Sizing and capacity have of course been adjusted for the Cornelia application. One notable exception is the substitulion of a heat exchanger for the central heat pump. The central heat exchanger will be a single shell-and-tube type unit. Water box covers should be of the "marine" type so that tube cleaning and replacement will be less difficult. The tubes should be seamless copper and individually replacable. The heat exchanger should be constructed in accordance with the A:S.M.E. Code for Unfired Pressure Vessels. 


\subsubsection{EXPECTED PERFORMANCE}

A performance analysis on the Cornelia HP-WHR system was performed follow. ing the same procedures and utilizing the same basic assumptions (with one exception, as noted below) as for the previous Conyers system analysis (presented in section 8.3 .3$)$. All energy inputs to the system were tallied, including pump work, cooling tower fan work, system auxiliaries power, and end-user heat pump power: That total (in Btu equivalents) was then compared to the net heating or cooling effect provided to lie structures within the system service area. Estimating the monthly performance in this manner revealed syslem pcrformance in the peak heating, peak cooling, and simultaneous heating and cooling modes. Since the Cornelia system, when operating in the heating mode, utilizes a central heat exchanger rather than a central heat pump to extract heat from the wastewater stream, there will necessarily be a change in the circulating water conditions during the heating season. Cooling mode conditions will be similar to those in effect on the Conyers system. Conditions are as noted below:

Distribution Media Temperatures

HEATING MODE

Supply

Return

$$
65^{\circ} \mathrm{F}
$$$$
55^{\circ} \mathrm{F}
$$

COOLING MODE

$$
80^{\circ} \mathrm{F}
$$$$
90^{\circ} \mathrm{F}
$$

The results of the monthly performance analysis are summarized in Table 9-8 below. The full analysis and calculational procedures are presented in Appendix D. 
TABLE 9-8

CORNELIA HP-WHR SYSTEM PERFORMANCE

\begin{tabular}{|c|c|c|c|c|c|}
\hline & $\begin{array}{c}\text { Heating Btu } \\
\text { Delivered to Space } \\
\times 10^{9} \\
\end{array}$ & $\begin{array}{c}\text { Cooling Btu } \\
\text { Delivered to Space } \\
\times 10^{9} \\
\end{array}$ & $\begin{array}{c}\text { Central Plant } \\
\text { Energy Input } \\
\text { KWH } \\
\end{array}$ & $\begin{array}{c}\text { End-User } \\
\text { Energy Input } \\
\text { KWH } \\
\end{array}$ & $\begin{array}{l}\text { System } \\
\text { C.0.P. }\end{array}$ \\
\hline JAN. & 4.6 & 0 & 25,906 & 449,262 & 2.836 \\
\hline FEB. & 3.8 & 0 & 19,485 & 371,129 & 2.850 \\
\hline MARCH & 3.1 & .14 & 14,512 & 319,171 & 2.845 \\
\hline APRIL & 1.2 & .23 & 4,822 & 144,154 & 2.794 \\
\hline MAY & .37 & 1.30 & 25,374 & 188,494 & 2.287 \\
\hline JUNE & .06 & 2.80 & 57,721 & 334,017 & 2.139 \\
\hline JULY & 0 & 3.70 & 77,660 & 433,636 & 2.120 \\
\hline AUG. & 0 & 3.60 & 102,621 & 421,916 & 2.011 \\
\hline SEPT. & .17 & .92 & 25,394 & 124,426 & 2.132 \\
\hline OCT. & 1.20 & .37 & 4,258 & 160,562 & 2.791 \\
\hline NOV. & 2.90 & 0 & 14,219 & 283,230 & 2.857 \\
\hline DEC. & 4.50 & $\underline{0}$ & 23,502 : & 439,496 & 2.848 \\
\hline TOTAL & 21.9 & 13.06 & 396,474 & $3,669,493$ & \\
\hline
\end{tabular}

As Table 9-8 indicates, heating season performance (C.O.P.) is better than would be expected with air-to-air heat pumps, and cooling system performance is comparable to air-to-air heat pumps or standard electric air-conditioning systems.

With the monthly system perfurmance thus detined for each month during the annual cycle, the overall systéiu C.O.P. can be easily derived. Considering the system as"a "black-box," its performance can be determined by the expression 


$$
\text { c.0.P. }=\frac{Q_{\text {out }}}{W_{\text {in }} \times 3413}
$$

where

$$
\begin{aligned}
& \mathrm{Q}_{\text {out }}=\text { heating or cooling effect provided by the system, Btu } \\
& \mathrm{W}_{\text {in }} \quad=\text { work input to the system, } \mathrm{KWH}
\end{aligned}
$$

Thus, substituting from Table 8-6:

$$
\begin{aligned}
\text { C.0.P. } & =\frac{\left(21.9 \times 10^{9}+13.06 \times 10^{9}\right)}{(396,174+3,669,493) \times 3413} \\
& =2.519
\end{aligned}
$$

\section{COMPONENT ENERGY USE}

In order to identify the areas of energy usage on the HP-WHR system which would benefit system performance the most through decreased consumption, the performance analysis also included a breakdown of individual component energy consumption. Overall central plant power consumption was first analyzed and plotted as illustrated in Table 9-9 and Figure 9-11. Power use within the central plant was then further disaggregated according to individual components, as summarized in Table 9-10.

As with the Conyers system, the largest energy user on the system is the collective end-user heat pump.. Therefore, hydronic units with improved C.0.P.'s, several of which are under development, offer the prospect of significantly reduced energy consumption in this area of system performance improvement.

Benefits similar to those identified for the Conyers system can also be gained through the judicious selection of energy efficient pumps and motors and through the development of innovative, energy conscious operating procedures. 
TABLE 9-9

ELECTFICITY USAGE ANALYSIS

FOF COFNELIA HF-ICES

IN COOFEFATION WITH THE TECHNOLOGY DEVELOFPENT LAR

GEOFEGIA TECH ENGINEEFING EXFEFIMENT STATION

ATLANTA: GEOKGTA 30.332

\section{I $N F U T$ I A $A$ A}

IILLING FEFIOI

ACTLAL REMAN
618
618
618
618
600
655
600
600
600
618
618
618

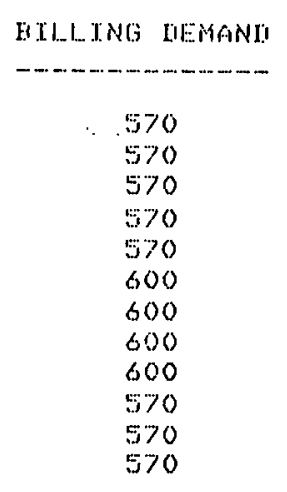

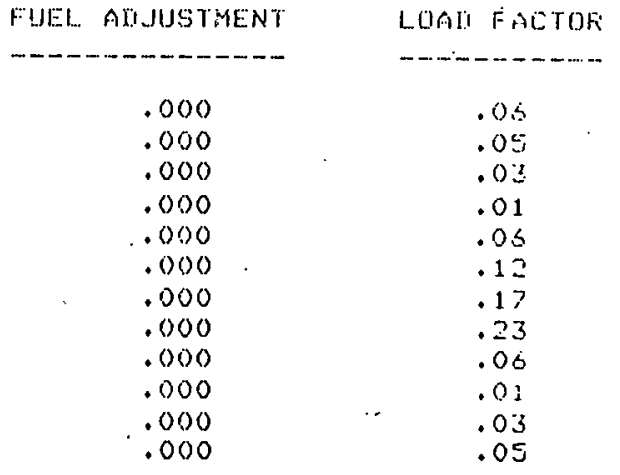

L. OCAL TAX IS $\$ .03$

\section{F F O JECTE TI E LECTRIC I T Y C O S T}

EILLING FEFIOI
JANUAFY
FEEFIUAFYY
MAFICH
AFFIIL
MAY
JUNE
JULY
AUGUST
SEFTEMEEF
OCTOOEF:
NOUEMFER
LECEMEEF

TOTFL
BILLING AMUUNT

1413.22

1097.98

853.83

379.86

1337.10
2975.18

3954.08

$51.79, .54$

1388.08

285.36

$839 \cdot 45$

1295.20

\& 21018.89 
F L O T OF CONSUMFTION FIG. $9-11$

CONSUMF TON (KWH)

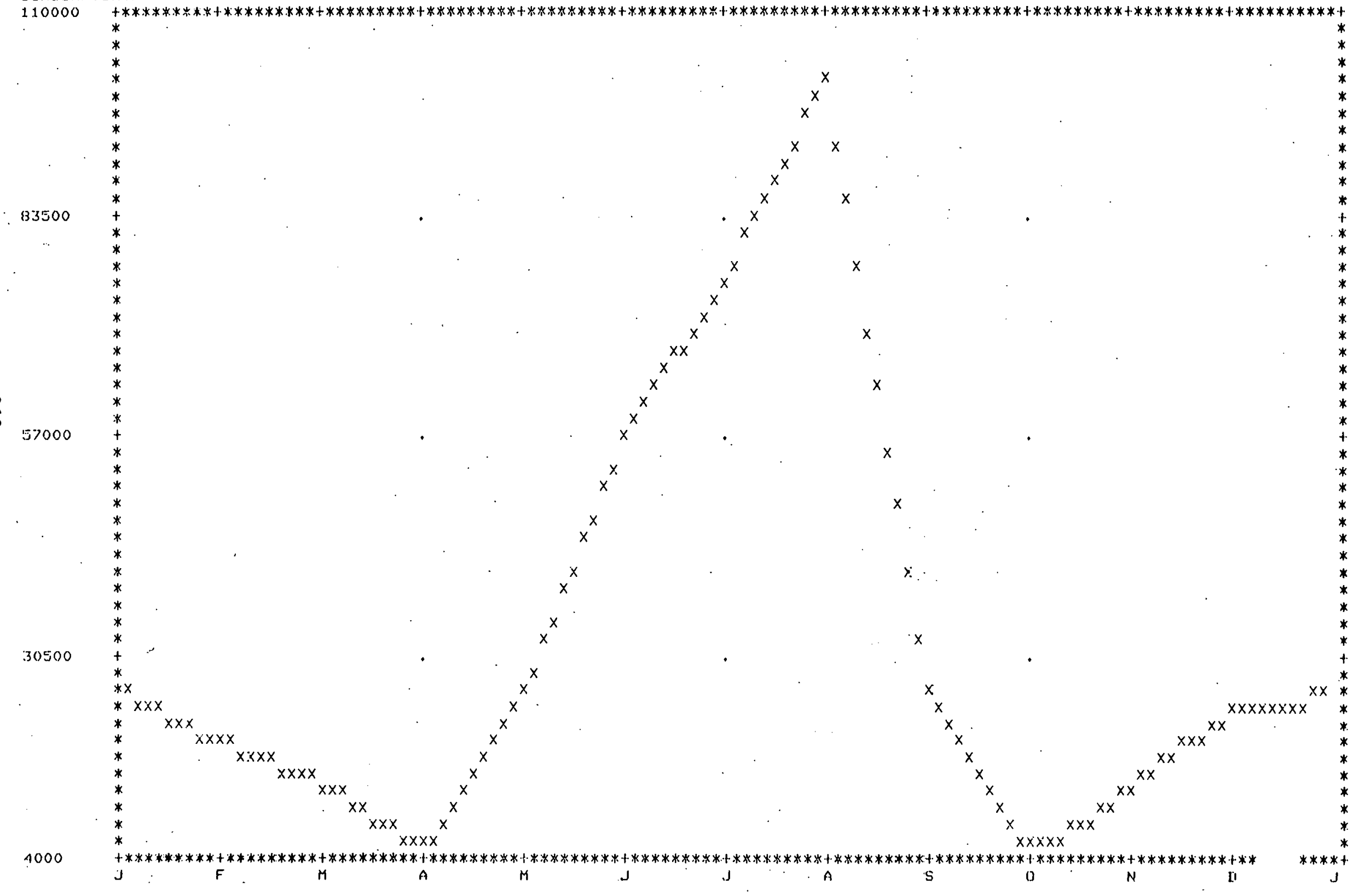


TABLE 9-10

CORNELIA HP-WHR SYSTEM

ANNUAL COMPONENT ENERGY USE

\begin{tabular}{|c|c|c|c|}
\hline Item & Energy Use & $\begin{array}{l}\text { Percent of } \\
\text { Central Plant }\end{array}$ & $\begin{array}{r}\text { Percent of } \\
\text { System }\end{array}$ \\
\hline . & $\mathrm{KWH}$ & & \\
\hline Distribution Pumps & 149,540 & 37.7 & 3.7 \\
\hline Circulating Pumps & 141,239 & 35.6 & 3.5 \\
\hline Sewage Pumps & 25,192 & 6.4 & 0.6 \\
\hline Cooling Tower & 70,903 & 17.0 & 1.7 \\
\hline Misc. Electrical & 9,600 & 2.4 & 0.2 \\
\hline Central Plant Total & 396,474 & 100.0 & i \\
\hline End-Use Heat Pumps & $3,669,493$ & & 90.3 \\
\hline System Total & $4,065,967$ & & 100.0 \\
\hline
\end{tabular}

ENERGY CONSERVATION POTENTTAL

The Heat Pump-Wastewater Heat Recovery System shows the potential to favorably alter the existing energy use patterns within a community and to proulute the overall conservation of primary energy sources. In the case of the Cornelia community, the existing energy use pattern shows a reliance on electric energy for cooling and natural gas and electric energy for heating.

The energy consumed on-site by the conventional space conditioning systems in meeting the heating and cooling requirements projected by the computerized load estimate was first calculated. The assumptions were that heating requirements were met with natural gas fired furnaces operating at a $65 \%$ thermal 
efficiency or with electric resistance heaters and that cooling requirements were met with electrically driven air-conditioning units with C.O.P.'s of 2.2. Each commercial service zone was treated independently since their source of energy for heating differs. Zone C-1 employs approximately 60 percent natural gas heating and 40 percent electric resistance heating. Zones $\mathrm{C}-2$ and $\mathrm{C}-3$ utilize electric resistance type heaters. Zone I-4, the industrial application, is assumed to require the same quantity of energy under either the conventional system schieme or the HP-WHR scheme.

Based on the above assumptions and observations, the conventional systems consume annually the following amount of energy:

\begin{tabular}{|c|c|c|}
\hline & Cooling & Heating \\
\hline Zone $\mathrm{C}-1$ & $1,331,000 \mathrm{kWH}$ & $\begin{array}{l}2,490,000 \text { KWH } \\
+130,769 \text { THERMS }\end{array}$ \\
\hline Zone $\mathrm{C}-2$ & $146,498 \mathrm{KWH}$ & $527,395 \mathrm{KWH}$ \\
\hline Zone $\mathrm{C}-3$ & $266,361 \mathrm{KWH}$ & $996,191 \mathrm{KWH}$ \\
\hline Zone I-4 & $35,000 \mathrm{KWH}$ & ------- \\
\hline TOTAL & $1,778,859 \mathrm{KWH}$ & $\begin{array}{l}4,913,586 \text { KWH } \\
+130,769 \text { THERMS }\end{array}$ \\
\hline
\end{tabular}

The total HP-WHR system energy requirement of 4,065,967 KWH (from Table 9-10) compares favorably with the above total of 4,792,445 KWH plus 130,769 therms for conventional system on-site consumption. It is noted that the comparison reflects a $15 \%$ reduction in electric energy consumption plus $100 \%$ reduction in natural gas consumption. These reductions are attributable to the effective displacement of electric resistance heating and natural gas heating by the heat pump system.

In order to compare the projected primary energy resource consumption of 
the HP-WHR system to that of the conventional space conditioning systems, the procedures for determining annual fuel and resource energy utilization, as outlined in ASHRAE Standard 90-75, ENERGY CONSERVATION IN NEW BUILDING DESIGN, 58 were followed. As can be seen from the results of this assessment as illustrated on the following pages, the primary effect of HP-WHR system operation would be to conserve approximately $84 \%$ of the natural gas which would have been utilized in the Cornelia service area. Due to the reduction in overall electric energy requirements, an across-the-board reduction in the consumption of coal, crude oil, nuclear, and hydro power will also be noticed. A secondary, but desirable, effect would be to free the additional quantities of natural gas for use in satisfying other, less flexible energy requirements. 
ANNUAL FUEL AND ENERGY CALCULATION FORM 12-1

\begin{tabular}{|c|c|c|c|c|c|c|c|c|c|c|c|c|}
\hline \multirow[b]{2}{*}{ Line } & \multirow[b]{2}{*}{ Column } & \multicolumn{2}{|c|}{$\begin{array}{l}\text { Building/Project } \\
\text { Energy Req'ments } \\
\end{array}$} & \multicolumn{9}{|c|}{ Fuel and Energy Supplied to Slte } \\
\hline & & A1 & A2 & B1 & B2 & B3 & B4 & BS & B6 & B7 & B8 & B9 \\
\hline & Function & $\begin{array}{c}\text { Thermal } \\
10^{6} \text { Btu }\end{array}$ & $\begin{array}{c}\text { Electric } \\
10^{3} \text { KWH }\end{array}$ & $\begin{array}{c}\text { Coal } \\
10^{6} \mathrm{Btu}\end{array}$ & $\begin{array}{c}\text { Gas } \\
10^{6} B 1 \mathrm{u}\end{array}$ & $\begin{array}{c}\text { Light Oil } \\
10^{6} \text { Btu } \\
\end{array}$ & $\begin{array}{c}\text { Heavy Oil } \\
10^{6} \text { Btu }\end{array}$ & $\begin{array}{l}\text { Elec. Win. } \\
10^{3} \mathbf{K W H}\end{array}$ & $\begin{array}{l}\text { Elec. Sum. } \\
10^{3} \mathrm{KWH}\end{array}$ & $\begin{array}{l}\text { Elec. Ann. } \\
10^{3} \mathrm{KWH}\end{array}$ & Other & Oth \\
\hline 1 & Heating & & & & 13,071 & & & 4013.5 & & & & \\
\hline 2 & Cooling & & & & & & & & 1778.8 & & & \\
\hline 3 & Water Heating & & & & & & & & & & & \\
\hline 4 & HVAC Auxiliaries & & & & & & & & & & & \\
\hline 5 & Lighting & & & & & & & & & & & \\
\hline 6 & Elevators & & & & & & & & & & & \\
\hline 7 & Computers & & & & & & & & & & & \\
\hline 8 & Cooking & & & & & & & & & & & \\
\hline 9 & Process & & & & & & & & & & & \\
\hline 10 & Other & & & & & & & & & & & \\
\hline 11 & Other & & & & & & & & & & & \\
\hline 12 & Other & & & & & & & & & & & \\
\hline 13 & Total Carry Fwd. Io & Form 12-2 & & & 13,077 & & & 4013.5 & 1778.8 & & & \\
\hline
\end{tabular}

\section{CORNELIA-CONVENTIONAL SYSTEMS}

\begin{tabular}{|c|c|c|c|c|c|c|c|c|c|c|c|c|}
\hline & \multicolumn{3}{|c|}{$\begin{array}{l}\text { Annual Fuel and Energy } \\
\text { Calculation Form 12-2 }\end{array}$} & $\begin{array}{l}\text { C.o. } \\
\text { Total }\end{array}$ & $\begin{array}{c}\text { RUF } \\
\text { From }\end{array}$ & & $\begin{array}{l}\text { Fuel and } \\
\text { To Meet }\end{array}$ & $\begin{array}{l}\text { Energy Reso } \\
\text { Energy Reg }\end{array}$ & $\begin{array}{l}\text { urces Used } \\
\text { uirements o }\end{array}$ & $\begin{array}{l}\mathbf{n} \text { Site and } \mathbf{O} \\
\text { Building/P }\end{array}$ & $\begin{array}{l}\text { Site } \\
\text { ject }\end{array}$ & \\
\hline \multirow[t]{2}{*}{ Line } & \multirow{2}{*}{\multicolumn{3}{|c|}{$\begin{array}{l}\text { Fuel and Energy } \\
\text { Supplied to Site }\end{array}$}} & From & Supplier & C1 & C2 & C3 & Ce & Cs & $\mathrm{C}_{6}$ & C7 \\
\hline & & & & $\begin{array}{c}\text { Form } \\
12-1 \\
\text { Line 13 }\end{array}$ & $\begin{array}{l}\text { or From } \\
\text { Tables }\end{array}$ & $\begin{array}{l}\text { S. Tons } \\
\text { Coal }\end{array}$ & $\begin{array}{l}\text { MCF } \\
\text { Nat'l }\end{array}$ & $\begin{array}{c}\text { BBL } \\
\text { Crude Oil }\end{array}$ & $\begin{array}{l}\text { Grams } \\
\text { U-235 }\end{array}$ & $\begin{array}{c}10^{3} \text { KWH } \\
\text { Hydro }\end{array}$ & Orher & Other \\
\hline 14 & \multicolumn{3}{|c|}{ Fuel Oil, Light } & & & & & & & & & \\
\hline 15 & \multicolumn{3}{|c|}{ Fuel Oil, Heavy } & & & & & & & & & \\
\hline \multirow[t]{2}{*}{16} & \multirow[t]{2}{*}{ Gas } & Nat'l & $\mathrm{MCF}$ & \multirow[t]{2}{*}{13,077} & \multirow[t]{2}{*}{1.16} & & 15,169 & & & & & \\
\hline & & Oil & BBL & & & & & & & & & \\
\hline 17 & \multicolumn{3}{|c|}{ Coal } & & & & & & & & & \\
\hline \multirow[t]{7}{*}{18} & \multicolumn{3}{|c|}{ Elec. Winter } & 4013.5 & & & & & & & & \\
\hline & & Coal & S. Tons & & .22 & 1083.6 & & & & & & \\
\hline & & Gas & MCF & & .56 & & 2247 & & & & & \\
\hline & & Oil & BBL & & .53 & & & 2127 & & & & \\
\hline & & Nuc & Grams & & 3.84 & & & & 15,411 & & & \\
\hline & & Hydro & $10^{3} \mathrm{KWH}$ & & .07 & & & & & 280.9 & & \\
\hline & \multicolumn{3}{|c|}{ Other } & & & & & & & & & \\
\hline \multirow[t]{7}{*}{19} & \multicolumn{3}{|c|}{ Elec. Summer } & \multicolumn{2}{|l|}{1778.8} & & & & & & & \\
\hline & & Coal & S. Tons & & .26 & 462.5 & & $\dot{-}$ & & & & \\
\hline & & Gas & MCF & & 1.04 & & 1850 & & & & & \\
\hline & & Oil & BBL & & .56 & & & 9.96 & & & & \\
\hline & & Nuc & Grams & & 3.84 & & & & 6830 & & & \\
\hline & & Hydro & $10^{3} \mathrm{KWH}$ & & -.04 & & & & & 71.1 & & \\
\hline & & Other & & & & & & & & & & \\
\hline \multirow[t]{7}{*}{20} & \multicolumn{3}{|c|}{ Elec. Annual } & & & & & & & & & \\
\hline & & Coal & S. Tons & & & & & & & & & \\
\hline & & Gas & $\mathrm{MCF}$ & & & & & & & & & \\
\hline & & Oil & BBL & & & & & & & & & \\
\hline & & Nuc & Grams & & & & & & & & & \\
\hline & & Hydro & $10^{3} \mathrm{KWH}$ & & & & & & & & & \\
\hline & & Other & & & & & & & & & & \\
\hline 21 & (Other) & & & & & & & & & & & \\
\hline 22 & & & & & tal Resource: & 1546.1 & 19,266 & 3123 & 22,241 & 352 & & \\
\hline
\end{tabular}


ANNUAL FUEL AND ENERGY CALCULATION FORM 12-1

\begin{tabular}{|c|c|c|c|c|c|c|c|c|c|c|c|c|}
\hline \multirow[b]{2}{*}{ Line } & \multirow[b]{2}{*}{ Column } & \multicolumn{2}{|c|}{$\begin{array}{c}\text { Building/Projecl } \\
\text { Energy Req'ments }\end{array}$} & \multicolumn{9}{|c|}{ Fuel and Energy Supplied to Site } \\
\hline & & AI & $\mathbf{A 2}$ & B1 & $\mathbf{B 2}$ & $\mathbf{B 3}$ & B4 & B5 & B6 & B7 & $\mathbf{8 8}$ & B9 \\
\hline & Function & $\begin{array}{c}\text { Thermal } \\
10^{\circ} \mathrm{Btu} \\
\end{array}$ & $\begin{array}{c}\text { Electric } \\
10^{3} \mathrm{KWH}\end{array}$ & $\begin{array}{c}\text { Coal } \\
10^{6} \mathrm{Blu}\end{array}$ & $\begin{array}{c}\text { Gas } \\
10^{6} \mathrm{Blu} \\
\end{array}$ & $\begin{array}{c}\text { Lighi Oil } \\
10^{6} \text { Blu }\end{array}$ & $\begin{array}{c}\text { Heavy Oil } \\
10^{6} \mathrm{~B} 1 \mathrm{u}\end{array}$ & $\begin{array}{l}\text { Elec. Win. } \\
10^{3} \mathrm{KWH}\end{array}$ & $\begin{array}{l}\text { Elec. Sum. } \\
10^{3} \mathrm{KWH}\end{array}$ & $\begin{array}{l}\text { Elec. Ann. } \\
10^{3} \text { KWH }\end{array}$ & Other & Other \\
\hline 1. & Heating. & 21,900 & & & & & & 2274.7 & & & & \\
\hline 2. & Cooling & 13,060 & & & & & & & 1791.3 & & & \\
\hline 3 & Water Heating & & & & & & & & & & & \\
\hline 4 & HV.AC Auxiliaries & & & & & & & & . & & & \\
\hline 5 & Lighting & & & & & & & & & & & \\
\hline 6 & Elevators & & & & & & & & & & & \\
\hline 7 & Computers & & & & & & & & & & & \\
\hline 8 & Cooking & & & & & & & & & & & \\
\hline 9 & Process & & & & & & & & & & & \\
\hline 10 & Other & & & & & & & & & & & \\
\hline 11 & Other & & & & & & & & & & & \\
\hline 12 & Other & & & & & & & & & & & \\
\hline 13 & Total Carry Fwd. I & Form 12-2 & & & & & & 2274.7 & 1791.3 & & & \\
\hline
\end{tabular}

\section{CORNELIA-HP-WHR SYSTEM}

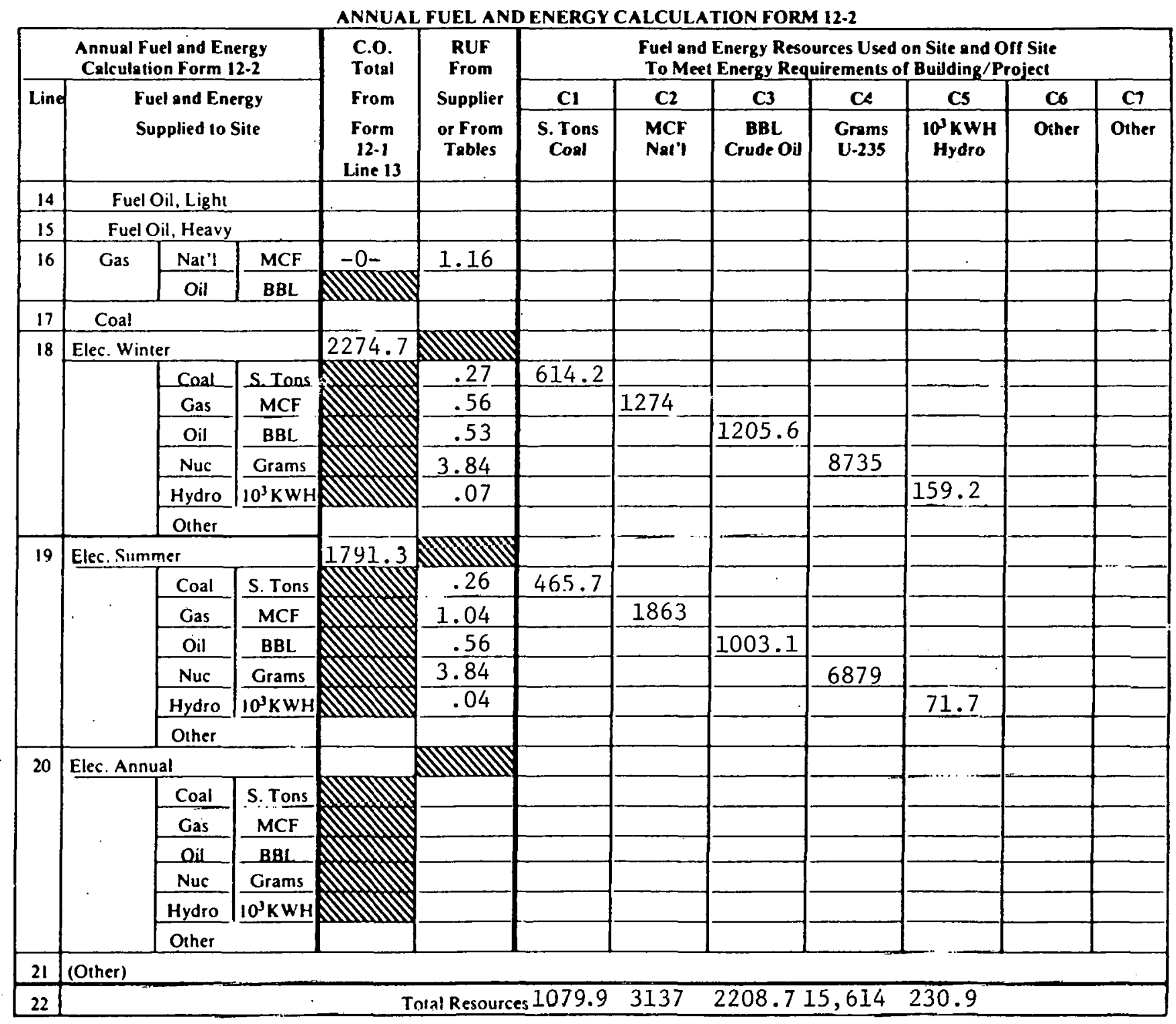




\section{SECOND LAW PERFORMANCE ANALYSIS}

A second law performance analysis was performed for the Cornelia HP-WHR system during the peak heating season, peak cooling season and a period when both heating and cooling was required. The analysis was conducted on a monthly basis.

The same set of assumptions used in the Conyers study are applied to the Cornelia analysis. The results of the analysis are tabulated below.

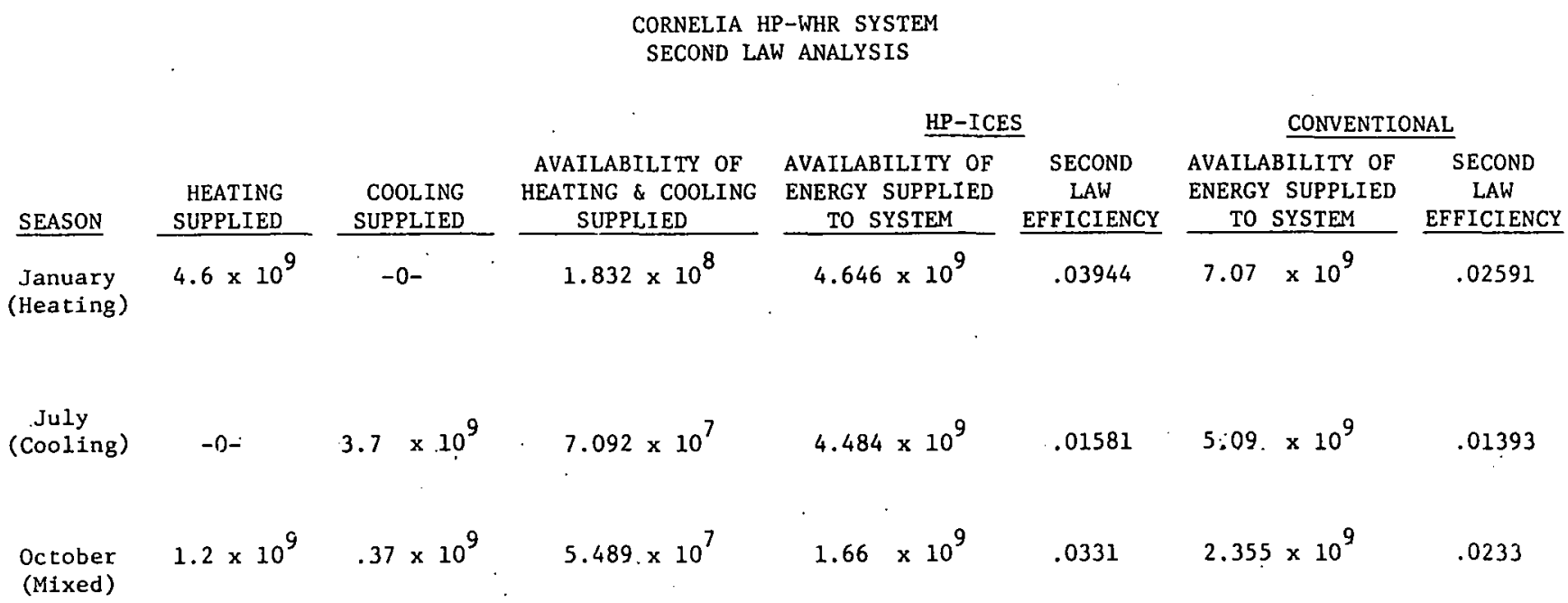




\section{...4 EXPECTED ECONOMICS}

This section evaluates the expected economic performance of the HP-WHR system as compared to conventional heating and cooling systems in the Cornelia area. First costs, operating costs and maintenance costs for each of the compared systems are estimated in order to determine annualized costs to consumers. A net present value comparison for the system is also made. System design and performance has been presented in previous sections of this report. For the purposes of this analysis it is assumed that some form of government entity will own and operate the central utility and distribution system. End-users will own and operate their own heat pump systems and purchase thermal energy from the central plant. The purchase price for the thermal energy will be determined by the cost to produce and deliver the energy plus maintenance costs, personnel costs, administrative costs, and debt service.

It is anticipated that the thermal utility would provide distribution and metering equipment to the property line of the customer. Piping and equipment installed on the user's property would be paid for and become the property of that user.

Debt service for the central plant was based on a 7 percent per year interest rate with payments over a 25 year period. This interest rate appeared to be in the high-end of a range that would be expected for Cornelia.

The following cost analysis is broken into three parts: first costs, operating costs, life cycle costs. A summary of results is presented in the latter part of the section.

\section{FIRST COSTS}

First costs are categorized as costs incurred by the central utility or costs incurred by the end-users. In Cornelia's case, it is anticipated that 
the central utility's costs will be those associated with the central plant, distribution system and metering. End-users will be responsible for the retrofit of their own HVAC system and for piping from their heat pump unit to the meter connection.

Central plant first costs were based on the equipment sizes and types presented in the system design section. A detailed cost breakdown is presented in Appendix D. A summary of these costs follows:

$\begin{array}{lc}\text { Cenlial rlant } & \$ 848,283 \\ \text { Distribution System } & \$ 275,020 \\ \begin{array}{l}\text { Metering Equipment } \\ \text { (100-2" meters, in- } \\ \text { cluding installation) }\end{array} \\ \text { Total } & \$ \frac{30,000}{\cdot}\end{array}$

End-user system costs were computed on the basis of $100 \mathrm{ft}$. of 2" pipe per end-user to connect to the distribution system and $\$ 800$ per installed ton of air conditioning capacity. The $\$ 800$ per ton is assumed to include any salvage value of equipment removed from the end-user buildings. For Cornelia the retrofit cost is approximately:

$$
\begin{array}{lll}
1450 \text { tons installed } \times \$ 800 & & \\
\text { Total cost of retrofit } & = & \$ 1,160,000 \\
\text { Piping: } \begin{aligned}
100 \text { users } \times 100 \mathrm{ft} . \\
\times \$ 4.00(\text { installed) }
\end{aligned} & = & \$ \quad \\
\text { Total retrofit cost } & = & \$ 1,200,000
\end{array}
$$

The retrofit costs are based on the individual prices each end-user would be required to pay if the work were contracted on an individual basis.

\section{OPERATING COSTS}

Operating costs were based on the results of the performance analysis 
presented in section 9.2.3. The cost of electric power for the central plant was computed from Georgia Power Company's PL-1 rate schedule. Power for enduser systems was assumed to cost $5.75 \mathrm{c} / \mathrm{KWH}$. The cost of thermal energy delivered to end-users by the HP-WHR system will be discussed in a subsequent section. Frum Table $9-9$ of the performance analysis, the annualized cost for power to the central plant will be approximately $\$ 21,050$. End-users on the HP-WHR system will use approximately 3,669,500 KWH per year. This electricity will cost approximately $\$ 210,996$ under individual billings.

Maintenance costs for the HP-WHR central station are estimated at 5 percent per year of the cost of the station and 0.5 percent per year for the distribution system. These maintenance costs are:

$\underline{\text { Item }}$

Central Station Equipment

Diștribution System \& Meters

Total
Annua 1

Maintenance Cost

$\$ 42,414$

$\$ 1,447$

$\$ 43,861$

End-user maintenance costs were assumed to be $\$ 10$ higher per installed ton of air conditioning capacity than would comparable system maintenance on conventional systems. This figure includes a provision for replacement costs of units in order to perpetuate the systein.

$$
1450 \times \$ 10=\$ 14,500 \text { per year }
$$

HP-WHR SYSTEM OPERATION AS A THERMAL UTILITY

In order to compare the HP-WHR scheme to conventional utility schemes, it is necessary to perform an analysis from the end-user's viewpoint. To account for thermal energy distributed from the central plant, it is anticipated that the system will be operated as a thermal utility. The charges to the 
end-users will be based on meter readings and will be sufficient to cover the central plant's operating and maintenance costs, debt service, and administrative costs associated with operation of the system.

The cost figures contained in this report were generated for the Cornelia system using the stated electric energy costs, an administrative cost of 10 percent of total owning and operating costs, and debt service based on an interest rate of 7 percent per year over 25 years. It is recognized that the seven percont interest rate is somewhat arbicrary and wi.l vary with the type of financing arrangements actually implemented; however, it was sèlecléd ac a compromise between typical 1977 yields for Municipal Class A bonds and Utility bonds issued by private companies.

The total annual cost to the end-users for thermal service was computed as follows:

\author{
CORNELIA - HP-WHR SYSTEM \\ THERMAL UTILITY CHARGES \\ (COMPONENT COSTS IN 1979 DOLLARS)
}

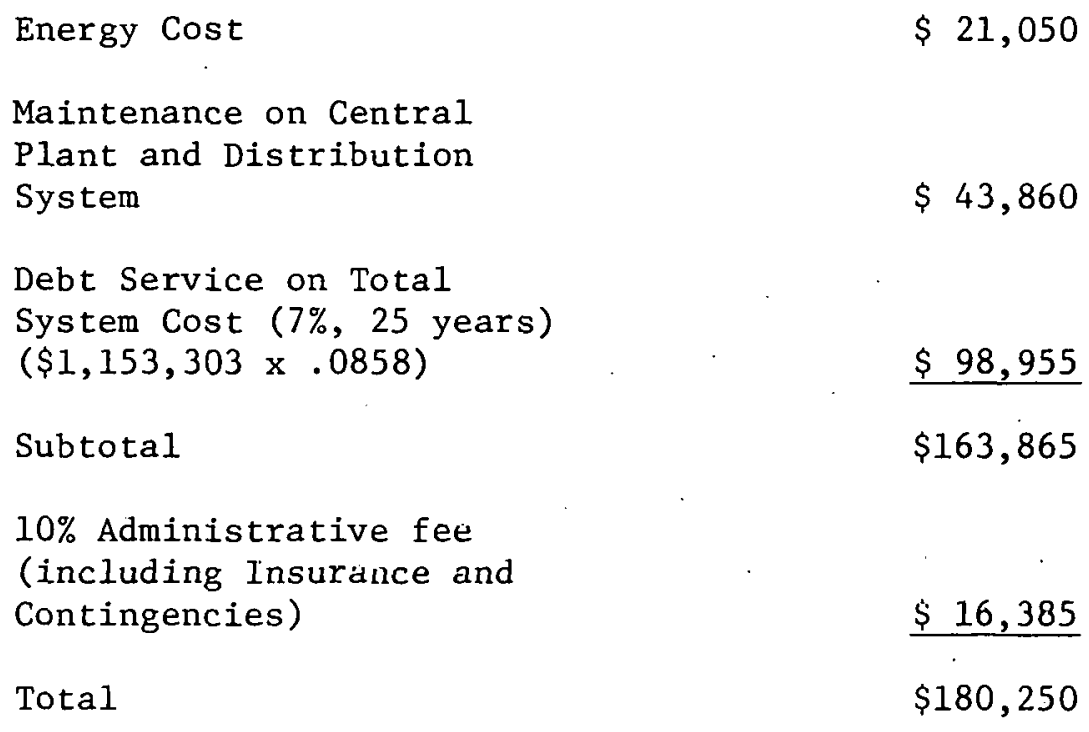

Based on the above total, the necessary cash flow for the system will be as projected in Table 9-11. 
TABL̇E $9-11$

CORNELIA HP-WHR SYSTEM

THERMAL UTILITY CHARGES

CASH FLOW

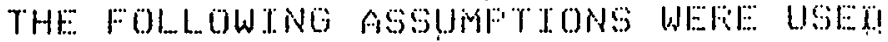

ANALYSIS FEFTOII OF 20 YEAFS TNTEFEST FATE OF .O FEFCNT SAL/COST ESCALATION , 000 MAINT, ESCALATTON= .080 AUEFAGE UTILITY ESCALATTON:E: 110 TNCOME: ESCALATTON:.OOO

\begin{tabular}{|c|c|c|c|c|c|c|}
\hline \multicolumn{2}{|c|}{ IIEET $S_{\circ} /$} & ANNUAI & $: 0057 \%$ & \multicolumn{2}{|c|}{ AMMIN. } & \multirow[t]{2}{*}{$00 s \%$} \\
\hline YFi & OFi COST & MAIN Y IECO & WTTLTTES & & II FAC & \\
\hline 0 & 98955. & 0. & 0. & 0. & $* 1.000$ & - \\
\hline $\begin{array}{l}1 \\
2\end{array}$ & $\begin{array}{l}9395 \% . \\
98955 .\end{array}$ & $\begin{array}{l}47369 . \\
51158 .\end{array}$ & $\begin{array}{l}23660 \\
20036 .\end{array}$ & $\begin{array}{l}16969 \\
17609\end{array}$ & $\begin{array}{l}* 1.000 \\
* 1.000\end{array}$ & $\begin{array}{l}186608 \\
193634\end{array}$ \\
\hline 3 & 98955 & • & 29709 & $1829 \%$ & $* 1.000$ & 201294. \\
\hline 4 & 98955. & 59671. & $31.5 \%$ & $190 \% 8$ & $* 1.000$ & 209640 \\
\hline 5 & $9995:$ & 64445 & $354 \%$ & 1.9087. & $* 1.000$ & $218 \%$ \\
\hline 6 & 90955. & 69600 & 39372. & $20 \% 93$ & $* 1.000$ & 228720 \\
\hline 7 & 98950 & 75168. & $43 \% 03$. & $21 \% 83$ & $* 1.000$ & 239609 \\
\hline 8 & 98950 & 81182 & $48 \because 11$. & $2286 \%$ & $* 1.000$ & 251512. \\
\hline 9 & 98955. & 87676 & $638.4 \%$ & 24048. & $* 1.000$ & 264326. \\
\hline 10 & $9995 \%$ & 94890 & 99770 & 26428 & *.. .000 & 278797 \\
\hline $1 \mathrm{l}$ & 98955 & 102266. & 663.84 & $26 \% 97$ & $* 1.000$ & $294322+$ \\
\hline 12 & $9 \$ 955$ & 110447 & 73642. & 23304 & 41.000 & 311349 \\
\hline 1.3 & 93955. & 119283. & 81743. & 29990 & $* 1.000$ & 329979 \\
\hline 14 & 98955 & 128825 & 907396 & 31952 & $w 1.000$ & 390367 \\
\hline L & 93955 & 1.35 . 31. & $100 \% 16$. & 33880. & $* 1.000$ & 372682. \\
\hline 16 & $98931:$ & 1.50262. & 11.794 . & 36101. & $* 1.000$ & 397112. \\
\hline 17 & $989 \div 3$ & 162283 & 124092 & 39533. & $x .000$ & 423602 \\
\hline 18 & 98950 & 179265. & 137742 & 41196. & *1.000 & 453158 \\
\hline 19 & $9895 \%$ & $18929 \%$ & 192893. & 4.114 & $* 1.000$ & 48629 \\
\hline 20 & 98955. & 204430. & 169712 . & 47810 & $* 1.000$ & 90406 \\
\hline 21 & $989: 30$ & 220794. & 188380 & 50912 & $* 1.000$ & 969931. \\
\hline $2 \%$ & 98956. & 238447 & 209102 & 94690 & * 1.000 & 601154 \\
\hline 23 & 98953 & 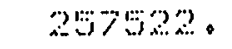 & 232103. & 38006. & *. & 647430 \\
\hline 24 & 98956 & 278124. & 257634. & 63471. & $* 1.000$ & $69018 \%$. \\
\hline 25 & 98955 & 300374. & $2958 \% 4$. & 68300 & $* 1.000$ & 793833 \\
\hline
\end{tabular}




\section{LIFE CYCLE COSTS}

A life cycle cost analysis was prepared for the Cornelia HP-WHR system and the existing conventional systems. The analysis was performed from the end-user point of view, since the consumer will ulitmately pay all costs associated with each system. In the case of thermal energy distributed by the HP-WHR system, central plant capital and energy costs are embedded in the cost of service to the end-user.

The present value of the cash flow for each alternative was determined for a twenty-five year period at the stated discount factor. The follnwing general formula was used:

$$
\mathrm{PV}_{i}=\mathrm{FC}_{i}+\underset{y=1}{25}\left[f(j, y) \times\left(\mathrm{ADC}_{i}+\mathrm{AMC}_{i}\right)\right]
$$

Where:

$$
\begin{aligned}
\mathrm{PV}_{i} & =\text { Present value of the } i^{\text {th }} \text { alternative } \\
\mathrm{FC}_{i} & =\text { First cost of the } i^{\text {th }} \text { alternative } \\
\mathrm{f}(\mathrm{j}, \mathrm{y}) & =\text { The present worth factor at } j \text { percent interest for y years } \\
\mathrm{ADC}_{i} & =\text { Annual operating costs of the } i^{\text {th }} \text { alternative } \\
\mathrm{AMC}_{i} & =\text { Annual maintenance costs of the } i^{\text {th }} \text { alternative }
\end{aligned}
$$

The results of the life cycle cost analysis are presented in Table 9-12 for the conventional systems as the base case and Table 9-13 for the HP-WHR system alternative. The present value figure is given as a positive number; however, in actuality it should be realized that the number is a present value of present and future costs. 
TABLE 9-12

CORNELIA CONVENTIONAL SYSTEMS (BASE CASE)

LIFE CYCLE COST ANALYSIS

\begin{tabular}{|c|c|c|c|c|c|c|c|c|}
\hline & $\underline{Y R}$ & $\begin{array}{c}\text { DEBT SERVICE } \\
\text { OR COST } \\
\end{array}$ & $\begin{array}{c}\text { BASE } \\
\text { MAINTENANCE } \\
\end{array}$ & $\begin{array}{l}\text { UTILITY } \\
\text { N.GAS } \\
\end{array}$ & $\begin{array}{l}\text { COSTS } \\
\text { ELECT. }\end{array}$ & $\begin{array}{l}\text { TOTAL } \\
\text { COSTS } \\
\end{array}$ & $\begin{array}{c}\text { DISCOUNT } \\
\text { FACTOR } \\
\end{array}$ & $\begin{array}{c}\text { DISCOUNTED } \\
\text { COSTS } \\
\end{array}$ \\
\hline \multirow{3}{*}{$1980=$} & 0 & 0 . & 0. & 0 & 0 & $\quad 0$ & 1.000 & 0 . \\
\hline & 1 & 0 . & 0 . & 48,025 . & 369,702 . & 417,727 . & .909 & 379,714 . \\
\hline & 2 & 0 . & $0:$ & 54,268 . & 410,369 & $464,637$. & .826 & 383,790 . \\
\hline \multirow[t]{23}{*}{$\therefore$} & 3 & 0 . & 0 . & 61,323 & 455,510 & 516,833 . & .751 & 388,142 . \\
\hline & 4 & 0 . & 0 . & 69,295 . & 505,616 . & 574,911 . & .683 & 392,664 . \\
\hline & 5 & 0 . & 0 . & 78,303 & 561,234 . & 639,537 . & .621 & 397,152 . \\
\hline & 6 & 0. & 0 . & 88,483 . & 622,970 . & 711,453 . & .564 & 401,259 . \\
\hline & 7 & 0 . & 0 . & 99,986 & 691,496 . & 791,482 . & .513 & 406,030 \\
\hline & 8 & 0 . & 0. & 112,984 . & 767,561 & 880,545 . & .467 & 411,215 . \\
\hline & 9 & 0 . & 0 . & 127,672 . & $851,993$. & 979,665 . & .424 & 415,378 . \\
\hline & 10 & 0. & 0 . & 144,269 . & 945,712 . & $1,089,981$. & .386 & 420,733 . \\
\hline & 11 & 0 . & 0 . & 163,024 . & $1,049,740$ & $1,212,764$ & .350 & 424,467 . \\
\hline & 12 & 0 . & 0 . & 184,217 . & $1,165,211$. & $1,349,428$ & .319 & 430,468 . \\
\hline & 13 & 0 . & 0 . & 208,165 & $1,293,385$ & $1,501,550$. & .290 & 435,449 . \\
\hline & 14 & 0 . & 0 . & 235,227 . & $1,435,657$. & $1,670,884$. & .263 & 439,442 . \\
\hline & 15 & 0 . & 0. & 265,806 . & $1,593,579$ & $1,859,385$ & .239 & 444,393 . \\
\hline & 16 & 0. & 0 . & 300,361 . & $1,768,873$ & $2,069,234$. & .218 & $451,093$. \\
\hline & 17 & 0 . & 0 . & 339,408 . & $1,963,449$. & $2,302,857$ & .198 & 455,966 . \\
\hline & 18 & 0 . & 0 . & 383,531 . & $2,179,428$ & $2,562,959$ & .180 & 461,333 . \\
\hline & 19 & 0 . & 0 . & 433,390 & $2,419,166$ & $2,852,556$ & .164 & 467,819 . \\
\hline & 20 & 0 . & 0 . & 489,731 . & $2,685,274$ & $3,175,005$ & .149 & 473,076 . \\
\hline & 21 & 0 . & 0 . & 553,396 . & $2,980,654$. & $3,534,050$ & .135 & 477,097 . \\
\hline & 22 & 0 . & 0 . & 625,338 & $3,308,526$ & $3,933,864$. & .123 & 483,865 . \\
\hline & 23 & 0 . & 0 . & 706,632 . & $3,672,464$. & $4,379,096$ & .112 & 490,459 . \\
\hline & 24 & 0 . & 0 . & 798,494 . & $4,076,435$. & $4,874,929$. & .102 & 497,243 . \\
\hline & 25 & 0 . & 0 . & 902,298 . & $4,524,843$ & $5,427,141$ & .092 & $499,297$. \\
\hline OTALS & & & & & & $9,772,473$. & & $, 927,544$. \\
\hline
\end{tabular}

\section{ASSUMPTIONS:}

1) Natural Gas Cost Escalation - 13\%

2) Electric Cost Escalation - $11 \%$

3) Discount Rate - $10 \%$ 
TABLE $9-13$

CORNELIA HP-WHR SYSTEM

LIFE CYCLE COST ANALYSIS

\begin{tabular}{|c|c|c|c|c|c|c|c|c|}
\hline & $\underline{\mathrm{YR}}$ & $\begin{array}{c}\text { DEBT SERVICE } \\
\text { OR COST } \\
\end{array}$ & $\begin{array}{r}\text { ADDITIONAL } \\
\text { MAINTENANCE } \\
\end{array}$ & $\begin{array}{l}\text { UTILITY } \\
\text { ELECT. }\end{array}$ & $\begin{array}{l}\text { COSTS } \\
\text { THERMAL }\end{array}$ & $\begin{array}{l}\text { TOTAL } \\
\text { COS_S } \\
\end{array}$ & $\begin{array}{l}\text { DISCOUNT } \\
\text { FACTOR } \\
\end{array}$ & $\begin{array}{c}\text { DISCOUNTED } \\
\text { COSTS } \\
\end{array}$ \\
\hline \multirow{26}{*}{1980} & 0 & $\$ 1,200,000$. & 0 & 0 & 0 & 0 . & 1.000 & $\$ 1,200,000$. \\
\hline & $=1$. & 0 & 15,660 . & 234,206 . & 186,658 . & $436,5 \div 4$. & .909 & 396,800 \\
\hline & 2. & 0 . & 16,913 . & 259,968 . & 193,654 . & 470,535 & .826 & 388,662 . \\
\hline & 3 & 0 . & 18,266 . & $288 ; 565$ & 201,294 . & 508,125 & .751 & 381,602 . \\
\hline & 4 & 0 . & 19,727 . & 320,307 . & 209,640 . & $549,674$. & .683 & 375,427 . \\
\hline & 5 & 0. & 21,305 . & 355,541 . & 218,757 . & $595,603$. & .621 & 369,869 . \\
\hline & 6 & 0 . & 23,010 & 394,650 & 228,720 . & $64 \epsilon, 330$. & .564 & 264,558 . \\
\hline & 7 & 0 . & 24,850 & 438,061 & 239,609 & $70 \approx, 520$. & .513 & 360,393 . \\
\hline & 8 & 0 & 26,838 . & 486,248 & 251,512 . & 764,598 . & .467 & 357,067 . \\
\hline & 9 & 0 & 28,986 . & 539,736 . & 264,526 . & 833,248 . & .424 & 353,297 . \\
\hline & 10 & 0 . & 31,304 . & $599,106$. & 278,757 . & 909,167 . & .386 & 350,938 . \\
\hline & 11 & 0 . & 33,809 . & 665,008 . & 294,322 . & 993,139 & .350 & 347,599 . \\
\hline & 12 & 0 . & 36,513 . & $738,159$. & 311,349 . & $1,085, C 21$. & .319 & 346,441 . \\
\hline & 13 & 0 . & 39,435 . & 819,357 & 329,979 . & $1,183,771$. & .290 & 344,744 . \\
\hline & 14 & 0. & 42,589 . & 909,486 & 350,367 . & $1,302,<42$. & .263 & 342,542 . \\
\hline & 15 & 0 . & 45,996 . & $1,009,529$ & 372,682 . & $1,428,207$. & .239 & 341,341 . \\
\hline & 16 & 0 & 46,676 . & $1,120,577$. & 397,112 . & $1,567,365$. & .218 & 341,686 . \\
\hline & 17 & 0 . & 53,650 . & $1,243,841$. & 423,862 . & $1,721,353$. & .198 & 340,828 . \\
\hline & 18 & 0 . & 57,942 . & $1,380,663$ & 453,158 & $1,8 \subseteq 1,763$. & .180 & 340,517 . \\
\hline & 19 & 0. & 62,578 & $1,532,536$. & 485,249 . & $2,080,363$. & .164 & 341,180 . \\
\hline & 20 & 0. & 67,584 . & $1,701,115$. & 520,406 . & $2,289,105$ & .149 & 341,077 . \\
\hline & 21 & 0. & 72,991 . & $1,888,238$ & 558,931 . & $2,520,160$ & .135 & 340,222 . \\
\hline & 22 & 0. & 78,830 & $2,095,944$ & 601,154 . & $2,775,928$. & .123 & 341,439 . \\
\hline & 23 & $0:$ & 85,136 . & $2,326,498$ & 647,438 . & $3,059,072$. & .112 & 342,616 . \\
\hline & 24 & 0 . & 91,947 . & $2,582,413$ & 698,185 . & $3,372,545$ & .102 & 344,000 . \\
\hline & 25 & 0. & 99,303 . & $2,866,479$ & 753,833 . & $3,719,615$. & .092 & 342,205 . \\
\hline & & & 144,838 . & 96,231 . & 71,154 & $, 412,223$. & & {$[0,037,045$} \\
\hline
\end{tabular}

ASSUMPTIONS :

1) Maintenance and Replacement Cost Escalation - 8\%

2) Electric Cost Escalation - 11\% (3\% Over Base Inflation Rate)

3) Thermal Utility Charge Escalation - 11\% (From Table 9-11)

4) Discount Rate - $10 \%$ 


\section{SUMMARY OF EXPECTED ECONOMICS}

The results of the life cycle economic analysis indicate that the HP-WHR system as proposed for the Cornelia community is cost competitive in the immediate market with the conventional space conditioning systems alternative. Indeed, on the basis of the results presented in Tables 9-12 and 13, implementation of the HP-WHR system would result in a net benefit to the end-users of $\$ 890,405$. This favorable comparison results in part from the definition of the system service area and in part from the site-specific wastewater conditions in the community. By limiting the scope of the proposed service area to commercial installations, the type of conventional space conditioning systems which will be displaced by the HP-WHR system are limited. Specifically, in the Cornelia service zones a high percentage of the heating units which will be displaced are electric resistance types. With the HP-WHR system offering heating C.0.P.'s of approximately 2.8 , the energy expenditures are greatly reduced while delivering a comparable thermal load. The relatively high wastewater temperatures experienced on the Cornelia sewage system also affect system economics by allowing the use of a direct heat exchanger during the heating season in lieu of a central heat pump. Energy expenditures for central plant power are thus reduced, and correspondingly system performance and economics are improved. It should be noted that this system, as was the Conyers HP-WHR system, is essentially cooling dominated. It is anticipated that, if the system concept were adapted for use in the colder climes, system economics would be even further improved. 


\subsubsection{PLAN FOR HP-WHR SYSTEM PHASING - CORNELIA, GEORGIA}

An HP-ICES will operate in its community as a form of public utility which will proivde a needed and potentially widespread (in relation to the overall community) service. Serving in this capacity, the system is subject to the need for long-range planning in order to provide its service in a manner most beneficial, service-wise and cost-wise to the end-user. The primary concern is that the system be designed and constructed to fulfill the needs of the existing viable service areas. However, consideration must alsu be given to expanding the system in the most efficient manner and at the most advantageous time to accommodate future growth with1u the community: Chaper 6.0 - PROJECTED GROWTH discusses methods of projecting growth within a specific community and addresses construction phasing of central plant facilities and the distribution system for ranges of growth rate situations. The following paragraphs apply the general approaches outlined in the earlier chapter to the Cornelia demonstration community situation.

The initial approach of the Cornelia - based HP-WHR system will be to provide thermal utility services to a fairly compact area of commercial establishments (two shopping centers: one existing, one under construction) along the newly constructed Cornelia bypass, an industrial plant in the same general sector of town (suuthwest), and the central business district. The central business district has realized its ultimate build out potential (with regard to space availability and restrictions) and there now exists a trend toward renovating or remodeling downtown area shops. The city's major industrial installation, the Fieldale poultry processing plant, is well established in their process needs with no major plant revisions or expansions planned in the foreseeable future. The existing shopping center at the intersection of Level Grove Road and the Cornelia bypass already accommodates three tenants, two restaurants and one large grocery store, 
and exhibits potential for more commercial growth in the immediate future.

CENTRAL PLANT PHASING - In general, a central plant installation for a community (or service area) which expects a moderate rate of growth, 20 to $50 \%$, during the planning period (the category into which Cornelia fits) can be handled with initial construction of the major portions of plant capacity, then minor expansions to the central facilities at appropriate times in the planning period. Minor expansions include installing larger pump motors, changing pump impellers, adding new heat exchangers, or adding new equipment in space already provided in the initial construction. The proposed central plant layout for the Cornelia system is based on the above mentioned approach. The major building structure will be constructed to accommodate all equipment which would be necessary to serve the ultimate build out potential of the system. The lines, sumps and pumps which serve on the sewer tie-in subsystem will be constructed initially to handle 100 to $110 \%$ of the ultimate flow which could be expected through the accessible section of the sewer mains by the end of the projection period. Initial equipment installation (circulating pumps, distribution pumps, thermal storage tanks, and cooling tower) will provide adequate system capacity to serve the needs of the existing service areas plus any growth projerted to occur in these areas over the next five to ten years. At the time when additional capacity is required, a minor plant expansion would involve the installation of an additional circulating pump, distribution pump, cooling tower cell, and if required, Lliermal storage capacity. All equipment additions could be handled with little or no major modification to the in-plant piping systems or structure. Costs for system expansion within the central plant should thus be minimized. DISTRIBUTION SYSTEM PHASING - There are several characteristics of the design and construction of high-volume water distribution (and return) 
lines which will influence the manner in which such systems will be constructed and expanded. First, water and sewer and, in this case, thermal utility lines have a useful life of approximately 50 years. Secondly, a major portion of the cost of constructing such lines is not in material costs but in manpower and equipment expenditures for the construction process. Hence, the most economical way to provide additional capacity generally is to construct a larger line initially rather than a parallel line at a later date.

For the central business district, a distribution leg will be constructed initially with adequate capacity to serve all putential customers in this service area. Due to the degree of development of this area of the community, no extraordinary expansion of this commercial district is anticipated which could not be accommodated by simply allowing additional hook-ups to the system.

For the Fieldale industrial process, whose needs are well established and with little prospect of expansion in the near future, a separate distribution leg will be constructed with adequate initial capacity to provide their total requirements.

For the newly developing commercial district along the bypass, it is anticipated that fairly accurate projections of the ultimate build-out potential of the area can be made. A major consideration is that the somewhat limited availability of accessible acreage will restrict the commercial growth of the area to the moderate range.

Since it is likely that the ultimate potentid would dictate only.a small incremental increase in system capacity over what would be constructed to serve only the projected mid-range requirements, it is probable that a full capacity distribution leg would be constructed for this area also. There are several residential areas peripheral to the potential commercial and industrial service areas which are not addressed in the 
initial development of the Cornelia HP-WHR system. If indeed these areas prove serviceable after the initial system is constructed and under development, they can be included in future system expansions, to the extent that thermal energy is still available from the community wastewater, with the construction of distribution trunk lines from the central plant into the potential service areas. 


\subsection{INSTITUTIONAL CONSIDERATIONS}

9.3.1 CITY OF CORNELIA, GEORGIA REVIEW OF LOCAL ORDINANCES AND CODES

The local codes and ordinances of the City of Cornelia were reviewed to determine what impacts or restrictions they might impose on the development of a Heat Pump Centered-Integrated Community Energy System. This review indicated that there were several local building codes which would need to be reviewed in depth in conjunction with the design and construction of an HP-ICES. The local building codes which have been adopted for the City of Cornelia are as follows :

1. Southern Standard Building Code - 1970 Edition.

2. Southern Standard Plumbing Code - 1971 Edition.

Since these codes are some of the same codes used in the Conyers and Rockdale County area the same comments and discussion for Conyers would apply to Cornelia.

There were no other local ordinances or codes that would affect or restrict the construction of a Heat Pump Centered-Integrated Community Energy System within the City of Cornelia. 


\subsection{COMPONENT TESTING}

\subsection{INTRODUCTION}

The equipment to be utilized in this HP-ICES scheme will, for the most part, be standard, "off-the-shelf" components that are readily available from the major HVAC equipment manufacturers. However, due to the novel application of this equipment, it is expected that Application Ratings will not be available for the range of operating conditions that will be in effect for this system. Since it is the intention of this proposal to provide a.system that offers improved performance over standard Heat Pump systems, performance data specific to this application will be developed through component testing. Three areas will be considered: 1.) baseline data on the thermal encrgy source(s), 2.) Central Station heat pump equipment performance, and 3.) end-user heat pump equipment performance. With this specific performance data in hand, the detail design of the system can be optimized according to energy supply and demand.

\subsection{THERMAL ENERGY SOURCE(S) - BASELINE DATA}

Each application of this scheme may utilize one or more of several potential thermal energy sources. Obviously, each will require heat reclaim equipment particular to the suurce. However, the low grade energy that is available from a community's wastewater effluent will, in all probability, be the most widely accessible source. Therefore, the focus of this section will be to determine the baseline data, con sidering wastewater effluent as the primary energy source, that the HP-WHR system performance will depend upon. The parameters that will be considered are temperature and flow. Discussions of the approach to be taken in obtaining these data follow. 


\subsubsection{TEMPERATURE}

One assumption that the performance of this HP-ICES scheme is based upon is that community wastewater effluent temperature will be greater than or equal to ground temperature. Several factors, such as soil type and thermal diffusivity, and factors particular to the design and operation of individual wastewater collection and treatment systems, will affect the effluent temperature. However, this base assumption appears to be generally valid.

A cursory look at estimated operating temperatures can be found in a tabulation of ground temperatures contained in Technical Guidelines for Energy Conservation. ${ }^{46}$ Also, predictions of estimated operating temperatures (i.e. earth temperatures) can be derived from the procedures developed by Kusuda and Achenback. ${ }^{19}$ In general, this type survey and estimate will be a suitable first step in determining applicability to a specific region or location. However, to obtain a data base from which an overall system Coefficient of Performance (C.O.P.) can be derived, specific data must be gathered at the point of application. Temperature measurements should be taken at the appropriate points in the sewage treatment plants serving the demonstration communities including raw sewage influent, plant effluent, proposed supply tie-in point(s) (if different from plant effluents), and ground temperature. Measurements should be made on an hourly basis for a period of one week (168 hours) during each of the following months: January, April, July, and October. The preferred method of data taking would be temperature transducers (i.e. thermocouples or resistance temperature devices) in conjunction with a multipoint strip chart recorder. Additionally, available plant operating 
records should be surveyed to verify the correlation between the empirical data and typical conditions.

\section{2 .2 FLOW RATES}

The amount of thermal energy avallable at the sewage treatment plant will also depend upon the mass flow rate of the energy supply medium (plant Influent/effluent). Flow rates may be available in the form of plant influent flow recordings and/or E.P.A. 201 Facilities Plans. However, the mass flow rate available as a thermal energy source may, depending on the design and/or operation of each particular sewage treatment plant, differ from the rates documented in available reports or records. Therefore, the following flow measurements are recommended: raw sewage influent (possibly available from existing instrumentation), plant effluent, and flow at the proposed supply tie-in point(s) (if different from plant effluent). Again, measurements should be made on an hourly basis for a period of one week (168 hours) during the months of January, April, July, and October. Flow data collection periods should correspond with the periods of temperature data collection mentioned in section 10.2:1.

Existing automatic flow monitoring instrumentation should be utilized where possible. Two principal types of flow measurement instrumentation, the Kennison Flow Nozzle-type installation, and the Parshall Flume insta1lation, are in widespread use in modern sewage treatment plants and will yield flow rate information of sufficient accuracy for this study.

The Kennison Nozzle installation, pictured in Figure $10 \div 1$, makes use of the Venturi principle but typirally employs a nozzle, instead of the Venturi tube, inserted in (or at the end of) a pipe. The throat of the nozzle is considerably larger in diameter than the throat of a Venturi tube sized for the same range of flow, and the resulting total loss of head is approximately the same. These nozzles can he used on pipes 
varying in size from 6 to 36 inches in diameter and can be used for metering flows up to 18 million gallons per day (MGD). 21

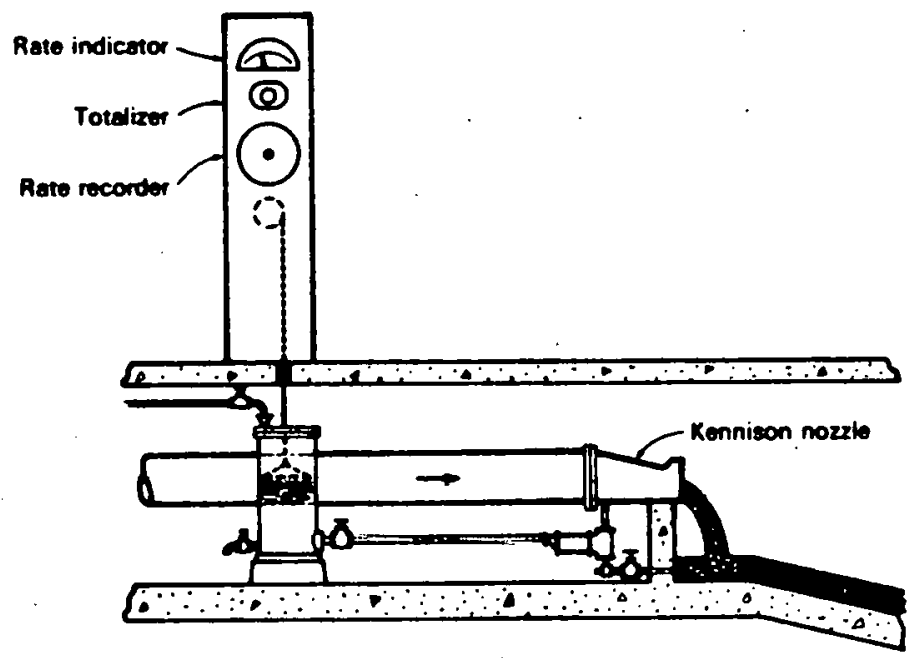

Kennison flow nozzle installetton Ifrom BIF.

SOURCE: Wastewater Engineering, Metcalf and Eddy, Inc. ${ }^{21}$

\section{FIGURE 10-1}
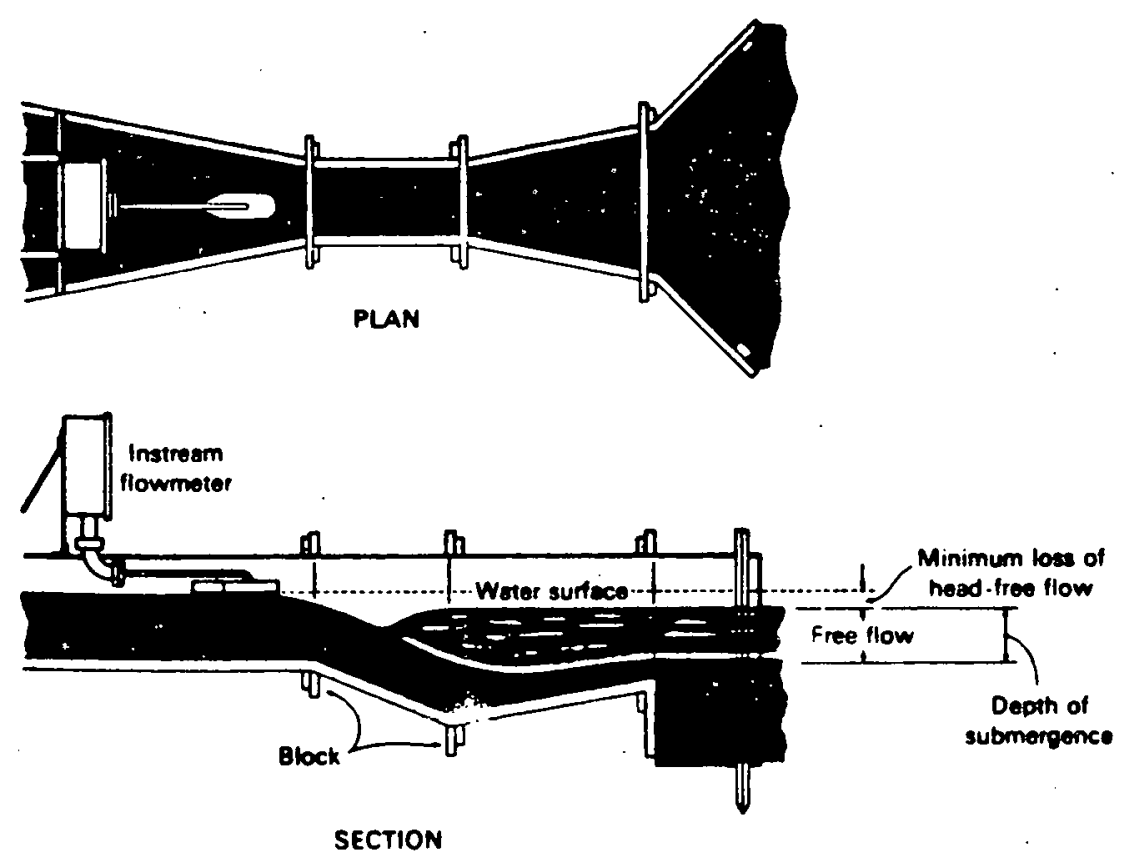

Schematic of Parshall fume metering installation [from Fischer Porter].

SOURCE: Wastewater Engineering, Metcalf and Eddy, Inc. 21

FIGURE 10-2 
The Parshall Flume installation, pictured in Figure 10-2, utilizes the Venturi principle for the measurement of water flow in open channels. Because the throat width of the flume is constant, the discharge can be obtained from a single upstream measurement of depth.21

Temporary flow measurement methods can be utilized where necessary. A simple and accurate method of flow measurement in open channels is the use of one of several weir configurations: rectangular, triangular (or $\mathrm{V}$-notched), or trapezoide1. The rate of discharge over a weir can be directly related to the head of the discharge over the weir by the general equation:

$$
\begin{aligned}
& \mathrm{Q}_{1}=\mathrm{ch}^{\mathrm{n}} \\
& \text { Where } \\
& \mathrm{Q}_{1} \quad=\quad \text { free discharge, cfs } \\
& \text { c }=\text { constant, defined for each weir configuration } \\
& \mathrm{h}=\text { measured head, ft. } \\
& \mathrm{n}=\text { exponent, defined for each particular weir }
\end{aligned}
$$

For the widely used triangular (V-notch) weir the equation is defined as follows:

$$
\mathrm{Q}=2.5 \mathrm{~h}^{5 / 2}
$$

SOURCE: Wastewater Engineering, Metcalf and Eddy, Inc. ${ }^{21}$

A preferred method of flow measurement in closed pipes is the use of an orffice plale and the attendant differential pressure instrumentation. In accordance with Torricelli's theorem that the velocity of flow through an orifice is equal to the velocity acquired by a freely falling body in a space corresponding to the head over the orifice, the discharge through an orifice is :

$$
Q=\mathrm{CAV}=\mathrm{cA} \sqrt{2 \mathrm{gH}}
$$


Where

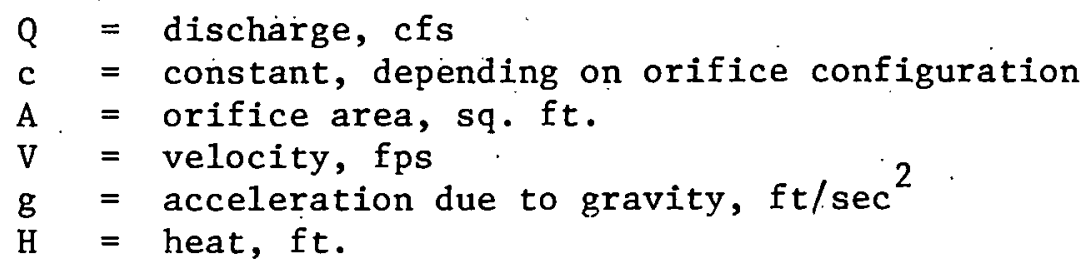

SOURCE: 'Wàstewater Engineering, Metcalf and Eddy, Inc. ${ }^{21}$

An acceptable alternative method to orifice plates would be the use of an Annubar-type device which also relates flow to the differential pressure acrosa the devire.

Depending on the specific point of application, the above mentioned methods may be impractical or impossible, in which case reasonable estimates may be developed through computation. This method involves applying standard flow formulas to field-measured data such as depth of flow and slope of discharge pipes. In addition, a coefficient of roughness must be selected. The method is, at best, an approximation dependent upon the steadiness of flow at the time of observation. Nevertheless, this method may serve in place of, or as a "ballpark" verification of, more sophisticated methods.

\section{2 .3 SUMMARY}

With the above mentioned data in hand, a detailed estimate of the quantities of thermal energy available at the system-to-treatment plant interface can be developed. This data will also form the basis for the performancc evaluation of the overall HP-ICES scheme.

\subsection{CENTRAL STATION HEAT PUMP EQUIPMENT}

Once a data base is established for the conditions and amounts of thermal energy that are available at the source(s), a comprehensive performance analysis of the HP-WHR scheme can be undertaken. Obviously, 
the key component in this scheme is the Central Station Heat Pump

Equipment and its performance as the interface between the energy source(s) and the distribution medium. Since performance data for the Central Station equipment will likely not be available for the specific range of conditions of the thermal energy source, a significant effort should be directed toward developing this data to be used in the detailed performance ana1ysis.

\subsubsection{PERFORMANCE TESTING}

Test procedures for Centrifugal Water-Chilling Packages are outlined in ARI Standard 550-77 (Air Cond1tioning and Refrigeration Institute) and will be adopted for the performance testing to be done in conjunction with this analysis.

Testing should be performed in a laboratory environment, similar to that utilized for industry rating tests, where all variables may be controlled to the tolerances set forth in the ARI 550-77 standard. It may be desirable to contract an outside agency to perform the actual testing.

At least four sets of performance tests should be performed; each set to reflect the specific initial conditlons documented in one of the four baseline data tests. The following test data, relevant to the performance of the unit, will be taken:
A. Temperature of water entering cooler, ${ }^{\circ} \mathrm{F}$
B. Temperature of water leaving cooler, ${ }^{\circ} \mathrm{F}$
C. Chilled water flow rate, GPM or $\mathrm{lb}$. per $\mathrm{hr}$.
D. Temperaturc of enlering condenser water, ${ }^{\circ} \mathrm{F}$
E. Temperature lcaving condenser water, ${ }^{\circ} \mathrm{F}$
F. Condenser water flow rate, GPM or $1 \mathrm{~b}$. per $\mathrm{hr}$.
G. Power input to compressor motor, KW

From this data, a heat balence will be performed (to the prescribed 
closure of 7.5 per cent) to substantiate the results of the test. With validated test results, an accurate C.0.P. can be derived for each set of baseline and operating conditions. Likewise, actual capacity in tons can be derived. General formulas for the heat balance, C.0.P., and capacity are included in Appendix D.

\subsubsection{WATER QUALITY}

A significant factor that will affect the performance of the Central Station equipment is the quality of water available from a sewage treatment system to be ulilized ae the thermal energy source. Due to the presence of suspended solids in the form of BUV (or decompocable nrganic matter) in raw sewage, there is the possibility of methane gas generation and retention in some segments of the HP-WHR system. The most significant problem involved in utilizing sewage as the thermal energy source, though, is that of an increased fouling factor on the heat exchanger surfaces.

Methane gas generation occurs in a sewage treatment system when the organic suspended solids (BOD), settled and collected at various points in the system, are reduced by biochemical digestion (typically in a covered, anaerobic sludge digestor). Such sludge digestors may utilize portions of the methane gas for temperature regulation within the digestor, while other designs may simply dispose of the excess gas with an open-flame flare. In order to avoid unnecessary methane generation in the Central Station. equipment and its associated piping, the organic suspended solid content in the portion of the wastewater circulated through the Central Station equipment heat exchanger will be millimized by extracting it from the sewage treatment system at points following sludge removal (providing that the wastewater at these points is of sufficient temperature). It is expected that the remaining organic suspended solids will be minimal and 
that any appreciable build-up in the heat exchanger can be avoided by optimizing the wastewater flow rate through the Central Station equipment. The design of most treatment plants will allow existing, open-type clariflers to serve as accumulators for the thermal supply medium. Thus, the need for an enclosed, thermal supply medium storage vessel, along with the potential for methane gas generation/retention in the HP-WHR system, is avoided. If, in fact, such a vessel is required by the design of a particular sewage treatment system, provisions for methane disposal may be included in the design in accordance with standard wastewater engineering practice. In regard to clarifier performance as utilized in the HP-WHR scheme, standard manufacturers data is available in reference to storage capacity (volume), surface area, surface settling rates, maximum and minimum retention times, etc. Temperature and flow data will be developed at the clarifier as explained in sections 10.2.1 and 10.2.2 if it, in fact, proves to be the most advantageous tie-in point for the Central station equipment. Increased fouling factors on the Central Station equipment heat exchanger surfaces will prove to be the most troublesome problem associated with water quality in the HP-WHR system. The ARI standard for waterchiller testing assumes a fluid with a fouling factor of .0005 (also widely used as the rule-of-thumb in indnstry). llowever, water quality data surveyed from various sewage trcatment plants indicates that fouling factors may range to several times that figure. The fouling factor for water samples taken from the Chicago Sanitary Canal has been quantified at .006 to .008 . (a table of typical fouling factors from Reference 7 is reproduccd in Appendix $D$ as Table D-1.)

The first step in defining a fouling factor for the quality of wastewater to be circulated through the Central Station equipment heat exchangers 
should be collecting wastewater samples, representative of the water that will be circulated, at the point in the sewage treatment process where the thermal energy supply medium will be extracted. A full water quality analysis should be performed by a qualified testing agency or laboratory, and the analysis compared to typical analyses for the types of fluids for which a fouling factor has been defined. This comparison should give a "ball-park figure" for the expected fouling factors.

In order to obtain better defined data, though, more testing would be required. An addilional pcrformanre test may be desirable in which the average baseline conditions are duplicated and the water supply to the evaporator simulates the water quality of the thermal energy source. Such a test would reveal the immediate discernable effects (if any) of water quality on C.O.P. and give an indirect indication of the fouling factor. (The decrease in performance resulting from a higher fouling factor is roughly equivalent to raising the leaving condenser water temperature $2^{\circ} \mathrm{F}$ for every .0005 increase in the fouling factor.) Figure 10-3 shows the estimated percentage reduction of the nominal C.0.P. at fouling factors ranging from .0005 to .0025 for either the evaporator or condenser. Continued testing under the above specified conditions will quantify the long term effects on the Central Station equipment C.O.P. and allow calculation of the actual fouling factor. (Formulas and definitions concerning fouling factors are included in Appendix D.) Moderately high fouling factors (.0005 to .0025) may dictate simply that a larger evaporator heat exchanger be specified for the Central Station equipment. Very high fouling factors (over .0025) may require that a mechanical cleaning system for the heat exchanger be specified. Several methods are acceptable, ranging from manual inspection and flushing, to reverse-flow activated 
brush scrubbers, to a continuous cycle, spherical rubber scrubber system such as an Amertap.

Once a range of values for the expected fouling factor of the wastewater is determined, a final equipment test (or set of tests), incorporating the appropriate mechanical cleaning system(s), is recommended to develop the baseline information necessary to evaluate the performance of these systems in this particular application. From this performance evaluation, general guidelines for design specifications and operating procedures in the HP-WHR system application can be developed.

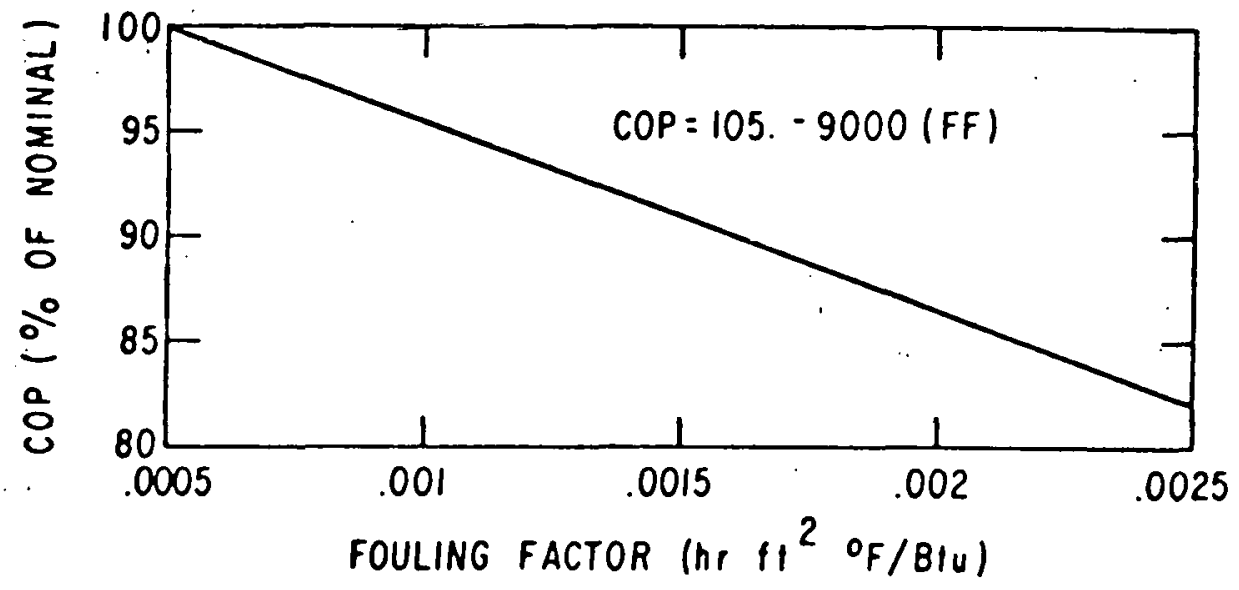

REDUCTION OF PACKAGE CHILLER C.O.P. AS A FUNCTION OF FOULING FACTOR

SOURCE: Central Cooling - Compressive Chillers, Christian 5

FIGURE $10-3$

\subsection{END-USER HEAT PUMP EQUIPMENT}

The ultimate community acceptance of this HP-ICES scheme will depend on the energy efficiency of the heat pump equjpment in use in homes and places of business. This scheme offers the inftlal advantage of utilizing in the end-user segment water source or hydronic heat pumps. However, it is expected that the performance of the end-user equipment will be even 
more improved by the effect of cascading the heat gain of the hydronic heat pump with that of the Central Station equipment. Obviously, the performance of the end-user equipment will depend upon the conditions in the distribution medium supplied by the Central Station equipment. Again it is expected that application ratings for this specific set of conditions will not be available. To complete the data needed for the detailed performance analysis, tests on the end-user heat pump equipment must be performed.

\subsubsection{PERFUKMANCE TESTING}

Test procedures for Water-source heat pumps are outlined in ARI standard 320-76 (Air-Conditioning and Refrigeration Institute) ${ }^{53}$ and will be adopted for the performance testing to be done in conjunction with this analysis.

As with the components selected for use at the Central Station, end-user equipment should be tested in a laboratory environment where all variables may be controlled to the tolerances set forth in the ARI 320-76 standard. Again, it may be desirable to contact an outside agency to perform the actual testing. Four sets of performance tests should be performed; each set to reflect the distribution medium conditions documented in one of the four Central Station equipment tests. Test conditions set forth in the procedures for the standard rating test should be adhered to, with the exception of the water temperature entering the refrigerant-to-water heat exchanger, which will correspond to the output temperature of the distribution medium from the Central Station equipment.

From the performance data gathered in these tests, accurate C.0.P.'s (or Energy Efficiency Ratios, EER's, as appropriate) can be derived for each set of seasonal operating conditions. 


\section{.4 .2 PROCESS HEAT RECLAIM EQUIPMENT}

In addition to residential and commercial space heating and cooling needs; it is expected that portions of the thermal load from this HP-ICES may be applied in industrial processes. However, due to the wide variety of heat exchangers that may be utilized in industry, it is impractical to outline a specific performance testing procedure for each. Instead, procedures will be outlined and performance data developed as specific applications (and the required equipment) are identified.

\subsection{SUMMARY}

With all pertinent performance data documented, typical operating conditions can be predicted and analyzed according to the procedures developed in Chapter 3. The result of the comprehensive performance analysis will be an overall system coefficient of performance (C.O.P.) which can be used in economic analyses, energy effectiveness studies, and other similar performance comparisons with other systems. Satisfactory performance, considering all the parameters discussed in previous sections, will allow the utilization in a community system of heretofore wasted heat in sufficient quantities to make such an HP-WHR system practicable. The ultimate success of this HP-ICES scheme will depend on its economic feasibility, either now or fin the foreseeable future. Quite obviously, the economic feasibllity will directly relate to optimizing the overall system C.O.P. for the specific operating conditions for each site of application.

\section{$10.6 \cdot$ METHODOLOGY}

Since the performance testing of the heat pumps (either Central Station or end-user) dictates a change in magnitude of only one parameter, temperature of the thermal source, over the standard test procedures, the 
test methodology set forth in the applicable ARI standards will be adopted for this performance analysis. Specific standards that apply are as follows:

ARI 320-76 Standard for Water-Source Heat Pumps 53

ARI $550-77$

Standard for Centrifugal Water-Chilled Packages 54

ASHRAE 14-67. Methods of Testing for Rating Mechanical 51 Condensing Units

ASHRAE 37-69 Methods of Testing for Rating Unitary Air 52 Conditioning and Heat Pump Equipment

Additionally, recommendations set forth in Cliapter 12 of the ASHRAE Handbook of Fundamentals, "Measurement and Instruments", 50 will be followed in the test procedures.

Unfortunately, it is beyond the scope of this discussion to outline detailed test procedures for each specific piece of equipment that will be utilized in this HP-ICES scheme. Accordingly, detailed test procedures will be developed at the outset of the actual testing program. A procedure for testing and analysis was developed in "Demonstration of Building Heating with a Heat Pump Using Thermal Effluent" by Peter W. Sector, ${ }^{33}$ and will be used as a model in developing the detailed test procedures for this program. 


\subsection{ANALYSES DESCRIPTION \\ 11.1 INTRODUCTION}

The specific assumptions and methodology pertaining to the various analyses made in this report are described in the body of the report within each section. However, this section provides additional insight into the assumptions and calculations used in the Potential Applications Expected Economics and Performance sections of the report.

The tendency in most cases was to be conservative in the analyses and make what was considered to be reasonable assumptions. Practical engineering approximations and common industry practices were used where necessary. It was the intent of the authors to provide engineering calculations which would be familiar to the practicing engineering professional who might wish to utilize the concept in a specific application.

\subsection{POTENTIAL APPLICATIONS}

The potential applications section of the report is concerned with estimating the energy saving potential of the HP-WHR scheme on a national basis. The estimate was developed using the best wastewater effluent flow statistics available. Unfortunately, the wastewater effluent statistics are based on domestic water consumption figures and fail to include numerous thermally attractive sources such as industrial discharges directly to surface water streams and power plant waste heat.

The application of the HP-WHR concept is also dependent on population (user) density, since the distribution system will apparently be the dominant capital cost. High user densities will tend to increase the heat recovery application factor and enhance the energy effectiveness and thus the desirability of the scheme.

In order to develop a more accurate picture of potential applications 
it will be necessary to develop a new primary data-base correlating wastewater effluents, thermal quality, and density of energy users.

\subsection{EXPECTED ECONOMICS}

The expected economics of the HP-WHR scheme is ultimately the determining factor in whether or not the scheme will be pursued seriously and implemented. Unfortunately, generalized economic performance is. not accurate enough for a thorough evaluation of the system's performance in a1l cases.

It is possible to make some specific observations about lhe effccts certain economic assumptions impose on the overall attractiveness of the system. These areas are discussed here.

First, the capital cost of the central plant and distribution system seriously impact the cost of energy supplied through thermal transport media. It appears that the distribution system is by far the most important of these capital costs. For that reason, areas with high densities of thermal users will prove more economical.

Financing is another area critical to the cost of the capital equipment. The interest rate and mortgage time could penalize the system during the initial years of operation. Of course, as time goes on, the fixed costs will remain constant and will become less important as rising energy costs and inflation affect variable operating costs.

Escalation rates for various fuel sources and the electric rate differential between residential and large municipal customers has an impact on when the HP-WHR scheme will become competitive with conventional energy sources such as natural gas. 
The present worth factor is another variable affecting the outcome of the analysis. In the case of the factor and that of the fuel and inflation escalation estimates, an accurate analysis would require consideration of the best site-specific information available at the time the analysis is made.

Finally, the relative cost of alternative heating and cooling systems for the residential customer will influence the HP-WHR system reception by the ultimate consumer. Future community developments will certainly be more. receptive to such a scheme than would retrofit candidates since the incremental cost over standard alternatives associated with the heat pump system will be small.

\subsection{PERFORMANCE ANALYSIS}

The objective of our performance analysis is to determine the energy requirements of the HP-WHR system delivering a given amount of heating or cooling effect for a community when using wastewater effluent as a heat source or sink. Additionally, the HP-WHR system will be compared with conventional systems serving the same function. The HP-WHR is modelled as shown in Figures 3-1 and 3-2 for the heating and cooling modes. As indicated in the figures, the system's principal components are: a central heat pump, distribution pipe lines, water pumps, sţorage resorvoirs and end-user heat pumps. In actual practice, the system may consisl of a battery of central heat pumps, one or more storage reservoirs, booster pumps, etc. For purposes of our analysis, we have included one end-user heat pump and a single centra1 heat pump unit. The total energy required to deliver a unit of heating or cooling affect to one residential end-user involves proportional energy inputs to the central heat pump unit, the end-user unit and the associated pumping energy involved in water flow through evaporators, condensers, distribution pipe lineo and provision for thermal losses. Each component 
will be discussed separately and a procedure for calculating the total energy (electrical or mechanical) input to the system is outlined utilizing available performance data. Sample calculations are included in the appendices.

\subsubsection{SELECTION OF DESIGN LOADS}

Two geographical regions in the United States were selected for the study of the HP-WHR system. The details of the houses and the design loads are given below. The selection of the design heating and cooling loads was based on the information presented in Reference 27.

Location: Northwest Central Region

House 1: Design heating load $=55,000 \mathrm{Btuh}$

Design outside temperature $=20^{\circ} \mathrm{F}$ (heating)

Design inside temperature $=75^{\circ} \mathrm{F}$

$\left(65^{\circ} \mathrm{F}\right)$ degree-days $=8300$

Design cooling loads $=11,500$

Design outside air temperature $=89^{\circ} \mathrm{F}$ (cooling)

Design inside air temperature $=78^{\circ} \mathrm{F}$ (cooling)

Summer equivalent full load cooling hrs $=600$

Location: South Atlantic Region

House 2: Design heating load $=31,000 \mathrm{Btuh}$

Design outside temperature $=22^{\circ} \mathrm{F}$ (heating)

Design inside temperature $=75^{\circ} \mathrm{F}$

$\left(65^{\circ} \mathrm{F}\right)$ degree-days $=2920$

Design cooling loads $=25,150 \mathrm{Btu} / \mathrm{hr}$

Design outside air temperature $=95^{\circ} \mathrm{F}$ (cooling)

Design inside air temperature $=78^{\circ} \mathrm{F}$ (cooling)

Summer equivalent full load cooling hrs $=1000$

\subsubsection{ASSUMPTIONS}

a) The basic vapor compression cycle as described in section $11,4.3$ is used as a basis for the definition of terms used in the analysis. The heat pumps that are used in this analysis are selected from manufacturers' models listed for study in References 5,6 , and 7 , sized to suit the design loads used in our analysis. Brand names of the models are omitted. Heat pumps and their characteristics are presented in section 11.4.9.

b) The water distribution lines are buried approximately six 
feet underground to minimize heat 1oss. Under these conditions, the temperature change of the water due to heat loss or gain would be very small since the operating water temperatures are low. This assumption is justified by an example in section 11.4 .8 .

c) The thermal storage is designed so that the heat losses or gains would be negligible. An approximate analysis of the temperature change of water in the reservoir is discussed in section 11.4.8.

d) The thermal properties of the clarified effluent are assumed to be the same as those of water.

3) Apart from the heat exchange between the refrigerant and the heat transfer medium (water-to-air), heat losses to the surroundings are negligible.

Other assumptions will be stated as they are made in the course of the analysis and calculations.

\subsubsection{VAPOR COMPRESSION CYCLE}

The heat pump used in the anlaysis of the HP-WHR system is based on the vapor compression refrigeration cycle (Figure 11-1). The ideal cycle consists of the following processes:

1.) isentropic compression of the vapor

2.) constant pressure heat rejection from the refrigerant in the condenser to the surroundings

3.) irreversible adiabatic expansion (throttling) in the expansion valve

4.) constant pressure heat absorption by the refrigerant in the evaporator from the surroundings

In actual cycles, there are losses due to the pressure drops in the flow tubes, heal loss. from the tubes, inefficiency of the compression process, etc. 


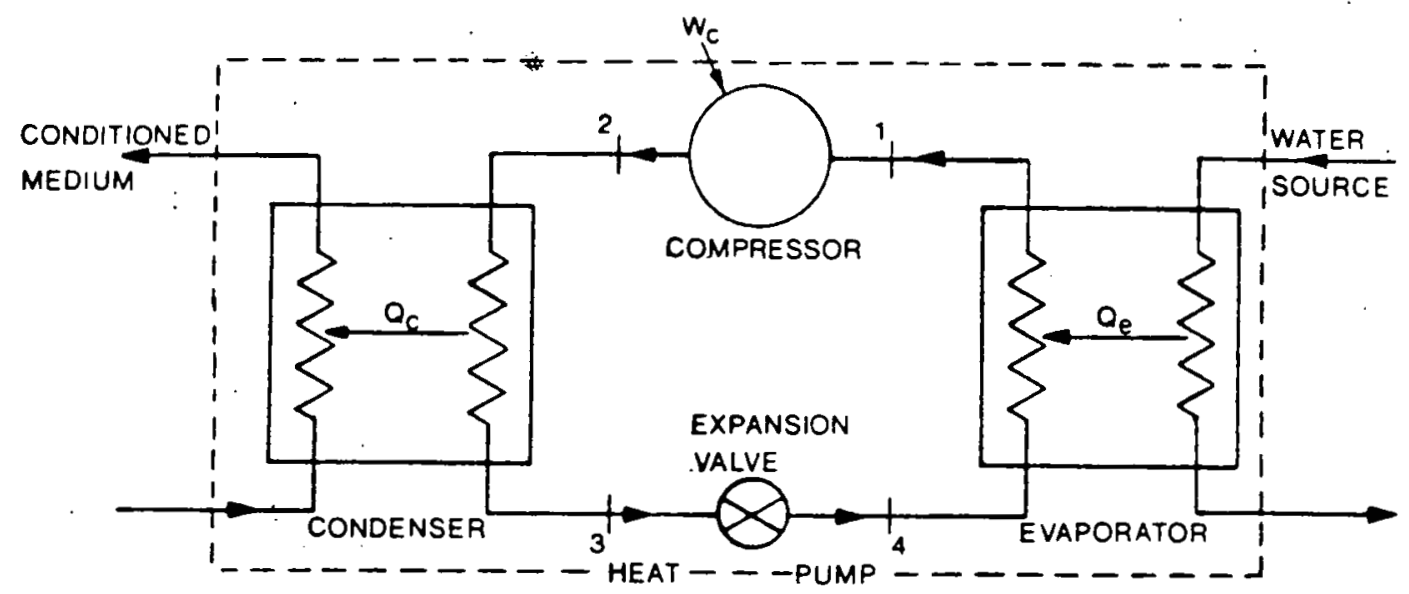

BASIC VAPOR COMPRESSION CYCLE

FIGURE $|1-|$

The coefficient of performance of the heat pump is given by

$$
\begin{aligned}
\underset{(\text { idea1) }}{\operatorname{COP}} & =\frac{\mathrm{Q}_{c}}{\text { Energy input }}=\frac{\mathrm{h}_{2}-\mathrm{h}_{3}}{\mathrm{~h}_{2}-\mathrm{h}_{1}} \\
\underset{(\operatorname{cop} \text { tual) }}{\operatorname{cop}} & =\frac{\mathrm{Q}_{c}}{\mathrm{E}_{\mathrm{th}}}
\end{aligned}
$$

Where $E_{t h}$ is the total energy input to the unit including motor losses and $Q_{c}$ is the heat rejected in the condenser.

The coefficient of performance of the chiller (refrigerator) is given by

$$
\underset{\text { (refrigerator or chiller) }}{\operatorname{COP}}=\frac{Q_{c}}{E_{t h}}
$$

Where $Q_{c}$ is called the refrigerating effect or cooling. 
Heat Rejection Factor (HRF):

This is the ratio of heat exchanged in the condenser to that exchanged in the evaporator and it is related to the coefficient of performance $\mathrm{COP}$ as follows. Using the development in Reference 49, we have

$$
\begin{aligned}
& \mathrm{COP}=\frac{[(\mathrm{HRF}) \mathrm{E}]}{[\mathrm{HRF}-1]} \\
& \mathrm{HRF}=\frac{(\mathrm{COP})}{(\mathrm{COP}-\mathrm{E})}
\end{aligned}
$$

Where

E is 1.0 minus the proportion of input power not delivered to the condenser, expressed as a decimal, and its value depends on the manner in which the compressor is cooled. Throughout our analysis we have assumed that $E=0.92$.

Also it can be shown that

$$
\mathrm{COP}_{\text {heat }} \text { pump }=\mathrm{COP}_{\text {refrigerator }}+\mathrm{E}
$$

\section{4 .4 CALCULATION PROCEDURE}

Calculation procedure for the energy requirement of the HP-WHR system to deliver a given amount of heating effect to the end-user :

Heating mode - Reference ls made to Figure 3-1 and it is assumed that the heat extracted from the distribution water flowing through the evaporator of the end-user heat pump equals the heat rejected to the water in the condenser of the central heat pump.

The total energy requirements include the work input to the compressors of the end-user heat pump, the central heat pump and the energy required to overcome the distribution losses. 
End-user heat pump:

$$
Q_{\text {ce }}=\text { heating load }
$$

work input to end-user heat pump:

$$
\mathrm{W}_{\text {ce }}=\frac{\mathrm{Q}_{\text {ce }}}{\mathrm{COP}_{\text {end-user }}}
$$

Heat absorbed in the evaporator:

$$
Q_{\text {ee }}=\frac{Q_{\text {ce }}}{\text { HRF }}
$$

\section{Where}

HRF is called the heat rejection factor given by

$$
\mathrm{HRF}=\frac{\mathrm{COP}}{(\mathrm{COP}-\mathrm{E})}
$$

Where

COP is the Coefficient of Performance of the heat pump.

$$
\mathrm{Q}_{\mathrm{e}}=\dot{\mathrm{m}}_{\mathrm{w}} \mathrm{c}_{\mathrm{p}}\left(\mathrm{T}_{\mathrm{el}}-\mathrm{T}_{\mathrm{e} 2}\right)
$$

Where

$\mathrm{T}_{\mathrm{e} 1}$ and $\mathrm{T}_{\mathrm{e} 2}$ are the entering and leaving temperatures of water flowing through the evaporator, $\dot{\mathrm{m}}_{\mathrm{w}}$ the mass rate of flow of water and $c_{p}$ its specific heat.

Using the above equation the mass rate of flow of water is calculated and used for the computation of pressure drops as explained in the analysis section. Centrai heat pump:

$$
\begin{array}{cc}
Q_{c} & =Q_{e} \\
\text { (central heat pump) } & \text { (end-user heat pump) }
\end{array}
$$

Where $Q_{c}=$ heat rejected in the central station heat pump

$$
Q_{e}=\text { heat absorbed in the end-user heat pump }
$$


Work input to compressor of central heat pump is defined by the following equation:

$$
\mathrm{W}_{\mathrm{c}}=\frac{\mathrm{Q}_{\mathrm{c}} \text { (central heat pump) }}{\operatorname{CoP} \text { (central heat pump) }}
$$

Total energy input to compressor:

$$
\begin{aligned}
\Sigma \mathrm{W}_{\mathrm{c}} & =\underbrace{\mathrm{W}_{\mathrm{c}}}_{\mathrm{c}}+\mathrm{W}_{\mathrm{c}} \\
\Sigma \mathrm{W}_{\text {losses }} & =\mathrm{W}_{\mathrm{p}}+\text { losses unaccounted } \\
& =0.05 \Sigma \mathrm{W}_{\mathrm{c}}
\end{aligned}
$$

Note: In the section on analysis it is shown that the pump energy associated with one end-user is approximately $5 \%$ of the total energy input to the compressors. However, as indicated in the sample calculations, the reduction in system $C O P$ would be $4-5 \%$ if the losses increased to $10 \%$.

Total energy input to the HP-WHR system is defined by the following equation:

$$
\mathrm{E}_{\text {system }}=\Sigma \mathrm{W}_{\mathrm{c}}+\Sigma \mathrm{W}_{\text {1osses }}
$$

and therefore:

$$
\operatorname{COP}_{\text {system }}=\frac{\text { (heating 1oad) }}{E_{\text {system }}}
$$

A similar calculation procedure is used for the cooling mode. 


\subsubsection{ANNUAL ENERGY CONSUMPTION}

The calculation of the annual energy consumption of the HP-WHR system Lu deliver a given amount of heating or cooling effect involves the use of the part load performance data on the end-user heat pump (water-to-air), the central unit (water-to-water), the pumps and information on the transient performance of the thermal storage reservoir. Information on the part load performance of water-to-water compressive chiller is available (Reference 7) but no precise data on part load performance of water-to-air heat pumps is reported in technlcal litcrature at the present time, The end-user consumes about twice the energy consumed by the central heat pump in the HP-WHR system.

As discussed in section 3.5.2, heat pumps suffer dynamic efficiency losses due to part load operation during the year. Assuming that the dynamic efficiency losses of the HP-WHR system are similar to those of conventional heat pumps,its annual steady state energy consumption is adjusted as follows:

Annual energy consumption $=$ steady state energy consumption $\mathbf{x} \mathbf{F}$ Where the factor $F$ allows for the dynamic efficiency losses. According to Reference 10 the values of $F$ are:

$\begin{array}{ll}\text { Heating season } & F=1.096 \\ \text { Cooling season } & F=1.164 \\ \text { Annual } & F=1.118\end{array}$

Conventional systems: The procedure explained in the chapter on Energy Estimating Methods in Reference 49 , is used as the basis for computing the annual energy consumption of gas warm air heating systems. The annual energy consumption by the air-to-air heat pump was calculated by using the seasonal performance factor obtained from Reference 5 . 
and the heat extracted from the distribution system,

$$
\mathrm{Q}_{\mathrm{E}} \quad=\frac{\mathrm{Q}_{\mathrm{H}}}{\mathrm{HRF}}
$$

Where HRF heat rejection factor.

For the heat pump operating in the cooling mode

$$
\mathrm{W}_{\mathrm{c} 2}=\frac{\mathrm{Q}_{\mathrm{L}}:}{\mathrm{COP}_{\text {cooling }}}=\frac{\mathrm{Q}_{\mathrm{L}}}{\left(\mathrm{COP}_{\text {heating }}{ }^{-\mathrm{E}}\right)}
$$

and the heat rejected $Q_{c}=Q_{L} \times H R F$

If the heat rejected $Q_{c}$ by end-user pump 2 (cooling mode unit) equals $Q_{E}$, the heat extracted from the distribution water by end-user pump 1, then there will be no net change in the energy of the distribution water and no work will be required by the central heat pump.

That is

$$
\mathrm{Q}_{\mathrm{L}} \mathrm{HRF}=\frac{\mathrm{Q}_{\mathrm{H}}}{\mathrm{HRF}_{2}}
$$

For the special case $\mathrm{HRF}_{1}=\mathrm{HRF}_{2}=\mathrm{HRF}$ :

$$
\frac{\mathrm{Q}_{\mathrm{H}}}{\mathrm{Q}_{\mathrm{L}}} \quad=\mathrm{HRF}^{2}
$$

For other loads, the net energy (heat) added to or cxtracted from the effluent will depend on the net demand (heating \pm cooling) of the load from the community. EXAMPLE: Consider the case of two heat pumps whose COP's are the same, that is 2.96 , and $E=0.92$, then

$$
\begin{gathered}
\mathrm{HRF}_{\mathrm{i}}=\frac{2.96}{2.96-.92}=1.456=\mathrm{HRF}_{2} \\
\frac{\mathrm{Q}_{\mathrm{H}}}{\mathrm{Q}_{\mathrm{L}}}=(1.456) \times(1.456)=2.12
\end{gathered}
$$


HRF

$=1.456$

COP

heating mode

$$
=2.96, \text { cop } \text { cooling mode }=2.04
$$

1) $?_{H}=55,000$ Btuh heating

2) $\mathrm{Q}_{\mathrm{L}}=25,943$ Btuh cooling

$$
\begin{aligned}
& W_{c 1}=\frac{55000}{2.96}=18581 \\
& W_{c 2}=\frac{25943}{2.04}=12717
\end{aligned}
$$

TOTAL $\Sigma \mathrm{W}=31298$ Btuh

and heat delivered (in the condenser) to space $=37613 \times \mathrm{HRF}_{2}=55000$ Total 1oad $=55000+25943=80943$

$$
\text { Total } \Sigma \mathrm{W}_{\mathrm{c}}=31,298+0.05 \Sigma \mathrm{W}_{\mathrm{c}}=32862
$$

Net $\operatorname{COP}$ system $=\frac{80,943}{32,862}=2.463$ 
The need for simultaneous heating and cooling will probably arise during the early parts of Fall and Spring seasons when the Internal heat galns in some buildings exceed the heat loss. The total energy requirements of HP-WHR system in such a situation will depend on the distribution of heating and cooling loads and the water distribution system will have to be designed to handle the simultaneous demands of heating and cooling loads.

The energy requirements of the HP-WHR system can be calculated by assuming the model as shown in Figure $11-2$.

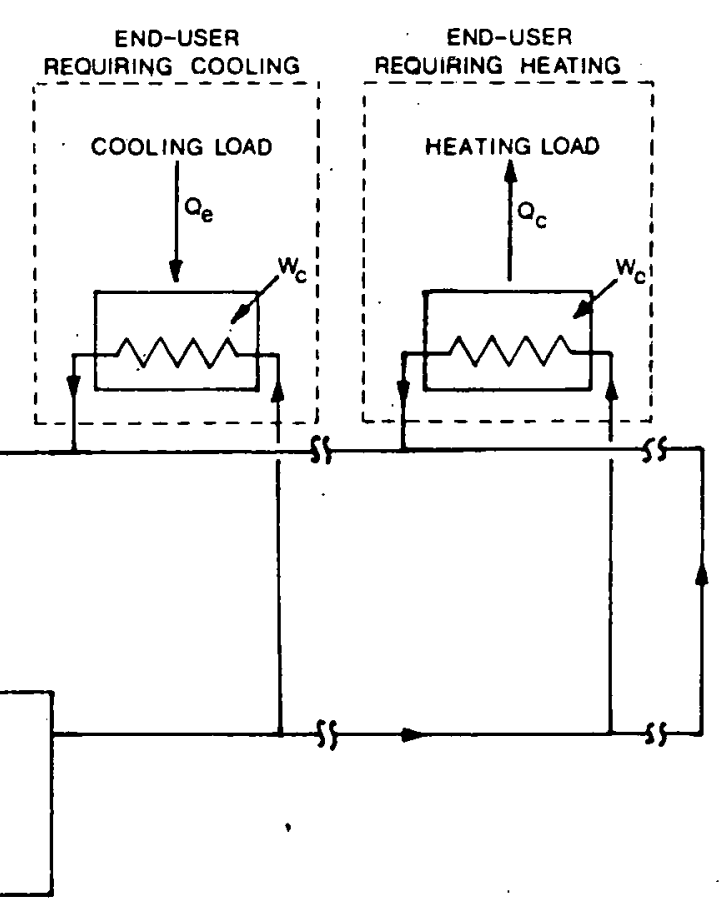

MODEL FOR SIMUIITANEOUS HEATING AND COOLING FIGURE $\| 1-2$

In this system, the heat rejected by the heat pumps acting in the cooling mode can be used as a heat source for the heat pumps acting in the heating mode, and the net effect is a reduction in the work of the compressor of the central unit. As an example, let $\eta_{H}$ and $Q_{L}$ be the heating and cooling loads respectively of and in heat pumps 1 and 2 . Using the equations in section 11.4 .3 , we have

$$
W_{\mathrm{cl}}=\frac{Q_{H}}{\mathrm{COP}}
$$




\subsubsection{DISTRIBUTION SYSTEM LOSSES}

Distribution losses consist of pressure losses due to friction in the pipe lines, thermal losses in pipes and the storage. Since the energy input to overcome these losses is part of the total energy input to the system, the order of magnitude of such losses is discussed in this section.

\section{Frictional loss in a pipe:}

Frictional losses in a pipe depend on the diameter of the pipe, the velocity of water and the roughness of pipe. For a velocity of in the range of $6 \mathrm{ft} / \mathrm{sec}$, and a friction factor value of $\mathrm{f}=0.04$, the head loss for a $1000 \mathrm{ft}$. length of pipe is given by

$$
\mathrm{H}=\mathrm{f} \frac{\mathrm{L}}{\mathrm{D}}\left(\frac{\mathrm{V}^{2}}{2 \mathrm{~g}}\right)=0.04 \times \frac{1000}{1} \times \frac{6^{2}}{2(32.2)}=22^{\prime}
$$

It is common practice to allow a frictional loss of about $25 \mathrm{ft}$. per $1000 \mathrm{ft}$. length of pipe.

Pump work:

The pressure drop due to flow of water in the condenser and evaporator tubes is usually of the order of $12 \mathrm{ft}$. to $25 \mathrm{ft}$. (Reference $5 \& 7$ ).

The work of the pump $W$ required to overcome a total frictional

head loss $\Delta \mathrm{H}$ distribution pipeline, the evaporator and the condenser tubes for a mass rate of flow of $\dot{\mathrm{m}} \mathrm{lbm} / \mathrm{hr}$ per one end-user can be estimated as follows :

$$
\mathrm{W}=\frac{\dot{\mathrm{m}}}{778} \frac{\dot{\Delta}}{\mathrm{x} \eta_{\mathrm{p}}} \quad \mathrm{Btu} / \mathrm{hr}
$$

Where $\eta_{p}$ is the efficiency of the pump. In addition, it may be necessary to pressurize the water for distribution to residences at higher elevations. 
For a mass rate of flow of $3832.75 \frac{1 \mathrm{bm}}{\mathrm{hr}}$ and a total head loss $\Delta \mathrm{H}=(12+25+25+22)=84^{\prime}$, the work of the pump assuming an efficiency of $50 \%$ becomes $827.6 \frac{\mathrm{Btu}}{\mathrm{hr}}$. In the sample calculations for the heating mode the pumping loss is shown to be $3.45 \%$ of the energy input to the compressors. In order to allow for unaccounted losses, the thermal and distribution losses are assumed to be $5 \%$ of the total energy input to the compressors in all performance calculations. However, increasing the distribution losses to $10 \%$ would reduce the system COP by about $4-5 \%$.

The work required to pressurize the water by $100 \mathrm{psi}$ and the consequent temperature change is discussed in Appendix D.

Heat Loss and Temperature Drop in the Distribution Piping:

The heat loss from pipes buried underground depends on the thermal conductivity of the soil, the pipe size and material, the ground temperature and inside water flow conditions. The thermal conductivity $\mathrm{K}$ of the soil varies widely depending on whether the soil is dry and sandy, wet and clay, etc., and has to be investigated for the particular area under consideration. The thermal conductivity values taken from Reference 46 are given in the TABLE $11-1$ and, as suggested by the author, to be used only when precise data are unavailable from a site-specific soil survey.

Heat Loss from Pipe:

The heat loss per foot length of buried pipe is given by Reference 46 and 7 is used as a guide:

$$
Q=K_{p}\left(T_{p}-T_{g}\right), \frac{B t u}{h r-f t}
$$

Where

$$
K_{p}=\text { heat transfer factor, } \frac{B t u}{\text { hr.ft.oF }}
$$




$$
\begin{aligned}
& \mathrm{T}_{\mathrm{p}}=\text { temperature of fluid in the pipe } \\
& \mathrm{T}_{\mathrm{g}}=\text { undisturbed earth temperature } \\
& \mathrm{K}_{\mathrm{p}} \text { is given by } \\
& R=\frac{1}{K_{p}}=\frac{1}{C}+\frac{6}{\pi K_{s}} \ln \left\{\frac{d}{r}+\left(\frac{d}{r}\right)^{2}-1\right\} \\
& C=\text { thermal conductance of pipe: }\left(\frac{\mathrm{Btu}}{\mathrm{hr}-\mathrm{ft} \mathrm{t}^{2 \circ} \mathrm{F}}\right) \\
& \text { When } \\
& \mathrm{d}=\text { distance of ground surface lo center of pipe (ft.) } \\
& r_{0}=\text { outside radius of pipe: (inches). } \\
& \mathrm{K}_{\mathrm{S}}=\text { thermal conductivity of soil }\left(\frac{\mathrm{Btu}-\mathrm{inch}}{\mathrm{hr} \cdot \mathrm{ft}^{2-O} \mathrm{~F}}\right) \\
& \text { and } \\
& \frac{1}{c}=\frac{1}{h_{i} 2 \pi r_{i}}+\frac{6}{\pi k_{w}} \ln \frac{r_{0}}{r_{i}}
\end{aligned}
$$

Where

$$
\begin{aligned}
r_{i}= & \text { inside radius of pipe }(\mathrm{ft}) \\
\mathrm{K}_{\mathrm{w}}= & \text { thermal conductivity of pipe material }\left(\frac{\mathrm{Btu}-\mathrm{inch}}{\mathrm{hr}-\mathrm{ft} \mathrm{t}^{2}-{ }^{\circ} \mathrm{F}}\right) \\
\mathrm{h}_{i}= & \text { surface conductance at the inside surface } \\
& \text { of pipe (water side): }\left(\frac{\mathrm{Btu}}{\mathrm{hr}-\mathrm{ft} \mathrm{t}^{2}-{ }^{\circ} \mathrm{F}}\right) .
\end{aligned}
$$

Additional thermal resistance can be added to the pipe if insulation is used.

$$
\mathrm{K}_{\mathrm{p}} \text { factors can be calculated for various other systems, such as two }
$$
pipe running in a tunnel, a single pipe with different kinds of insulations, are presented in the form of graphs in Ruference 46. Heat loss factors can also be obtained from manufacturers.

For the case of a single plastic bare pipe (O.D. = 12"), buried six feet deep in the ground at $55^{\circ} \mathrm{F}$ (medium dry, sand and clay soil), the $K_{p}$ factor was found to be 1.422 . The heat loss per foot length of pipe 
TABLE $\cdot 11-1$

THERMAL CONDUCTIVITY OF SOIL

$$
\mathrm{k}_{\mathrm{s}}{ }^{*}-\frac{\mathrm{Btu}-\text { in }}{\mathrm{hr}-\mathrm{ft} \mathrm{t}^{2}-{ }^{\circ} \mathrm{F}}
$$

Type Soi1

\begin{tabular}{cccc} 
Moisture Content & Sandy & Silty & Clay \\
\hline $\begin{array}{c}\text { Dry } \\
\text { Medium }\end{array}$ & 2 & 1 & 1 \\
Wet & 13 & 9 & 7 \\
& 15 & 15 & 15
\end{tabular}

* These data are approximate values and should be used only when precise data are unavailable from the site.

SOURCE: Technical Guidelines for Energy Conservation, National Bureau of Standards. ${ }^{46}$ 
for water at $80^{\circ} \mathrm{F}$ was found to be $35.5 \frac{\mathrm{Btu}}{\mathrm{hr}}$.ft. For dry and sandy soil, the heat loss would be $9.5 \frac{\mathrm{Btu}}{\mathrm{hr} . \mathrm{ft}}$

Temperature drop in pipe 1ines:

$$
\begin{aligned}
& \text { Heat loss } \mathrm{Q}=\dot{\mathrm{m}} \mathrm{C}_{\mathrm{pw}}\left(\mathrm{T}_{2}-\mathrm{T}_{1}\right) \\
& \dot{\mathrm{m}}=\rho \mathrm{A}_{\mathrm{c}} \overline{\mathrm{V}}
\end{aligned}
$$

Using a heat loss of $(35.5 \times 5280) \frac{\mathrm{Btu}}{\mathrm{hr}}$ for 1 mile length pipe and a flow velocity of $6 \mathrm{ft} / \mathrm{sec}$, the temperature drop $\left(\mathrm{T}_{1}-\mathrm{T}_{2}\right)$ is found to be less than a degree. This will be offset by the temperature rise due to pressurization in the pipe and frictional losses. The temperature rise due to a pressure increase of $100 \mathrm{psi}$ is shown in the section on pump analysis. Thermal storage:

The size of the thermal storage tank should have sufficient capacity to maintain a constant supply of water for several hours. It should have sufficient thickness and should be dimensioned for minimum surface area to minimize heat losses. The rate of change of temperature of water in the reservoir at any instant can be estimated by an energy balance. Fig. 11-3

$$
\dot{\mathrm{Q}}=\dot{\mathrm{m}}\left(\mathrm{h}_{2}-\mathrm{h}_{1}\right)+\dot{\mathrm{M}} \frac{\mathrm{dE}}{\mathrm{d} \theta}
$$

Where

$$
\begin{aligned}
E & =\text { the internal energy of water in the reservoir } \\
& =\mathrm{C}_{\mathrm{V}}(\mathrm{T})
\end{aligned}
$$

(symbol legend cont'd) 


$$
\begin{aligned}
\theta & =\text { time } \\
\dot{Q} & =\text { rate of heat loss from the storage reservoir and } \\
C_{v} & =\text { specific heat of water }=1.0 \frac{\mathrm{Btu}}{1 \mathrm{bm}-\mathrm{O} R} \\
\mathrm{~T} & =\text { temperature of water } \\
\dot{\mathrm{m}} & =\text { mass rate of flow } \\
\mathrm{M} & =\text { mass of water in the storage } \\
\dot{\mathrm{m}}\left(\mathrm{h}_{2}-\mathrm{h}_{1}\right) & =\text { total enthalpy change of water entering and leaving the }
\end{aligned}
$$

The volume of the tank containing say, $5 \times 10^{6}$ gallons would be $6.67 \times 10^{5} \mathrm{ft}^{3}$. For minimum surface areas, the diameter and height would be :

$$
\begin{aligned}
& D=94.7 \mathrm{ft} .=\text { diameter } \\
& \mathrm{L}=94.7 \mathrm{ft} .=\text { height }
\end{aligned}
$$

The exposed surface area

$$
A_{s}=35217.6 \mathrm{ft}^{2}
$$

The effect of the heat transfer $Q$ on the rate of change of internal energy, $\frac{d E}{d \theta}$ can be studied by neglecting $\dot{m}\left(h_{2}-h_{1}\right)$ for the given instant. Then

$$
\begin{aligned}
& \qquad \begin{array}{l}
Q=U A\left(T-T_{0}\right)=M \frac{d E}{d \theta} \\
\text { Where } \\
T_{0} \text { is the temperature of surroundings }
\end{array} \\
& \text { Assuming a " } U \text { " value of } 0.3 \frac{\mathrm{Btu}}{\mathrm{hr} \cdot \mathrm{ft}^{2}-\mathrm{O}_{\mathrm{F}}} \text { (based on inside area) for }
\end{aligned}
$$

wall structure composed of thick concrete and exposed to outside air temperature of $0^{\circ} \mathrm{F}$, and inside waler temperature of $80^{\circ} \mathrm{F}$, we have

$$
\frac{\mathrm{dE}}{\mathrm{d} \theta}=\frac{-0.3 \times \frac{35217.6(80-0)}{5 \times 10^{6} \times 8.33 \times 1.0}}{10^{6}}
$$

or

$$
\frac{\mathrm{dT}}{\mathrm{d} \theta}=-0.0203 \frac{{ }^{\circ} \mathrm{F}}{\mathrm{hr}}, \text { since } \mathrm{C}_{\mathrm{v}}=1.0
$$


This is the rate of change of temperature of water in the storage at the instant when its temperature is $80^{\circ} \mathrm{F}$. This analysis assumes that there are no temperature gradients within the reservoir. However, in the actual system temperature gradients may exist.

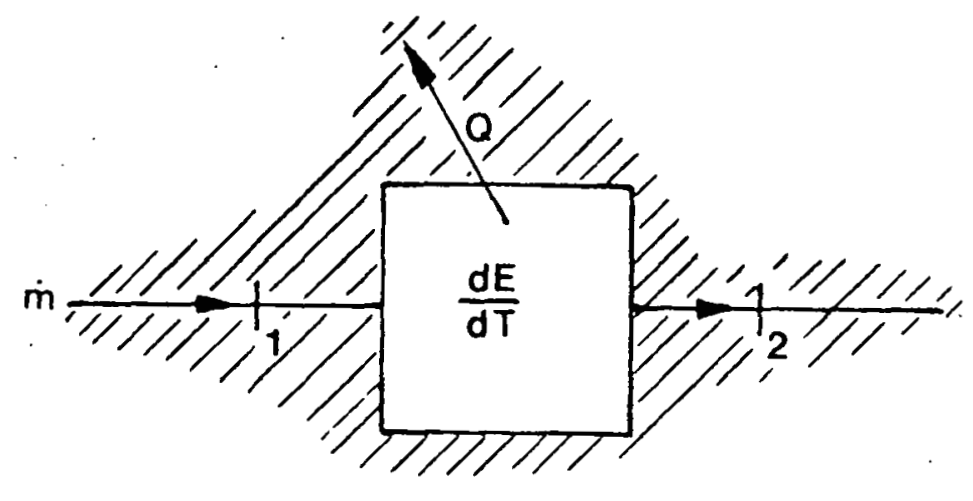

BLOCK DIAGRAM FOR THERMAL STORAGE ANALYSIS

FIGURE $11-3$ 


\subsubsection{HEAT PUMP PERFORMANCE DATA}

The discussion presented here illustrates the procedure for computing COP's from the information on actual heat pumps given in References 5,6,7. The TABLES and figures for the performance of heat pumps are presented only for illustration. They do not cover the full range of data used in our calculations. END-USER HEAT PUMPS - actual performance data on water-to-air end-user heat pump is obtained from the information given in References 5 and 7 in which the parameters such as heating capacity, cooling capacity, COP and EER are related to the entering water temperature by means of equations. Values of heating capacity and $\mathrm{COP}$ obtained by the use of these equations are shown in Figures 114 and 115 . The COP values used for the cooling mode of the heat pump were converted from EER values given in References 6 and 7 .

CENTRAL CHILLER - the performance of the central chiller is given by the relation (Reference 5)

$\%$ of nominal power input $=916.347+0.532633(x)-0.000559686\left(x^{2}\right)+$ $0.0000230630\left(x^{3}\right)$

$$
\begin{aligned}
& -32.7860(\mathrm{LCWT})+0.378447\left(\mathrm{LCWT}^{2}\right)-0.00142857\left(\mathrm{LCWT}^{3}\right) \\
& +\frac{1092.31}{\mathrm{LEWT}}+\frac{2071.02}{\mathrm{LEWT}}{ }^{2}
\end{aligned}
$$

Where:

$X=\%$ of full load

LCWT $=$ leaving condenser water temperature $\left({ }^{\circ} \mathrm{F}\right)$

LEWT $=$ leaving evaporator temperature $\left({ }^{\circ} \mathrm{F}\right)$

which permits us to find the COP of the chiller for various values of temperatures of water or effluent entering and leaving the central chiller. 


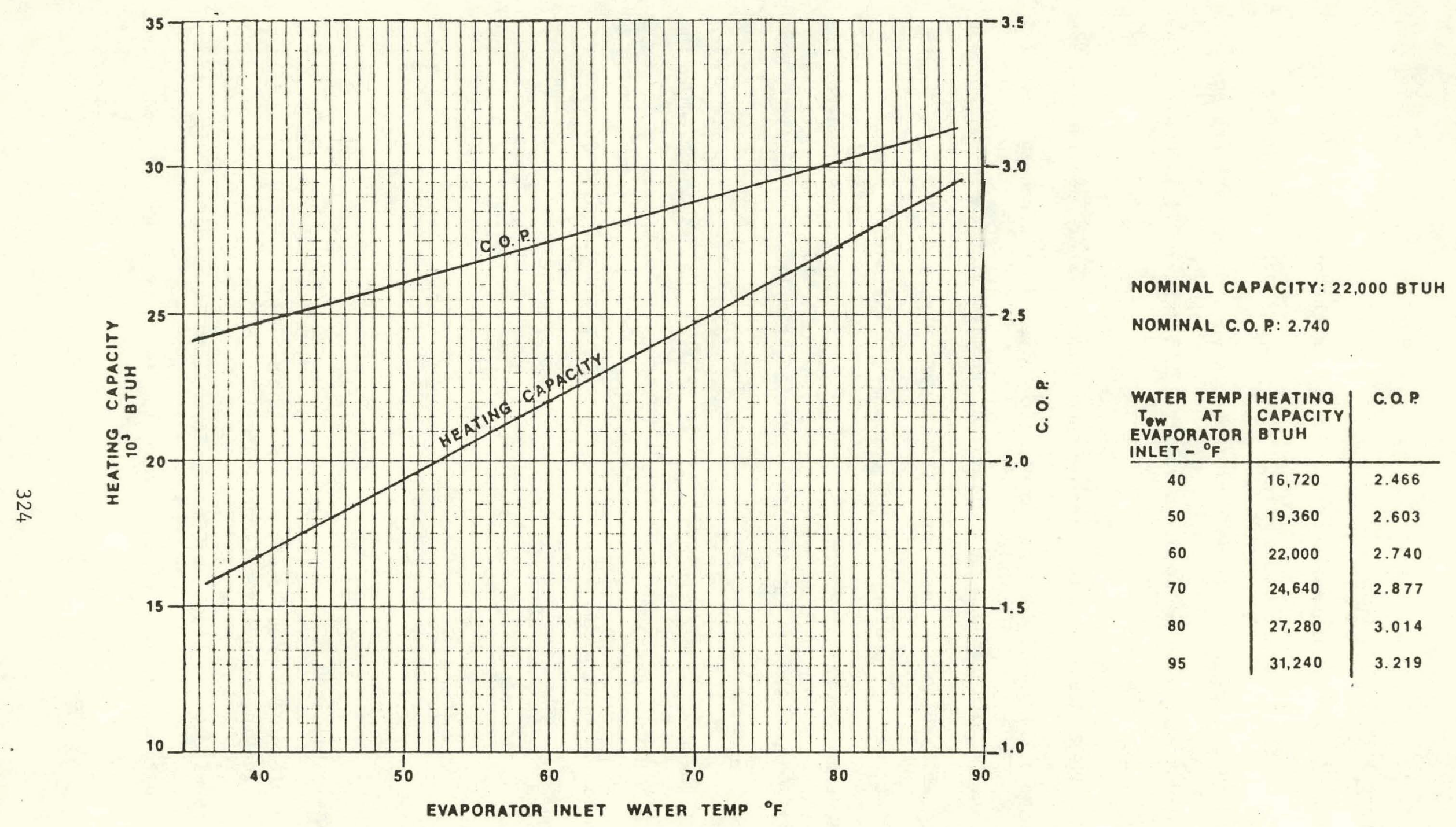

\section{WATER-TO-AIR HEAT PUMP \\ C.O.P. VS. INLET WATER TEMP.}

FIGURE II-4 


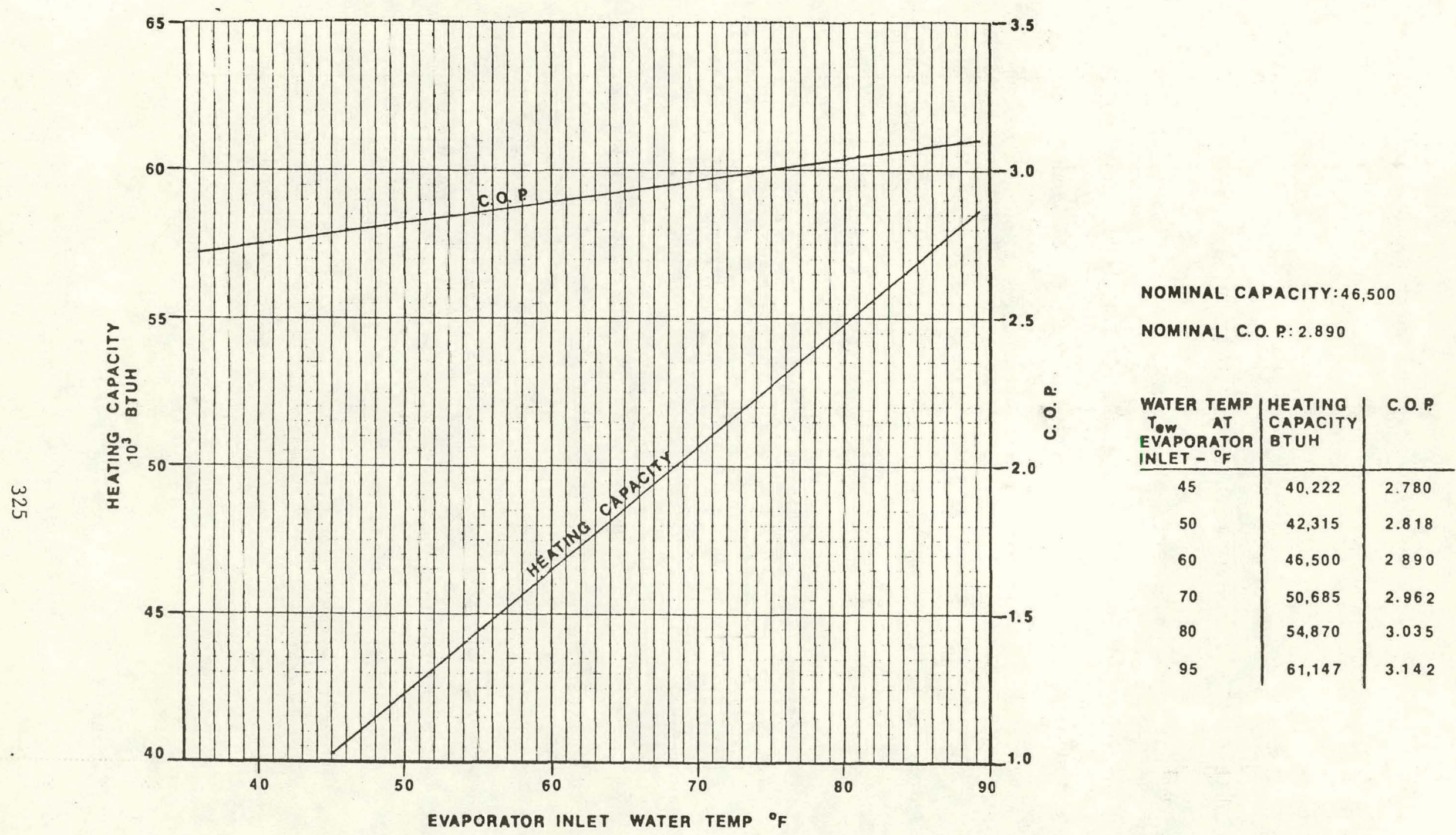

$\frac{\text { WATER-TO-AIR HEAT PUMP }}{\text { C.O.P VS. INLET WATER TEMP. }}$

FIGURE II-5 
The COP of the chiller for a given set of Water temperatures other than the rated conditions is given by

$$
\underset{\text { chiller }}{\mathrm{COP}} \quad=\frac{\mathrm{COP} \text { nominal }}{\text { nominal work input expressed as a decimal }}
$$

The COP chiller found for the given temperatures of water, is related to the COP heat pump by equation 11-6 given in section 11.4.3. The COP value, found by using equation $11-28$ were reduced to allow for the fouling tactors. Information on fouling factor correction presented in Reference 5 was used as a guide for this correction. The corrected values of COP used in our calculations were found by

$\begin{array}{cl}\begin{array}{c}\mathrm{COP} \\ \text { (corrected) }\end{array} & \begin{array}{l}\mathrm{COP} \\ \text { chiller or } \\ \text { heat pump }\end{array}\end{array}$

Where $F$ = fouling correction factor; a value of 0.931 for $F$ was assumed in one calculation.

TABLES $11-2$ and $11-3$ are included to indicate the values of COP for representative water temperatures ranges. Air-to-air heat pumps - The COP and EER values were computed using the information given in Reference 6 . The computed values of the COP's for air-to-air heat pumps for various outside air temperatures are listed in Chapter 3. For the purposes of illustration, a typical air-to-air heat pump cycle is pictured in Figure 11-6. 
TABLE :11-2

CENTRAL CHILLER

$\underline{\text { LCWT }}$

LEWT

COP

$90^{\circ} \mathrm{F}$

$50^{\circ} \mathrm{F}$

(Chiller) *

$80^{\circ} \mathrm{F}$

$50^{\circ} \mathrm{F}$

5.492

$70^{\circ} \mathrm{F}$

$50^{\circ} \mathrm{F}$

5.8864

6.023

LCWT = Leaving condenser water temperature

LEWT = Leaving evaporator water temperature

*COP of Chiller for Corrected for Fouling Factors 
TABLE 11-3

CENTRAL HEAT PUMP

$\begin{array}{lrc}\text { LCWT } & \text { LEWT } & \text { (Heat Pump)* } \\ 80^{\circ} \mathrm{F} & 40^{\circ} \mathrm{F} & 6.494 \\ 80^{\circ} \mathrm{F} & 50^{\circ} \mathrm{F} & 6.991 \\ 80^{\circ} \mathrm{F} & 60^{\circ} \mathrm{F} & 7.361 \\ 80^{\circ} \mathrm{F} & 70^{\circ} \mathrm{F} & 7.647 \\ & & \\ & & \\ & & \\ = & \text { Leaving condenser water temperature }\end{array}$

* $\mathrm{COP}$ of Heat Pump Corrected for Fouling Factors 


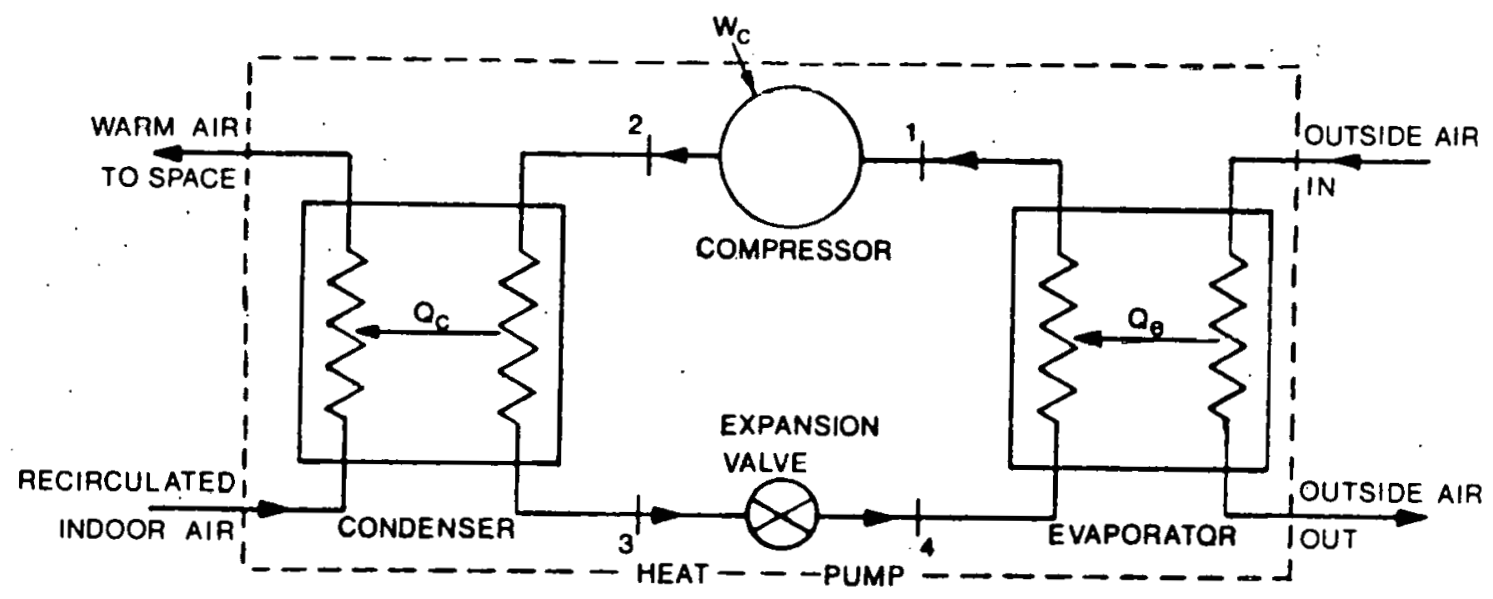

\section{AIR-TO-AIR HEAT PUMP}

FIGURE $11-6$

\subsubsection{SITE-SPECIFIC SYSTEM DESIGNS}

Calculations: Variable Pump Work

The distribution piping and pump system are designed and specified on the basis that a relatively constant head will be maintained on the system and flow will vary according to load. Pump work required will therefore also vary with load. The governing equation which calculates pump wnrk as a funclion of flow is developed below:

\section{System Pumping Coefficient}

$$
\begin{aligned}
\operatorname{HEAD}(\mathrm{ft}) & =\mathrm{C}_{\mathrm{v}}\left(\mathrm{GPM}_{\text {peak }}\right)^{2} \\
\therefore \quad \mathrm{C}_{\mathrm{v}} & =\frac{\mathrm{HEAD}}{\left(\mathrm{GPM}_{\text {peak }}\right)^{2}}
\end{aligned}
$$


Pump Work (Electrica1)

$$
\begin{aligned}
& \mathrm{W}_{\mathrm{e}}=\left[\frac{\mathrm{C}_{\mathrm{v}}(\mathrm{GPM})^{3}\left(8.33 \frac{\mathrm{Lbm}}{\mathrm{gal}}\right)}{\left(60 \frac{\mathrm{sec}}{\mathrm{min}}\right)\left(738 \frac{\mathrm{FT}-\mathrm{Lbf}}{\mathrm{sec}-\mathrm{kW}}\right)\left(n_{\text {pump }}\right)\left(\eta_{\text {motor }}\right)}\right] \times \text { hrs: } \\
& \text { Assuming } n_{\text {pump }}=.65 \text { and } \eta_{\text {motor }}=.80 \text {, the equation becomes: } \\
& \mathrm{W}_{\mathrm{e}}=\left[\frac{\mathrm{C}_{\mathrm{v}}(\mathrm{GPM})^{3}(8.33)}{(60)(738)(.65)(.80)}\right] \times \text { hrs } \\
& =\left(3.618 \times 10^{-4}\right)\left(\mathrm{C}_{\mathrm{v}}\right)(\mathrm{GPM})^{3}(\mathrm{hrs})
\end{aligned}
$$

In order to simulate in the calculational procedure the monthly load variations represented by the heating and cooling load duration curves, a percentage load factor can be inserted in conjunction with the flow factor (as shown below), and the hours at a particular percent of peak load can then be considered.

$$
\mathrm{W}_{\mathrm{e}}=\left(3.618 \times 10^{-4}\right)\left(\mathrm{C}_{\mathrm{v}}\right)\left(\text { LOAD FACTOR } \times \mathrm{GPM}_{\text {peak }}\right)^{3}(\mathrm{hrs})
$$

For particular system applications, system pumping coefficients and peak flows can be inserted in the general equation, and the simplified equation then has only percent of peak load vs. time to consider as variables. Finally, the appropriate heating or cooling load duration curves can be broken down into percent and time factors by the finite integral technique and input into the equation. The sum of all integrals under the curve gives the total pump work required for any particular period. 


\section{CONYERS HP-WHR SYSTEM}

$\begin{array}{lcr}\text { PUMP HEAD } & - & 500 \mathrm{FT} . \\ \text { PEAK COOLING FLOW } & - & 2618 \mathrm{GPM} \\ \text { PEAK HEATING FLOW } & - & 1202 \mathrm{GPM}\end{array}$

$$
C_{v}=\frac{500}{(2618)^{2}}=7.295 \times 10^{-5}
$$

$$
\begin{aligned}
& \text { COOLING: } W_{e}=\left(3.618 \times 10^{-4}\right)\left(7.295 \times 10^{-5}\right)(\mathrm{L} . \mathrm{F} . \times 2618)^{3} \mathrm{hrs} \\
& =473.55 \text { (L.F.) })^{3} \text { hrs } \\
& \text { HEATING: } W_{e}=\left(3.618 \times 10^{-4}\right)\left(7.295 \times 10^{-5}\right)(\text { L.F. } \times 1202)^{3} \mathrm{hrs} \\
& =45.83 \text { (L.F.) })^{3} \mathrm{hrs}
\end{aligned}
$$

\section{CORNELIA HP-WHR SYSTEM}

$\begin{array}{llr}\text { PUMP HEAD } & - & 325 \mathrm{FT} . \\ \text { PEAK COOLING FLOW } & - & 4309 \mathrm{GPM} \\ \text { PEAK HEATING FLOW } & - & 1954 \mathrm{GPM}\end{array}$

$$
c_{v}=\frac{325}{(4309)^{2}}=1.7504 \times 10^{-5}
$$

$$
\text { COOLING: } \begin{aligned}
\mathrm{W}_{\mathrm{e}} & =\left(3.618 \times 10^{-4}\right)\left(1.7504 \times 10^{-5}\right)(\mathrm{L} . \mathrm{F} . \times 4309)^{3} \mathrm{hrs} \\
& =506.64(\text { L.F. })^{3} \mathrm{hrs}
\end{aligned}
$$

$$
\text { HEATING: } \begin{aligned}
W_{e} & =\left(3.618 \times 10^{-4}\right)\left(1.7504 \times 10^{-5}\right)(\text { L.F. } \times 1954)^{3} \mathrm{hrs} \\
& 47.24 \text { (L.F. })^{3} \mathrm{hrs}
\end{aligned}
$$

In order to reduce the monthly heating and cooling load duration curves into a data set which could be input into the pump work equations, the bin 
method of. data reduction was employed. Peak heating load was assumed to occur at the $99 \%$ design temperature and peak cooling at the $2 \%$ design temperature. Bins were defined in $5^{\circ} \mathrm{F}$ increments from the design temperature to the appropriate datum $\left(65^{\circ} \mathrm{F}\right.$ for heating and $75^{\circ} \mathrm{F}$ for cooling), and the midpoint temperature for each bin was assigned a percent: of peak load figure. Duration at each average load level was then interpolated from the load duration curve. The data points, then in the proper form for use in the pump work equations, werc insprted in the appropriate healing or conling equation and the work calculation performed.

Several assumptions were necessary concerning system operation.

- During the heating season, if the estimated heating load dropped below $34 \%$, the required pump work during that period was assumed to remain constant at the $34 \%$ level, representing the work requirements to maintain the system minimum flow. Operation during periods of marginal or no load was also assumed to be at the $34 \%$ load level for the same reason.

- During the cooling season, if the estimated cooling load dropped below $10 \%$, the required pump work was assumed to remain constant at the $10 \%$ level to account for the minimum flow pump work. Likewise, operation during periods of marginal or no cooling load was assumed to be at the $10 \%$ load level.

- During periods requiring both heating and cooling, heating loads above the $34 \%$ level were accounted for in the normal manner. Heating loads of $1-34 \%$ were assumed to be met with operation at the $34 \%$ load leve1. Cooling loads of $10 \%$ and up were also accounted for as explained above. However, cooling loads of $1-10 \%$ and periods 
with no apparant heating or cooling load were assumed to require system operation at the $10 \%$ cooling load levels.

The results of the assessment of distribution pump power requirements are summarized in Appendices $C$ and $D$. 
THIS PAGE

\section{WAS INTENTIONALLY LEFT BLANK}




\section{REFERENCES}

AUTHORS

1. Ambrose, E. R., Heat Pumps and Electric Heating, John Wiley and Sons, Inc., New York, 1966.

2. Arkansas Power and Light Company, Market Research Section, Heat Pump Study, Little Rock, Arkansas, 1974.

3. Binkley, C., B. Collins, et al, Interceptor Sewers and Urban Sprawl, Lexington Books, Washington, D.C., 1975.

4. Calm, James M., "Recovery of Wasted Heat With Centralized and Distributed Heat Pump Systems," Presented at the ASME Winter Annual Meeting, 1978.

5. Christian, J. E., Central Cooling - Compressive Chillers, Argonne National Laboratory, ANL/CES/TE 78-2, Argonne, Illinois, March 1978.

6. Christian, J. E., Unitary Air-to-Air Heat Pumps, Argonne National Laboratory, AlNL/CES/TE 77-10, Argonne, Illinois, July 1977.

7. Christian, J. E., Unitary Water-to-Air Heat Pumps, Argonne National Laboratory, ANL/CES/TE 77-9, Argonne, Illinois, October 1977.

8. Clark, J.W., W. Viessman, and M. J. Hammer, Water Supply and Pollution Control, Dunn-Donnelley, New York, 1977.

9. Godfrey, R. S. (ed.), Building Construction Cost Data, Robert Snow Means Co., Inc., Massachusetts, 1977 .

10. Gordian Assuclares, Heat Pump Technology, A Survey of Technical Development, Market Prospects and Research Needs, Report HCP/M2121-01 for the Department of Energy, June 1978.

11. Holman, J. P., Heat Transfer, McGraw-Hill, Inc., U.S:A., 1972 .

12. James, R. W., S. A. Marshall and S. N. Salerja, "The Heat Pump as a Means of Utilizing Low Grade Heat Energy," B.S.E., Vol. 43, January 1976.

13. Jennings, B. H., Environmental Engineering, Analysis and Practice, International Textbook Co., Pennsylvania, 1970. 
14. Kelly, G. E. and J. Bean, "Dynamic Performance of Residential Air-to-Air Heat Pumps," Proceedings of the 2nd Annual Heat Pump Technology Conference, Oklahoma State University, Stillwater, Oklahoma, October 18-19, 1976.

15. Kennedy, A. and C. Lee, Integrated Community Energy Systems. (ICES) Commercialization Case Studies, Vol.1, Argonne National Laboratory, Energy and Environmental Systems Div., ANL/ICES-TM-4, Argonne, Illinois, 1978.

16. Kreith, F. J., Principles of Heat Transfer, International Textbook Co., Pennsylvania, 3rd Edition.

17. Kreith, F. J. and J. F. Kreidler, Solar Heating and Cooling, McGraw-Hill Book Company, New York, 1975.

18. Krenkel, P. A., and F. L. Parker (eds.), Biological Aspects of Thermal Pollution, Vanderbilt Univereity Press, Nashville, Tell1., 1969.

19. Kusuda, T. and P. R. Achenback, "Earth Temperature and Thermal Diffusivity at Selected Stations in the United States," ASHRAE, January 25-28, 1965, Chicago, Illinois.

20. Lin, K. C. and G. W. Heinke, "Plant Data Analysis of Temperature Significance in the Activated Sludge Process," Journal WPCF, February 1977.

21. Metcalf and Eddy, Inc., Wastewater Engineering: Collection, Treatment, Disposal, McGraw-Hill Book Company, New York, 1972.

22. Pallio, F. S., "Energy Conservation and Heat Recovery in Wastewater Treatment Plants," Water and Sewage Works Magazine, February 1977.

23. Parker, W. H., R. W. Beausoliel and G. E. Kelly, "Factors Affecting the Performance of Residential Air-Air Heat Pumps," Semiannual meeting of the American Society of Heating, Refrigeration, and Air-Conditioning Engineers, Chicago, Illinois, February 1977.

24. Phelps, E. B., Stream Sanitation, John Wiley and Sons, New York, 1944.

25. Phetteplace, G. and N. Labbe, Heat Distribution With Low Temperature Hot Water, Cold Regions Research and Engineering Laboratory, U. S. Corps of Engineers, Hanover, New Hampshire, August 1978.

26. Professional Builder: "Consumer/Builder Survey on Housing," January, 1976. 
27. Rand Corporation, Energy Use and Conservation in the Residential Sector: A Regional Analysis, Report PB-254-468 for the U.S. Department of Commerce, June 1975 .

28. Roensch, L. F., J.C. Grier and E. F. Klen, "The Achievement of Slime Control in Utility Surface Condensers Without Impairing Discharge Water Quality," Proceedings of the 40th Annual American Power Conference; April 26, 1978.

29. Rohsenow, W.M. and V.P. Hartnett, Handbook of Heat Transfer, McGraw-Hill, Inc., U.S.A., 1973.

30. Sawyer, C.N. and G. A. Rohlich, "Sewage Works Journal," $11: 946$, (1939).

31. Sawyer, C:N. and P.L. McCarty, Chemistry for Sanitary Engineers, McGraw-Hill Book Co., New York, 1967.

32. Schroepfer, G.J., M.L. Robins, and R. H. Susag, "The Research Program on the Mississippi River in the Vicinity of Minneapolis and St. Paul," Advances in Water Pollution Research, Vol. 1, Peramm Press Ltd., London, 1964:

33. Sector, Peter, W., "Demonstration of Building Heating with a Heat Pump Using Thermal Effluent," CRREL Technical Report SR 77-11, AD A041024, May 1977.

34. Sonntag, R. E. and G. J. Van Wylen, Introduction to Thermodynamics: Classical and Statistical, John Wiley and Sons, Inc., New York, 1971.

35. Sussman, M. V., "Availability Analysis," Proceedings of the Internatinnal Conference on Energy Use Management, Tucson, Arizona, October 1977.

36. Thurson, H.G.; W.J. Fabrycky and G.J. Thurson, Engineering Economy, Prentice Hall, Inc., New Jersey, 1.971.

37. Van Horne,J.C., Financial Management and Policy, 2nd edition, Prcntice-Hall, Inc., Englewood Cliffs, New Jersey, 1971.

38. Wagner, Tom, Population Projections for Georgia Counties, 1980-2010, State Data Center, Office of Planning and Budget," Atlanta, Ccorgia, September 1977.

39. Wood, B.D., Applirations of Thermodynamics, AddisonWesley Publishing Company, Inc., Massachusetts, 1969. 
TITLES

40. MOODY'S MUNICIPAL A AND GOVERNMENT MANLAL, 1978,

Volume 1

Moody's Investor's Service, Inc.

99 Church Street, New York, New York

41. Municipal Financing of Integrated Community Energy Systems, Argor:. : National Lagoratory, ANL/ICES-TM-3, November 1977

42. Munici-al Waste Facilities - Statistical Summary, 1968 Inventory, U.S. Department of the Interior, Federal Water Quality Administration, Division of Technical Support, Technical Data and Information Branch, 1969.

43. Natlunal Cas Survey, 1978, U.S.Departmer: of Energy, Ferieral Energy Regulatory Combissiun DOE/FERC.-008, Uc - 13; Washington, D.C., June 1978.

44. Population of: the United States, U.S. Department of Commerce, Social and Economic Statistics Administra-. tion, Bureau of the Census, Series P-23, No. 49, Washington, D.C., May 1974.

45. "Request for Proposals No. 78-437 - Heat Pump Centered Integrated Community Energy Systems, Phase I," Argonne National Laboratory, Argonne, Illinois, March 1978.

46. Technical Guildelines for Energy Conservation, National Bureau of Standards, AD/A-041 668, U.S. Department of Commerce, National Techinical Information Service, June 1977.

47. Water Quality Criteria, National Technology Advisory Committee, Federal Water Pollution Control Administration, Washington, D.C., 1968.

48. ASHRAE Equipment Handbook, American Society of Heating, Refrigerating, and Air-Conditioning Engineers, Inc., New York, 1975.

49. ASHRAE Systems Handbook, American Society of Heating, Refrigerating, and Air-Conditioning Engineers, Inc., New York, 1976.

50. ASHRAE Handbook of Fundamentals, American Society of Heating, Refrigerating, and Air-Conditioning Engineers, Inc., New York, 1977. 
51. ASHRAE Standard 14-67, "Methods of Testing for Rating Mechanical Condensing Units," American Society of Heating, Regrigeration, and Air-Conditioning Engineers, Inc., New York, 1967.

52. ASHRAE Standard 37-69, "Methods of Testing for Rating Unitary Air-Conditioning and Heat Pump Equipment," American Society of Heating, Refrigeration, and Air Conditioning Engineers, Inc., New York, 1969.

53. ARI Standard 320-76, "Standard for Water Source Heat Pumps,"Air-Conditioning and Refrigeration Institute, Arlington, Virginia, 1976.

54. ARI Standard 550-77, "Standard for Centrifugal Waterchilling Packages, "Air-Conditioning and Refrigeration Institute, Arlington, Virginia, 1966.

\section{SUPPLEMENTAL REFERENCES}

55. "Monthly Normals of Heating and Cooling Degree Days, 19411970," National Climatic Center, Asheville, North Carolina.

56. "Georgia - General Population Characteristics," U. S. Department of Commerce; Social and Economic Statistics Administration, Bureau of the Census, Washington, D.C., 1974.

57. Cornelia Community Development Concept Plan; Georgia Mountains Planning and Development Commission; Gainesville, Ga., 1978.

58. ASHRAE Standard 90-75, Energy Conservation in New Building Design; American Society of Heating, Refrigerating and Air Conditioning Engineers, Inc.; New York, 1975.

59. Potter, P. J., Power Plant Theory and Design, Ronald Press, New York, 1959.

60. City of Cornelia, 201 Faciltties Plan; E.P.A. Project \#C 130585-01-0; Hensley-Schmidt, Inc., Consultants; July 1977. 
THIS PAGE

\section{WAS INTENTIONALLY LEFT BLANK}


APPENDIX A 


\section{WEATHER DATA FOR TEST CITIES}

\begin{tabular}{|c|c|c|}
\hline city & $\begin{array}{l}\text { ASHRAE(a) } \\
\text { Heating } \\
\text { Degree Days }\end{array}$ & $\begin{array}{l}\text { Representative } \\
\text { Heat Ing Degree } \\
\text { Day Range }\end{array}$ \\
\hline Hous ton & 1278 & $500-2000$ \\
\hline Birmingham & 2551 & $2000-3000$ \\
\hline Atlanta & 2961 & $2500-3500$ \\
\hline Tulsa & 3680 & $3000-4000$ \\
\hline Phtladelphia & 4486 & $4000-5000$ \\
\hline Seattle & 4424 & -- \\
\hline Columbus & 5560 & $5000-6000$ \\
\hline Cleveland & 6351 & $6000-7000$ \\
\hline Concord & 7383 & $7000-8000$ \\
\hline
\end{tabular}

\begin{tabular}{|c|c|c|c|}
\hline & HER DATA US & IN THIS STUDY & \\
\hline $\begin{array}{l}\text { Heating } \\
\text { Degree Days. }\end{array}$ & $\begin{array}{l}\text { Cooling } \\
\text { Degree Days }\end{array}$ & $\begin{array}{l}\text { Year of } \\
\text { Weather Data }\end{array}$ & $\begin{array}{l}\text { Deviation } \\
\text { Level }\end{array}$ \\
\hline 1290 & 2339 & 1955 & $3 \%$ \\
\hline 2844 & 1928 & 1955 & $7 x$ \\
\hline $2821^{\circ}$ & 1589 & 1959 & $6 x$ \\
\hline 3504 & 1949 & 1950 & $6 x$ \\
\hline 4508 & 1104 & 1951 & $8 x$ \\
\hline 4407 & 183 & 1960 & $2 x$ \\
\hline 5467 & 809 & 1964 & $10 \%$ \\
\hline 6097 & 613 & 1964 & $10 \%$ \\
\hline 7377 & 349 & 1964 & $10 x$ \\
\hline
\end{tabular}

(a) Heating degree days from ASHRAE 1973 Systems Handbook. Chapter 43.

SOURCE: "HEAT PUMP TECHNOLOGY," GORDIAN ASSOCIATES (1978)10. 


\section{TABLE $\quad A-2$}

\section{MOUNTAINSIDE COMMERCIAL BUILDING HEATING AND COOLING OESIGN LOADS}

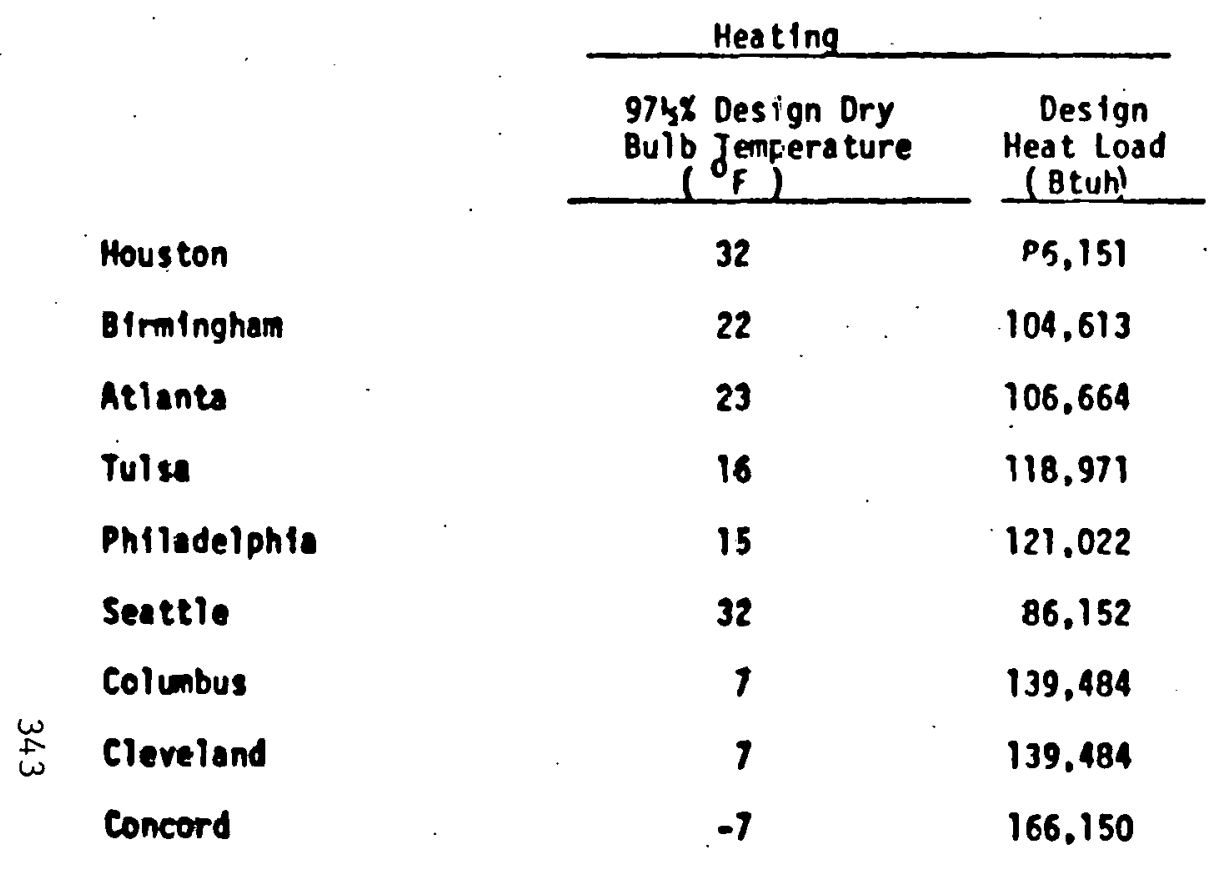

\begin{tabular}{|c|c|c|c|}
\hline \multicolumn{4}{|c|}{ Conling } \\
\hline $\begin{array}{l}\text { 25\% Design Dry } \\
\text { Bulb Temperature } \\
\text { (OF) }\end{array}$ & $\begin{array}{l}\text { 246. Des ign Wet } \\
\text { Bulb Temperature } \\
\text { (OF) }\end{array}$ & $\begin{array}{l}\text { Design Sensible } \\
\text { Cooling Load } \\
\text { (8tuh) }\end{array}$ & $\begin{array}{l}\text { Design Total } \\
\text { Cooling Load } \\
\text { (Btuh) } \\
\end{array}$ \\
\hline 94 & 80 & 143.447 & 206,119 \\
\hline 94 & 78 & 143.447 & 195.667 \\
\hline 92 & 77 & 139,380 & 189,992 \\
\hline 99 & 78 & 155,656 & 203,852 \\
\hline 90 & $n$ & 135,315 & 187,535 \\
\hline 79 & 65 & 112,937 & 124,957 \\
\hline 88 & 76 & 131.244 & 178,640 \\
\hline 89 & 75 & 133.277 & 176.653 \\
\hline 88 & 73 & 131.244 & 164.972 \\
\hline
\end{tabular}

SOURCE: "HEAT PUMP TECHNOLOGY," GORDIAN ASSOCIATES (1978)10 
TEST HOUSE

DESIGN TEMPERATURES AND HEAT LOAD FOR

HEATING ANO COOLING EQUIPMENT.

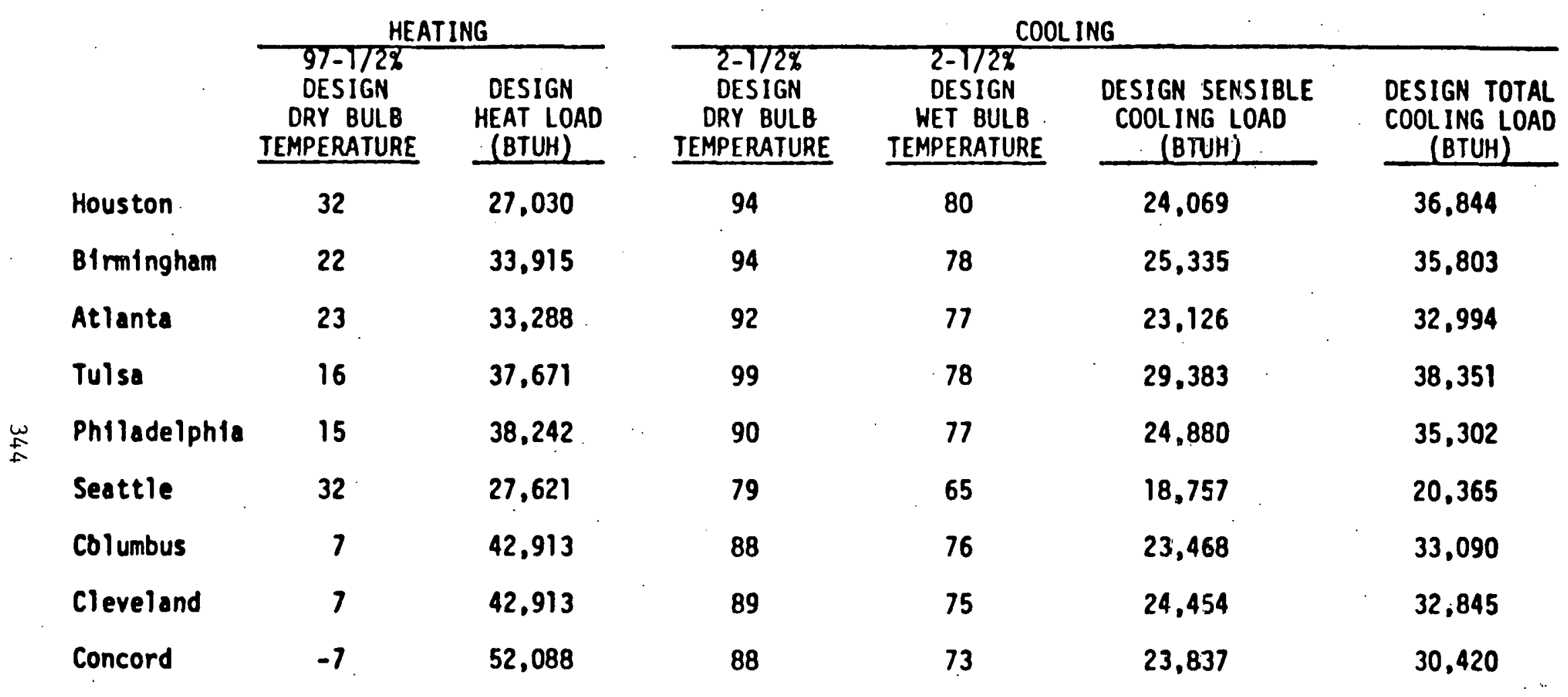

SOURCE: "HEAT PUMP TECHNOLOGY," GORdIAN ASSOCIATES (1978) 10 
MOUNTAINSIDE COMMERCIAL BUILDING GENERAL CHARACTERISTICS

\author{
Butlding Style \\ Gross Floor Area \\ Exposure \\ Occupancy \\ Lighting and Equipment Baseload. \\ Construction Walls
}

Roof

Windows and Doors

Floor Slab

cellings

Stafrwell
Tío storles, masonry construction

5580 square feet

Front of bullding faces north

40 persons (maximum)

14 KN (maximum)

Stucco surface over $12^{\prime \prime}$ concrete blocks (38 light, filled), 1-1/4" furring (16" on centers) and $1 / 2^{11}$ styrofoam. Inside surface is $1 / 2 "$ gypsum board. Net wall area: 4724 square feet.

$3 / 8^{\prime \prime}$ asphalt buflt up roof over $1 / 2$ " plyscore sheathing, $2^{\prime \prime} \times 10^{\prime \prime}$ rafters (16" on centers), fiberglass insulation (6") above 1/2" acoustical tile. Roof area: 2790 square feet.

Safety glass, 1/2" double glazed. Total glass area: 732 square feet. Concrete slab. on grade, $24^{\prime \prime}$ insulation Hung colling between floors carries ducts and electric and water services. Celling height is 11 feet for each floor

Center staircase located just inside front entrance, double back design with turnaround landing. 


\section{TEST HOUSE GENERAL CHARACTERISTICS}

House Style

Living Area

Room Complement

First Floor

Second Floor

Exposure

Exterior Surface

Doors

Roof

Glass Areas

Basement

Walls.

Floor

Crawl Space
Two stories, wood frame, 2 car garage

1850 sq. ft. (excluding basement).

Foyer, living room, dining room, family room, kitchen, powder room.

Master bedroom, large bedroom, 2 small bedrooms. 2 baths.

Front of house faces north.

Aluminum siding.

One - wood panel construction.

Black asphalt shingles over bullding paper and 5/8" plywood deck.

16 glass areas, including patio sliding door. (For total glass area see bldg. plans.) All windows are a luminum cased, double hung, weather stripped, double pave insulating glass. Basement windows (2) are single glazed, $1 / 8^{\prime \prime}$ sheet glass.

11 course, 8 inch concrete block

4 inch concrete slab over 4 inch gravel bed. $662 \mathrm{sq}$. ft.

4 Inch gravel bed over plastic vapor barrier. 
TABLE A-4

Table 5A. Summary of facilivies hoving sower systems and sewage disposal by population groups, alases, and drainges basins

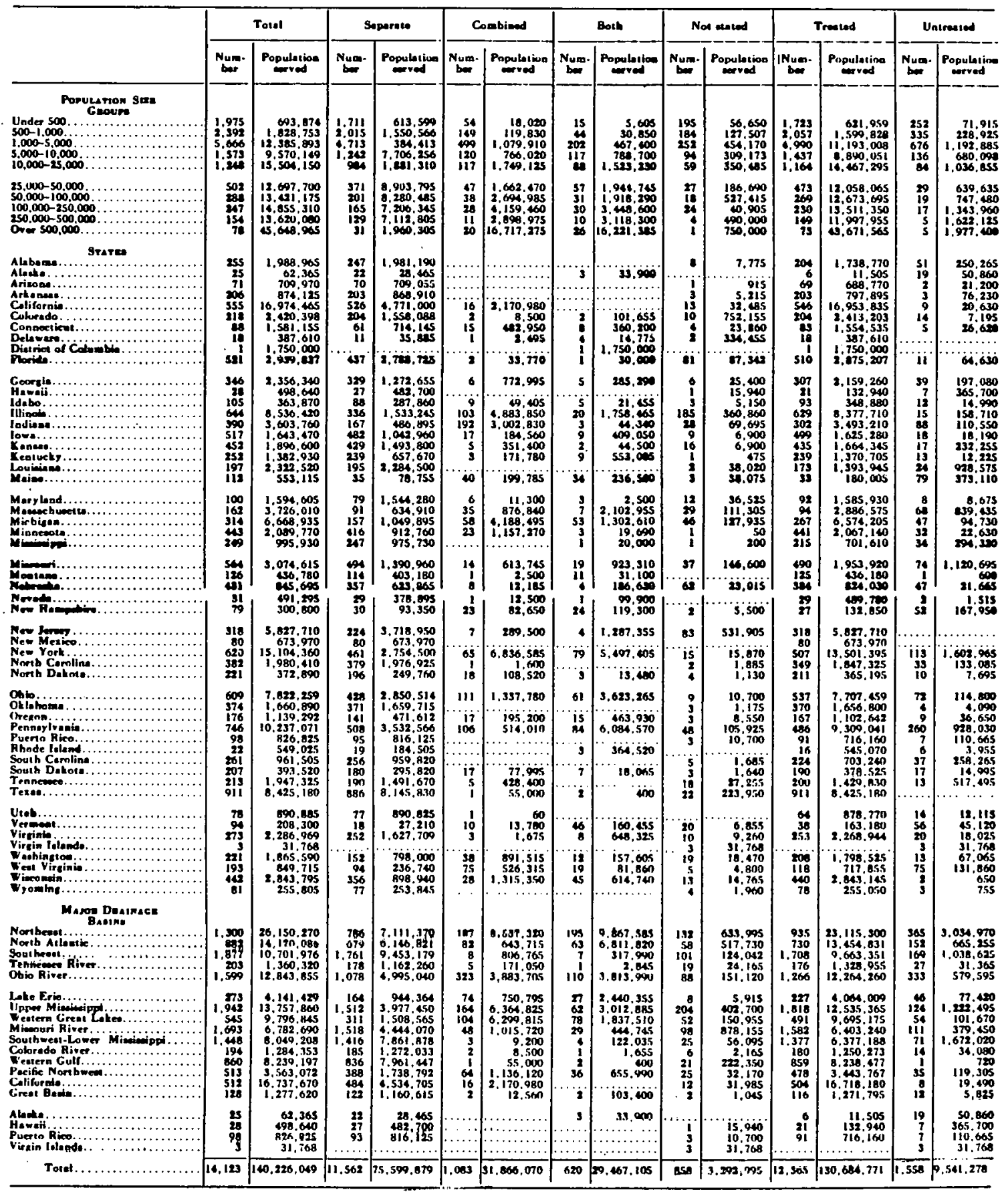

NOTE: Total U.S. Population in $1967-197,000,000$ (Est.)

SOURCE: Municipal Waste Facilities - Statistical Summary, 1968 Inventory. 41 
Table 11. Population served by seu'ers and sewage treatment-by geographical areas

\begin{tabular}{|c|c|c|c|c|c|c|}
\hline \multirow[t]{2}{*}{ Geostophic stens } & \multirow{2}{*}{$\begin{array}{l}1960 \text { renaun } \\
\text { population } \\
\text { of ewered } \\
\text { communitien }\end{array}$} & \multirow{2}{*}{$\begin{array}{l}\text { Eotimated } \\
\text { mopulasion } \\
\text { conneried } \\
\text { to eewern }\end{array}$} & \multirow{2}{*}{$\begin{array}{l}\text { Percent of } \\
\text { cennus } \\
\text { populatiun } \\
\text { connerted } \\
\text { to eewers }\end{array}$} & \multirow{2}{*}{$\begin{array}{l}\text { Perrent nf } \\
\text { ontional } \\
\text { total } \\
\text { populatiusn } \\
\text { connerted } \\
\text { to acwers }\end{array}$} & \multicolumn{2}{|c|}{$\begin{array}{l}\text { Percent of mnnecied } \\
\text { pupulalion-. } \\
\text { ewige diocherged }\end{array}$} \\
\hline & & & & & Treated & Row \\
\hline 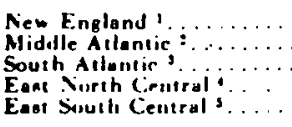 & $\begin{array}{r}8.976 .318 \\
28.823 .298 \\
13.167 .414 \\
20.136 .378 \\
5.060 .886\end{array}$ & $\begin{array}{r}6.918 .+105 \\
31.164 .1+1 \\
15.1116 .091 \\
29.47 .104 \\
6.315 .1511\end{array}$ & $\begin{array}{r}77.1 \\
108.1 \\
114.7 \\
112.8 \\
1116\end{array}$ & $\begin{array}{r}4.9 \\
22.2 \\
10.8 \\
21.0 \\
4.5\end{array}$ & $\begin{array}{l}79.0 \\
91.9 \\
94.6 \\
98.1 \\
83.0\end{array}$ & $\begin{array}{r}21.0 \\
8.1 \\
5.4 \\
1.0 \\
11.0\end{array}$ \\
\hline 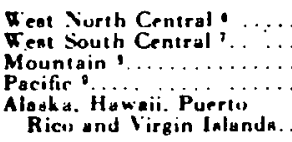 & $\begin{array}{r}10.237 .528 \\
11.618 .812 \\
4.624 .927 \\
13.075 .283 \\
1.522 .064\end{array}$ & $\begin{array}{r}10.316 .360 \\
13.282 .715 \\
6.242 .97 .3 \\
19.979 .347 \\
1.419 .598\end{array}$ & $\begin{array}{r}1008 \\
1143 \\
135.0 \\
152.8 \\
93.3\end{array}$ & $\begin{array}{r}7.4 \\
9.5 \\
4.5 \\
14.2 \\
1.0\end{array}$ & $\begin{array}{l}86.1 \\
92.4 \\
09.1 \\
99.4 \\
60.6\end{array}$ & $\begin{array}{r}13.9 \\
7.6 \\
.9 \\
.6 \\
39.4\end{array}$ \\
\hline Tural. & $123,843,107$ & $140.226,049$ & 113.2 & 100.0 & . 93.2 & 6.8 \\
\hline
\end{tabular}

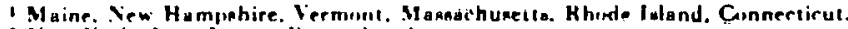

Tew Tork. Jen Jerney. Pennoyllania.

- Delanare. Mlaryland. Dintrit'l of Culumbia. Virginia. Weat Virginia. North Caroline. Suatb Caralina. Georria. Flurida.

Kho. Indiana. Illinarim, Michiean. Mimonain.

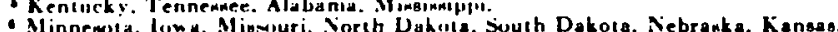

T Arkanama Luvisiona Oklahiome Tesido.

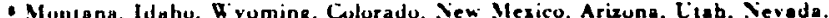

- Tathinston, Uregon. Califurnia.

Table 13. Percentage data for sewer systems and raw and treated dischargeby population groups

\begin{tabular}{|c|c|c|c|c|c|c|c|}
\hline \multirow[b]{2}{*}{$\begin{array}{l}\text { Population } \\
\text { oixe troupe }\end{array}$} & \multirow{2}{*}{$\begin{array}{c}\text { Percent } \\
\text { of toind } \\
\text { number of } \\
\text { owwered } \\
\text { rowmuni- } \\
\text { ties }\end{array}$} & \multirow{2}{*}{$\begin{array}{c}\text { Percent } \\
\text { of } 1960 \\
\text { cenaus } \\
\text { mpula. } \\
\text { tion of } \\
\text { owered } \\
\text { communi- } \\
\text { tiea }\end{array}$} & \multicolumn{4}{|c|}{ Percent of total population connected- } & \multirow{2}{*}{$\begin{array}{l}\text { Percent } \\
\text { of totol } \\
\text { number of } \\
\text { treatment } \\
\text { plante }\end{array}$} \\
\hline & & & $\begin{array}{l}\text { To cewer } \\
\text { eyotemo }\end{array}$ & $\begin{array}{l}\text { To raw dia- } \\
\text { charge or } \\
\text { treatment } \\
\text { facilition ' }\end{array}$ & $\begin{array}{l}\text { To raw } \\
\text { aewaze } \\
\text { diecharme } \\
\text { facilities }\end{array}$ & $\begin{array}{l}\text { To sewane } \\
\text { treatment. } \\
\text { fecilities }\end{array}$ & \\
\hline $\begin{array}{l}\text { Ynder } 500 \ldots \ldots \\
500-1.000 \ldots \ldots \\
1.000-5.000 \\
5.000-10.000 \\
10.000-25,000\end{array}$ & $\begin{array}{r}13.9 \\
17.5 \\
41.6 \\
11.7 \\
9.3\end{array}$ & $\begin{array}{r}1.5 \\
10.2 \\
8.6 \\
14.8\end{array}$ & $\begin{array}{r}.5 \\
1.4 \\
9.6 \\
7.9 \\
13.8\end{array}$ & $\begin{array}{r}1.5 \\
1.3 \\
8.8 \\
6.8 \\
11.1\end{array}$ & $\begin{array}{r}.8 \\
2.4 \\
12.5 \\
7.5 \\
10.9\end{array}$ & $\begin{array}{r}.5 \\
1.2 \\
8.0 \\
6.8 \\
11.1\end{array}$ & $\begin{array}{r}13.7 \\
16.4 \\
39.7 \\
11.4 \\
9.3\end{array}$ \\
\hline $\begin{array}{l}25.000-50.000 \ldots \\
50.000-100.000 \\
100.000-250.000 \\
250.000-500.000 \\
\text { O.er } 500.000 \ldots\end{array}$ & $\begin{array}{r}3.3 \\
1.6 \\
.7 \\
.3 \\
.2\end{array}$ & $\begin{array}{r}11.7 \\
11.3 \\
9.8 \\
10.4 \\
21.3\end{array}$ & $\begin{array}{r}11.3 \\
11.5 \\
9.7 \\
11.4 \\
22.7\end{array}$ & $\begin{array}{r}9.1 \\
9.6 \\
10.6 \\
9.7 \\
32.6\end{array}$ & $\begin{array}{r}6.7 \\
7.8 \\
14.1 \\
17.0 \\
20.7\end{array}$ & $\begin{array}{r}9.2 \\
9.7 \\
10.3 \\
9.2 \\
33.4\end{array}$ & $\begin{array}{l}3.8 \\
2.1 \\
1.8 \\
1.2 \\
.6\end{array}$ \\
\hline Total. & 100.0 & 100.0 & 100.0 & 100.0 & 100.0 & 100.0 & 100.0 \\
\hline
\end{tabular}

I Population erved by facilitice in pupulation nice groupo abown.

SOURCE: Municipal Waste Facilities - Statistical Summary, 1968 Inventory. 41 
APPENDIX B 
APPENDIX B

The following calculations were made to determine the annual energy inputs of the Central Plant and End User Schemes for the HP-WHR scheme.

\section{Basic Assumptions}

\section{Northern Climate}

No. of End-Users -- 470

Annual H.V.A.C. Load Requirements Per End-User

$$
\begin{array}{r}
\text { Heating - } 105.47 \times 10^{6} \mathrm{Btu} / \mathrm{Yr} \\
\text { Cooling - } 18.96 \times 10^{6} \mathrm{Btu} / \mathrm{Yr}
\end{array}
$$

\section{Southern Climate}

No. of End-Users -- 980

Annual H.V.A.C. Load Requirements Per End-User

$$
\begin{aligned}
& \text { Heating -- } 37.92 \times 10^{6} \mathrm{Btu} / \mathrm{Yr} \\
& \text { Cooling -- } 45.03 \times 10^{6} \mathrm{Btu} / \mathrm{Yr}
\end{aligned}
$$

\section{Northern Climate}

\section{Heating}

(1) Total heat required by end users $=470 \times 105.5 \times 10^{6}=4.96 \times 10^{10} \mathrm{Btu} / \mathrm{Yr}$

(2) Energy from distribution system $=4.96 \times 10^{10} \times\left(1-\frac{1}{3.03}\right)=$

$$
3.32 \times 10^{10} \mathrm{Btu} / \mathrm{Yr}
$$

(3) Energy input to central heat pump $=3.32 \times 10^{10} / 6.99=4.75 \times 10^{9} \mathrm{Btu} / \mathrm{Yr}$

(4) Kwh input to central heat pump $=4.75 \times 10^{9} / 3413=1,392,905 \mathrm{kwh} / \mathrm{Yr}$

(5) Central heat pump equivalent full load hours $=$

$$
3.32 \times 10^{10} \times\left(1-\frac{1}{6.99}\right) / 12 \times 10^{6}=2370 \mathrm{hr} / \mathrm{Yr}
$$




\section{Northern Climate (Continued)}

\section{Cooling}

(1) Tota1 heat rejection to distribution by end-users $=$ $470 \times 18.96 \times 10^{6} \times\left(1+\frac{1}{3.2}\right)=1.17 \times 10^{10} \mathrm{BLu} / \mathrm{Yr}$

(2) Energy input to central heat pump $=1.17 \times 10^{10} / 5.42=2.16 \times 10^{9} \mathrm{Btu} / \mathrm{Yr}$

(3) Kwh input to central heat pump $=2.16 \times 10^{9} / 3413=632,485 \mathrm{kwh} / \mathrm{Yr}$

(4) Central heat pump equivalent full load hours = $1.17 \times 10^{10} / 12 \times 10^{6}=975 \mathrm{hr} / \mathrm{Yr}$

\section{Southern Climate}

\section{Heating}

(1) Total heat required by end-users $=980 \times 37.92 \times 10^{6}=3.72 \times 10^{10}$

(2) Energy from distribution system $=3.72 \times 10^{10} \times\left(1-\frac{1}{3.03}\right)=2.49 \times 10^{10}$

(3) Energy input to central heat pump $=2.49 \times 10^{10} / 6.99=3.56 \times 10^{9} \mathrm{Btu} / \mathrm{Yr}$

(4) $\mathrm{Kw}$ input to central heat pump $=3.56 \times 10^{9} / 3413=1,043,500 \mathrm{kwh} / \mathrm{Yr}$

(5) Central heat pump equivalent full load hours $=$

$$
2.49 \times 10^{10} \times\left(1-\frac{1}{6.99}\right) / 12 \times 10^{6}=1778 \mathrm{hr} / \mathrm{Yr}
$$

\section{Cooling}

(1) Total heat rejection to distribution by end-uocrs $980 \times\left(45.03 \times 10^{6}\right) \times\left(1+\frac{1}{3.2}\right)=5.8 \times 10^{10}$

(2) Energy input to central heat pump $=5.8 \times 10^{10} / 5.42=1.07 \times 10^{10} \mathrm{Btu} / \mathrm{Yr}$

(3) Kwh input to central heat pump $=1.07 \times 10^{10} / 3413=3,131,062 \mathrm{kwh} / \mathrm{Yr}$

(4) Central heat pump equivalent full load hours =

$$
5.8 \times 10^{10} / 12 \times 10^{6}=4833 \mathrm{hr} / \mathrm{Yr}
$$




\section{Circulating Pumps}

Assume circulating pumps run

20 percent more hours than the central heat pump equivalent full load hours.

\section{Northern Climate}

$1.2 \times(2370+975) \times 75 \mathrm{hp} \times .745 \mathrm{kwh} / \mathrm{hp}=224,282 \mathrm{kwh} / \mathrm{Yr}$

Southern Climate.

$1.2 \times(1778+4833) \times 75 \mathrm{hp} \times .745 \mathrm{kwh} / \mathrm{hp}+594,990 \mathrm{kwh} / \mathrm{Yr}$

\section{Distribution Pumps}

Assume distribution pumps consume the same proportion of energy annually as. they do at full load.

Northern Climate $\simeq 6 \%$

Southern Climate $\simeq 5 \%$

(1) Northern Climate Pumping Energy =

$$
470 \times\left(105.5 \times 10^{6}+18.9 \times 10^{6}\right) \times .06 / 3413=1,027,858 \mathrm{kwh} / \mathrm{Yr}
$$

(2) Southern Climate Pumping Energy

$$
980 \times\left(37.9 \times 10^{6}+45.03 \times 10^{6}\right) \times .05 / 3413=1,190,615 \mathrm{kwh} / \mathrm{Yr}
$$

\section{Miscellaneous}

Auxiliary equipment such as controls, security lighting, etc., is estimated to consume an additional $12,000 \mathrm{kwh}$ annually. 
APPENDIX C 


\section{THIS PAGE \\ WAS INTENTIONALLY \\ LEFT BLANK}


CONYERS HP-WHR SYSTEM

COMPUTER PRINTOUT

THERMAL LOAD ASSESSMENT 


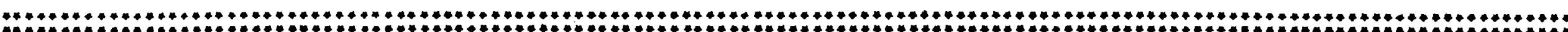
CONYERS HP-WHR SYSTEM

\section{TYPEE DEFINITIONS}

HEATING DATA R*

IYPE

JAN FEB MAR APR MAY JU

RES

6.780

$5.430 \quad 4.290$

1.380

$.270 \quad 0.000$

0.000

AUS

SSEP

OCI NOY OEC

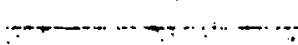

COOLING DATA RE*

\begin{tabular}{|c|c|c|c|c|c|c|c|c|c|c|c|c|}
\hline IYPE & JAN & FEB & MAR & APR & HAY & 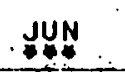 & sut & Aug & SEP & OCI & Noy & DEC \\
\hline RES & 0.000 & 0.000 & .140 & .340 & 1.940 & 4.040 & 5.080 & 4.880 & 2.860 & .720 & 0.000 & \\
\hline
\end{tabular}

* (Btu $\left.\times 10^{3} / \mathrm{sq} . \mathrm{ft.}\right)$ 
ZONE R-1.

\section{HE ATING DATAR* *}

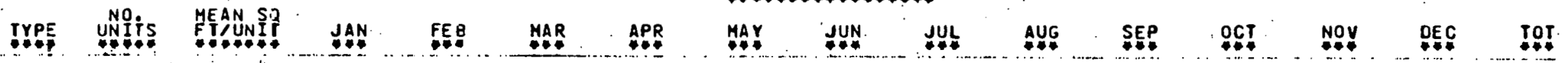

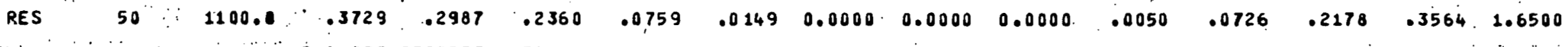

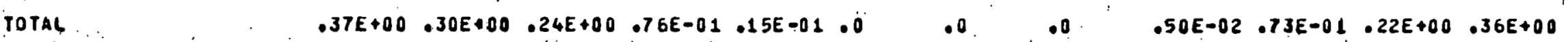

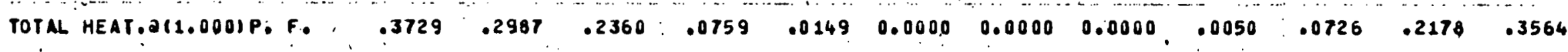

TYPE UNIYS MEAWNIP JAN FEB MAR APR HAY JUN JUL AUE SEP OCT NOY OEC IOT

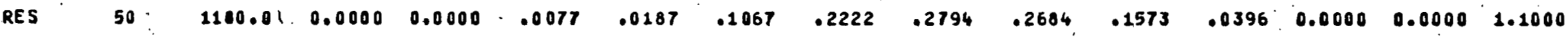

TOTAL $\quad .0 .0000 \quad 0.0000 \quad 00077.00187 \quad .1067 \quad .2222 \quad .2794 \quad .2684 \quad .1573 .00396 \quad 0.0000 \quad 0.0000$

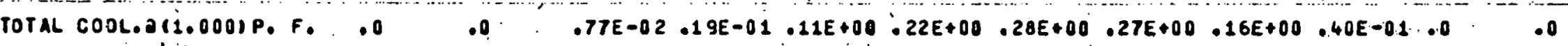


-...-- -

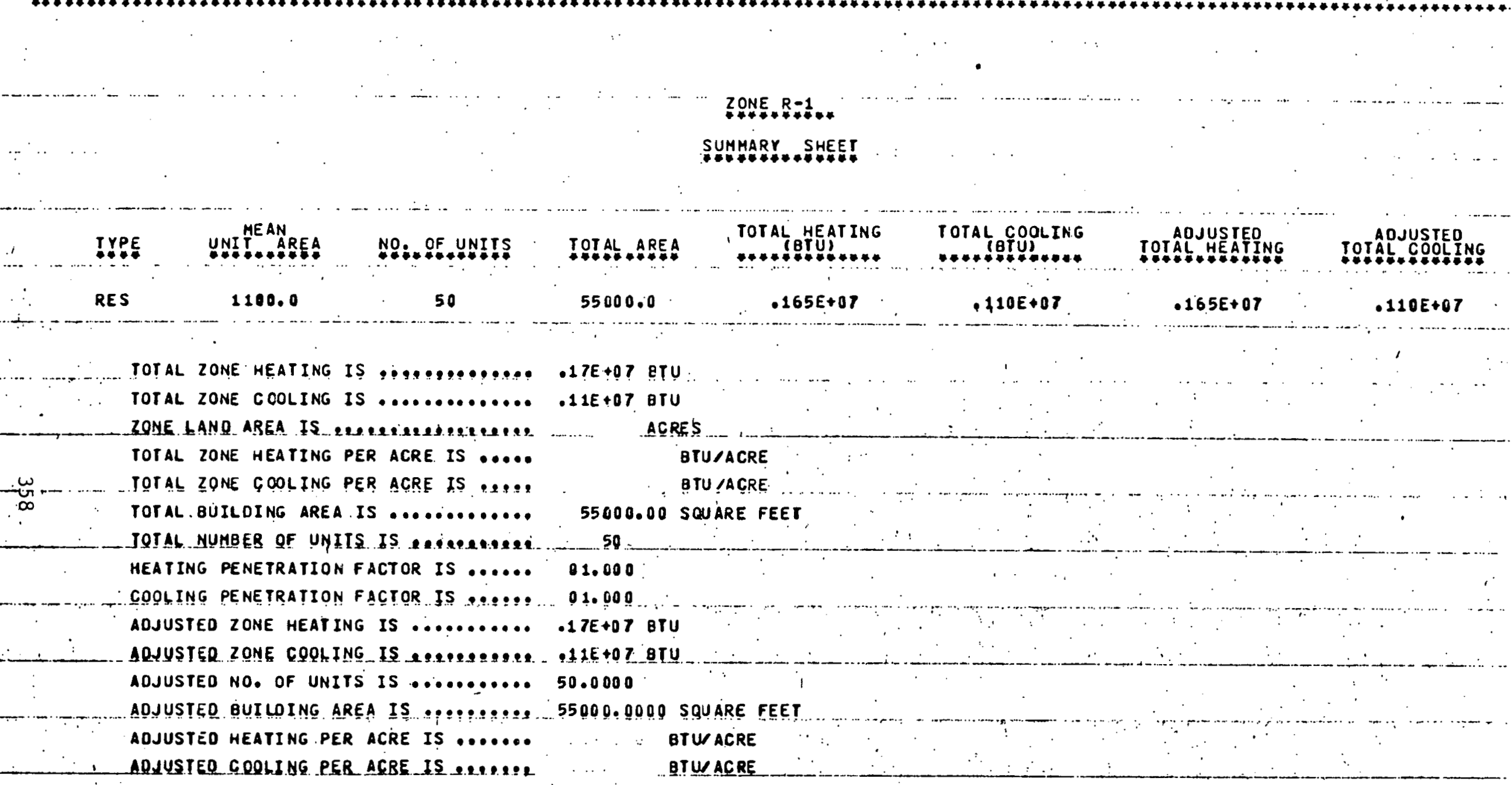




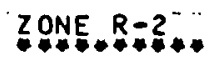

HEATING DATIAC * !

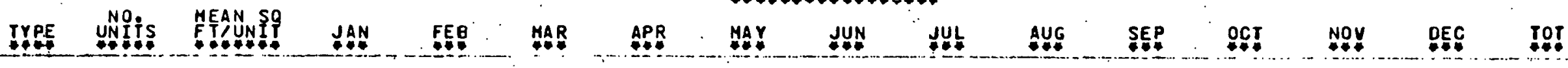

$\begin{array}{lllllllllllllllllllll}\text { RES } & 150 & 1200.0 & 1.2204 & .9774 & .7722 & .2484 & .0486 & 0.0000 & 0.0000 & 0.0000 & .0162 & .2376 & .7128 & 1.1664 & 5.4000\end{array}$

TOTAL $\quad .12 E+01.98 E+00.77 E+00.25 E+00.49 E-01.0 \quad 00.00 .016 E-01.024 E+00.71 E+00.012 E+01$

TOTAL HEAT.011.000IP. F. 1.2204 .9776 .7722 .2484 $.04860 .000000000000000 .0762 \quad .2376 \quad .7128 \quad 1.1664$

-.....

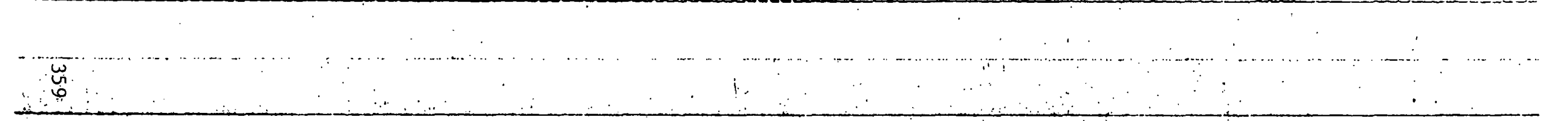

COOLING OAIA! *

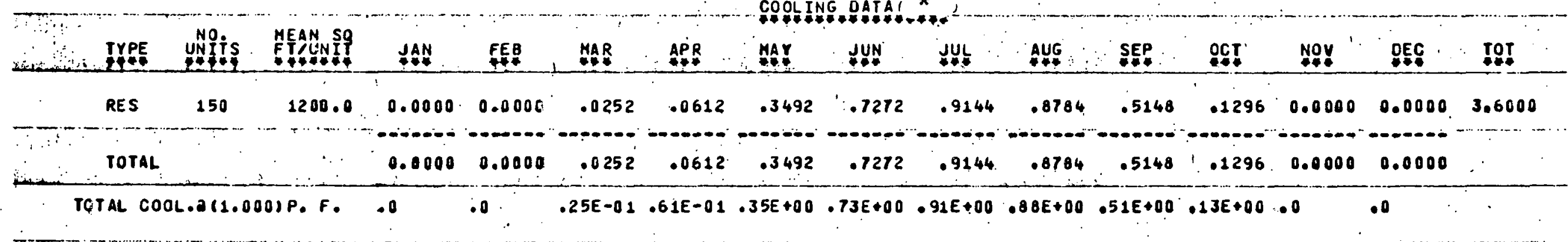

$$
+\times 10^{9}
$$




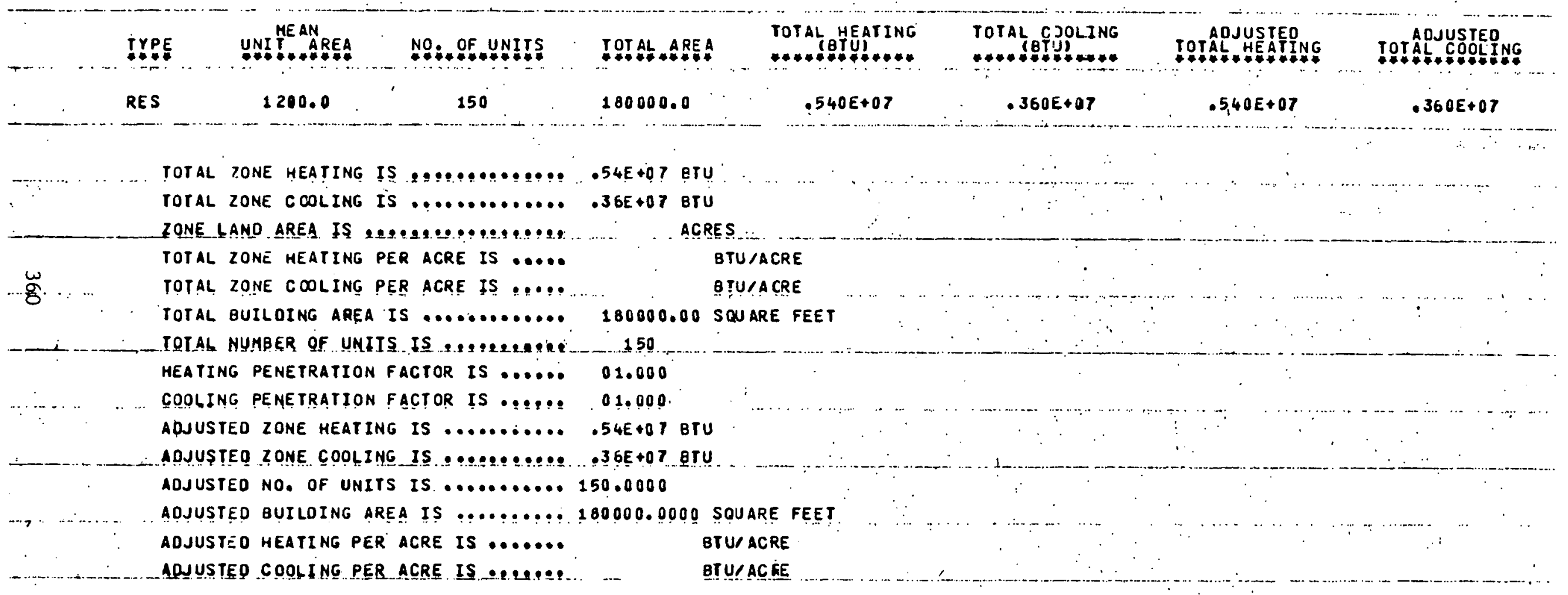




\section{ONE R=3. R.}

\section{HEATING DATA!* *}

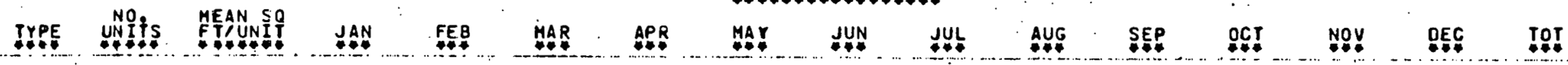

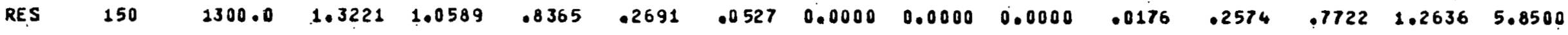

TOTAL $.13 E+01.11 E+01.84 E+00.27 E+00.53 E-01.0 \quad .0 .0 .0 .0 .018 E-01.26 E+00.77 E+00.13 E+01$

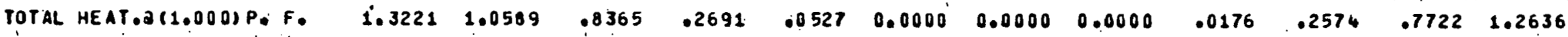

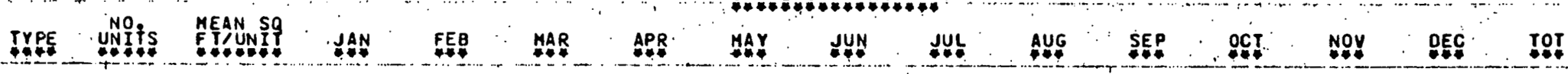

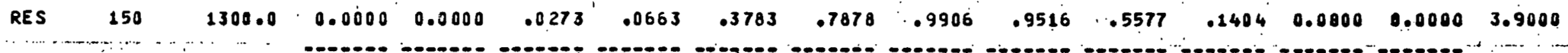

$\begin{array}{lllllllllllll}0.0000 & 0.0000 & .0273 & .0663 & .3783 & .7878 & .9906 & .9516 & 05577 & .01404 & 0.0000 & 0.0000\end{array}$

TOPAL COOL.a11.000IP. F. . 0.0 .0 . . $07 E-01.66 E-01.38 E+00.79 E+00.09 E+00.05 E+00.56 E+00.14 E+00.00 \quad .0$ 
.-

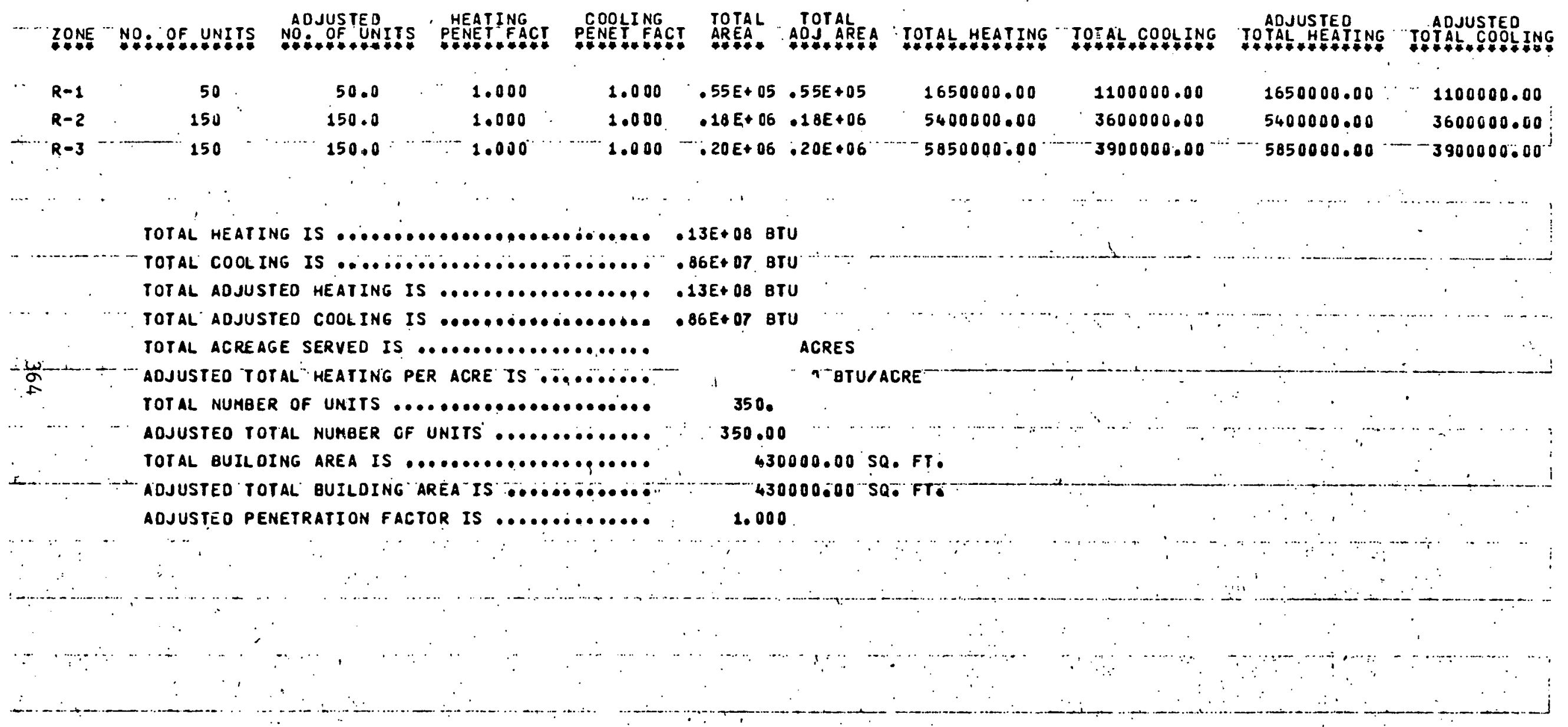


1. Heating and cooling loads are determined from computerized load estimates.

2. Heat to distribution system (HDS)

(assume End-User Heating C.O.P. = 2.9)

$$
\text { HDS }=\text { Monthly Heat Required } x\left(1-\frac{1}{2.9}\right)
$$

3. Heat required from sewage effluent (HSE)

(assume End-User Cooling C.O.P. $=2.5$ )

Cent. Heat Pump C.O.P. $=4.5$

$$
\mathrm{HSE}=(\mathrm{HDS}-1.4[\text { Cooling Required }])\left(1-\frac{1}{4.5}\right)
$$

4. Heat dissipated at cooling tower (HDCT)

(assume End-User Cooling C.0.P. = 2.5 )

Heating C.O.P. $=2.9$ )

$$
\mathrm{HDCT}=1.4 \text { (Cooling Required) }-\mathrm{HDS}
$$

5. Circulating pump energy consumption

(assume 30 percent extra consumption)

$$
\mathrm{KWH}=\frac{1.3 \times\left[\frac{\mathrm{HSE}+\mathrm{HDCT}}{10}\right] \times 90 \mathrm{ft} .}{.65(\text { efficiency }) \times\left(2.65 \times 10^{6} \mathrm{ft}-1 \mathrm{~b} / \mathrm{KWH}\right)}
$$

6. Sewage pump energy consumption

(assume 10 percent extra consumption)

$$
\mathrm{KWH}=\frac{1.1 \times\left[\frac{\mathrm{HSE}}{10}\right] \times 6 \text { Uft. }}{.65(\text { efficiency }) \times\left(2.65 \times 10^{\mathrm{b}} \mathrm{ft}-1 \mathrm{~b} / \mathrm{KWH}\right)}
$$

7. Distribution pump energy consumption

$$
\mathrm{KWH}=\frac{\left[\frac{\mathrm{HDS}+1.4 \text { (cooling required) }}{10}\right] \times 500 \mathrm{ft}}{.65(\text { efficiency) }} .
$$

8. Cooling tower energy consumption

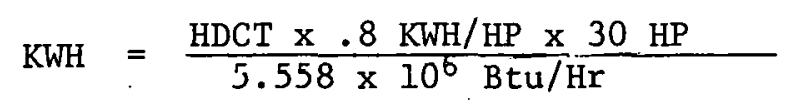


9. Central heat pump energy consumption (C.0.P. $=4.5)$

$$
\mathrm{KWH}=\frac{[\mathrm{HSE}] \times \frac{1}{4.5}}{3413 \mathrm{Btu} / \mathrm{KWH}}
$$




\section{COOLING}

$\underline{\text { MONTH }}$

JAN

FEB

MARCH

APRIL

MAY

JUNE

JULY

AUG .

SEPT .

OCT .

NOV.

DEC.

TOTALS $\underline{\text { HRS }}$
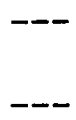

- -

244

530

664

744

744

563

276

1105.29

7515.68

$15,969.70$

$22,260.29$

$46,930.92$

$11,508.57$

668.78

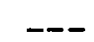

- -

3765 HRS $105,959.23 \mathrm{KWH}$
HEATING

HRS

$\underline{\text { KWH }}$

744

9707.88

672

6016.11

744

4349.97

476

1426.27

214

442.49

56

100.88

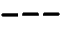

157

290.61

468

1321.16

720

3779.37

744

7662.83

4995 HRS $\cdot 35,097.57 \mathrm{KWH}$

TOTAL KWH REQUIREMENT - 141,056.80 KWH 
CONYERS HP-WHR SYSTEM

MONTHLY PERFORMANCE ANALYSIS

\begin{tabular}{|c|c|c|c|c|c|c|c|c|c|c|c|c|c|c|c|}
\hline & $\begin{array}{l}\text { HEATING } \\
\text { LOAD } \\
\times 10^{9} \\
\end{array}$ & $\begin{array}{c}\text { COOLING } \\
\text { LOAD } \\
\times 10^{9} \\
\end{array}$ & $\begin{array}{l}\text { HEAT } \\
\text { FROM } \\
\text { SEWAGE } \\
\end{array}$ & $\begin{array}{c}\text { HEAT }^{\text {TO }} \\
\text { TO } \\
\text { DIST. SYS. }\end{array}$ & $\begin{array}{c}\text { HEAT } \\
\text { DISS. @ } \\
\text { COOLING TOWER } \\
\end{array}$ & $\begin{array}{c}\text { CENT . H.P. } \\
\text { KWH } \\
\end{array}$ & $\begin{array}{l}\text { DIST. } \\
\text { PUMP } \\
\text { KWH } \\
\end{array}$ & $\begin{array}{l}\text { CIR. } \\
\text { PUMP } \\
\text { KWH } \\
\end{array}$ & $\begin{array}{c}\text { SEWAGE } \\
\text { PUMP } \\
\text { KWH } \\
\end{array}$ & $\begin{array}{c}\text { COOLING } \\
\text { TOWER } \\
\text { KWH } \\
\end{array}$ & $\begin{array}{c}\text { MISC. } \\
\text { AUX. } \\
\text { KWH. }\end{array}$ & $\begin{array}{c}\text { TOTAL } \\
\text { CENT. PL. } \\
\text { KWH } \\
\end{array}$ & $\begin{array}{l}\text { END } \\
\text { USER } \\
\text { KWH } \\
\end{array}$ & $\begin{array}{r}\text { TOTAL } \\
\text { SYSTEM } \\
\text { KWH } \\
\end{array}$ & $\begin{array}{l}\text { SYSTEM } \\
\text { C.0.P. } \\
\end{array}$ \\
\hline JAN. & 2.915 & 0 & 1.485 & 1.909 & 0 & 96,689 & 9,708 & 12,325 & 5,689 & 0 & 1,000 & 125,411 & 294,512 & 419,923 & 2.034 \\
\hline FEB. & 2.335 & 0 & 1.189 & 1.529 & 0 & 77,416 & 6,016 & 9,868 & 4,556 & 0 & 1,000 & 98,856 & 235,913 & 334,769 & 2.044 \\
\hline MARCH & 1.845 & .060 & 1.125 & 1.209 & 0 & 73,249 & 4,350 & 9,338 & 4,310 & 0 & 1,000 & 92,247 & 193,439 & 285,686 & 1.954 \\
\hline APRIL & .593 & .146 & .184 & $\therefore 388$ & 0 & 11,980 & 2,532 & 1,526 & 704 & 0 & 1,000 & 17,742 & 77,024 & 94,766 & 2.285 \\
\hline MAY & .116 & .834 & 0 & .076 & 1.092 & 0 & 7,958 & 7,417 & 0 & 4,715 & 1,000 & 21,090 & 109,464 & 130,554 & 2.132 \\
\hline JUNE & 0 & 1.737 & 0 & 0 & 2.432 & 0 & 16,071 & 16,519 & 0 & 10,502 & 1,000 & 44,092 & 203,574 & 247,666 & 2.055 \\
\hline JULY & 0 & 2.184 & 0 & 0 & 3.058 & 0 & 22,260 & 20,771 & 0 & 13,205 & 1,000 & 57,236 & 255,962 & 313,198 & 2.043 \\
\hline AUG. & 0 & 2.098 & 0 & 0 & 2.937 & 0 & 46,930 & 19,948 & 0 & 12,682 & 1,000 & 80,560 & 245,883 & 326,443 & 1.883 \\
\hline SEPT. & .039 & 1.230. & 0 & 0 & 1.722 & 0 & 11,799 & $1 i, 696$ & 0 & 7,435 & 1,000 & 31,930 & 148,095 & 180,025 & 2.065 \\
\hline oct. & .568 & .310 & 0 & .372 & .062 & 0 & 1,990 & 421 & 0 & 268 & 1,000 & 3,679 & 93,719 & 97,398 & 2.641 \\
\hline Nov. & 1.703 & 0 & .868 & 1.116 & 0 & 56,516 & 3,779 & 7,205 & 3,325 & 0 & 1,000 & 71,825 & 172,060 & 243,885 & 2.046 \\
\hline DEC. & 2.786 & 0 & 1.419 & $1: 825$ & 0 & 92,392 & 7,663 & 11,778 & 5,427 & 0 & 1,000 & 118,260 & 281,479 & 399,739 & 2.042 \\
\hline & 12.900 & 8.599 & & & & 408,242 & 141,056 & 128,812 & 24,011 & 48,807 & 12,000 & 762,928 & $2,311,124$ & $3,074,052$ & \\
\hline
\end{tabular}

POWER REQUIREMENTS:

PERCENT OF CENTRAL PLANT -

$\begin{array}{llllll}53.5 & 18.5 & 16.9 & 3.1 & 6.4 & 1.6\end{array}$

PERCENT OF SYSTEM -

$\begin{array}{llllll}13.3 & 4.6 & 4.2 & 0.8 & 1.6 & 0.4\end{array}$

(1) Btu $\times 10^{9}$

(2) END-USERS:

HTG C.O.P. $=2.91$

CLG C.O.P. = 2.53 
CONYERS HP-WHR SYSTEM

CONSTRUCTION COST ESTIMATES 
THIS PAGE

WAS INTENTIONALLY

LEFT BLANK 


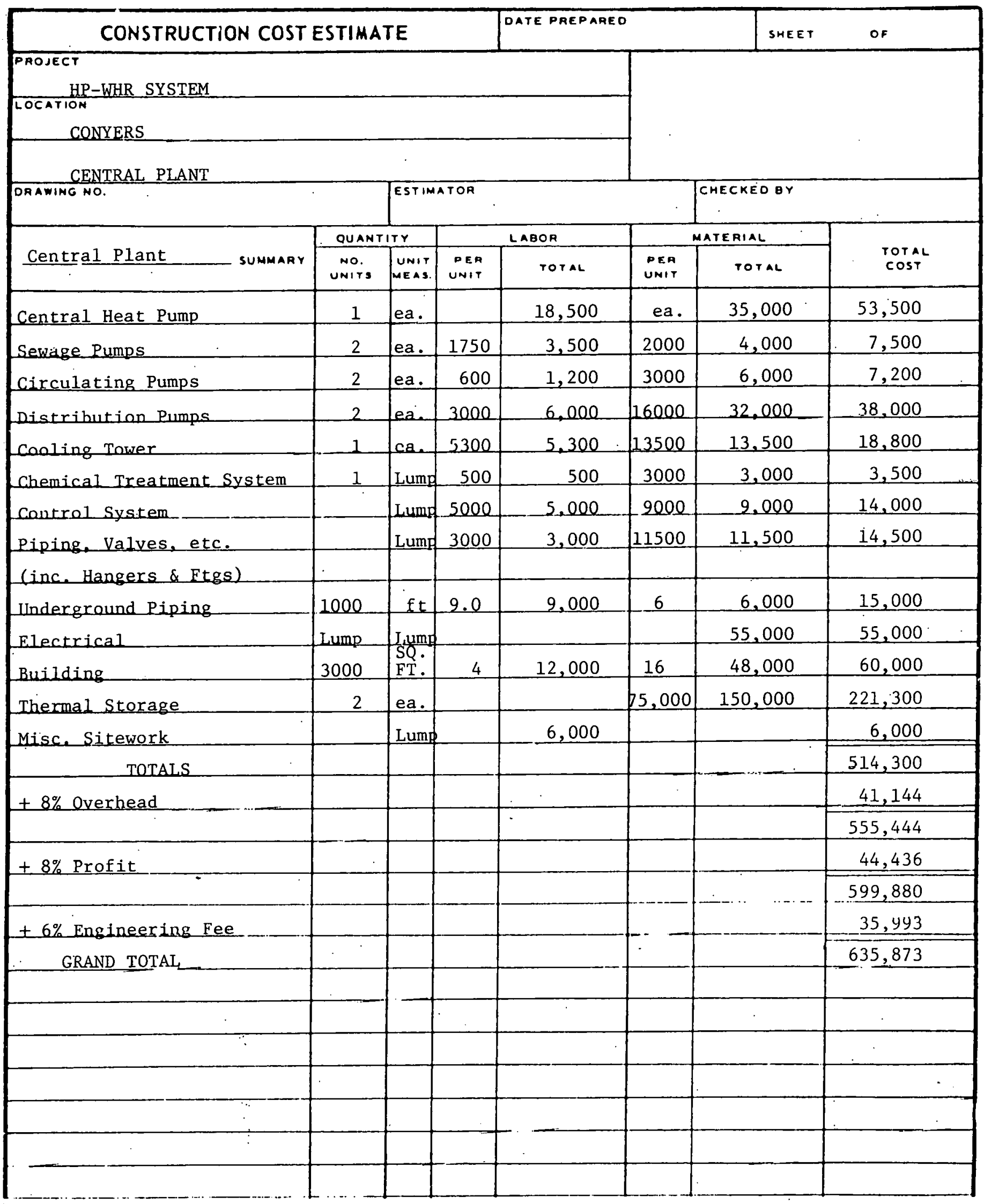




\section{ENGINEERING EXPERIMENT STATIQN \\ GEORGIA INSTITUTE OF TECHNOLOGY • ATLANTA. GEORGIA 30332}

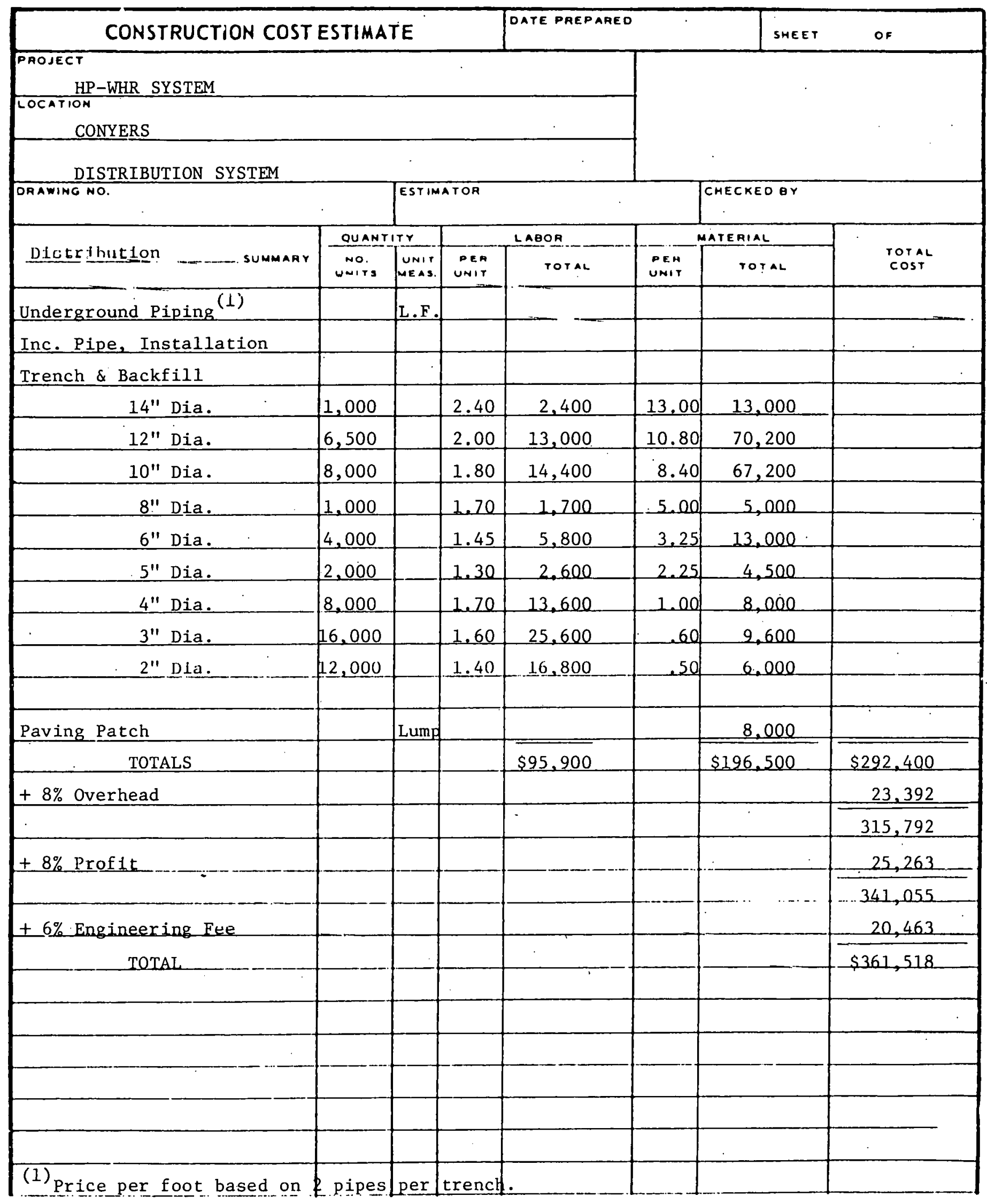


CONYERS HP-WHR SYSTEM

CONSTRUCTION COST ESTIMATE

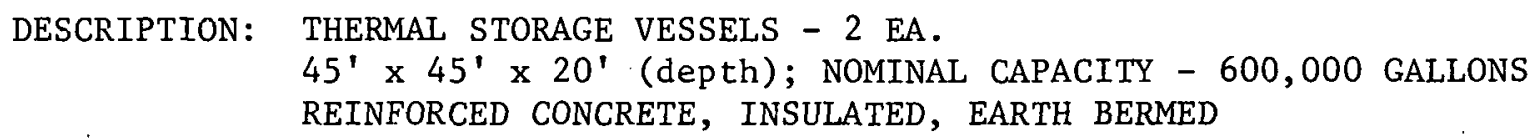

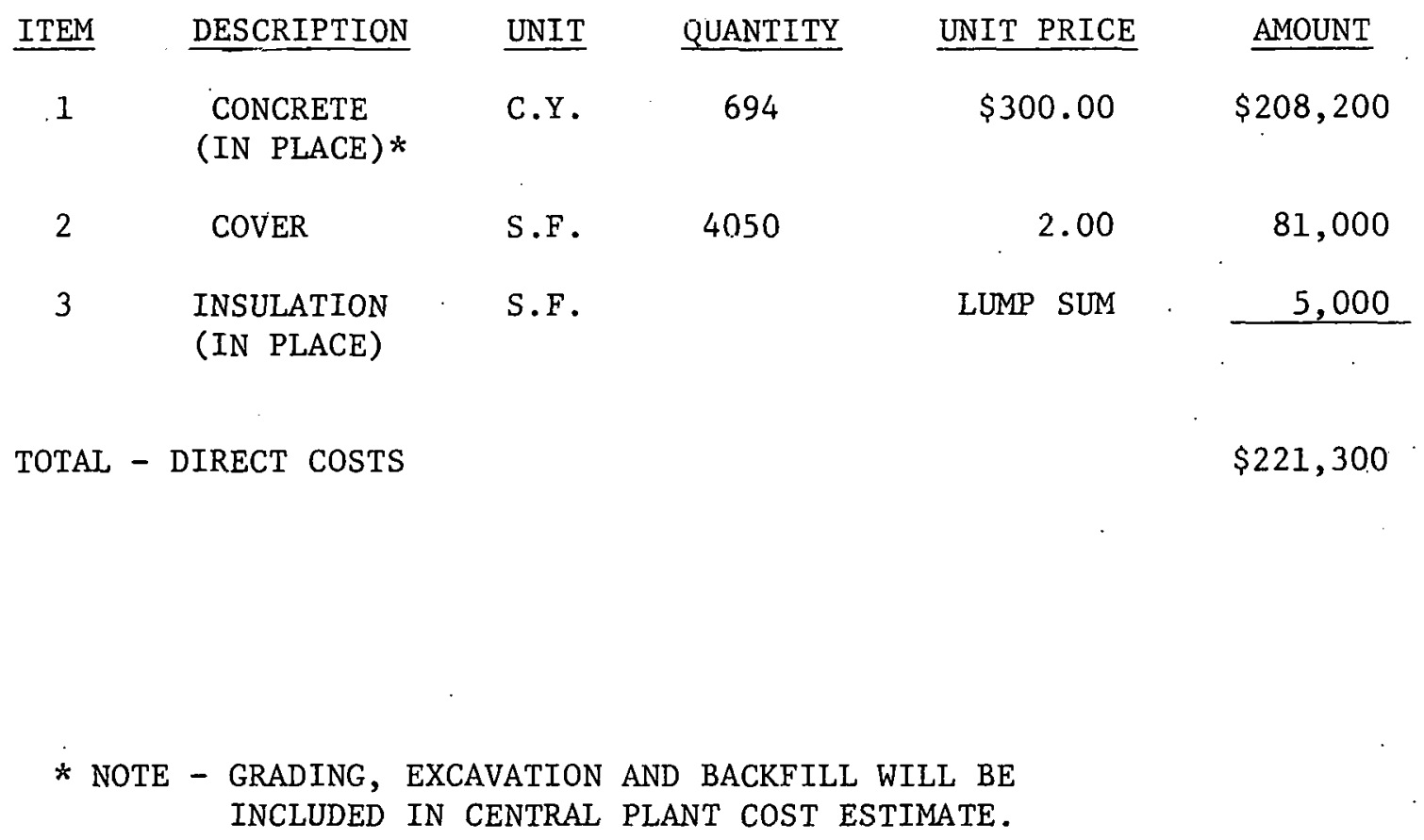


THIS PAGE

WAS INTENTIONALLY

LEFT BLANK 
APPENDIX D 
THIS PAGE

\section{WAS INTENTIONALLY LEFT BLANK}


CORNELIA HP-WHR SYSTEM

COMPUTER PRINTOUT

THERMAL LOAD ASSESSMENT 
THIS PAGE

\section{WAS INTENTIONALLY \\ LEFT BLANK}




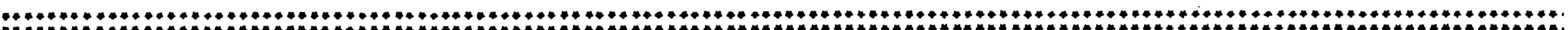

CORNELIA HP-WHR SYSTEM

\section{IYPE. OEFINITIONS}

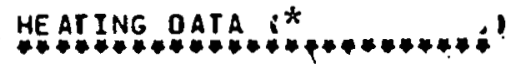

\begin{tabular}{|c|c|c|c|c|c|c|c|c|c|c|c|c|}
\hline IYPE & $J A N$ & EEP & MAR & APR : & MAY & JUN & sul & AUG & SEP & OCI & NOY & DEC \\
\hline COM & 10.500 & 8.650 & 7.650 & 2.700 & .850 & .150 & 0.000 & 0.000 & .400 & 2.800 & 6.650 & 10.250 \\
\hline INO & $\because 0.000$ & 0.000 & 0.000 & 0.000 & 0.000 & 0.000 & 0,000 & 0.000 & 0.000 & 0.000 & 0.000 & 0.000 \\
\hline
\end{tabular}

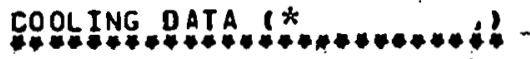

IYPE

AAN FEB MAR APR MAY HUN JUL AUG SEP OCT NOY OEC

$\begin{array}{llllllllllll}0.000 & 0.000 & .320 & .540 & 2.880 & 6.500 & 8.580 & 8.220 & 2.120 & .860 & 0.000 & 0.000\end{array}$

INO

230.000230 .000230 .000230 .000 .2300000230 .000230 .000230 .000230 .000230 .000230 .000230 .000

* (Btu $\times 10^{3} 1$ sq́q. $f$ t. $)$ 


\section{ONE. C-1.4.*}

\section{HEAIING DAIAL"}

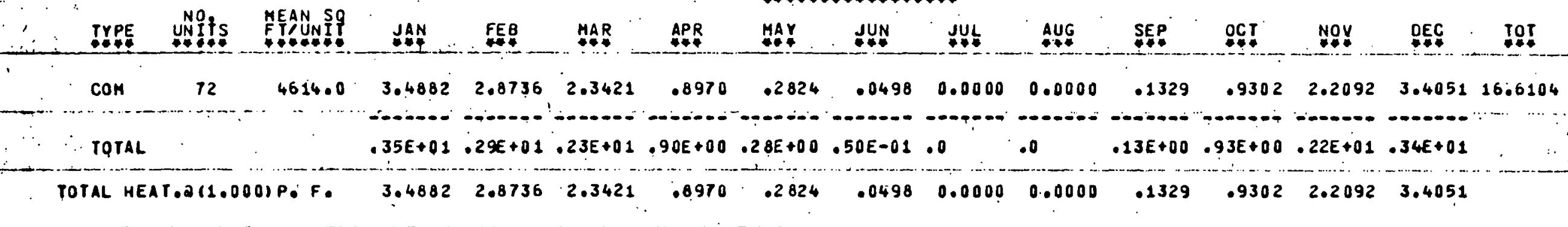

W

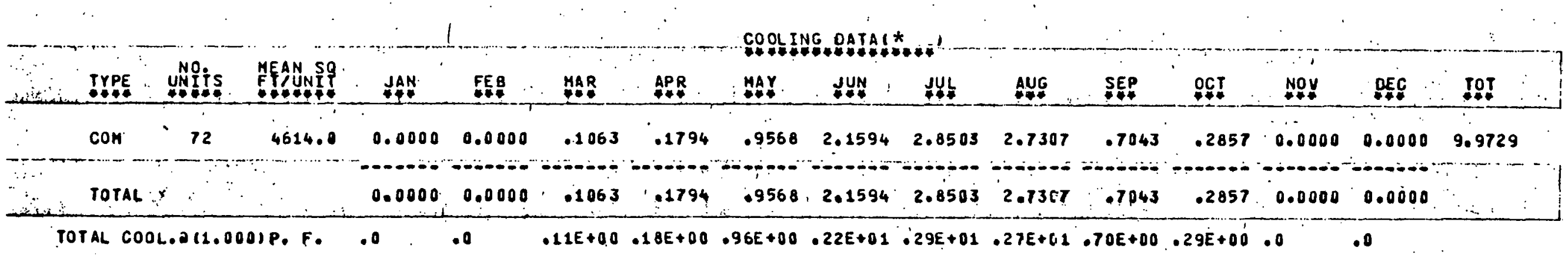


ZONE.

HEAIING OAIAL*

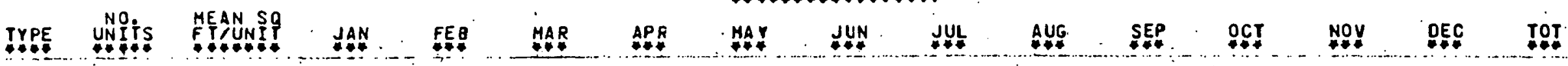

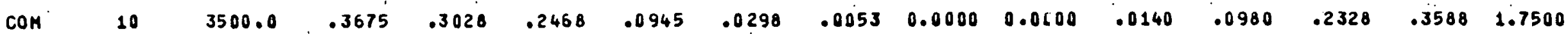

TOTAL . .37E+00.30E+00.25E+00.95E-01.30E-01.53E-02.0. .0 . . . . . . . $014 E-01.98 E-01.23 E+00.36 E+00$

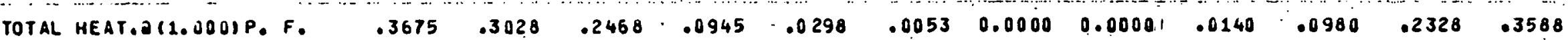

$\underset{N}{-\infty}$

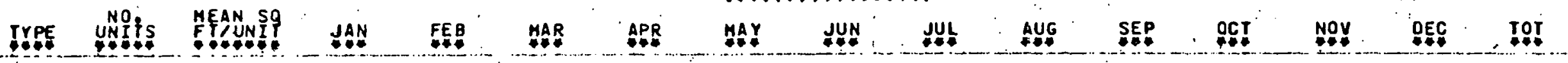

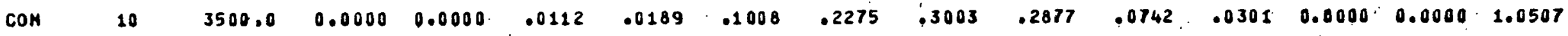

TOTAL

$\begin{array}{llllllllllllllllll}0.0000 & 0.0000 & .0112 & .0189 & .1008 & .2275 & .3003 & .2877 & 00742 & .0301 & 0.0000 & 0.0000\end{array}$

TOTAL COOL.211.000IP.F. .0 . .0 .11E-01.19E-01.10E+00.23E+00.30E+00.29E+00.74E-01.30E-01.0 . . . . . . . 


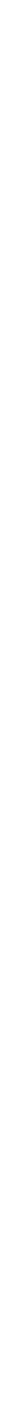




\section{ZONE C-3.}

\section{MEAING DATAi*}

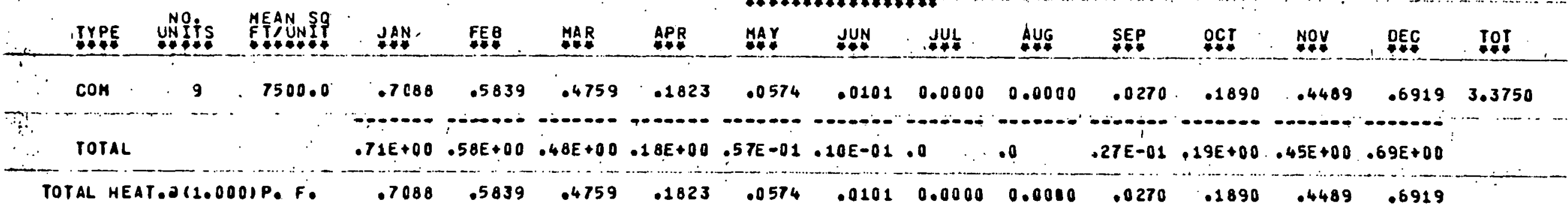

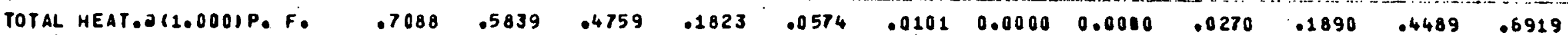

$\underset{\infty}{\infty}$

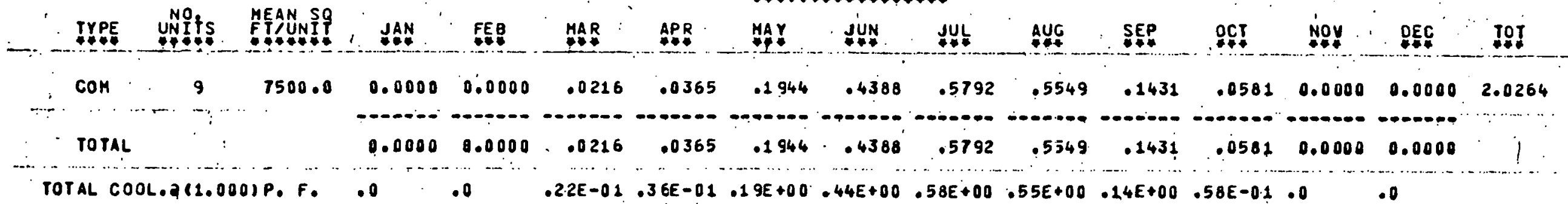




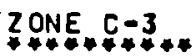

SUMMARY SHEET

\begin{tabular}{|c|c|c|c|}
\hline IYPE & UNI MEAN AREA & NO:OF UNITS & IOTAL AFE \\
\hline & 50 & 9 & 67500.0 \\
\hline
\end{tabular}

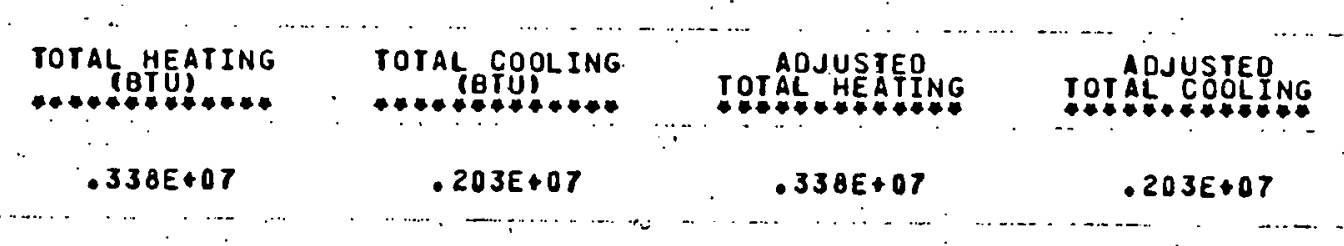

TOTAL ZONE HEATING IS $\ldots . . . . . . . .$.

TOTAL ZONE COOLING IS ...............

$.34 E+0 ?$ B

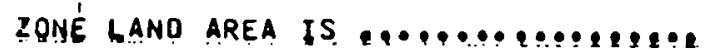
TOTAL ZONE HEATING PER ACRE IS ..... NOTIAL ZONE COOLING PER ACRE IS ....., TOTAL BUILOING AREA IS ............ TOTAL NUMBER OF UNITS IS . .2. . ...... HEATING PENETRATION FACTOR IS ....... COOLING PENETRATION FACTOR IS ......, AOJUSTEO ZONE HEATING IS ...........

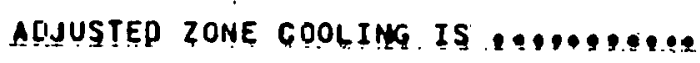
AQUUSTEO NO. OF UNITS IS ............ AOJUSTED QUILOING AREA IS , ,........ AOJUSTED HEATING PER ACRE IS ....... $.20 E+07$ BTU AQUUSTED GOQLIUG PER ACRE. IS 242,1

B TU/ACRE

67500.00 SQUARE FEET

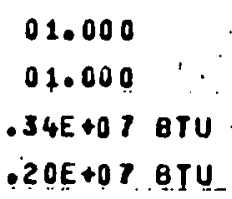

01.000

04.000

. उ4E+0 7 QTU

$20 E+07$ BTU

9.0000

67500.0000 S SQUARE FEET

DTU/ACRE

BTU/ACRE 


\section{ZONE}

HEATING DATA:*

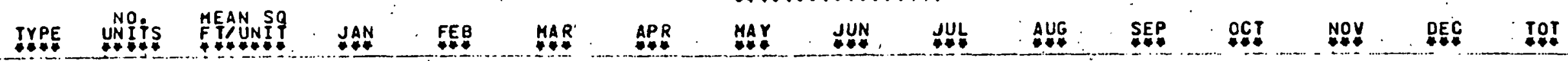

\begin{tabular}{|c|c|c|c|c|c|c|c|c|c|c|c|c|c|c|c|}
\hline & 0 & 海 & & 0000 & 1.0000 & .0000. & 0.0000 & 0.0000 & 0.0000 & 0.0000 & 0.0000. & 0.0000 & 0.0000 & 0.0000 & 0.0000 \\
\hline IND $\cdots$ & 1 & 1.0 & 0.0000 & 0.0000 & 0.0000 & 0.0000 & 0.0000 & 0.0000 & $0.0000^{\circ}$ & 0.0000 & 0.0000 & 0.0000 & 0.0000 & 0.0000 & 0.0000 \\
\hline & & & & n...... & $=-$ & $\cdots$ & $\ldots . .$. & $\ldots$ & $\ldots$ & $-\cdots+--$ & $\cdots$ & .......... & $-1,-\infty$ & n-...- & \\
\hline
\end{tabular}

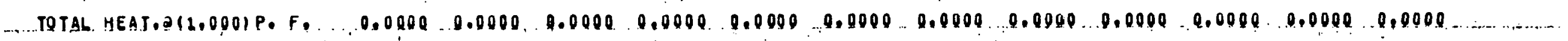

$i$

$\underset{\infty}{\infty}$

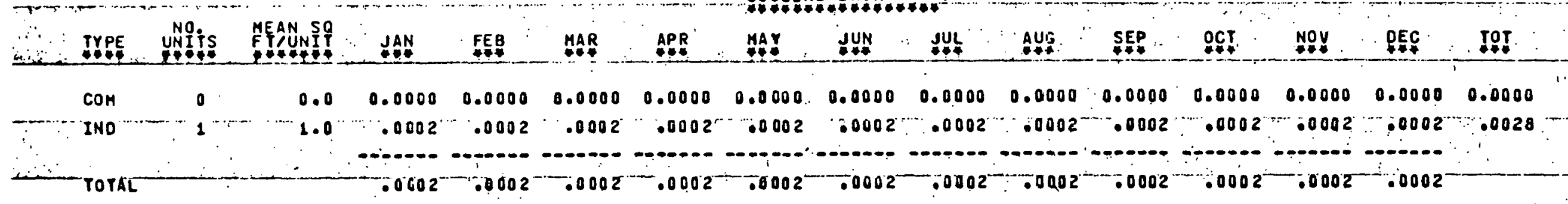

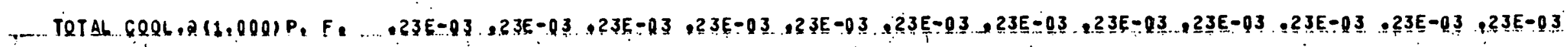




\section{ZONE I I -4}

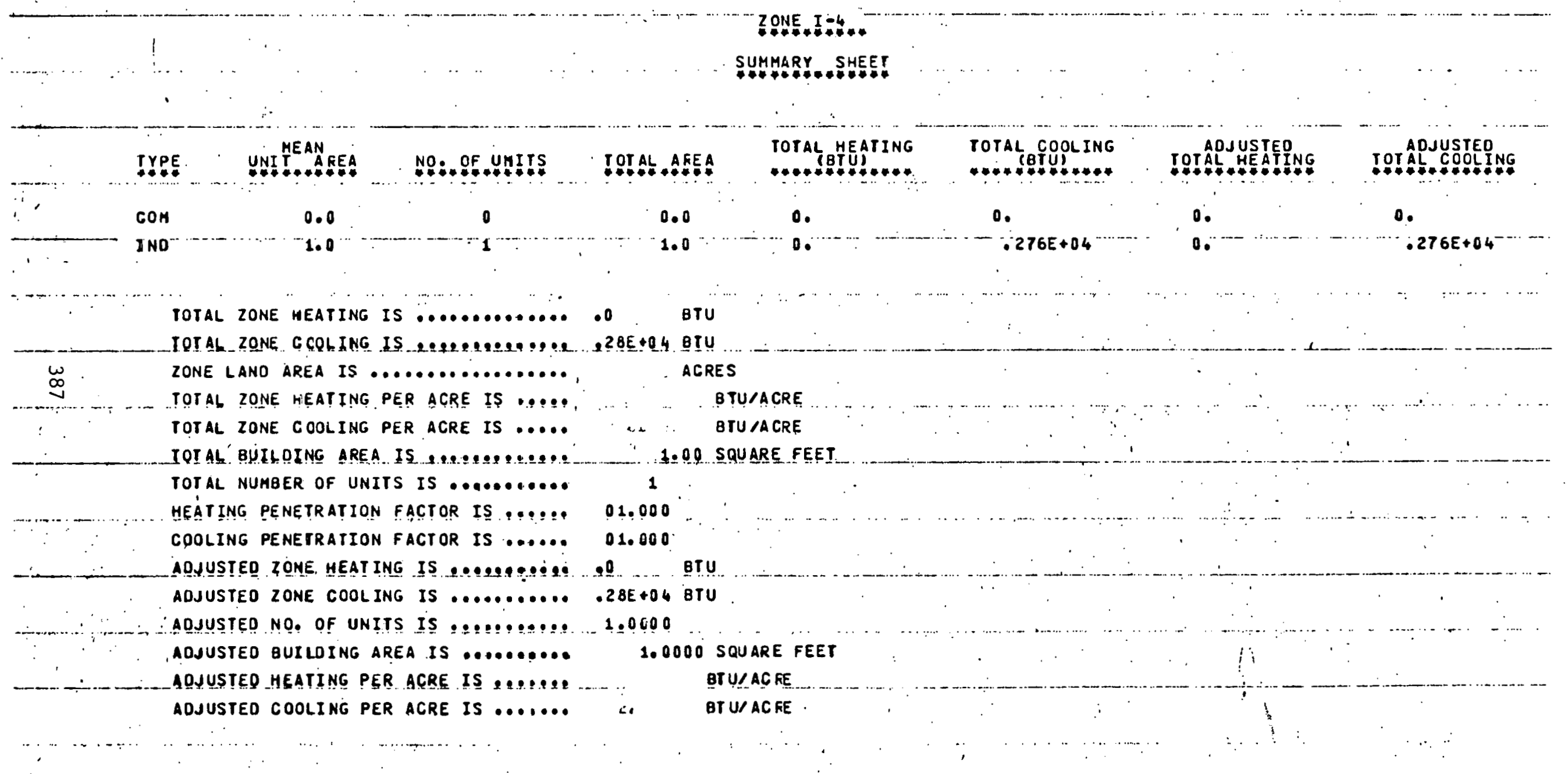


TOIAL. SUMMARY SHEET

HEATING DATA (*.)

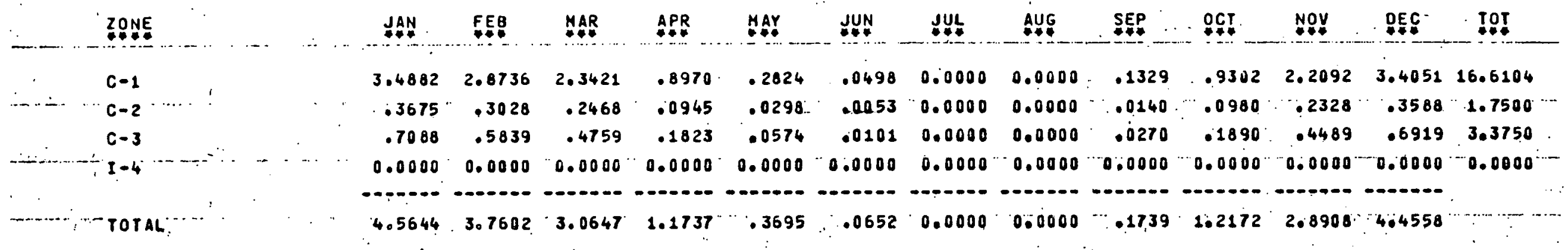

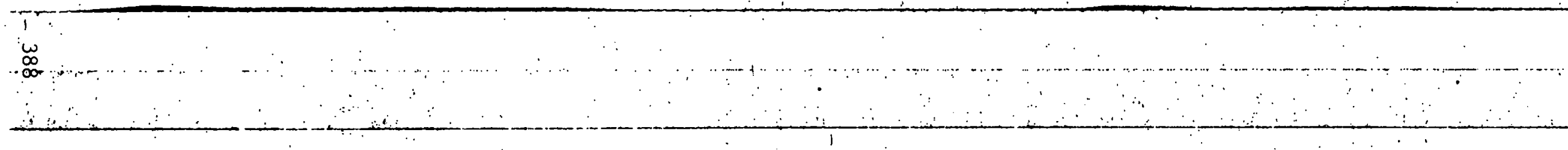

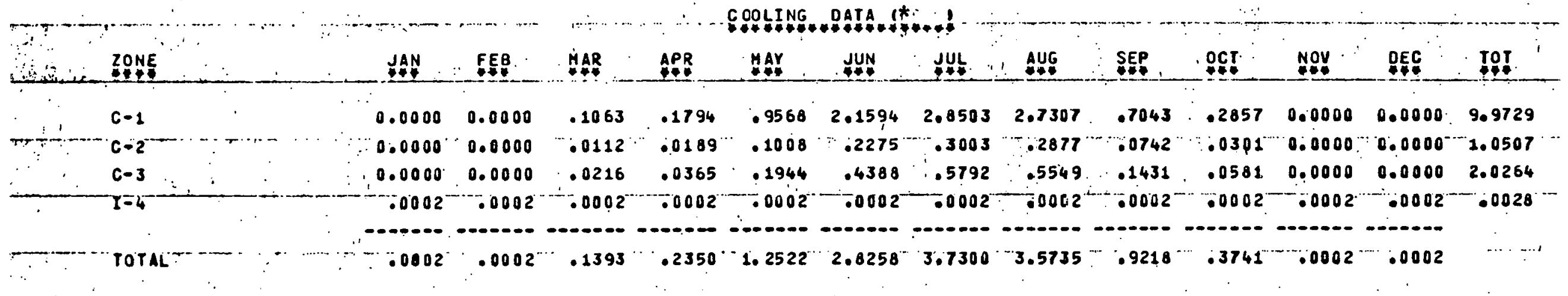


1. Heating and cooling loads determined from computerized load estimates.

2. Heat to distribution system (HDS) (assume end-user heating C.0.P. = 3.0)

$$
\text { HDS }=\text { Monthly Heat Required } \times\left(1-\frac{1}{3.0}\right)
$$

3. Heat Required from sewage effluent (HSE) (assume end-user cooling C.0.P. = 2.5)

$$
\mathrm{HSE}=\mathrm{HDS}-\left(1+\frac{1}{2.5}\right) \times \text { Monthly Cooling Required }
$$

4. Heat dissipated at cooling tower (HDCT)

(assume end-user cooling C.O.P. $=2.5$ )

heating C.O.P. $=3.0$

$\mathrm{HDCT}=1.4$ (Monthly Cooling Required) - H.D.S.

5. Circulating pump energy consumption: (assume 30 percent extra consumption)

$$
\mathrm{KWH}=\frac{1.3 \times\left[\frac{\mathrm{HSE}}{20}+\frac{\mathrm{HDCT}}{10}\right] \times 80 \mathrm{ft} .}{.65 \text { efficiency } \times 2.65 \times 10^{6} \mathrm{ft}-1 \mathrm{~b} / \mathrm{KWH}}
$$

6. Sewage pump energy consumption (assume 10 percent extra consumption)

$$
\mathrm{KWH}=\frac{1.1 \times\left[\frac{\mathrm{HSE}}{20}\right] \times 60 \mathrm{ft} .}{.65 \text { efficiency } \times 2.65 \times 10^{6} \mathrm{ft}-1 \mathrm{~b} / \mathrm{KWH}}
$$

3

7. Distribution pump energy consumption:

$$
\mathrm{KWH}=\frac{\left[\frac{\mathrm{HDS}+1.4(\text { Cooling })}{.65 \text { efficiency } \times 2.65 \times 10^{6} \mathrm{ft}-1 \mathrm{~b} / \mathrm{KWH}}\right.}{\mathrm{10}}
$$

8. Cooling tower energy consumption:

$$
\mathrm{KWH}=\frac{\mathrm{HDCT} \times .8 \mathrm{KWH} / \mathrm{HP} \times 50 \mathrm{HP}}{9.28 \times 10^{6}}
$$




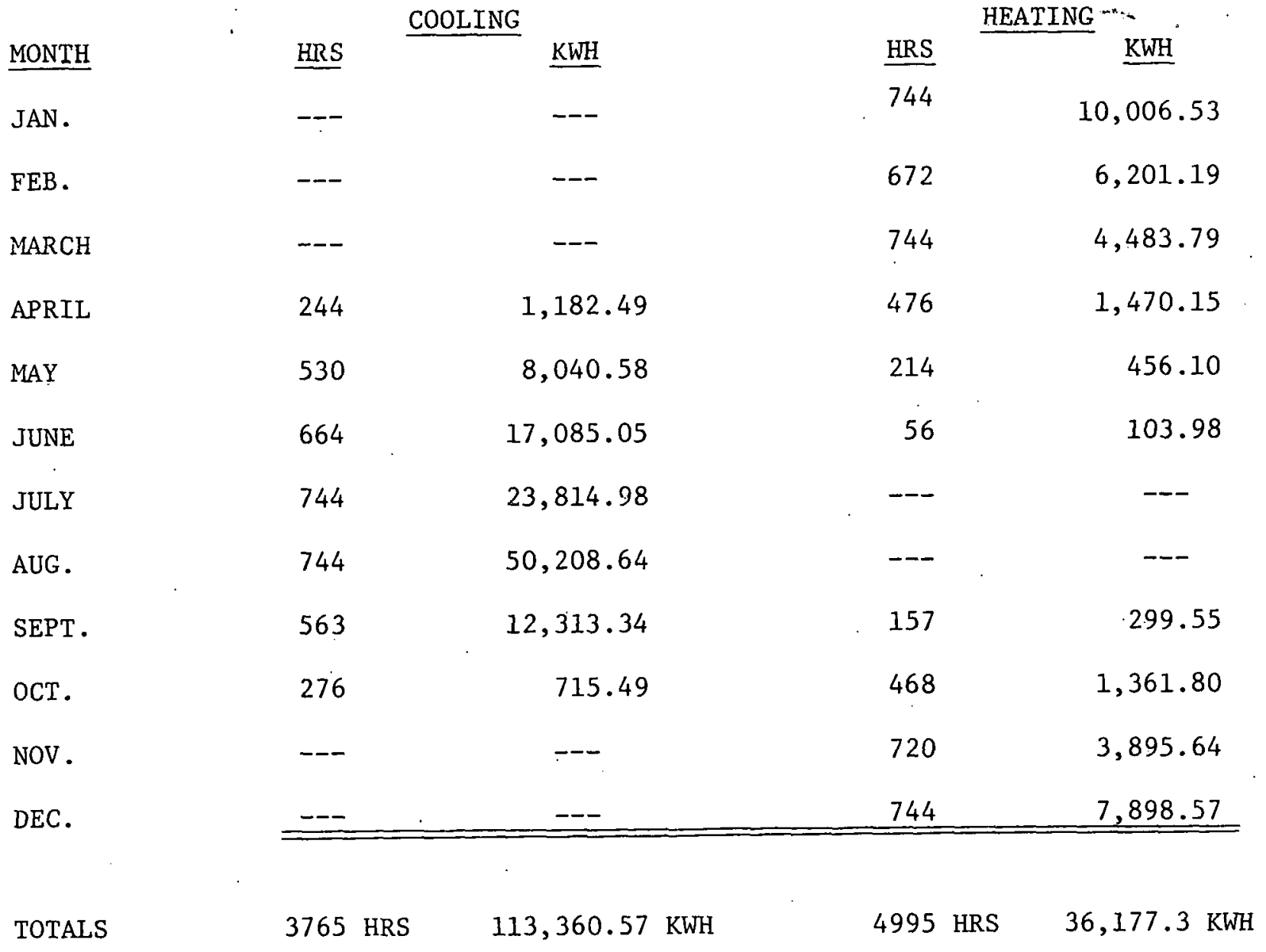

TOTAL KWH REQUIREMENT - 149,537.87 KWH 


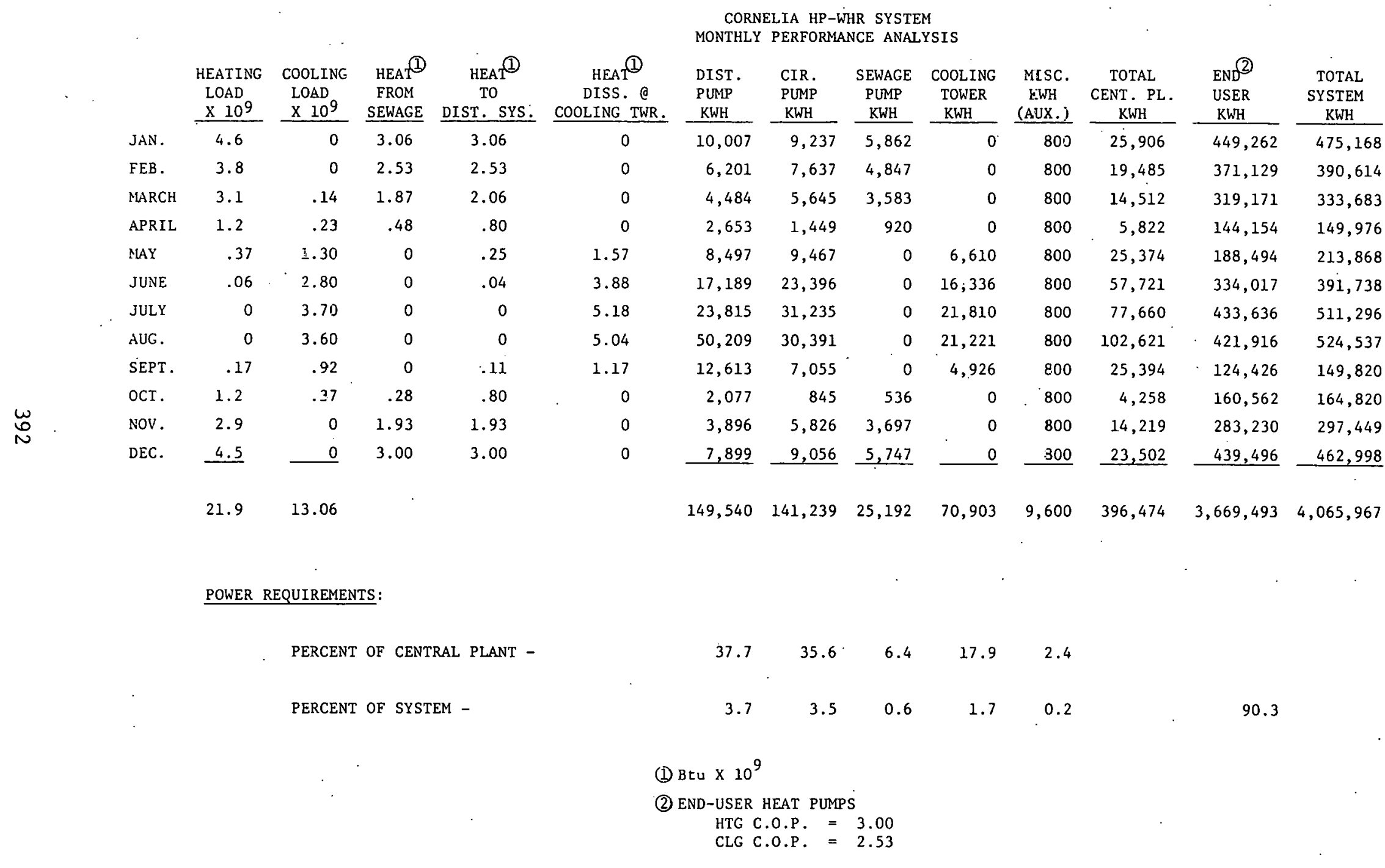


CORNELIA HP-WHR SYSTEM

CONSTRUCTION COST ESTIMATES 
THIS PAGE

\section{WAS INTENTIONALLY \\ LEFT BLANK}




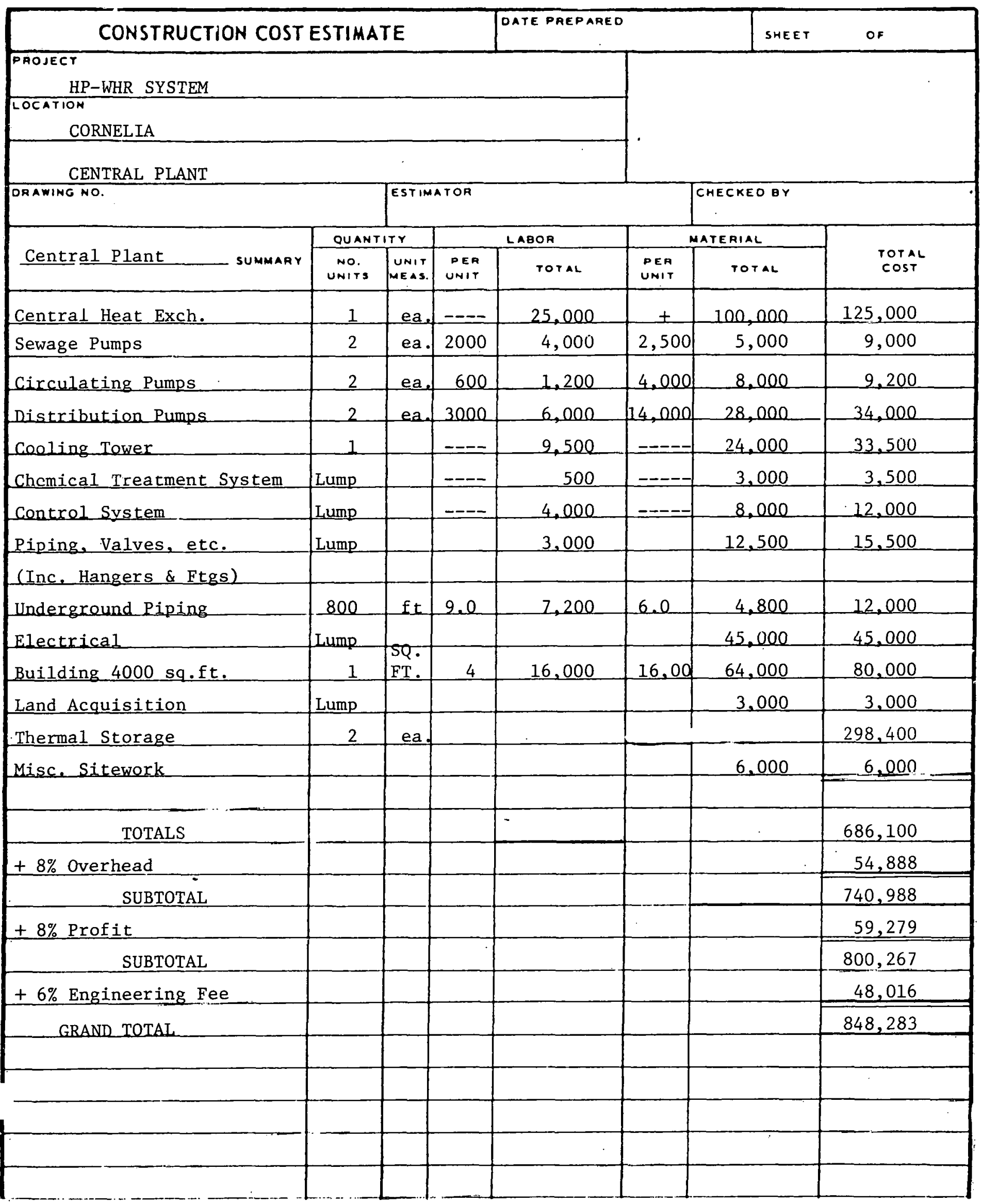




\section{ENGINEERING EXPERIMENT STATIDN \\ GEORGIA INSTITUTE OF TECHNOLOGY • ATLANTA, GEORGIA 30332}

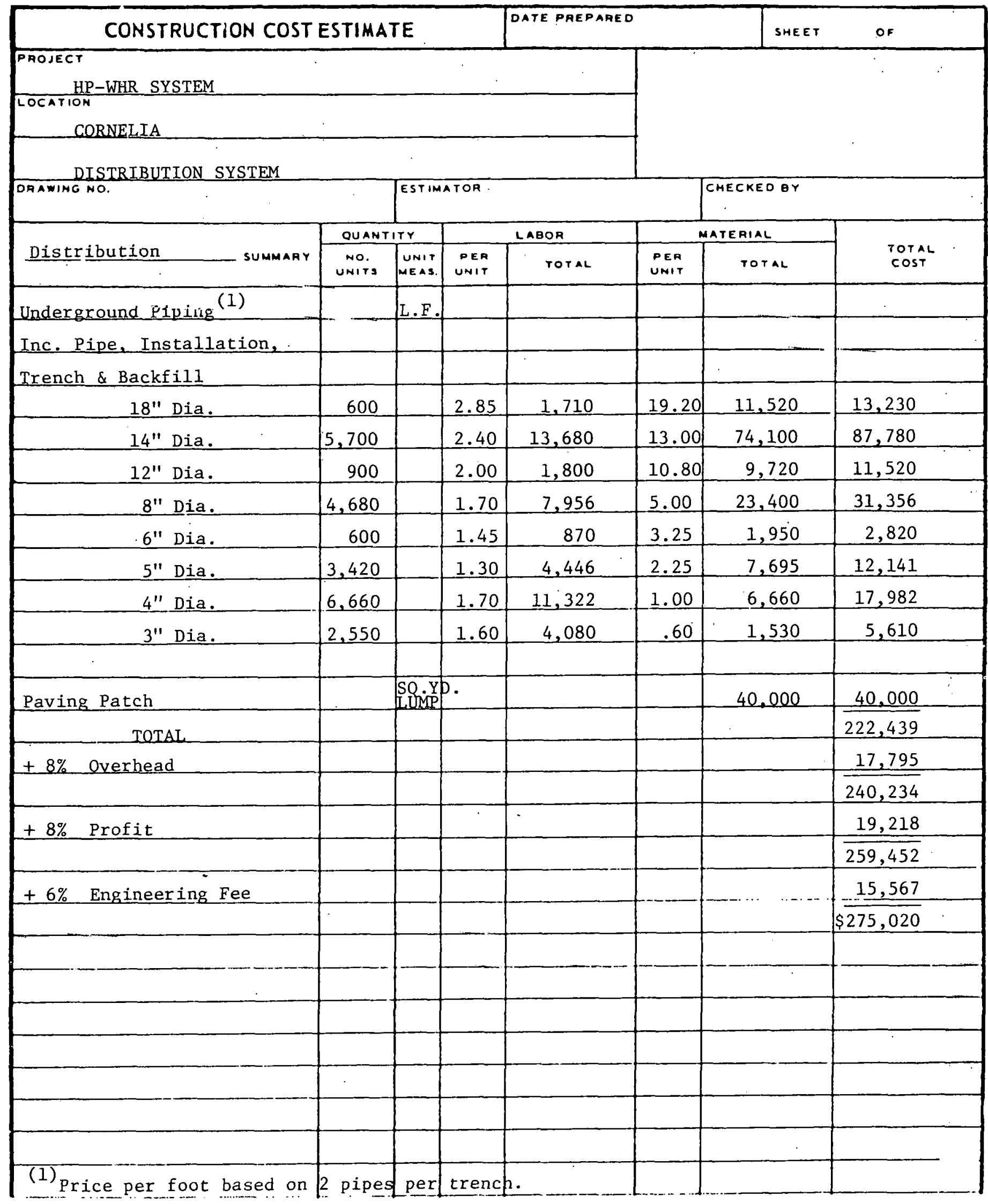


CORNELIA HP-WHR SYSTEM

CONSTRUCTION COST ESTIMATE

DESCRIPTION: THERMAL STORAGE VESSELS - 2 EA.

$50^{\prime} \times 60^{\prime} \times 35^{\prime}$ (depth); NOMINAL CAPACITY - 1,400,000 GALLONS

REINFORCED CONCRETE, INSULATED, EARTH BERMED

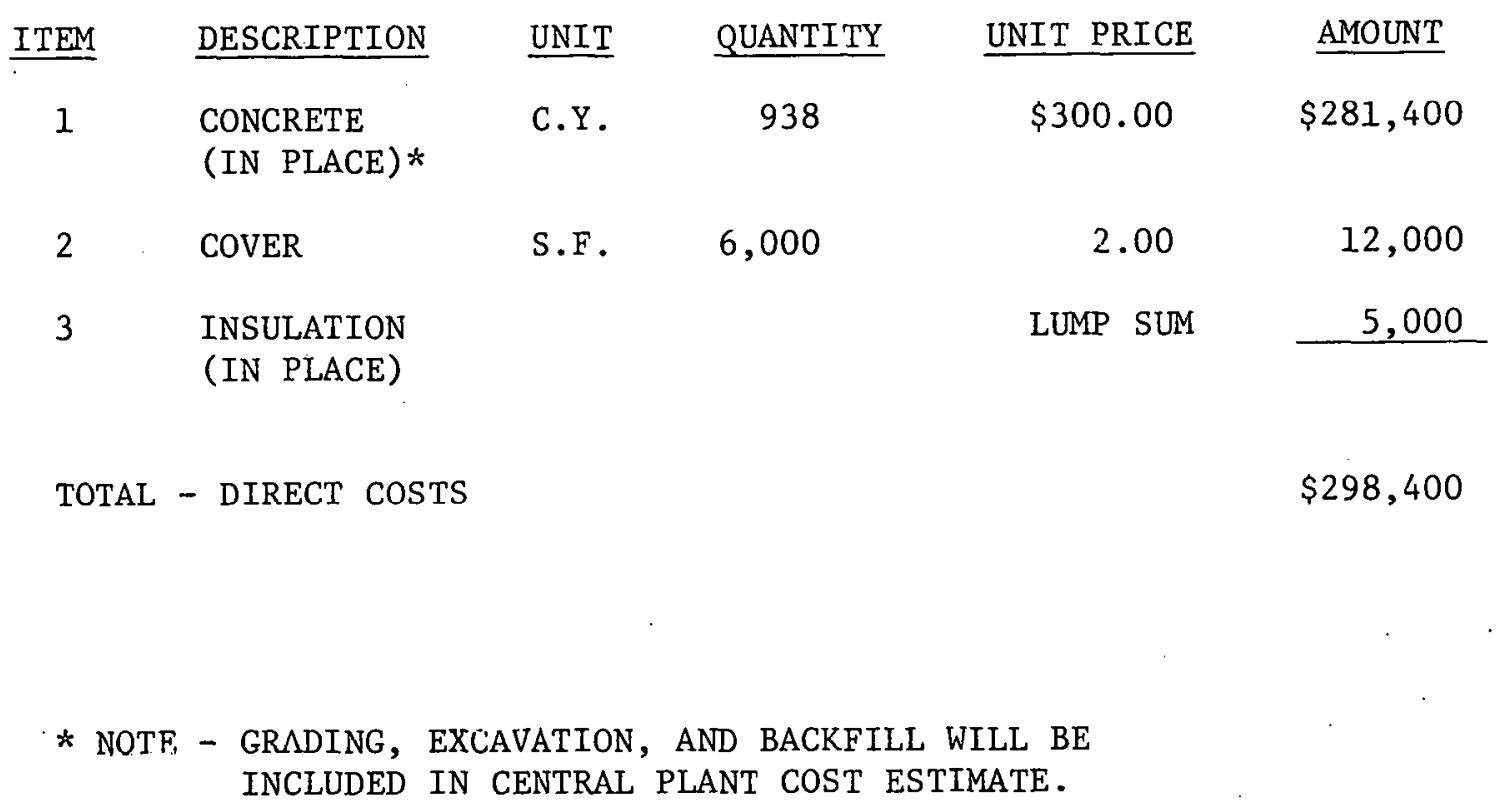




\section{THIS PAGE}

\section{WAS INTENTIONALLY LEFT BLANK}


APPENDIX E 
THIS PAGE

\section{WAS INTENTIONALLY LEFT BLANK}




\section{HEAT BALANCE}

In most cases, heat losses or heat gain caused by radiation, convection, bearing friction, oll coolers, etc., are relatively small and may not be considered in the overall heat balance, but may be compensated for in the heat balance closure allowance.

In a hermetic package, where the motor is cooled by refrigerant gas, chilled water, or condenser water, the motor cooling load will be included in the measured condenser load, hence:

$$
q_{E V}+q_{K W} \text { INPUT }=q_{c}
$$

Where

$$
\begin{aligned}
\mathrm{q}_{\mathrm{EV}} & \text { net cooling capac1ty of liquid cooler, Btuh } \\
\mathrm{q}_{\mathrm{KW}} \text { INPUT }= & \begin{array}{l}
\text { electric energy input to the compressor motor, } \\
\text { expressed in Btuh }
\end{array} \\
\mathrm{q}_{\mathrm{C}} & \text { net heat rejected to the condenser, Btuh }
\end{aligned}
$$

CLOSURE: THE HEAT BALANCE FOR THE TEST RUN SHOULD BE WITHIN 7.5 PER CENT. SOURCE: ARI STANDARD 550-77 54

\section{COEFFICIENT OF PERFORMANCE (C.O.P.)}

The Coefficient of Performance can be calculated, for any specific set of operating conditions, from the following formuln:

$$
\begin{aligned}
\text { C.O.P. } & =\frac{\text { Total Heat Out }}{\text { Heat In }} \\
& =\frac{\text { Compressor heat }+ \text { Evaporator heat }}{\text { Compressor heat }}
\end{aligned}
$$

\section{Where}

$$
\begin{aligned}
\text { Compressor heat }= & \text { Power supplied to unit (KWH) } \\
& \times 3413(\mathrm{BTU} / \mathrm{K} ! \mathrm{H}) \text { (includes fan power) }
\end{aligned}
$$




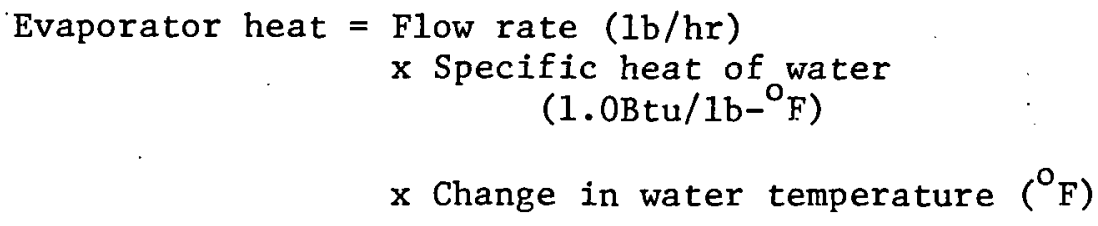

\section{ACTUAL CAPACITY}

The actual capacity, in tons, can be determined by the following formula:

$$
\begin{aligned}
& \text { tons } \cdots \mathrm{W}\left(\mathrm{T}_{\mathrm{e}}-\mathrm{T}_{1}\right) / 12,000 \\
& \text { Where } \\
& \begin{aligned}
\mathrm{W} & =\text { flow rate of chilled water, } 1 \mathrm{~b} \text { per } \mathrm{hr} \\
\mathrm{T}_{\mathrm{e}} & =\text { temperature of water entering the unit, }{ }^{\mathrm{o}_{\mathrm{F}}} \\
\mathrm{T}_{1} & =\text { temperature of water leaving the unit, }{ }^{\mathrm{o}} \mathrm{F}
\end{aligned}
\end{aligned}
$$

NOTE: The specific heat of water is implicit in the equation and is assumed to be $1.0 \mathrm{Btu} / 1 \mathrm{bm}-{ }^{\circ} \mathrm{F}$

SOURCE: ARI Standard 550-77.54 


\section{FOULING FACTORS}

Fouling factors must be obtained experimentally by determining the values of U(overall heat transfer coefficient) for both clean and dirty conditions in the heat exchanger. The fouling factor is thus defined as:

$$
\mathrm{R}_{f}=\frac{1}{\mathrm{U}_{\text {Dirty }}}-\frac{1}{\mathrm{U}_{\mathrm{Clean}}} \quad \frac{\left(\mathrm{HR}-\mathrm{Ft}^{2}-{ }^{\mathrm{O}} \mathrm{F}\right)}{\text { Btu }}
$$

and the overall heat transfer coefficient, $U$, is defined for a simple double-pipe heat exchanger as:

$$
U_{i}=\frac{1}{\frac{1}{h_{i}}+\frac{A_{i} \ln \left(r_{o} / r_{i}\right)}{2 \pi K L}+\frac{A_{i}}{A_{o}}\left(\frac{1}{h_{o}}\right)} \quad\left(\frac{B t u}{h r-F t^{2}-o_{F}}\right)
$$

Where

$h_{i}, h_{0}=$ convection heat transfer coefficient

$A_{i}, A_{0}=$ surface areas of inside tube

$r_{0}, r_{i}=$ inner and outer radii of inside tube

$\mathrm{K}=$ conduction heat transfer coefficient of tube material

L $\quad=$ length of exchanger tibes

SOURCE: Heat Transfer, J. P. Holman. 11 
TABLE 7. Fouling Resistances

\begin{tabular}{|c|c|c|c|c|}
\hline \multicolumn{5}{|c|}{$\begin{array}{l}\text { Typical fouling resistances are referred to the surface } 0 \\
\text { the absence of specific data for setting proper resistances } \\
\text { by the values tabulated below. } \\
\text { Water }\end{array}$} \\
\hline Temperature of Heating Medium & \multicolumn{2}{|c|}{ Up to $240^{\circ} \mathrm{F}$} & \multicolumn{2}{|c|}{$240-400^{\circ} \mathrm{F}$} \\
\hline Temperature of Water & $125^{\circ} \mathrm{F}$ & or less & Over! & $25^{\circ} \mathrm{F}$ \\
\hline \multirow{2}{*}{ Types of Water } & \multicolumn{2}{|c|}{$\begin{array}{c}\text { Watcr veiocily } \\
\text { ft/sec }\end{array}$} & \multicolumn{2}{|c|}{$\begin{array}{c}\text { Waler velucity } \\
\text { ft/sec }\end{array}$} \\
\hline & \begin{tabular}{|c|}
$3 \mathrm{ft}$ \\
and less \\
\end{tabular} & \begin{tabular}{|c|} 
Over \\
$3 \mathrm{ft}$
\end{tabular} & $\begin{array}{c}\mathrm{ft} \\
\text { and less }\end{array}$ & $\begin{array}{c}\text { Over } \\
3 \text { fi }\end{array}$ \\
\hline $\begin{array}{l}\text { Sea water } \\
\text { Brackigh walet } \\
\text { Coolsig tuwer and artificial spay pond } \\
\text { Tredted makeup } \\
\text { Untreated } \\
\text { City or well water (such a Great Lakes) } \\
\text { Great Lakes } \\
\text { River water } \\
\text { Minimum } \\
\text { Mississippi } \\
\text { Delaware, Schuylkill } \\
\text { East River and New York Bay } \\
\text { Chicago Sanitary Canal }\end{array}$ & $\begin{array}{l}0.0005 \\
0.022 \\
0.001 \\
0.003 \\
0.001 \\
0.001 \\
0.002 \\
0.003 \\
0.003 \\
0.003 \\
0.008\end{array}$ & $\begin{array}{l}0.0005 \\
0.001 \\
0.001 \\
0.003 \\
0.001 \\
0.001 \\
0.001 \\
0.002 \\
0.002 \\
0.002 \\
0.006\end{array}$ & $\begin{array}{l}0.001 \\
0.003 \\
0.002 \\
0.005 \\
0.002 \\
0.002 \\
0.003 \\
0.004 \\
0.004 \\
0.004 \\
0.010\end{array}$ & $\begin{array}{l}0.001 \\
0.002 \\
0.002 \\
0.004 \\
0.002 \\
0.002 \\
0.002 \\
0.003 \\
0.003 \\
0.003 \\
0.008\end{array}$ \\
\hline $\begin{array}{l}\text { Muddy or silty } \\
\text { Hard (over } 15 \text { grains/gal) } \\
\text { Engine jockel } \\
\text { Distilled } \\
\text { Treated boiler feedwater } \\
\text { Boiler blowdown }\end{array}$ & $\begin{array}{l}0.003 \\
0.003 \\
0.001 \\
0.0005 \\
0.001 \\
0.002\end{array}$ & $\begin{array}{l}0.002 \\
0.003 \\
0.001 \\
0.0005 \\
0.0005 \\
0.002\end{array}$ & $\begin{array}{l}0.004 \\
0.005 \\
0.001 \\
0.0005 \\
0.001 \\
0.002\end{array}$ & $\begin{array}{l}0.003 \\
0.005 \\
0.001 \\
0.0005 \\
0.001 \\
0.002\end{array}$ \\
\hline
\end{tabular}

SOURCE: Handbook of Heat Transfer, W.M. Rohsenow and J..P. Hartnett. 
APPENDIX F 


\section{THIS PAGE}

\section{WAS INTENTIONALLY LEFT BLANK}


Reference is made to Figure 3-1 and the equations and procedure outlined in the analysis section (See 9.4.4).

DATA :

$$
\begin{aligned}
& \begin{aligned}
& \mathrm{T}_{\mathrm{fi}}= \text { temperature of effluent entering the evaporatof of the central } \\
& \text { heat pump }=60^{\circ} \mathrm{F}
\end{aligned} \\
& \begin{array}{l}
\mathrm{T}_{\text {fo }}=\text { temperature of effluent leaving the evaporator of the central } \\
\text { heat pump }=50^{\circ} \mathrm{F}
\end{array} \\
& \begin{aligned}
& \mathrm{T}_{\mathrm{el}}= \text { temperature of water entering the evaporator of the end user } \\
& \text { heat pump }=80^{\circ} \mathrm{F}
\end{aligned} \\
& \begin{aligned}
& \mathrm{T}_{\mathrm{e} 2}= \text { temperature of water leaving the evaporator of the end user } \\
& \text { heat pump }=70^{\circ} \mathrm{F}
\end{aligned} \\
& \begin{aligned}
& \mathrm{T}_{\mathrm{cl}}= \text { temperature of water entering the condenser of the central } \\
& \text { heat pump }=70^{\circ} \mathrm{F}
\end{aligned} \\
& \begin{aligned}
\mathrm{T}_{c 2} & =\text { temperature of water leaving the condenser of central unit } \\
& =80^{\circ} \mathrm{F}
\end{aligned} \\
& \text { COP of the end user heat pump }=3.035 \text { (from Fig. 9-5) } \\
& \text { COP of the central heat pump }=6.991 \text { (from Table 9-3) } \\
& \mathrm{Q}=\text { design heating' load }=55,000 \mathrm{Btuh}=\mathrm{Q}_{\mathrm{f}}=\text { end-user load of the } \\
& \mathrm{W}_{\mathrm{ce}}=\text { energy input to compressor of the end user heat pump = } \\
& \frac{Q_{c, \text { (end user unit) }}}{\text { COP }}=\frac{55,000}{3.035} \text { Btuh }=18121.9 \mathrm{Btuh}
\end{aligned}
$$

Heat rejection factor $\mathrm{HRF}=\frac{\mathrm{COP}}{\mathrm{COP}-0.92}=\frac{3.035}{3.035-0.92}$

$$
\mathrm{HRF}=1.435
$$

Heat absorbed in the evaporator of the end user heat pump $Q_{e}$ (end user heat pump) $=\frac{55,000}{1.435}=38327.52 \mathrm{Btuh}$

Heat rejected in the condenser of the cenlral station heat pump $=Q_{e}$ (cnd user heat pump) $=38327.52$

Work input to compressor of the central station heat pump: $W_{c c}=\frac{38327.52}{6.991}=$ 5482.41 
Total compressor energy input: $\quad \Sigma_{c}=\dot{W}_{c e}+\dot{W}_{c c}=23603$ Btuh

\section{PUMPING ENERGY:}

Mass rate of flow of water through the evaporator of the end user unit $=\dot{M}_{w} \Delta h$ (end-user heat pump) $=\dot{M}_{w} C_{p w}(80-70)=38327.52$

Where

$$
\begin{aligned}
& \mathrm{C}_{\mathrm{pw}}=1.00 \\
& \dot{\mathrm{M}}_{\mathrm{w}}=3832.751 \mathrm{bm} / \mathrm{hr}
\end{aligned}
$$

The same mass flows through the cundenser of the central heat pump. MASS RATE OF FLOW OF EFFLUENT:

$\operatorname{HRF}\left(\right.$ centra1 heat pump) $=\frac{6.991}{6.991-0.92}=1.152$

Heat extracted from the effluent in the central station $=\frac{38327}{1.152}=33269.97$ $\dot{M}_{\text {eff }}=$ mass rate of flow of effluent $=\frac{33269.97}{1 \times(10)}=3327.001 \mathrm{bm} / \mathrm{hr}$

$$
\dot{\mathrm{M}}_{\mathrm{eff}}=3327.0 \mathrm{1bm} / \mathrm{hr}
$$

For these mass rates of flow the pumping energies for water flow through the condenser of the central pump, evaporator of the end user heat pump and the effluent pump were calculated, using the procedure outlined in the analysis section and the information given in References 5 and 7 . $\mathrm{E}_{\text {system }}=$ Total energy input to the system: $\Sigma \mathrm{W}_{c}+\Sigma \mathrm{W}_{\mathrm{p}}+\begin{gathered}\text { other losses } \\ \text { (Leakage, thermal, etc.) }\end{gathered}$

It is noted that the pumping energy $(827$. Btu/hr) is $3.5 \%$ of the compressor input. Increasing the pumping energy by $40 \%$ (to allow for other losses) would bring it to $4.9 \%$ (or $5 \%$ approximate).

Total energy input to compressor $=23,603.00$ Btuh. $5 \%$ of compressor energy. $=1180.00$ 
Total energy input to system $=24,783.00 \mathrm{Btu} / \mathrm{hr}=E_{\text {System }}$

$$
\begin{aligned}
\text { COP system } & =\frac{55,000}{24,783 .} \\
& =2.219
\end{aligned}
$$

NOTE: If in an actual system the pumping energy and other losses is $10 \%$ of the total energy input to compressor, then system COP would become 2.118 - a reduction of $4.55 \%$ in the COP system. 
In the process of raising the pressure (or head) of the distribution medi (water or clarified effluent), energy is consumed by the pump. The energy added to increase the pressure increases the enthalpy of water resulting in an increase of temperature. Since heat transfer from the pump casing is negligible, inefficiencies due to frictional losses in the pumping process tend to increase the temperature of the fluid. Pumping energy and the temperature increase of water during the pumping process is relatively small as shown in the following analysis:

$$
W_{p}=\frac{V_{f}\left(P_{2}-P_{1}\right)}{n} \times \frac{144}{778} \quad \frac{B t u}{1 b m}
$$

Where

$\mathrm{V}_{\mathrm{f}}=$ Specific volume of water at its temperature (which) is almost a constant over the temperature range)

$\mathrm{P}_{1,} \mathrm{P}_{2}=$ Inlet and exit pressures respectively, $\frac{1 \mathrm{bm}}{\mathrm{IN}^{2}}$

$W_{p}=$ Work input to pump.

$\eta_{p}=$ Efficiency of the pump

Also energy balance around the pump yields

$$
\begin{aligned}
& q+h_{1}=w_{p}+h_{2} \\
& -\left(w_{p}\right)=h_{2}-h_{1}
\end{aligned}
$$

For example, for a pressure rise of

$$
\mathrm{P}_{2}-\mathrm{P}_{1}=100 \mathrm{psi} \text {; water entering at } 80^{\circ} \mathrm{F}, \mathrm{V}_{\mathrm{f}}=0.01607 \frac{\mathrm{ft}^{3}}{1 \mathrm{bm}}
$$


and assuming pump efficiency of $70 \%$, we have from equation (D-1):

$$
\begin{aligned}
&-W_{p}= \frac{0.01607(100)(144)}{.70}=330.58 \mathrm{ft}-\frac{1 \mathrm{bf}}{1 \mathrm{bm}} \\
& \text { or } \quad-w_{\mathrm{p}}=\frac{330.58}{778}=0.425 \frac{\mathrm{Btu}}{1 \mathrm{bm}}
\end{aligned}
$$

Also, the enthalpy increase, $\left(h_{2}-h_{1}\right)=\left(W_{p}\right)=0.425 \frac{\mathrm{Btu}}{1 \mathrm{bm}}$

The temperature rise of water $=C_{p}\left(T_{2}-T_{1}\right)-h_{2}-h_{1}=0.425$

$$
\text { Where } \mathrm{C}_{\mathrm{p}}=\text { specific heat of water }=1.00 \frac{\mathrm{Btu}}{\mathrm{lbm}} \mathrm{F} \text {. }
$$

The temperature rise of water during the pumping process is therefore approximately $0.425^{\circ} \mathrm{F}$ for a pressure increase of $100 \mathrm{psi}$. 
Reference is made to the ASHRAE Systems Volume, 1976. (Ref. 49).

a. Conventional Fuel:

For $40 \%$ oversized furnace, $C_{f}=1.79$

Assumed rated efficiency; Eff $=0.75$

$\mathrm{H}_{\mathrm{L}}=$ Heating Load $=55,000$ Btuh

$C_{D}$, For Northwest Central Region

$=0.57$ (Degree Days $=8238$,

$T D=(75-(-20))=95^{n} \mathrm{~F}$

$$
\begin{aligned}
& E_{\text {Heating }}=\left(\frac{\mathrm{H}_{\mathrm{L}} \times \mathrm{DD} \times 24}{\mathrm{TD} \times \mathrm{Eff} .}\right) \mathrm{C}_{\mathrm{D}} \times \mathrm{C}_{\mathrm{F}} \\
& =155.717 \times 10^{6} \mathrm{Btu}
\end{aligned}
$$

b. Air to Air Heat Pump:

$\mathrm{C}_{\mathrm{F}}=1.0$

$\mathrm{E}_{\text {Heating }}=\left(\frac{\mathrm{H}_{\mathrm{L}} \mathrm{X} \text { DD X 24 }}{\text { TD X COP Seasonal }}\right) \quad \mathrm{C}_{\mathrm{D}}$

$\mathrm{COP}_{\text {Seasonal }}$ for N.W. Central Region $=1,382$

$\mathrm{COP}_{\text {Seasonal }}$ for $\mathrm{S}$. Atlantic Region $=2,220$

For the Northwest Central region with C.O.P. Season $=1.382$ $\mathrm{E}_{\text {Heating }}=47.2 \times 10^{6} \mathrm{Btu} / \mathrm{yr}$ 


\section{Distribution}

ANL

J. Calm (50)

A. Kennedy (25)

K. Macal

'T. Marc iniak

J. Pascual (2)

V. $R a b 1$

J. Tschanz

ANL Libraries (C. Archer)

ANL Washington (B. Graves) (10)

TIS Files (E.N. Pettitt)

$\underline{D O E}$

S. Cavros

J. Kaminsky

G. Leighton

J. Millhone

J. Rodousakis (25)

I. Sewe11

D. Walter

DOE-TIC (27)

\section{External}

C. Brett, University of Alabama (2)

P. Swenson, Consolidated Natural. Gas Service Company (2)

F. Dubin, Dubin-3loome Associates (2)

H. Lorsch, Franklin Research Center (2)

D. Wade, Georgia Tech Research Institute (15)

P. Anderson, Honeywell Energy Resources Center (2)

L. Katter, Rocket Research Company (2)

THIS REPORT SUPERSEDES ANL/ICES-TM-28 